\title{
Challenging the patient centred paradigm: designing feasible guidelines for doctor patient communication
}

Citation for published version (APA):

Veldhuijzen, W. (2011). Challenging the patient centred paradigm: designing feasible guidelines for doctor patient communication. [Doctoral Thesis, Maastricht University]. Maastricht University. https://doi.org/10.26481/dis.20110617wv

Document status and date:

Published: 01/01/2011

DOI:

10.26481/dis.20110617wv

Document Version:

Publisher's PDF, also known as Version of record

\section{Please check the document version of this publication:}

- A submitted manuscript is the version of the article upon submission and before peer-review. There can be important differences between the submitted version and the official published version of record.

People interested in the research are advised to contact the author for the final version of the publication, or visit the DOI to the publisher's website.

- The final author version and the galley proof are versions of the publication after peer review.

- The final published version features the final layout of the paper including the volume, issue and page numbers.

Link to publication

\footnotetext{
General rights rights.

- You may freely distribute the URL identifying the publication in the public portal. please follow below link for the End User Agreement:

www.umlib.nl/taverne-license

Take down policy

If you believe that this document breaches copyright please contact us at:

repository@maastrichtuniversity.nl

providing details and we will investigate your claim.
}

Copyright and moral rights for the publications made accessible in the public portal are retained by the authors and/or other copyright owners and it is a condition of accessing publications that users recognise and abide by the legal requirements associated with these

- Users may download and print one copy of any publication from the public portal for the purpose of private study or research.

- You may not further distribute the material or use it for any profit-making activity or commercial gain

If the publication is distributed under the terms of Article $25 \mathrm{fa}$ of the Dutch Copyright Act, indicated by the "Taverne" license above, 


\section{Challenging the patient centred paradigm: designing feasible guidelines for doctor patient communication}


The research reported here was carried out at

\section{Maastricht University}

in the School of Health Professions Education

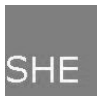

In close collaboration with CAPHRI School for Public Health and Primary Care

\section{caphri}

(C) J.W. Veldhuijzen, Maastricht 2011

Layout: Tiny Wouters

Omslag: Design Wemke Veldhuijzen en Roger Jeurissen. Beeld Wemke Veldhuijzen Production: Datawyse | Universitaire Pers Maastricht

ISBN: 9789081736503

The printing of this thesis was generously sponsored by the $\mathrm{SBOH}$, employer of GP-trainees and aiotho's. 


\title{
Challenging the patient centred paradigm: designing feasible guidelines for doctor patient communication
}

\author{
PROEFSCHRIFT \\ Ter verkrijging van de graad van doctor \\ aan de Universiteit Maastricht, \\ op gezag van de Rector Magnificus, \\ Prof. mr. G.P.M.F. Mols, \\ volgens het besluit van het College van Decanen, \\ in het openbaar te verdedigen \\ op vrijdag 17 juni 2011 om 14.00 uur
}

door

Jorinde Welmoed Veldhuijzen 


\section{Promotores}

Prof. dr. C.P.M. van der Vleuten

Prof. dr. T. van der Weijden

Prof. dr. G. Elwyn

Co-promotor

Dr. P.M. Ram

\section{Beoordelingscommissie}

Prof. dr. J.F.M. Metsemakers (voorzitter)

Dr. J. van Dalen

Dr. S. van Dulmen

Prof. dr. B. Kremer

Prof. dr. M. Wieringa- de Waard 


\section{Contents}

$\begin{array}{llr}\text { Chapter } 1 & \text { Introduction } & 7\end{array}$

Chapter 2 Much variety and little evidence: a description of 35 guidelines for doctor patient communication

Chapter 3 Characteristics of communication guidelines that facilitate or impede guideline use: a focus group study

Chapter 4 Exploring characteristics of communication guidelines that enhance training and learning communication

Chapter 5 How doctors move from generic goals to specific communicative behaviour in real practice consultations

Chapter $6 \quad$ Beyond patient centeredness: the multitude of competing goals that doctors pursue in consultations

Chapter 7 The goal driven nature of doctor-patient communication in primary care encounters

Chapter 8 An exploration of the extent to which doctors modify their goals to those of their patients and its effect on goal achievement by patients

Chapter 9 Interpersonal perception in the context of doctor-patient relationships: A dyadic analysis of doctor-patient communication

Chapter 10 General discussion

Summary

Samenvatting

Appendix

Dankwoord 



\section{Chapter 1}

\section{Introduction}




\section{Introduction}

Doctor patient communication, the main theme of this thesis, has received a great deal of attention since the second half of the $1980 \mathrm{~s}^{1}$. Communication with patients has been designated "a core clinical competency"2, "the main ingredient of medical care" 3 , "the chief source of knowledge about the patient" 4 and even "the most powerful therapeutic agents in existence" 5 .

A central theme in doctor patient communication is the extent to which doctors elicit patients' perspectives and adjust their actions accordingly. Due to their differing needs, social roles and knowledge, patients and doctors have very different perspectives on consultations ${ }^{6}$. Some authors have even gone so far as to describe doctors and patients as "coming from different worlds"7-9. In order to bridge this difference, patient-centred communication is widely endorsed as the standard for good communication in health care ${ }^{1,10,11}$. In patient-centred communication patients' agendas are considered and their ideas, expectations and concerns are at the heart of doctor patient interaction 1,10,11.

An abundance of studies has focussed on skills training methods that can be effective in stimulating doctors to adopt patient-centred communicative behaviours ${ }^{12-14}$. Nonetheless, evaluations of medical practice have shown that patient-centred communication is rare ${ }^{15-17}$. In this thesis the perspective on changing the way doctors communicate with their patients is widened from evaluation of skills training methods to the broader perspective of implementation science. This perspective is the theoretical background for a user-centred analysis of problems related to the implementation of recommendations for doctor patient communication. The central aim of this thesis is to investigate how recommendations for good communication can be designed to provide optimal support for doctors in improving their communication.

This introductory chapter starts with a description of the historical background within which the notion originated that doctors had to change the way they communicated with their patients, the actions undertaken so far to achieve this change and the impact of these actions. Having provided a background to the thesis, we outline the scope of the thesis and the theoretical perspective, present a literature-based framework of factors relevant to effective implementation of communication guidelines and identify gaps in the literature. Finally, we formulate the research questions of the thesis, describe the study settings and methodology and present a thesis outline. 


\section{The evolution of the belief that doctors' communication can and should be changed}

Interest in changing doctor patient communication arose in the 1970s as a result of four developments. One was the movement towards a more holistic medical model, which broadened the dominant biological perspective on disease. Another development was the increased interest in patient autonomy and patients' right to self-determination. Then there was the bloom of psychological theory resulting in the belief that behaviour could be transformed by interventions and, finally, the invention of the tape-recorder. These movements will be described in more depth in the following sections.

\section{A more holistic model for medicine}

In the days of Hippocrates, illness was studied within the context of individual patients as an idiosyncratic imbalance within an individual, resulting in complaints $^{18}$. In the $19^{\text {th }}$ century, the focus shifted from individual patients to diseases, as knowledge about pathogenesis increased. Illness came to be viewed as symptoms resulting from disease, a malfunctioning of the body that could be objectified and studied outside the context of the individual patient. Pathological and physiological explanations for diseases were proposed. This shift enabled the evolution of what has been labelled 'modern medicine', an empirical science based on processes and effects observed in groups of patients ${ }^{19}$. In the first half of the $20^{\text {th }}$ century medicine mainly focussed on biological malfunctions which could be discovered from the description of symptoms, physical examinations and physical tests. In the second half of the $20^{\text {th }}$ century, a more holistic model came to the forefront, claiming that doctors aspiring to be good clinicians had to understand and 'treat' not only the biological aetiologies and consequences of disease, but also the psychological and social aetiologies and consequences of illness ${ }^{20}$. This movement was especially influential in general practice ${ }^{21}$. This broadened the scope of the medical interview from physical symptoms to biological, psychological and social functioning and the consequences of disease and illness for these domains. The inclusion of social and psychological aspects of illness in diagnostic and management considerations meant a considerable broadening of the topics for doctor patient communication. As a result it was deemed necessary for doctors to change their communicative behaviour to encompass this broader model of medicine 2122 . 


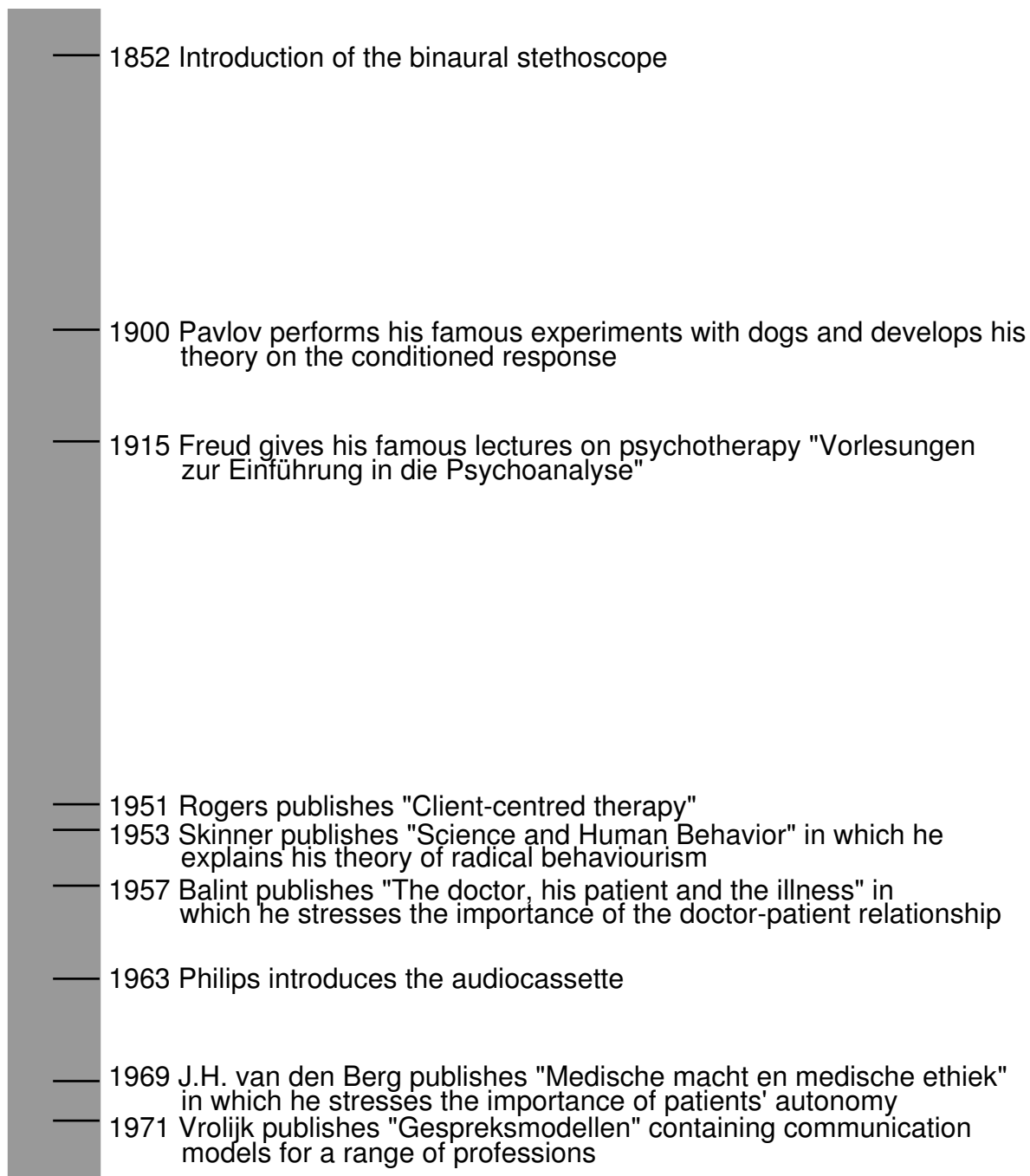

1977 Science publishes Engels' paper: "The need for a new medical model: a challenge for biomedicine"

1985 Schouten publishes "Anamnese en advies" one of the first and most used dutch publications on doctor patient communication

1990 Shared decision making becomes a research area on its own 


\section{An increase of interest in patient autonomy}

Technological developments in modern medicine have been fast and far-reaching, resulting in a massive increase in diagnostic and therapeutic possibilities. As a consequence, the influence of medicine on the lives of patients has expanded. Due to medical interventions, patients live longer but at the same time experience more negative effects from interventions. In the first half of the $20^{\text {th }}$ century, doctors typically decided what was best for their patients. In reaction to this, a movement sprang up in the 1970s promoting patient autonomy, claiming that patients had the right to determine what happened to their bodies ${ }^{23}$. To promote self determination in patients, exchange of information between doctors and patients was considered necessary to help patients understand their health status and decide which medical interventions they preferred 2223.

\section{The rise of the belief that behaviour can be transformed}

From the 1920s onward, psychological theory gained increasing societal influence with the development of Freud's psychoanalytic theories and the evolution of behaviourism. Psychoanalytic theory emphasised that neurosis could be understood and treated ${ }^{24}$ and behaviourist theory claimed that most behaviour is learned and therefore amenable to training ${ }^{25}$. In the second half of the 20th century, cognitive psychology came to the forefront and, with it, the belief that mental processes could be objectified and understood. Together, these psychological theories fuelled public belief that mental processes, emotions and behaviour could be understood and influenced by interventions, such as training and psychotherapy. So while holistic medicine with more emphasis on patient autonomy created a wish for change in doctors' communicative behaviour, public confidence that behaviour could be modified by external interventions fostered the belief that change in doctors' communication was within reach.

\section{Tape recorders}

Tape recording was invented in the first half of the 20th century and tape recorders became widely available in the 1960s. It was instrumental in opening the black box of the doctor's office. The possibility to tape real consultations greatly facilitated research into doctor patient communication. At the same time, it enhanced communication training, because taped consultations proved a powerful medium for feedback. 


\section{Changing doctors' communication: the actions taken.}

As described in the preceding paragraphs, the belief that doctors' communication with patients should and could be changed was on the increase in the 1970s. In order to realise this change, descriptions were made of how doctors ought to communicate $26-28$ and communication curricula were developed and implemented in medical schools and institutes providing postgraduate vocational training in general practice ${ }^{13,26}$. As psychologists and other behavioural scientists were regarded as experts in communication and behavioural change, their involvement in both processes was extensive 26,29 .

\section{Provision of descriptions of how doctors ought to communicate}

Starting in the 1960s, many authors in many countries have described what they consider appropriate doctor patient communication. Famous examples are the "Calgary Cambridge Guides" (Silverman, Kurz and Draper) ${ }^{30}$ and for the Dutch situation: "Anamnese en advies" (History and advice) (Schouten)27. No uniform term was used to designate documents that presented recommendations as to how doctors should communicate. Many were referred to as communication models $26,31,32$, others used terms like frameworks ${ }^{11}$ or guides ${ }^{33}$. Most of the recommendations were generic, i.e. general descriptions of desired communicative behaviours to be displayed by doctors in all situations, regardless of individual patients and specific medical and situational characteristics ${ }^{26}$. Situation-specific recommendations were given for a few situations only, of which the best known example is breaking bad news.

\section{Patient centredness as a pluriform ideal of good communication}

Most of the communication documents in use today state that the recommendations are based on principles of patient centredness. This statement is problematic, however, because patient centredness is a pluriform construct which has been used to refer to a variety of concepts ${ }^{29}$. Mead and Bower describe five conceptual dimensions to which the term patient centredness can refer:

1. using a biopsychosocial perspective;

2. sharing power and responsibility;

3. understanding the illness experience of individual patients;

4. building a therapeutic alliance;

5. awareness of the influence of the doctor as an individual.

The dimensions 'using a biopsychosocial perspective' and 'understanding the illness experience of individual patients' are related to the rise of holistic medicine. The first reflects a broadened diagnostic view, the second relates to health management that is attuned to individual patients. 'Sharing power and 
responsibility' originates from the movement towards more patient autonomy, while 'building a therapeutic alliance' and 'awareness of the influence of the doctor as an individual' are in alignment with the belief that doctors, in addition to their roles as mediators assessing symptoms, making diagnoses and proposing appropriate treatments, should also show personal engagement with their patients, as this can play an important role in the processes and outcomes of health care ${ }^{29}$.

Some authors have attributed the multitude of concepts underlying the construct of patient centredness to the notion that the origin of the concept of patient centeredness was political or ideological and not scientific ${ }^{29,34}$. De Haes describes this as: "Patient centredness was almost to be considered synonymous with good care and patient centred communication equivalent to good communication. It seems thus that by defining patient centredness authors have also defined good care and communication. As a result every element of health care that was considered good could have been called patient centred. Thus, a circular process seems to have evolved." Data on the benefits and risks of different communicative behaviours could have interrupted this vicious cycle but at the time evidence on the effects of communication was lacking. Because the concept of patient centredness was multiform, patient centred communication was not a univocal concept and, inevitably, recommendations formulated as operationalisations of patient-centred communication varied in content ${ }^{1,29,34}$.

\section{Attempts to reach consensus about the elements of good communication}

To deal with the diversity of recommendations for communication, attempts have been made to find common ground in descriptions of patient-centred communication and elements that constitute good communication. De Haes describes the following common elements in models of patient-centred communication: attention to patients' psychosocial as well as physical needs; ascertainment of patients' concerns; conveying a sense of partnership; active facilitation of patient involvement in decision making ${ }^{35}$. In the Kalamazoo consensus statement, a group of expert researchers and teachers in doctor patient communication delineated a set of elements of physician-patient communication which they considered essential for good doctor patient communication: build a relationship; open the discussion; gather information; understand the patient's perspective; share information; reach agreement on problems and plans; provide closure ${ }^{11}$.

\section{Development of communication curricula}

\section{Skills training versus individual development}

In order to teach new generations of doctors to communicate in line with the new recommendations for patient-centred communication, communication curricula were developed for medical schools and vocational training, the latter at first 
mainly in general practice. From the start there has been discussion on the best line of approach. The approach that has become dominant in Europe is the communication skills training approach in which learners are trained to perform a pre-specified set of behaviours. The aim is for learners to become progressively skilled in performing the desired behaviours ${ }^{13,36}$. Creating opportunities to practise communication skills either in role play or in contacts with simulated or real patients is the cornerstone of this approach ${ }^{13}$. In the US there has been more emphasis on doctors' personal development. Central in this more humanistic approach is the emphasis on the cultivation of personality traits that are considered characteristic of a good doctor, in the expectation that these will promote desired behaviours ${ }^{37}$. By teaching a diversity of personal development courses, using literature, cinema, poetry and other stimuli, universities try to cultivate attributes that will promote the doctor-patient relationship, such as "being present, attentive, curious and unhindered by preconceptions"38.

The evidence underpinning the didactics of communication training

From the start of communication skills training in the 1970s, research has investigated which training methods are most effective. Empirical studies have shown that the following elements can enhance the effectiveness of communication training: a longitudinal training programme, training in small groups, learner-centred approaches, a combination of knowledge about communication and opportunities to practise, and constructive feedback from peers and facilitators ${ }^{12-14}$. There has been little research done on the effects of personal development courses to promote the propensity of doctors to be mindful in relation with a patient, which might be due to the absence of clearly formulated objectives and corresponding measurement instruments.

\section{Assessment of doctor patient communication}

In the assessment of doctor patient communication the same contrast between attention to skills and personal development can be found. Checklists of observable behaviours are currently the gold standard for assessing communication skills ${ }^{36,39}$. Communicative behaviours are assessed based on direct observation or recordings of consultations with simulated or real patients. Assessors can be peers, trained patients and experts in communication, such as behavioural scientists. Assessment related to the doctor patient relationship, usually described as assessment of interpersonal skills, relies mainly on satisfaction questionnaires completed by patients ${ }^{36}$.

\section{The effectiveness of attempts to change doctors' communication}

Many studies have examined whether communication skills can be taught. In fact, so many studies have addressed this issue that there have been calls to stop 
researching the "crashingly obvious" 40 . What has been demonstrated, however, is that students can be trained to display a pre-specified set of behaviours in training settings (refs). This does not necessarily imply that they will transfer these behaviours to their professional practice.

There are strong indications that the impact of communication training on doctors' communication in real patient encounters is limited at best. Studies describing communicative behaviour of doctors in clinical practice have repeatedly reported that doctors show few of the patient-centred behaviours promoted in communication programmes. Doctors have been reported to fail to adequately explore patients' beliefs, preferences and emotions ${ }^{15,41-46}$, give information ${ }^{16,46,47}$ and share decisions with their patients $16,17,47$.

Although medical students can be taught to show patient centred communicative behaviour in practice situations, training effects tend to level out or even decline during clinical training48-50. Communication studies among residents and specialists show much less patient-centred behaviour and much smaller training effects than studies involving preclinical students ${ }^{16,51-53}$. Despite a societal shift in favour of patient-centred medicine in the last decade, the communicative behaviours of general practitioners have become only slightly more patient centred for patients in general and even somewhat less patient centred for specific groups of patients during the same period 54,55 .

These findings point to the sobering conclusion that the vast effort to shape or change how doctors communicate with their patients has in fact been rather ineffective in practice.

\section{The scope of this thesis}

Despite extensive investments in communication training, there seems to have been little impact on doctor patient communication in clinical practice. One can think of several hypotheses that might explain this: ineffective training methods, invalid measurements, doctors' inability to acquire the skills to apply recommendations or doctors considering the recommendations unsuitable for clinical practice. Studies that have followed students over preclinical and clinical training showed that exposure to clinical practice had an inhibiting effect on patient centred attitudes and on the application of patient-centred recommendations for communication $48,56,57$. This effect is sometimes referred to as the 'corrupting effect' of clinical practice and which is often explained as caused by the presence of a 'hidden curriculum' in clinical practice with negative attitudes towards patient centredness $56,58,59$. This finding reduces the likelihood that training, measurement or ability problems explain the lack of impact of communication training but suggests that medical students, despite being able to learn different communicative behaviours, do not apply them in practice. 
Doctors' attitudes towards patient centredness have often been explored from the perspective that negative attitudes and laziness are the cause of doctors' nonadherence to recommendations for communication ${ }^{58,60}$. However, it seems more plausible that useful insights into ways to facilitate effective implementation of communication recommendations are to be gained from investigating doctor patient communication from the point of view that doctors are eager to deliver high quality health care. Based on this viewpoint, there are two obvious reasons why doctors might fail to apply the communication recommendations they have been trained to perform.

1. Doctors do not believe that the recommended communicative behaviour is feasible in clinical practice.

2. Doctors do not believe that the recommended communicative behaviour is useful in clinical practice.

\section{Feasibility of recommendations}

Not many studies have explored what shapes doctor patient communication in clinical practice and whether and how current recommendations for doctor patient communication fit into that process.

There has been some discussion on the amount of consultation time involved in adherence to the recommendations for patient-centred communication. The evidence is inconclusive, with some studies showing that patient-centred consultations take more time ${ }^{61-63}$ and others showing no differences in consultation length $33,43,64$. Some developers of recommendations for doctor patient communication have dismissed as irrelevant the criticism that their recommendations are unfeasible because they take up too much time. Their position is that patient centred communication is more important than practical feasibility and they interpret the criticism as a sign that health care might need to be reformed so as to allow more time for consultations ${ }^{26,30}$.

The fact that recommendations for patient-centred communication were not formulated in response to practical concerns or a need experienced by clinicians, but rather originated from ethical, or even ideological, concerns may have compromised their feasibility 34 . It is difficult to argue against the strong appeal to high moral and ethical principles underlying the recommendations. This may have impeded discussions about practical concerns and the feasibility of recommendations.

In conclusion, little is known about the feasibility of the current recommendations for doctor patient communication, but there are indications that it is hampered by insufficient attention to the real world needs, constraints and requirements of clinical practice. 


\section{Usefulness of recommendations}

\section{Impact of communication}

The relevance of improving doctor patient communication has been investigated extensively by measuring its impact on patient outcomes and other outcome variables. Quality of communication has been shown to be related to several aspects of the quality of care. On the patient level, the communicative behaviour of doctors is related to satisfaction ${ }^{65-67}$, empowerment ${ }^{66,68,69}$, trust ${ }^{68-70}$, adherence to treatment ${ }^{65,68}$ and health outcomes $66,71-73$. On the societal level it is related to the use of health care resources 61,66 and unnecessary prescribing of antibiotics ${ }^{74}$. On the level of the doctors it is related to satisfaction ${ }^{67}$, frequency of burn-out ${ }^{75,76}$ and frequency of doctors being sued ${ }^{77-79}$. However, several problems complicate accurate and detailed determination of the degree to which the implementation of communication recommendations is instrumental in achieving these positive effects.

First of all, most of the evidence is weak ${ }^{80}$. Because many of the relations are based on observational studies, it is uncertain whether a causal effect was actually present. A study by Stewart et al., for example, showed that positive outcomes were related to behaviour of the doctor that the patient experienced as patient centred, but not to behaviour of the doctor that was defined as patient centred by the researchers ${ }^{81}$. Evidence from randomised controlled trials on the effects of patientcentred communication is contradictory. In the Cochrane review by Lewin on the effects of training doctors and or patients to enhance patient centredness half of the studies found no effect on satisfaction and one study even had a negative effect on patient satisfaction. Of the eight studies measuring effects on patient health care behaviour only two found a positive effect, and one a negative. Of the studies measuring the effects on health status one found a positive effect, two found mixed results and five studies found no effects ${ }^{34,82}$. Furthermore, almost all studies compared effects of training in patient-centred communication with effects of no communication training, so positive results may be due to a Hawthorne effect instead of patient centredness.

Second, it is possible that the current recommendations are outdated. Many were formulated in the 1970s and 1980s, whereas most of the research is of a more recent date ${ }^{1,26}$. Also recommendations may be outdated due to societal change, as the 'typical' patient in the 1970 s and 1980 s is likely to differ considerably from the 'typical' patient of the $21^{\text {st }}$ century.

Third, it is difficult to pinpoint which recommendations are related to positive outcomes. Many studies state that effects of patient-centred communication were investigated, but fail to clearly define the patient-centred behaviours involved 83 . Because of the variety in recommendations for patient-centred communication, it remains unclear which behaviours cause which effects. This variety may also explain why effects of training in patient-centred communication are 
inconclusive ${ }^{34,82}$. As a consequence there is no clear rationale for deciding which recommendations should be incorporated in communication guidelines to achieve positive outcomes.

In conclusion, despite positive outcomes associated with patient-centred communication, doubts remain whether the application of recommendations for doctor patient communication does in fact yield positive effects.

In the two preceding sections we explored the hypothesis that communication training has only a limited impact on doctor patient communication, because the current recommendations are unfeasible and/or not sufficiently useful for clinical practice. The conclusion seems justified that this hypothesis is plausible. Recent literature offers no reason to reject it. This hypothesis therefore deserves further exploration in this thesis. The overarching aim of this thesis is to estimate the feasibility and usefulness of recommendations for doctor patient communication in influencing how doctors communicate and to offer suggestions for improving the recommendations to enhance their implementation and ability to promote good doctor patient communication in clinical practice.

\section{Theoretical perspective}

\section{A theoretical perspective on the quality of recommendations for doctor patient communication}

The literature has not addressed the question of what makes a recommendation for doctor patient communication a good recommendation, in other words there are no quality criteria for recommendations on doctor patient communication. As pointed out earlier, the concept of good communication underpinning the recommendations is patient centeredness, a concept that is ambiguous due to its many different underlying constructs. Because of this lack of quality criteria and the ambiguity of the concept of good doctor patient communication we decided to look outside the literature on doctor patient communication for a theoretical perspective that could help us to evaluate the quality of recommendations for doctor patient communication. We found this perspective in the literature on quality of care, more specifically in the research on development and implementation of clinical practice guidelines. The Dutch Institute for Healthcare defines a clinical practice guideline as "a document containing recommendations, guidance and instructions for medical practice, intended to support daily practice in health care and based on results of scientific research and the consequent discussion and formation of opinion, aimed at the explicit statement of good medical practice" 84 . Recommendations on breaking bad news are usually referred to as 'guidelines,' but most documents containing recommendations for doctor patient communication are presented as 'models', 'frameworks' or 'guides', terms 
that do not suggest prescriptive content. Nevertheless, although descriptions of doctors' desired communicative behaviours, unlike most clinical practice guidelines, do not contain disease-related recommendations on medical technical aspects of care, they do seem to meet the above definition of clinical practice guidelines.

Interpretation of recommendations for communication as clinical practice guidelines

Clinical practice guidelines promote evidence-based medicine by making the results of medical research available to practitioners. Recommendations included in guidelines are arrived at through procedures developed to optimise the scientific quality, acceptability and feasibility of practice guidelines. Clinical guidelines function as professional aids, reflecting the current state of medical knowledge. They can be used to inform both teaching and other quality improvement activities 85,86 . Implementation research has studied how guideline adherence can be promoted and has resulted in a vast body of knowledge on effective guideline implementation 87 .

The theoretical perspective underlying the construct of clinical practice guidelines comprises a great deal of knowledge about both their scientific quality and implementation. Hence, this perspective is likely to provide insights into both the quality and the implementation of recommendations on doctor patient communication. Therefore we have given the clinical guideline construct a central place in this thesis. The definition of a communication guideline that we use in this thesis is that of a document containing recommendations, guidance or instructions about doctor patient communication, intended to support daily practice in health care and based on results of scientific research and the consequent discussion and formation of opinion, aimed at the explicit statement of good medical practice.

\section{A framework for the implementation of communication guidelines}

This section presents a short description of theories regarding the implementation of change on the level of individual practitioners and evidence regarding effective implementation of guidelines. Based on this literature a framework is proposed describing factors that are considered relevant for the implementation of communication guidelines (Figure 1.1). Additionally, gaps are identified in the literature that is relevant to this framework and research questions are formulated to address these gaps. 


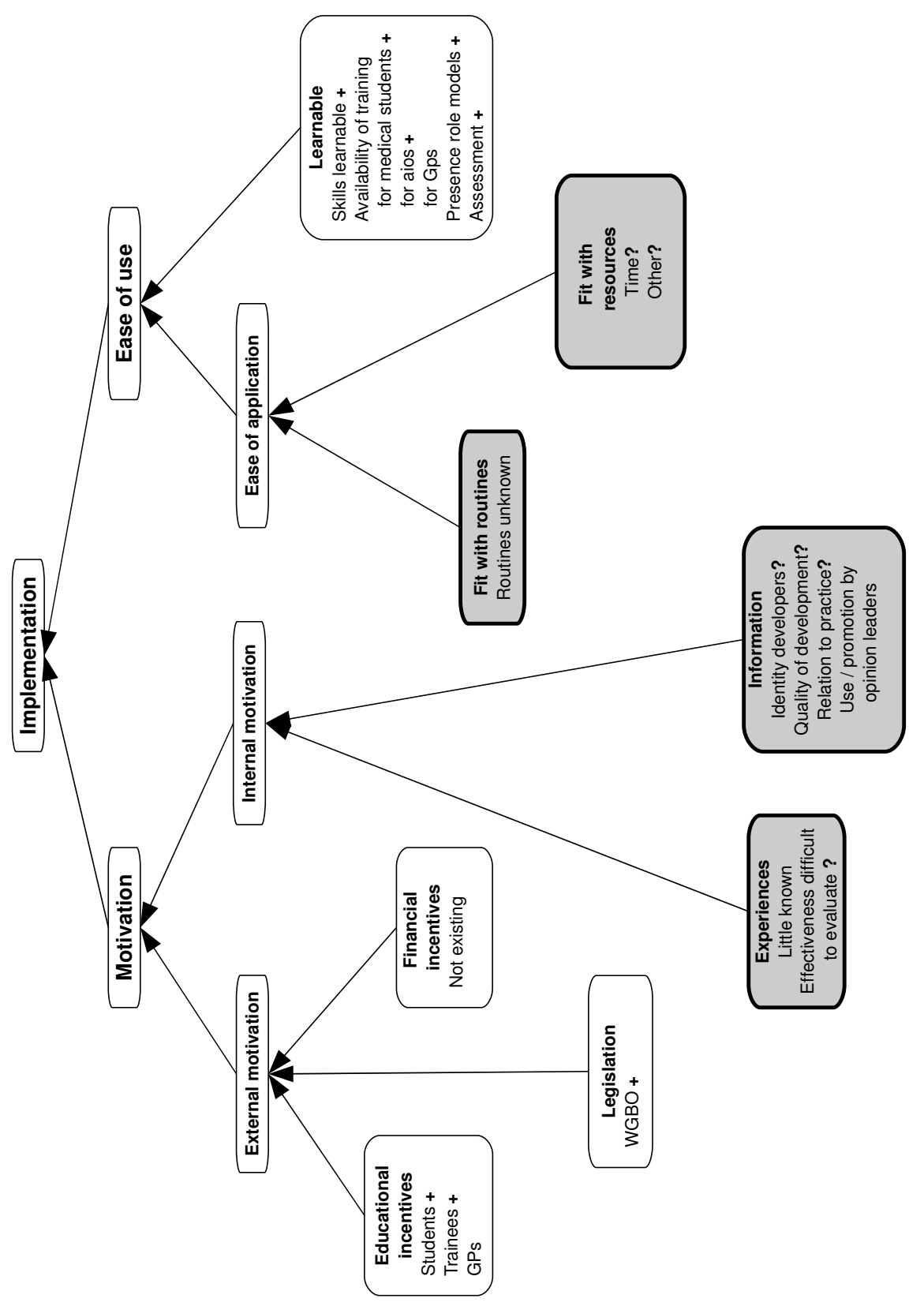

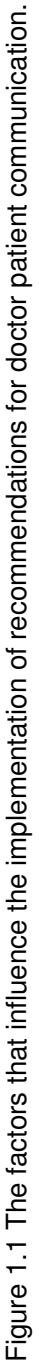




\section{Theories on the implementation of change}

Grol et al. performed a comprehensive study of theories relevant to the implementation of change in health care. They describe theories related to individual professionals, social context of change, and organisational, administrative and economic content 88 . Although social and organisational theories would probably yield additional insights into problems of the effective implementation of communication guidelines, in this thesis we only look at theories with relevance to guideline implementation at the level of individual practitioners. The reason for this restriction is that what happens inside a doctor's office, especially with regard to communication, is mainly left to individual doctors' professional responsibility. With regard to medical management doctors are obliged to record their actions and there are many protocols or guidelines that describe preferred behaviour and limit doctors autonomy. Such control is less evident in the case of doctor patient communication, partly because there are fewer protocols and guidelines and partly because doctors' communicative behaviours are not recorded or otherwise objectified. The level of individual health care workers therefore seems the most relevant perspective from which to study the implementation of communication guidelines, although obviously individual health care workers are also influenced by society at large.

Groll et al. categorise theories relating to factors of the implementation of guidelines at the level of individual practitioners as cognitive theories, educational theories and attitude theories. ${ }^{88}$ The component that all these theories have in common with regard to implementation is motivation to change.

\section{Cognitive theories}

Cognitive theories focus on factors influencing decision making. Rational decision making theories assume that people weigh the advantages and disadvantages of different behaviours and then choose the option they believe is best suited to their particular purpose. According to this theory motivation to apply recommendations is influenced by information about the benefits and risks involved in applying them ${ }^{89}$. Theories on behavioural scripts suggest that doctors learn from experience. Doctors compare present situations with earlier similar ones and then behave in a manner found to be useful in those earlier situations ${ }^{89}$. This suggests that when they try out recommended behaviours, recommendations that yield favourable results will tend to get implemented. So, according to this theory, motivation to implement communication recommendations depends not so much on appropriate information about benefits but on whether benefits are actually experienced by doctors. 


\section{Educational theory}

Educational theory considers learners' motivation to learn an important determinant of effectiveness of training. For adult learners, intrinsic motivation is considered a better facilitator of change than extrinsic motivation. Therefore motivation is likely to be higher when doctors experience that the knowledge and skills that are learned are relevant, i.e. they help to solve clinical problems or achieve clinical objectives 90 .

\section{Motivational theories}

Motivational theories, such as the theory of planned behaviour, describe intention to perform a behaviour as a strong determinant of whether the behaviour will actually occur. This intention is determined by attitudes towards the behaviour, subjective norms and perceived efficacy ${ }^{91}$. Positive behavioural attitudes rest on the belief that the behaviour, in this thesis the application of recommendations for doctor patient communication, will result in a positive outcome ${ }^{91}$. Positive behavioural attitudes seem related to what educationalists refer to as internal motivation. Positive subjective norms are the belief that important others, such as colleagues or patients, will approve of the behaviour ${ }^{91}$. These norms thus appear to be related to external motivation. Perceived efficacy, the belief that one is able to perform a certain behaviour, influences both types of motivation because it impacts the belief that rewards are to be expected from the behaviour, regardless of whether these are internal or external.

\section{Attributes of guidelines relevant to their implementation}

Several attributes of guidelines that users appreciate and that have a positive influence on guideline implementation illustrate the importance of motivation. Users prefer guidelines that are credible, i.e. the quality of which they feel they can trust $^{92}$. It was found that positive effects resulted from recommendations that "offer support for complex problems experienced in practice," are "compatible with existing norms and values," are supported by scientific evidence and do not yield negative reactions from patients ${ }^{93-96}$. These are all attributes that were found to enhance doctors' motivation to apply recommendations.

Other attributes with proven positive effects on implementation or on positive evaluations from users suggest that implementation is also considerably enhanced if the required change is easy to accomplish because it is clearly described, supported by training or simply not too demanding. This is illustrated by the positive attributes "concrete, clear and simple to use," "easy to look up," and not requiring "a change of existing routines" or "new skills." 


\section{Formulation of the framework}

In order to build a theoretical framework of factors that play a role in the implementation of communication guidelines, we have integrated the most important elements of the theories on the implementation of change and the attributes of guidelines relevant to implementation and organised them hierarchically.

Motivation to apply a guideline and ease of use of a guideline appear to be the most important determiners of implementation on the level of individual professionals and are therefore highest in the hierarchy (Figure 1.1). As described in the section on educational theory, motivation can be external and internal. Ease of use also consists of two aspects. Recommendations may be easy to apply at the first try or the competencies required to apply them may be easy to learn, which makes for ease of use after some practice. Therefore ease of use is divided into two subsections: ease of application and ease of learning. This results in a total of four determinants: internal motivation, external motivation, ease of application and ease of learning.

\section{Filling in the framework}

The factors identified in the literature as influencing the four determinants are described in the following paragraphs. In so far as it is available, information on the presence of these factors in the case of doctor patient communication will be provided. An overview of these factors and their probable influence on doctor patient communication is given in Figure 1.1.

\section{External motivation}

Factors that have been reported to create external motivation for specific behaviours in health care workers are financial incentives, legal repercussions and educational incentives ${ }^{97-100}$.

Financial incentives are used increasingly by governments and health insurance companies to promote specific behaviours of clinicians ${ }^{101}$. To the best of our knowledge, financial incentives for adherence to communication guidelines do not exist.

Legislation in the area of doctor patient communication does exist, however. The law (WGBO, wet geneeskundige behandelingsovereenkomst (act on medical treatment agreement)) demands in many countries that patients are informed of the benefits and risks of treatment and their consent is sought before treatment is started102,103. Although its exact influence on communication has not been examined, some authors believe that this law has reinforced general practitioners' patient-centred communicative behaviours ${ }^{54}$.

Competence achievement incentives for the application of communication guidelines are present in undergraduate and postgraduate medical training. There 
are national qualification requirements in the area of doctor patient communication that have to be met by medical students and general practice trainees ${ }^{16,104,105}$ (. Although there is no national standard for communication assessment, students and general practice trainees usually are assessed on their communicative behaviour, in the case of GP trainees this usually concerns patient contacts in practice settings. There are no educational incentives for practising general practitioners (GPs) nor are there specific requirements in the area of doctor patient communication for re-accreditation of GPs, or for accreditation of practices.

\section{Internal motivation}

When we interpret doctors' internal motivation for using guidelines in the same way as positive behavioural attitudes are interpreted in the theory of planned behaviour, internal motivation results from the belief that using a guideline will have effects that are appreciated by the user of the guideline, i.e. the doctor. In light of the cognitive theories described earlier, this belief can have two sources. It can be based on positive information suggesting that application of the guideline will lead to desired results. It can also be based on positive experiences with guideline application, i.e. experienced favourable results of the recommended behaviour.

From guideline research we know that trust in a guideline is created by the knowledge that it has been developed by a trusted source, such as a national professional or specialist body (for the Netherlands the Dutch college of General Practitioners (NHG), or the Dutch Institute for Health Care Improvement (CBO)), by the belief that the developmental processes were of high quality and grounded in a sound evidence base, by an explicit relationship between recommendations and practice, i.e. the recommendations help solve problems and reach goals and targets that are relevant to users and by support for guideline use from opinion leaders ${ }^{106}$. Opinion leaders in medicine are usually doctors who have also gained recognition as expert researchers in their field and who provide continuing professional development in their specialty. As far as doctor patient communication is concerned, many of the recognised experts are behavioural scientists and communication is usually not a subject of continuing professional development. This implies that support from opinion leaders is unlikely to play an important role in promoting the use of communication guidelines. There is little information in the literature on the procedures of the development of communication guidelines or on their developers.

In order to experience positive results from the application of a guideline doctors have to evaluate its effects. Besides higher satisfaction scores ${ }^{67}$, there are few outcome data that indicate a positive impact of communication guidelines on the doctors who apply them. Almost all outcome measures for doctor patient communication described in the literature are on the level of the patient: patient health, patient health care consumption, patient satisfaction or patients' levels of 
anxiety or decisional regret65,66,107. Two requirements must be met if these outcomes are to lead to positive experiences for doctors: first doctors have two regard these effects as important. Secondly, doctors need to be able to determine the influence of their communication on their patients. In order to do so, doctors have to be able to accurately estimate changes in patients' beliefs, emotions, satisfaction and behavioural attitudes. As doctors and patients are considered to experience the medical consultation in very different ways due to differences in their backgrounds and roles ${ }^{8,9}$, it is to be expected that effects on patients are difficult to establish for doctors.

\section{Ease of application}

Literature on guideline implementation suggests that the following factors are relevant to the ease of application of a guideline: The extent to which a guideline can be incorporated into existing routines and the extent to which application of the guideline can be accomplished with the available resources ${ }^{106}$. In the case of recommendations on communication, time has been mentioned as a relevant resource $26,108,109$. As described in previous sections, there is disagreement in the literature concerning the effects of the adoption of patient-centred communication guidelines on consultation time ${ }^{33,61-63}$.

\section{Ease of learning}

If a guideline does not fit in existing routines and requires acquisition of new competencies, its application will depend on how easy the competencies in question can be learned and the availability of training or other learning resources and support 87 . Effective training is supported by good didactics, the presence of role models and adequate assessment instruments ${ }^{13,110}$.

As described earlier, medical students have been shown to be able to learn isolated skills required for the application of communication guidelines through training with simulated patients 40,50 . Thus, efforts to learn isolated communication skills within a training context seem effective.

Communication training is available for medical students and GP trainees and to a much smaller extent for trainees in other specialties ${ }^{13}$. Training in specific communicative competencies, such as motivational interviewing or breaking bad news is available for GPs, and, again to a smaller extent, for other specialists. But few training opportunities in generic communicative competencies are offered to GPs and other specialists.

There is extensive knowledge on effective didactics for communication training and most training courses seem to be state of the art ${ }^{13,51}$. Training in the Netherlands is often partly provided by behavioural scientists and partly by doctors. So, if medical trainees have difficulty identifying with behavioural scientist role models, they can find acceptable role models in the doctors. Validated assessment instruments for 
communication skills are present for medical students and for performance assessment of GPs and GP trainees ${ }^{111}$.

\section{Gaps in the literature}

There are considerable gaps in the literature with regard to effective implementation of communication guidelines. This is illustrated by the question marks in Figure 1.1. We will review each of the areas for which important information is lacking.

The literature offers little objective information about the quality of the communication guidelines that are currently in use in medical education. For most of them, little is known about who developed them or which development procedures were used. It is also unclear whether they are aligned with the needs of clinical practice. This is partly because many guidelines are described in the literature as patient centred but do not clearly indicate which outcomes they are supposed to facilitate and partly because little is known about the need of clinicians with regard to communication with their patients. Consequently, since we have little to go on in determining the strengths and weaknesses of communication guidelines, we cannot determine whether the available information on communication guidelines can reinforce doctors' internal motivation to apply them.

We also know little about doctors' experiences in relation to the strengths and weaknesses of communication guidelines. We do not know how doctors' communicative behaviour comes to be established in practice and therefore we know little about the influence of resources or the ease of fitting guidelines in existing routines. In summary, we do not really know how easy or how difficult it is for doctors to apply communication guidelines. The same holds for doctors' positive and negative experiences with outcomes of the use of communication guidelines. Little has been written on what doctors consider import outcome measures of communication. As we stated earlier doctors have to be able to estimate how their communication affects their patients in order to evaluate the effectiveness of communication. We suspect that it is difficult for doctors to do so, given the considerable differences that are assumed to exist between doctors' and patients' experiences of consultations. And, since most of the research in this area has focussed either on the doctor's perspective or on the patient's perspective, the differences between doctors and patients experiences and needs during the same consultations remain uncharted territory. 


\section{Research questions}

Based on the gaps in the literature described above, we formulated the following three research questions:

1. What are strengths and weaknesses of the guidelines for doctor patient communication that are currently in use? (Chapters 2, 3 and 4)

2. What drives communicative behaviour of doctors in clinical practice? (Chapters 5, 6 and 7)

3. To what extent are doctors' and patients' opinions and goals regarding consultations congruent? (Chapters 8 and 9)

\section{Setting of the study}

The studies were carried out in general practice settings in the Netherlands. The Netherlands has a history of a strong position of general practice in education and health care, with much attention to research and training in doctor patient communication 26,112 . Worldwide, most studies of communication training and patient centeredness have been executed either in medical schools or in general practice $^{29}$. As this thesis focuses on the usefulness and feasibility of recommendations for doctor patient communication, a setting was chosen where there was long term experience with the use of those recommendations. General practice was selected because of its long time involvement in communication training and its positive attitudes towards patient centeredness ${ }^{113}$.

\section{Methods}

The research questions are aimed at creating a better understanding of the practice in which recommendations for communication are used and the role of these recommendations in that practice. To understand the practice in all its complexity, a methodology was chosen that enabled studies to be conducted 'in vivo' and minimised distortions due to the research. That is why the studies are observational or investigative but not interventional. We used a mixed methods approach in which the methodology of different studies was tailored to the nature of the research questions. The main aim of most of the studies was to understand processes or to identify relevant factors. Therefore we primarily used qualitative methods. Data collection methods depended on the topic of interest (materials, processes that drive behaviour) and on whether it was considered helpful or disturbing to stimulate participants to reflect on their reactions. Stimulating reflection can be helpful because it is assumed to lead to more meaningful answers, but it can also be disturbing because it can lead to post-hoc rationalisations and thereby distort answers ${ }^{114,115}$. In the study in chapter seven we tested hypotheses derived from the earlier qualitative studies and explored the size of the effects observed in those studies. Therefore this study was quantitative. In the final two studies we explored the congruence of doctors' and patients' opinions 
and needs using dyadic data, i.e. doctor and patient data derived from the same consultations. Because we wanted to describe the levels of congruence we used quantitative methods.

This thesis project was designed as a series of studies to be conducted chronologically. This allows for a cyclic nature of the research starting with a reflection on the literature, followed by formulation of research questions, data collection and analysis. Reflection on the results of one study provided the starting points for a new study cycle. In this way there was continual adjustment of the research questions and methods to the findings of the completed studies.

\section{Outline of thesis}

The three chapters following this introduction describe different aspects of the quality of the Dutch communication guidelines for GPs. Chapter two describes the guidelines and their strengths and weaknesses assessed by a validated rating scale. In chapter three we describe a focus group study among guideline users exploring the strengths and weaknesses of communication guidelines as experienced in clinical practice. Chapter four uses data from same focus group study but focuses on the guidelines' strengths and weaknesses with regard to learning and training. In the next three chapters we explore how doctors' communicative behaviour is established. In chapter five a model of how doctors select communicative actions during patient encounters is presented, based on data from stimulated recall interviews with GPs. In chapter six the consultation goals that drive GPs' communication are described, based on data from the focus groups and the stimulated recall interviews and an extensive data set of think aloud interviews with GPs. In chapter seven we quantitatively test the hypothesis that doctor patient communication is goal directed by exploring whether consultation goals predict ratings on a communication assessment instrument. The last two chapters examine differences between doctors' and patients' perspectives in relation to consultations. In chapter eight we explore the match between the goals of doctors and patients and its effect on patient satisfaction by comparing data from think aloud interviews with GPs with data from a patient questionnaire about the same consultations. In chapter nine the match between the opinions of patients and the opinions of doctors on the quality of doctors' communicative competence is explored by means of doctor- and patient-related versions of the same questionnaire. Finally, the findings in the preceding chapters are integrated and discussed in chapter 10. In the appendix of this thesis the author's personal views on and experiences with doctor patient communication are described.

This thesis is based on eight papers about the studies performed. Since every chapter was written to be read on its own, repetition and overlap across chapters are inevitable. 


\section{Literature}

1. Bensing J. Bridging the gap. The separate worlds of evidence-based medicine and patient-centered medicine. Patient Educ Couns 2000;39:17-25.

2. Makoul G, Krupat E, Chang $\mathrm{CH}$. Measuring patient views of physician communication skills: development and testing of the Communication Assessment Tool. Patient Educ Couns 2007;67:333-42.

3. Stephens GG. Reflections of a post-flexnerian physician. In: White K, editor. The taks of medicine. Menlo Park, California: The Henry J. Kaizer family foundation, 1988.

4. Cassell EJ. The theory of doctor-patient communication. Cambridge, Massachusetts: MIT press, 1985.

5. White K. The task of medicine. Menlo Park, California: The Henry J. Kaizer family foundation, 1988.

6. Toombs K. The Meaning of Illness: A Phenomenological Account of the Different Perspectives of Physician and Patient: Kluwer Academic Publishers, 1992.

7. Bochner S. Doctors, patients and their cultures. In: Pendleton DA, J.C. H, editors. Doctor patient communication. London: Academic press, 1983:127-138.

8. Mishler EG. The discourse of medicine: Dialectics of medical interviews. New Yersey: Ablex Publishing Corporation, 1984.

9. Rubin BD. The health caregiver-patient relationship: Pathology, etiology, treatment. In: Ray EB, Donohew L, editors. Communication and health: Systems and applications. Hillsdale, New York: Lawrence Erlbaum Associates, Inc, 1990:51-68.

10. Epstein RM, Franks P, Fiscella K, Shields CG, Meldrum SC, Kravitz RL, et al. Measuring patient-centered communication in patient-physician consultations: theoretical and practical issues. Soc Sci Med 2005;61:1516-28.

11. Makoul G. Essential elements of communication in medical encounters: the Kalamazoo consensus statement. Acad Med 2001;76:390-3.

12. Gysels M, Richardson A, Higginson IJ. Communication training for health professionals who care for patients with cancer: a systematic review of training methods. Support Care Cancer 2005;13:356-66.

13. Kurtz S, Silverman J, Draper J. Teaching and learning communication skills in medicine. Oxford - San Franscisco: Radcliffe Publishing, 2005.

14. Aspegren K. BEME Guide No. 2: Teaching and learning communication skills in medicine-a review with quality grading of articles. Medical Teacher 1999;21:563 570.

15. Matthys J, Elwyn G, Van Nuland M, Van Maele G, De Sutter A, De Meyere M, et al. Patients' ideas, concerns, and expectations (ICE) in general practice: impact on prescribing. Br J Gen Pract 2009;59:29-36.

16. Campion P, Foulkes J, Neighbour R, Tate P. Patient centredness in the MRCGP video examination: analysis of large cohort. Membership of the Royal College of General Practitioners. Bmj 2002;325:691-2.

17. Elwyn G, Hutchings H, Edwards A, Rapport F, Wensing M, Cheung WY, et al. The OPTION scale: measuring the extent that clinicians involve patients in decision-making tasks. Health Expect 2005;8:34-42.

18. Jouanna J. Hippocrates; medicine and culture. Baltimore: John Hopkins University Press, 1999.

19. Foucault M. The birth of the clinic: An archaeology of medical perception. New York: Vintage, 1975.

20. Engel GL. The need for a new medical model: a challenge for biomedicine. Science 1977;196:129-36. 
21. McWhinney IR. The need for a transformed clinical method. In: Stewart M, Roter D, editors. Communicating with medical patients. Newbury Park, California: Sage publications, 1989.

22. McWhinney IR. Why we need a new clinical method. In: Stewart M, Belle Brown J, Weston WW, McWhinney IR, McWilliam CL, Freeman TR, editors. Patient-Centered Medicine: Transforming the Clinical Method. Thousand Oaks, CA: Sage, 1995.

23. van den Berg J. Medische macht en medische ethiek. Nijkerk: Callenbach, 1969.

24. Freud S. Vorlesungen zur Einführung in die Psychoanalyse. Leipzig-Vienna, 19151917.

25. Skinner BF. Science and human behavior: Free Press, 1965.

26. Van Dalen J, Bartholomeus P, Kerkhofs E, Lulofs R, Van Thiel J, Rethans JJ, et al. Teaching and assessing communication skills in Maastricht: the first twenty years. Med Teach 2001;23:245-251.

27. Schouten J. Anamnese en advies. Houten: Stafleu, 1985.

28. Stewart M, Roter D. Communicatiing with medical patients. Newbury Park, California: Sage publications, 1989.

29. Mead N, Bower P. Patient-centredness: a conceptual framework and review of the empirical literature. Soc Sci Med 2000;51:1087-110.

30. Silverman J, Kurtz S, Draper J. Skills for communicating with patients. Oxon: Radcliffe Medical Press, 1998.

31. Levenstein JH, McCracken EC, McWhinney IR, Stewart MA, Brown JB. The patientcentred clinical method. 1. A model for the doctor-patient interaction in family medicine. Fam Pract 1986;3:24-30.

32. Hantho A, Jensen L, Malterud K. Mutual understanding: a communication model for general practice. Scand J Prim Health Care 2002;20:244-51.

33. Silverman J, Kurtz S, Draper J. Skills for communicating with patients. Oxford - San Francisco: Radcliffe, 2005.

34. de Haes H. Dilemmas in patient centeredness and shared decision making: a case for vulnerability. Patient Educ Couns 2006;62:291-8.

35. de Haes $\mathrm{H}$, Bensing J. Endpoints in medical communication research, proposing a framework of functions and outcomes. Patient Educ Couns 2009;74:287-94.

36. Duffy FD, Gordon GH, Whelan G, Cole-Kelly K, Frankel R, Buffone N, et al. Assessing competence in communication and interpersonal skills: the Kalamazoo II report. Acad Med 2004;79:495-507.

37. Epstein RM. Mindful practice. JAMA 1999;282:833-9.

38. Zoppi K, Epstein RM. Is communication a skill? Communication behaviors and being in relation. Fam Med 2002;34:319-24.

39. Cushing A. Assessment of non-cognitive factors. In: Norman G, van der Vleuten C, Newble D, editors. International handbook of research in medical education. Dordrecht: Kluwer, 2002:711.

40. Skelton JR. Everything you were afraid to ask about communication skills. $\mathrm{Br} J \mathrm{Gen}$ Pract 2005;55:40-6.

41. Marvel MK, Epstein RM, Flowers K, Beckman HB. Soliciting the patient's agenda: have we improved? JAMA 1999;281:283-7.

42. Rhoades DR, McFarland KF, Finch WH, Johnson AO. Speaking and interruptions during primary care office visits. Fam Med 2001;33:528-32.

43. Levinson W, Gorawara-Bhat R, Lamb J. A study of patient clues and physician responses in primary care and surgical settings. JAMA 2000;284:1021-7.

44. Rogers MS, Todd CJ. The 'right kind' of pain: talking about symptoms in outpatient oncology consultations. Palliat Med 2000;14:299-307. 
45. Maguire P, Faulkner A, Booth K, Elliott C, Hillier V. Helping cancer patients disclose their concerns. Eur J Cancer 1996;32A:78-81.

46. Britten N, Stevenson FA, Barry CA, Barber N, Bradley CP. Misunderstandings in prescribing decisions in general practice: qualitative study. BMJ 2000;320:484-8.

47. Kennelly C, Bowling A. Suffering in deference: a focus group study of older cardiac patients' preferences for treatment and perceptions of risk. Qual Health Care 2001;10 Suppl 1:i23-8.

48. Pfeiffer $\mathrm{C}$, Madray $\mathrm{H}$, Ardolino A, Willms J. The rise and fall of students' skill in obtaining a medical history. Med Educ 1998;32:283-8.

49. Craig JL. Retention of interviewing skills learned by first-year medical students: a longitudinal study. Med Educ 1992;26:276-81.

50. van Dalen J, Kerkhofs E, van Knippenberg-Van Den Berg BW, van Den Hout HA, Scherpbier AJ, van der Vleuten CP. Longitudinal and concentrated communication skills programmes: two dutch medical schools compared. Adv Health Sci Educ Theory Pract 2002;7:29-40.

51. Kramer AW, Dusman H, Tan LH, Jansen JJ, Grol RP, van der Vleuten CP. Acquisition of communication skills in postgraduate training for general practice. Medical Education 2004;38:158-67.

52. Hulsman RL, Ros WJ, Winnubst JA, Bensing JM. Teaching clinically experienced physicians communication skills. A review of evaluation studies. Medical Education 1999;33:655-68.

53. Libert Y, Conradt S, Reynaert C, Janne P, Tordeurs D, Delvaux N, et al. [Improving doctor's communication skills in oncology: review and future perspectives]. Bull Cancer 2001;88:1167-76.

54. van den Brink-Muinen A, van Dulmen SM, de Haes HC, Visser AP, Schellevis FG, Bensing JM. Has patients' involvement in the decision-making process changed over time? Health Expect 2006;9:333-42.

55. Bensing JM, Tromp F, van Dulmen S, van den Brink-Muinen A, Verheul W, Schellevis FG. Shifts in doctor-patient communication between 1986 and 2002: a study of videotaped general practice consultations with hypertension patients. BMC Fam Pract 2006; 7:62.

56. Jaye C, Egan T, Parker S. 'Do as I say, not as I do': Medical Education and Foucault's Normalizing Technologies of Self. Anthropology \& Medicine 2006;13:141 - 155.

57. Tsimtsiou Z, Kerasidou O, Efstathiou N, Papaharitou S, Hatzimouratidis K, Hatzichristou D. Medical students' attitudes toward patient-centred care: a longitudinal survey. Med Educ 2007;41:146-53.

58. Haidet P, Dains JE, Paterniti DA, Hechtel L, Chang T, Tseng E, et al. Medical student attitudes toward the doctor-patient relationship. Med Educ 2002;36:568-74.

59. Krupat E, Pelletier S, Alexander EK, Hirsh D, Ogur B, Schwartzstein R. Can changes in the principal clinical year prevent the erosion of students' patient-centered beliefs? Acad Med 2009;84:582-6.

60. Cote L, Leclere H. How clinical teachers perceive the doctor-patient relationship and themselves as role models. Acad Med 2000;75:1117-24.

61. Epstein RM, Franks P, Shields CG, Meldrum SC, Miller KN, Campbell TL, et al. Patientcentered communication and diagnostic testing. Ann Fam Med 2005;3:415-21.

62. Zyzanski SJ, Stange KC, Langa D, Flocke SA. Trade-offs in high-volume primary care practice. J Fam Pract 1998;46:397-402.

63. Flocke SA, Miller WL, Crabtree BF. Relationships between physician practice style, patient satisfaction, and attributes of primary care. J Fam Pract 2002;51:835-40. 
64. Levinson W, Roter D. Physicians' psychosocial beliefs correlate with their patient communication skills. J Gen Intern Med 1995;10:375-9.

65. Williams N, Ogden J. The impact of matching the patient's vocabulary: a randomized control trial. Fam Pract 2004;21:630-5.

66. Little P, Everitt H, Williamson I, Warner G, Moore M, Gould C, et al. Observational study of effect of patient centredness and positive approach on outcomes of general practice consultations. Bmj 2001;323:908-11.

67. Roter DL, Stewart M, Putnam SM, Lipkin M, Jr., Stiles W, Inui TS. Communication patterns of primary care physicians. Jama 1997;277:350-6.

68. Croom A, Wiebe DJ, Berg CA, Lindsay R, Donaldson D, Foster C, et al. Adolescent and Parent Perceptions of Patient-Centered Communication while Managing Type 1 Diabetes. J Pediatr Psychol.

69. Arora NK, Weaver KE, Clayman ML, Oakley-Girvan I, Potosky AL. Physicians' decisionmaking style and psychosocial outcomes among cancer survivors. Patient Educ Couns 2009;77:404-12.

70. Fiscella K, Meldrum S, Franks P, Shields CG, Duberstein P, McDaniel SH, et al. Patient trust: is it related to patient-centered behavior of primary care physicians? Med Care 2004;42:1049-55.

71. Clever SL, Ford DE, Rubenstein LV, Rost KM, Meredith LS, Sherbourne CD, et al. Primary care patients' involvement in decision-making is associated with improvement in depression. Med Care 2006;44:398-405.

72. Stewart MA. Effective physician-patient communication and health outcomes: a review. CMAJ 1995;152:1423-33.

73. Beck RS, Daughtridge R, Sloane PD. Physician-patient communication in the primary care office: a systematic review. J Am Board Fam Pract 2002;15:25-38.

74. Cals JW, Butler CC, Hopstaken RM, Hood K, Dinant GJ. Effect of point of care testing for $C$ reactive protein and training in communication skills on antibiotic use in lower respiratory tract infections: cluster randomised trial. BMJ 2009;338:b1374.

75. Travado L, Grassi L, Gil F, Ventura C, Martins C. Physician-patient communication among Southern European cancer physicians: the influence of psychosocial orientation and burnout. Psychooncology 2005;14:661-70.

76. Krasner MS, Epstein RM, Beckman H, Suchman AL, Chapman B, Mooney CJ, et al. Association of an educational program in mindful communication with burnout, empathy, and attitudes among primary care physicians. JAMA 2009;302:1284-93.

77. Ambady N, Laplante D, Nguyen T, Rosenthal R, Chaumeton N, Levinson W. Surgeons' tone of voice: a clue to malpractice history. Surgery 2002;132:5-9.

78. Levinson W, Roter DL, Mullooly JP, Dull VT, Frankel RM. Physician-patient communication. The relationship with malpractice claims among primary care physicians and surgeons. Jama 1997;277:553-9.

79. Beckmann $\mathrm{CH}$. How to avoid being swept away by the rising tide of malpractice litigation. Am J Cardiol 2003;91:585-6.

80. Griffin SJ, Kinmonth AL, Veltman MW, Gillard S, Grant J, Stewart M. Effect on healthrelated outcomes of interventions to alter the interaction between patients and practitioners: a systematic review of trials. Ann Fam Med 2004;2:595-608.

81. Stewart M, Brown JB, Donner A, McWhinney IR, Oates J, Weston WW, et al. The impact of patient-centered care on outcomes. J Fam Pract 2000;49:796-804.

82. Lewin SA, Skea ZC, Entwistle V, Zwarenstein M, Dick J. Interventions for providers to promote a patient-centred approach in clinical consultations. Cochrane Database Syst Rev 2001(4):CD003267. 
83. Cegala DJ, Lenzmeier Broz S. Physician communication skills training: a review of theoretical backgrounds, objectives and skills. Med Educ 2002;36:1004-16.

84. CBO KvdG. Richtlijnontwikkeling binnen het kwaliteitsinstituut voor de gezondheidszorg CBO: Kwaliteitsinstituut voor de gezondheidszorg CBO, 2000.

85. Burgers J. Quality of clinical practice guidelines. Katholieke Universiteit Nijmegen, 2002.

86. Burgers J, Grol R, Eccles M. Clinical guidelines as a tool for implementing change in patient care. In: Grol R, Wensing M, Eccles M, editors. Improving patient care; the implementation of change in clinical practice: Elsevier, 2005.

87. Grol R, Wensing M, Eccles M. Improving patient care; the implementation of change in clinical practice: Elsevier limited, 2005.

88. Grol RP, Bosch MC, Hulscher ME, Eccles MP, Wensing M. Planning and studying improvement in patient care: the use of theoretical perspectives. Milbank Q 2007;85: 93-138.

89. Doyle J. Rational Decision Making. In: Wilson R, Kiel F, editors. The MIT Encyclopedia of the Cognitive Sciences. Cambridge, Massachusetts: MIT press, 1997.

90. Kaufman DM. Applying educational theory in practice. BMJ 2003;326:213-6.

91. Armitage CJ, Conner M. Efficacy of the Theory of Planned Behaviour: a meta-analytic review. Br J Soc Psychol 2001;40(Pt 4):471-99.

92. Watkins C, Harvey I, Langley C, Gray S, Faulkner A. General practitioners' use of guidelines in the consultation and their attitudes to them. Br J Gen Pract 1999;49:115.

93. Grol R, Eccles M, Maisonneuve H, al e. Developing clinical practice guidelines. The European experience. Dis Man Health out 1998;4:255-66.

94. Burgers JS, Cluzeau FA, Hanna SE, Hunt C, Grol R. Characteristics of high-quality guidelines: evaluation of 86 clinical guidelines developed in ten European countries and Canada. Int J Technol Assess Health Care 2003;19:148-57.

95. Grol R, Dalhuijsen J, Thomas S, Veld C, Rutten G, Mokkink H. Attributes of clinical guidelines that influence use of guidelines in general practice: observational study. Bmj 1998;317:858-61.

96. Foy R, MacLennan G, Grimshaw J, Penney G, Campbell M, Grol R. Attributes of clinical recommendations that influence change in practice following audit and feedback. Journal of Clinical Epidemiology 2002;55:717-722.

97. Custers T, Hurley J, Klazinga NS, Brown AD. Selecting effective incentive structures in health care: A decision framework to support health care purchasers in finding the right incentives to drive performance. BMC Health Serv Res 2008;8:66.

98. Van Zanten ME. More than 10 years registration of continuing medical education as part of quality control by the Netherlands Society for Oto-Rhino-Laryngology and Cervico-Facial Surgery. Clin Otolaryngol Allied Sci 2003;28:72-4.

99. Murthy KK. Medical negligence and the law. Indian J Med Ethics 2007;4:116-8.

100. Garattini L, Gritti S, De Compadri P, Casadei G. Continuing Medical Education in six European countries: a comparative analysis. Health Policy;94:246-54.

101. Nedza SM. Commentary: A call to leadership: the role of the academic medical center in driving sustainable health system improvement through performance measurement. Acad Med 2009;84:1645-7.

102. Gevers JK. [Evaluation of the Dutch Medical Treatment Act (WGBO)]. Ned Tijdschr Geneeskd 2001;145:509-12.

103. Paterick TJ, Carso GV, Allen MC, Paterick TE. Medical informed consent: general considerations for physicians. Mayo Clin Proc 2008;83:313-9.

104. LHV, NHG. Competentieprofiel van de huisarts, 2005. 
105. Metz PdJCM, Verbeek-Weel DAMM, Huisjes PdHJ. Raamplan 2001 Artsopleiding; bijgestelde eindtermen van de artsopleiding: Vereniging Samenwerkende Nederlandse Universiteiten, 2001.

106. Grol R, Wensing M. Characteristics of succesvol innovations. In: Grol R, Wensing M, Eccles M, editors. Improving patient care; the implementation of change in clinical practice: Elsevier, 2005.

107. Smith A, Juraskova I, Butow P, Miguel C, Lopez AL, Chang S, et al. Sharing vs. caringThe relative impact of sharing decisions versus managing emotions on patient outcomes. Patient Educ Couns.

108. Mauksch LB, Dugdale DC, Dodson S, Epstein R. Relationship, communication, and efficiency in the medical encounter: creating a clinical model from a literature review. Arch Intern Med 2008;168:1387-95.

109. Dugdale DC, Epstein R, Pantilat SZ. Time and the patient-physician relationship. $J$ Gen Intern Med 1999;14 Suppl 1:S34-40.

110. Maguire P, Pitceathly C. Key communication skills and how to acquire them. BMJ2002;325:697-700.

111. van Thiel J, Ram P, van Dalen J. MAAS-global manual. Maastricht: Maastricht University, 2000. http://www.hag.unimaas.nl/Maas-Global_2000/index.htm.

112. Knottnerus JA. The Netherlands. Research in general practice. Lancet 1996;347:1236-8.

113. WONCA_europe. The european definition of family medicine / general practice. 2005.

114. Lyle J. Stimulated recall: a report on its use in naturalistic research. British Educational Research Journal 2010;29:861-78.

115. Checkland K, Harrison S, Marshall M. Is the metaphor of 'barriers to change' useful in understanding implementation? Evidence from general medical practice. J Health Serv Res Policy 2007;12:95-100. 


\section{Chapter 2}

Much variety and little evidence: a description of guidelines for doctor patient communication

W Veldhuijzen, PM Ram, T van der Weijden, MR Wassink, CPM van der Vleuten Med Educ. 2007;41:138-45 


\section{Abstract}

Aim

To explore the quality of the content of communication skills training programmes we analysed and assessed guidelines for doctor patient communication used in communication programmes for GP trainees.

\section{Method}

Guidelines for doctor patient communication were extracted from educational materials supplied by the eight Dutch university centres for vocational training in general practice. Four themes guided the analysis of the guidelines: content, type of contact, format and structure, and status. The quality of the guidelines was assessed with the AGREE instrument, a validated measurement instrument for guideline quality.

\section{Results}

We identified eighteen guidelines. Guideline content covered $64-100 \%$ of the GP qualification requirements. General consultations and specific situations were the subject of nine guidelines each. Format and structure differed between guidelines. Guideline use seemed not obligatory. AGREE scores were low.

\section{Conclusions}

Guidelines for doctor patient communication are difficult to identify in materials of GP training courses. Guideline quality is low; guidelines are little evidence based and little attention has been paid to applicability and involvement of users. GP qualification requirements are only partly covered. Guidelines differed substantially without clarity about the reasons behind different choices. Guideline status was low.

\section{Recommendations}

When studying the factors that influence training effect, the quality of training content should be considered as well as teaching methods. Communication skills training programmes should be based on evidence-based guidelines that have been developed according to similar standards as for medical technical guidelines. 


\section{Introduction}

Communication skills are an essential component of medical competence. Good communication improves care and enhances patient satisfaction, compliance and health outcomes ${ }^{1-6}$. Moreover, good doctor patient communication can lead to lower utilisation of health care resources ${ }^{6}$. Doctor patient communication has been shown to exhibit many shortcomings, therefore much effort has been put into communication skills training in pregraduate and postgraduate medical education ${ }^{7-9}$. Unfortunately, however, there appears to be a lack of evidence of actual improvement in doctor patient communication in clinical practice. Contrary to reported positive effects of communication skills programmes in educational settings, improvements observed in authentic health care settings are limited ${ }^{9-14}$. One might look for explanations in three areas: the designs of the studies that evaluated the effects of training, the measurement instruments used and the quality of the training programmes. The quality of training programmes can only be assessed if sufficient data about programmes are available. In an overview of studies of research on communication skills training for doctors, Cegala et al. reported that the majority of studies failed to provide sufficient details of training content ${ }^{11}$. The content of communication skills programmes are described in a few case reports only ${ }^{15,16}$.

The study reported in this paper focused on the content of communication skills programmes. The first step in developing a communication skills programme is to determine which behaviours are to be fostered by the programme. Programme developers are advised to select these behaviours on the basis of evidence from research6,17-19. Clinical guidelines are evidence-based descriptions of desired behaviour and intended to improve quality of care by influencing professional behaviour ${ }^{20,21}$. Therefore the quality of the content of a communication skills programme depends to a great extent on the quality of the communication guidelines on which the programme is based. To our knowledge, no systematic descriptions are available of guidelines for doctor patient communication used for communication skills programmes. Moreover, no quality assessments of available guidelines have been done with validated instruments.

We tried to answer the following three questions:

1. What guidelines for doctor patient communication are used on the eight Dutch centres for vocational training in general practice?

2. What do these guidelines look like, in terms of content, type of contact, format and structure, and status.

3. What is the quality of these guidelines?

We focussed on GP training in the Netherlands, because it has a rich history of evolution in communication skills training22. As we have not been able to find a measurement instrument that assesses specifically the quality of communication 
guidelines, we used the AGREE instrument to assess our guidelines. AGREE is an internationally validated instrument for the assessment of clinical guidelines, which evaluates guidelines with regard to clarity, development rigour, stakeholder involvement and applicability 23 .

\section{Methods}

\section{Identification of guidelines}

The coordinators of communication skills training of the eight GP training programmes in the Netherlands were interviewed by telephone and asked to indicate the guidelines for doctor patient communication that were used in their programmes. This question proved difficult to answer. The coordinators had trouble deciding of some materials were guidelines or not. Many coordinators did not have an overview on which guidelines were used. We therefore asked the coordinators to send us educational materials relating to communication skills. We limited the investigation to the written materials that were used as trainer guides or were handed out to GP trainees in the course. Next we scrutinised the materials in order to identify guidelines. We defined as guidelines documents that called itself a guideline in it's name or introduction, or that contained one or more recommendations regarding doctor patient communication in the form of tips, advice or instructions. Instructions for the observation and evaluation of specific GP behaviours (i.e. assessment instruments) were regarded as indirect recommendations to exhibit those behaviours and thus as guidelines. We sent lists of the identified guidelines to the coordinators, asking them to send us any guidelines they thought we had overlooked as well as written information on the development of the guidelines. Coordinators who did not respond were reminded by telephone.

\section{Description of guidelines}

Based on the experience of the authors with guidelines and communication skills programmes and on the conclusions of expert meetings ${ }^{24}$, the following four themes were chosen as the framework for the description of guideline characteristics:.

- the content of the guideline;

- the type of doctor patient contact to which the guideline applies, i.e. general consultations or specific situations, such as breaking bad news or managing psychosocial complaints, which might require specific skills;

- format and structure of the guidelines, i.e. what form do they take, how are the recommendations ordered?; 
- the status of the guideline, i.e. gives the guideline any clues about whether using it is obligatory or not?

The first author and the fourth author together drew up a list of relevant items for each theme. Considering that a complete qualitative content analysis of the guidelines would take to much time, 'content' was operationalised as the match with the requirements for qualification as a GP. The fourth author made descriptions of the guidelines on the basis of the list of items. The first author checked the accuracy of these descriptions.

Uncertainties and differences of interpretation were discussed until consensus was reached. The match with GP qualification requirements was determined by the number of recommendations in the qualification requirements that were covered by the guideline and vice versa. New items were added to the list whenever the first author or the fourth author noticed a guideline contained relevant characteristics that were not covered by the items in the list. Each guideline was examined and described for all of the items.

\section{Assessment of guideline quality}

Once the list of guidelines was completed, the quality of the guidelines (Table 2.1) was assessed using AGREE. The written information about the guidelines was used as an additional information source on guideline development. AGREE assesses guideline quality on 23 items in six domains (Box 2.1; Table 2.3). Scores are expressed as percentages of the maximum score. The first author scored all guidelines. Doubts were discussed with the fourth author.

\section{Results}

\section{Identification of guidelines}

All eight universities sent in written materials on doctor patient communication, varying from a single document containing recommendations for communication to syllabuses covering a whole year. Extracting guidelines from these materials proved difficult because passages in documents on communication could not always be easily separated from passages on other subjects. Distinguishing between guidelines and other types of information proved difficult as well. The only guideline that was plainly identified as such by its title was the guideline developed by the Dutch College of General Practitioners. Seven documents stated that they included recommendations for communication. The remaining documents had to be scrutinized for recommendations on doctor patient communication, because these were often 'hidden' in the text. 
In the material we examined, fifteen guidelines for doctor patient communication were identified (Table 2.1). When asked to send additional materials, two coordinators sent new guidelines. This yielded a total of eighteen guidelines.

All guidelines addressed verbal communication. Some guidelines contained also some recommendations for non-verbal communication. None of the guidelines contained references to written communication.

Seven guidelines are presented as 'models' in the title or in the introduction, three as 'assessment instruments' and one as 'guideline'. Seven guidelines did not contain indications about their nature. The number of recommendations in the guidelines varied between 5 and 66 .

Table 2.1 Guidelines for doctor patient communication, handed out to GP trainees, by university.

\begin{tabular}{|c|c|}
\hline University & Guidelines* $^{*}$ \\
\hline Erasmus University Rotterdam & - MAAS-global manual 2000 15, 28, 29 \\
\hline Radboud University Medical & - Syllabus consultations in general practice \\
\hline Centre Nijmegen & $\begin{array}{l}\text { - The five-consultations model } \\
\text { - MAAS-global manual } 2000 \text { 15, 28, } 29 \\
\text { - NHG-cahier 1: How may I help you? Why patients visit their GP. }\end{array}$ \\
\hline University of Groningen & $\begin{array}{l}\text { - Consultations in general practice } \\
\text { - MAAS-global manual } 200015,28,29 \\
\text { - NHG: General practitioner and patient: guidelines and starting points }\end{array}$ \\
\hline Leiden University & - MAAS-global manual 2000 15, 28, 29 \\
\hline Maastricht University & $\begin{array}{l}\text { - MAAS-global manual } 2000 \text { 15,28,29 } \\
\text { - A model for the structure of a consultation } \\
\text { - Calgary-Cambridge guides } 26 \\
\text { - } 6 \text { step conflict management model }\end{array}$ \\
\hline University of Amsterdam & $\begin{array}{l}\text { - The consultation model } \\
\text { - Phasing of a bad news conversation } \\
\text { - Talking about errors } \\
\text { - Counselling conversation model }\end{array}$ \\
\hline Utrecht University & $\begin{array}{l}\text { - No title, } 176 \text { pages, Syllabus year } 1 \\
\text { - Laconto } \\
\text { - A bad news model } \\
\text { - Managing medically unexplained complaints }\end{array}$ \\
\hline Free university of Amsterdam & $\begin{array}{l}\text { - Syllabus: consultations in general practice } \\
\text { - MAAS-global manual } 200015,28 \\
\text { - Model for the bad news conversation }\end{array}$ \\
\hline
\end{tabular}

\footnotetext{
* The titles of the guidelines have been translated from Dutch into English.
} 
Box 2.1

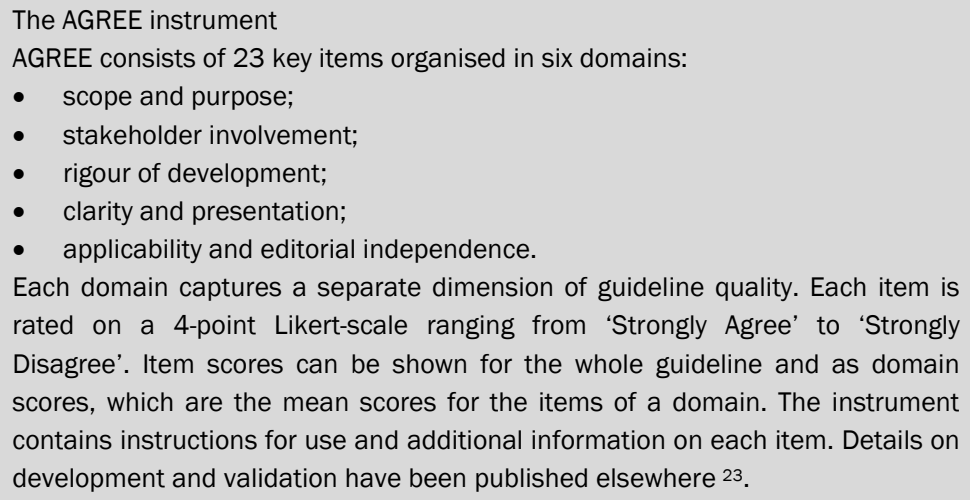

\section{Description of guidelines (Table 2.2)}

\section{Content}

One university's guidelines covered all GP qualification requirements. The guidelines of other universities covered less, with a minimum of $64 \%$.

Five universities used two or more guidelines for generic consultations. These guidelines did different recommendations and covered different qualification requirements accordingly. We were therefore unable to discern exactly which recommendations the universities wanted the trainees to follow.

Five guidelines contained only recommendations that did not match the qualification requirements. One guideline fully matched the qualification requirements, this was the guideline that also completely covered them.

None of the recommendations conflicted with the qualification requirements.

\section{Type of contact}

Nine guidelines referred to generic consultations, three to breaking bad news and one each to emerging conflict, psychosocial care, atypical complaints, somatic complaints, disclosing errors and counselling. None of the guidelines made reference to the setting of the consultation, for instance the GP's office, telephone call or house call. All the programmes used one to three guidelines for generic consultations and five programmes used one to three guidelines for specific consultations as well.

Nine guidelines were concerned with one consultation, four guidelines concerned two or more related consultations, and five guidelines did not indicate the time span involved. 


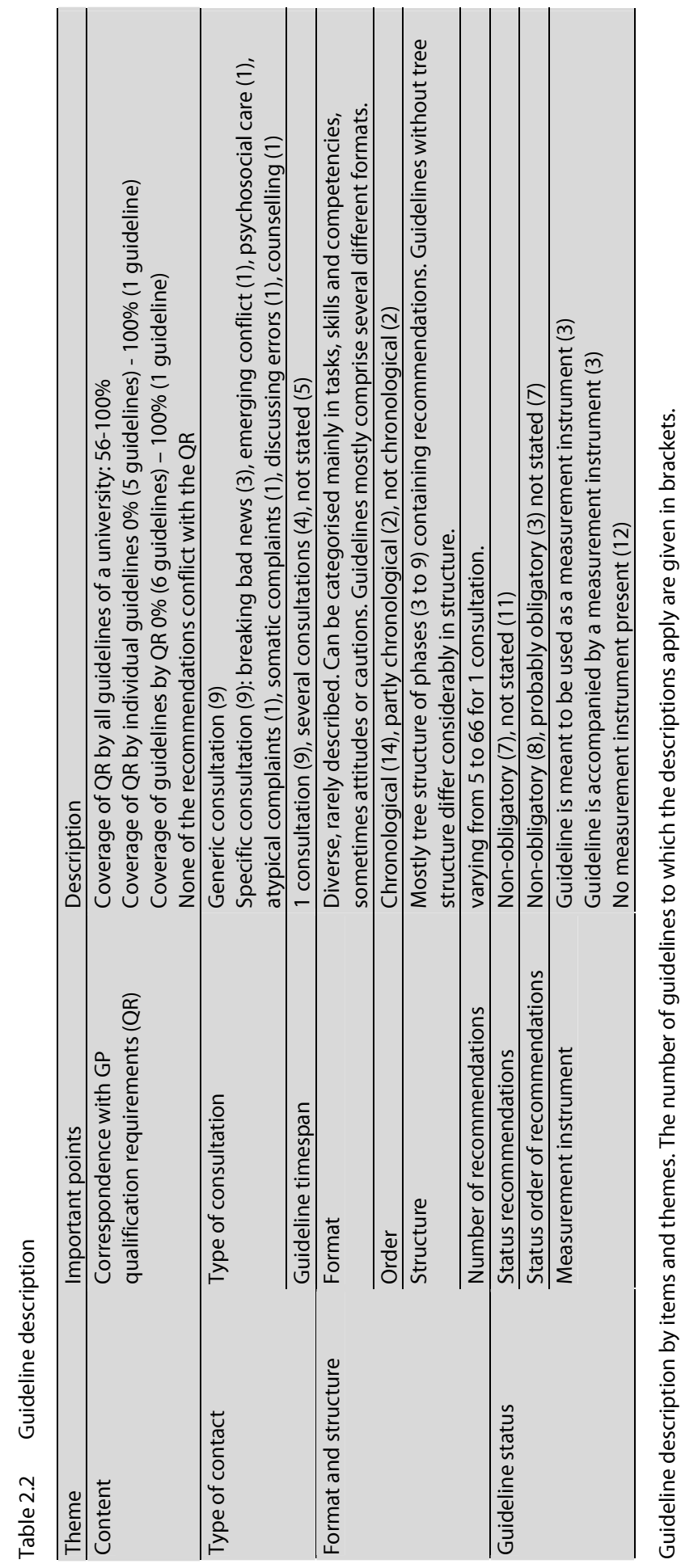




\section{Format and structure}

In sixteen of the eighteen guidelines the recommendations were to a greater or lesser extent ranked in a chronologic order. Twelve guidelines presented recommendations in a tree like structure consisting of consecutive consultation phases with recommendations for each phase. The numbers of phases and recommendations differed considerably. The structure of the remaining guidelines varied. The recommendations came in the shape of tasks, caveats, competencies and attitudes.

\section{Status}

In seven guidelines it was explicitly stated that their use was not obligatory. For example the Dutch Society of General Practitioners, which issues many medical technical guidelines of which application is strongly advised, states that their communication guideline is elaborated to stimulate discussion. None of the guidelines stated explicitly that it was obligatory to follow the recommendations. Three guidelines implicitly suggest the latter.

Because adherence to the guidelines is not mandatory, it would seem that GP trainees cannot be required to follow them. However, three of the guidelines are meant to be used as assessment instruments. Besides that, three assessment instruments with similar contents as guidelines were found. Apparently, demands are made in spite of the non-obligatory status of the guidelines.

\section{Guideline quality assessment}

The quality of the communication guidelines was assessed with the AGREE instrument. Mean scores on the AGREE instrument varied from $6 \%$ for the generic guideline of Utrecht University to $27 \%$ for the Calgary-Cambridge observation list. In the overall score for all the guidelines, four domains received mean scores below $20 \%$, i.e. 'editorial independence' $0 \%$; 'rigour of development' (3\%), 'applicability' (11\%) and 'stakeholder involvement' (17\%). The scores on the domains 'scope and purpose' (27\%) and 'clarity and presentation' (38\%) were higher. The AGREE scores of the communication guidelines were more than 50\% lower than the scores usually obtained by medical technical guidelines (Table 2.3) ${ }^{25}$.

Little information was provided about how the guidelines were developed. It would appear that the communication guidelines have no sound evidence base or it may be that supporting evidence was not recorded or supplied. As for applicability, some guidelines give criteria for monitoring adherence. Hardly any attention is paid to organisational barriers or cost implications. Guidelines score low on 'stakeholder involvement', because the methods used for development are not very patient or user centred. Although target users are identified, it is rarely mentioned whether a group developed the guideline and whether guideline users participated in the group, whether patients' views and preferences were taken into account and 
whether the guideline was piloted among prospective users.

Guideline goal and patient population are often described. Clinical questions that the guidelines should answer are almost never described. In the domain "clarity and presentation' a lack of clarity about different options was prominent, e.g. most guidelines give only a singular line of action.

Table 2.3 Quality scores on AGREE in percentages.

\begin{tabular}{|c|c|c|}
\hline & $\begin{array}{l}\text { Mean score } \\
\text { for DPC } \\
\text { guidelines }\end{array}$ & $\begin{array}{l}\text { Mean score } \\
\text { for medical } \\
\text { technical } \\
\text { guidelines } 25\end{array}$ \\
\hline Scope and purpose & 27 & 56 \\
\hline Objectives described & 33 & \\
\hline Clinical questions described & 9 & \\
\hline Patient population described & 40 & \\
\hline Stakeholder involvement & 17 & 58 \\
\hline Guideline development group includes all relevant professional groups & 13 & \\
\hline Patient views and preferences sought & 9 & \\
\hline Target users defined & 39 & \\
\hline Guideline piloted among target users & 6 & \\
\hline Development rigour & 3 & 47 \\
\hline Systematic methods used searching evidence & 0 & \\
\hline Criteria for selecting evidence described & 0 & \\
\hline Methods for formulating recommendations described & 0 & \\
\hline Health benefits, side effects and risks were considered & 6 & \\
\hline Explicit link between supporting evidence and recommendations & 9 & \\
\hline External review by experts before publication & 6 & \\
\hline Procedure for updating provided & 0 & \\
\hline Clarity and presentation & 38 & 74 \\
\hline Specific and unambiguous recommendations & 42 & \\
\hline Different management options presented & 22 & \\
\hline Identifiable key recommendations & 41 & \\
\hline Tools for application present & 46 & \\
\hline Applicability & 11 & 29 \\
\hline Organizational barriers in applying discussed & 2 & \\
\hline Cost implications of applying considered & 4 & \\
\hline Key review criteria for monitoring present & 26 & \\
\hline Editorial independence & 0 & 22 \\
\hline Guideline editorial independent from funding & 0 & \\
\hline Conflicts of interest recorded & 0 & \\
\hline
\end{tabular}

\section{Discussion}

As far as we know, this is the first study to describe the guidelines used in communication skills programmes for GP trainees and assess the quality of these guidelines. 
Guidelines for GP-patient communication proved difficult to find. Even communication programme coordinators had trouble identifying them and they were not easily distinguishable from other educational material, because only one of them defined itself as a 'guideline'. Our search yielded eighteen guidelines, all focussing primarily on verbal communication, with little attention for nonverbal communication. Nine guidelines referred to general consultations and nine referred to specific consultations. There are substantial differences between the types of contacts for which guidelines are developed, in the contents of the guidelines and in the format and structure of guidelines, without it being clear why these different choices were made. The contents of the guidelines even differed in guidelines for the same type of consultation that were used in singular communication skills programmes, and they corresponded only partly with the qualification requirements, making it unclear which behaviours are fostered by the programmes. Guideline status was unclear, as application was either not mandatory or application demands had not been defined in the guidelines, but guideline use is assessed in spite of this. Guideline quality was low, with AGREE items referring to evidence basedness and items referring to stakeholder involvement and applicability scoring especially low.

Although only locally used guidelines were included, one of them, the CalgaryCambridge guides is used in many countries ${ }^{26}$. It is recommended as "one of the most comprehensive and useful frameworks for instruction in communication skills available' and has received international praise for its scientific underpinnings. It is also the guideline with the highest quality in our study6,11,18. Still it scores only about half the mean score for medical technical guidelines ${ }^{25}$.

The AGREE measurement instrument has been internationally validated for the assessment of clinical guidelines and is mostly used for medical technical guidelines. We think however that communication guidelines should meet the same criteria of clarity, evidential support, stakeholder involvement and applicability as guidelines for medical technical skills. AGREE can therefore be used to assess these qualities. Editorial independence is probably less relevant for communication guidelines, because conflicts of interests seem unlikely.

Some of the choices we made in this study may be questioned. We included only guidelines that were available on paper and handed out to trainees or trainers. This excluded guidelines in recommended readings, which students would have to look up for themselves. Perhaps more guidelines are used in GP training than the ones we identified in this study.

We used a rather broad definition of guideline because we wanted to prevent unjustified exclusion of relevant guidelines. On the other hand, however, this may have caused inclusion of materials that were not intended as clinical guideline. Low 
scores of these pseudo-guidelines on the AGREE instrument may have depressed overall scores. However, the absolute effect of this is probably low, seeing that the highest sum score on the AGREE instrument found in this study was about half the score of medical technical guidelines.

In order to run an effective skills programme it should be clear which behaviours are to be fostered by the programme. The quality of the content of a communication skills programme depends to a great extent on the quality of the communication guidelines that describe these desired behaviours ${ }^{7}$. Our results show little clarity about which behaviours are desired, and a low guideline quality and status. Both this lack of clarity and this low status may reflect the difficulty of developing generic communication guidelines that have to relate to consultations with a myriad of different purposes.

The ability of guidelines to stimulate the change of behaviours in clinical practice is promoted by their clarity, quality and by their status ${ }^{27}$. The problems communication guidelines exhibit for these areas probably result in a lack of quality of training content that considerably adds to the difficulties of medical education to actually improve doctor patient communication in clinical healthcare.

When studying the factors that influence training effect in authentic health care settings, the quality of training content should be considered as well as teaching methods. To give an adequate description of the educational intervention, published evaluation studies should, besides describing teaching methods, contain enough information about the training content to give an impression of their quality.

To heighten the quality of training content communication guidelines should be used that are in correspondence with other guidelines and qualification demands. Problems in using generic guidelines for consultations with different purposes and patient preferences, should lead to a differentiation of communication guidelines instead of resulting in inconsistencies in programme content and low guideline status. In the development of communication guidelines the same quality demands should be made of supporting evidence, user involvement and applicability as are made for medical technical guidelines. Communication guidelines would then really deserve the name 'clinical guideline' and an according status, e.g. to be adhered to, unless there are reasons to deviate from them. Which format and structure are the most useful for communication guidelines and for which situations guidelines should be available, are questions that might be answered by further research. 


\section{Literature}

1. Bensing J. Doctor-patient communication and the quality of care. Soc Sci Med 1991; 32:1301-10.

2. Matthews DA, Suchman AL, Branch WT, Jr. Making "connexions": enhancing the therapeutic potential of patient-clinician relationships. Ann Intern Med 1993;118: 973-7.

3. Ong LM, de Haes JC, Hoos AM, Lammes FB. Doctor-patient communication: a review of the literature. Soc Sci Med 1995;40:903-918.

4. Stewart MA. Effective physician-patient communication and health outcomes: a review. CMAJ 1995;152:1423-33.

5. Stewart MA, Brown JB, Donner A, McWhinney IR, Oates J, Weston W. Final report: the impact of patient-centred care on patient outcomes on family practice: Thames Valley Practice Research Unit; 1996.

6. Silverman J, Kurtz S, Draper J. Skills for communicating with patients. Oxford - San Francisco: Radcliffe; 2005.

7. Kurtz S, Silverman J, Draper J. Teaching and learning communication skills in medicine. Oxford - San Franscisco: Radcliffe Publishing; 2005.

8. Simpson M, Buckman R, Stewart M, Maguire P, Lipkin M, Novack D, Till J. Doctor patient communication: the Toronto consensus statement. BMJ 1991:1385-7

9. Haidet P, Paterniti DA. "Building" a history rather than "taking" one: A perspective on information sharing during the medical interview. Archives of Internal Medicine. 2003;163:1134-40.

10. Lewin SA, Skea ZC, Entwistle V, Zwarenstein M, Dick J. Interventions for providers to promote a patient-centred approach in clinical consultations. Cochrane Database Syst Rev 2001:CD003267.

11. van Dalen J, Kerkhofs E, van Knippenberg-Van Den Berg BW, van Den Hout HA, Scherpbier AJ, van der Vleuten CPM. Longitudinal and concentrated communication skills programmes: two dutch medical schools compared. Adv Health Sci Educ Theory Pract 2002;7:29-40.

12. Cegala DJ, Lenzmeier Broz S. Physician communication skills training: a review of theoretical backgrounds, objectives and skills. Med Educ 2002;36:1004-16.

13. Hulsman RL, Ros WJ, Winnubst JA, Bensing JM. Teaching clinically experienced physicians communication skills. A review of evaluation studies. Med Educ 1999;33: 655-68.

14. Kramer AW, Dusman H, Tan LH, Jansen JJ, Grol RP, van der Vleuten CP. Acquisition of communication skills in postgraduate training for general practice. Med Educ 2004;38:158-67.

15. Van Dalen J, Bartholomeus P, Kerkhofs E, Lulofs R, Van Thiel J, Rethans JJ, Scherpbier AJ, Van Der Vleuten CP. Teaching and assessing communication skills in Maastricht: the first twenty years. Medical Teacher 2001;23: 245-51.

16. Shapiro J, Lie D. Using literature to help physician - Learners understand and manage 'difficult' patients. Academic Medicine 2000;75:765-8.

17. Schofield PE, Butow PN. Towards better communication in cancer care: a framework for developing evidence-based interventions. Patient Educ Couns 2004;55:32-9.

18. Suchman AL. Research on patient-clinician relationships: celebrating success and identifying the next scope of work. J Gen Intern Med 2003;18:677-8.

19. Spencer J, Silverman J. Education for communication: much already known, so much more to understand. Med Educ 2001;35:188-90. 
20. Burgers J. Quality of clinical practice guidelines. Nijmegen, Katholieke Universiteit Nijmegen; 2002.

21. Burgers JS, Van Everdingen JJE. Beyond the evidence in clinical guidelines. Lancet 2004;364:392-3.

22. de Melker RA. It takes two to tango. Huisarts en Wetenschap 2001;44:258-9.

23. Group. TAcW, Cluzeau FA, Burgers JS, et al. Development and validation of an international appraisal instrument for assessing the quality of clinical pracitce guidelines: the AGREE project. Qual Saf Health Care 2003;12:18-23.

24. Kramer A. Verslag invitational conference over consultvoering: Stichting Verenigde Universitaire Huisartsopleidingen; 2000.

25. Burgers JS, Boluyt N. An assessment using the AGREE instrument of the quality of clinical practice guidelines produced by the Dutch Institute for Healthcare Improvement (CBO) and the Dutch College of General Practitioners (NHG) evaluation. Huisarts en Wetenschap 2004;47:394-9.

26. Silverman J, Kurtz S, Draper J. Skills for communicating with patients. Oxon: Radcliffe Medical Press; 1998.

27. Grol R, Wensing M, Eccles M. Improving patient care; the implementation of change in clinical practice: Elsevier limited; 2005.

28. Hobma SO, Ram PM, Muijtjens AMM, Grol RPTM, van der Vleuten CPM. Setting a standard for performance assesment of doctor-patient communication in general practice MED-EDUC. Medical-Education 2004;38: 1244-52.

29. van Thiel J, Ram P, van Dalen J. MAAS-global manual. Maastricht: Maastricht University press; 2000. 


\section{Chapter 3}

\section{Characteristics of communication guidelines that facilitate or impede guideline use: a focus group study}

W Veldhuijzen, PM Ram, T van der Weijden, S Niemantsverdriet, CPM van der Vleuten 


\subsection{Abstract}

\section{Background}

The quality of doctor-patient communication has a major impact on the quality of medical care. Communication guidelines define best practices for doctor patient communication and are therefore an important tool for improving communication. However, adherence to communication guidelines remains low, despite doctors participating in intensive communication skill training. Implementation research shows that adherence is higher for guidelines in general that are user centred and feasible, which implies that they are consistent with users' opinions, tap into users' existing skills and fit into existing routines. Developers of communication guidelines seem to have been somewhat negligent with regard to user preferences and guideline feasibility. In order to promote the development of user centred and practicable communication guidelines, we elicited user preferences and identified which guideline characteristics facilitate or impede guideline use.

\section{Methods}

Seven focus group interviews were conducted with experienced GPs, communication trainers (GPS and behavioural scientists) and communication learners (GP trainees and medical students) and three focus group interviews with groups of GP trainees only. All interviews were transcribed and analysed qualitatively.

\section{Results}

The participants identified more impeding guideline characteristics than facilitating ones. The most important impeding characteristic was that guidelines do not easily fit into GPs' day-to-day practice. This is due to rigidity and inefficiency of communication guidelines and erroneous assumptions underpinning guideline development. The most important facilitating characteristic was guideline structure. Guidelines that were structured in distinct phases helped users to remain in control of consultations, which was especially useful in complicated consultations.

\section{Conclusions}

Although communication guidelines are generally considered useful, especially for structuring consultations, their usefulness is impaired by lack of flexibility and applicability to practice routines. User centred and feasible guidelines should combine the advantages of helping doctors to structure consultations with flexibility to tailor communication strategies to specific contexts and situations. 


\subsection{Background}

Most doctors are familiar with clinical guidelines for medical technical purposes, such as managing diabetes or hypertension. Guidelines for doctor patient communication are less commonly used, however, although there appears to be no reason why this domain should be excluded from guideline development. The doctor patient relationship is an important factor in health care and the quality of doctor-patient communication has been shown to impact strongly on the quality of medical care. Good doctor patient communication enhances patient satisfaction and work satisfaction of doctors, moreover it lowers use of health care resources, and improves health outcomes of patients ${ }^{1-14}$. Many authors have presented models, frameworks, guides or guidelines for best practices in doctor patient communication which can be used to shape the content of communication training courses $6,15-20$. Henceforward we will use the term 'communication guidelines' to refer to all documents containing evidence based recommendations for doctor patient communication, even when another designation is used in the document itself or in the literature. We use the term guideline because it has been clearly defined and because of the existing knowledge about implementing guidelines.

Clinical guidelines help practitioners to practise evidence based medicine in routine practice and are considered to be important tools for improving the quality of health care ${ }^{21-23}$. However, doctors' adherence to guidelines generally varies and can be quite low sometimes ${ }^{24-27}$. In the case of doctor patient communication, doctors have shown low adherence to guidelines, despite extensive training9,13,28-32.

Guideline implementation has been addressed by many recent studies. User centredness and feasibility of guidelines have been found to facilitate implementation $23,25,33$. This implies that it is important for guidelines to be in agreement with users' opinions, tap into users' existing skills and fit into existing routines. These characteristics can be enhanced by involving future guideline users in guideline development and evaluation ${ }^{23,25}$.

Implementation research has primarily focussed on medical technical guidelines. Doctor patient communication has been relatively neglected, with a noticeable dearth of studies on the applicability of communication guidelines ${ }^{34}$.

Efforts to address implementation problems of communication guidelines have focused primarily on improving the implementation strategy by optimising training methods. Optimal training methods combine explanation of communication theory with many opportunities for students to practise communication skills, within a longitudinal training programme $35-40$. 
Criticisms of the applicability of communication guidelines have been countered by suggestions for changing practitioners' attitudes or even the organisation of health care, but have rarely resulted in revisions of communication guidelines ${ }^{41-44}$. There is little evidence that doctors' views and preferences are being sought and taken into account when communication guidelines are being developed and evaluated ${ }^{16,45}$. Broadly speaking, there are indications that the use of communication guidelines can be promoted by making them more user centred and feasible.

We conducted ten focus groups interviews in which guideline users discussed characteristics of communication guidelines that facilitated or impeded their use. We explored ways to develop more user centred and applicable guidelines.

\subsection{Methods}

\section{Participants}

Since communication skills training has a long history in general practice, we conducted our study within the setting of the Dutch centres for postgraduate specialist training in general practice. These centres are located in the Departments of Family Medicine of the eight Dutch Faculties of Medicine. We sought the opinions of different groups of guideline users, because we hoped that this would yield a rich diversity of experiences. We asked the eight GP training centres to invite experienced GPs, communication trainers (GPs and behavioural scientists) and communication learners (GP trainees and medical students) to take part in a focus group interview at the training centre. Because not all centres use the same guidelines, the focus group participants differed as to which guidelines they used and for which purpose (clinical practice, learning, teaching) they used it. To elicit unbiased opinions from participants with lower status (i.e. trainees and students), including opinions that might be disagreeable to higher status participants (i.e. teachers), we organised three trainee-only focus groups in addition to the mixed group sessions planned for each of the eight training centres. The three trainee-only groups consisted of a group of first year trainees, a group of last year trainees and a combined group of first and last year trainees. The participants in the third group were selected based on their teachers' expectations that they would voice strong opinions, both positive and negative, about communication training.

\section{Data collection}

The moderator of the focus groups was experienced in qualitative interviews (WV). Each group focused on the guideline for GP patient communication that was most 
commonly used in the training centre where the interview was held (see appendix 1). We adhered to the definition of a communication guideline as a document "containing recommendations, guidance and instructions about doctor patient communication, intended to support daily practice in health care and based on results of scientific research and the consequent discussion and formation of opinion, aimed at the explicit statement of good medical practice'46. Participants were invited to discuss guideline features that facilitated or impeded guideline use as well as ways of improving the communication guidelines.

\section{Data analysis}

All focus group discussions were audiotaped and transcribed. The transcriptions were analysed by WV using specialised software (Atlas-ti). All phrases relating to the research questions and interview topics were coded and the resulting codes were placed in code networks displaying the relationships between the codes, to facilitate the formation of concepts, categories and hypotheses. Guideline characteristics that impeded and guideline characteristics that facilitated guideline use as well as suggestions for improvement were analysed for common themes and categorised according to these themes. To maximise richness of interpretation six of the ten focus group interviews were analysed independently by three different researchers with different backgrounds (PR, TvdW, and SN). These analyses were compared with those of the first researcher (WV) and differences of interpretation were discussed until consensus was reached.

\subsection{Results}

\section{Participation}

Because one GP training centre was unable to participate due to time constraints, we organised one focus group interview in each of seven training centres. Additionally, three trainees-only sessions were organised. In all, seven mixed focus group sessions and three trainee-only sessions were held. The attendants of the mixed groups were: six experienced GPs, nineteen communication trainers (eight experienced GPs, eleven behavioural scientists), seven GP trainees and four medical students. Twenty-seven GP trainees attended the trainee only groups. Mean duration of the focus group sessions was 90 minutes. All sessions were characterised by animated discussions.

\section{Communication guidelines}

Four training centres use the same communication guideline and three centres use a different guideline each (see appendix 1). This meant that we obtained results for four different guidelines. All guidelines pertain to general consultations and provide 
recommendations for consecutive phases of the consultation. More detailed descriptions can be found in Appendix 2.

Which guideline was discussed did not seem to have a major impact on the discussion. There were no pronounced differences between the guidelines with regard to barriers and facilitating factors that emerged during the group discussions. The behavioural science teachers tended to hold the most positive opinions of the guidelines and GP trainees were the most critical judges. There was no category of opinion, however, that was mentioned by one group only, or that was not mentioned by one of the groups, besides the differences in guideline use between learners and GPs, described in the next section.

\section{Guideline use}

While discussing impeding and facilitating characteristics of the guidelines, the guideline users mentioned different ways of using a guideline. Because this offers valuable insight into users' needs and how these affect impeding and facilitating characteristics, we will first focus on guideline use.

The participants described six different uses of the communication guideline (Table 3.1). Students and some trainees were the only ones to report full guideline use.

Table 3.1 Guideline use as described by the participants in the focus groups.

\begin{tabular}{|c|c|c|}
\hline $\begin{array}{l}\text { Integral or } \\
\text { partial use }\end{array}$ & Type of use & Description \\
\hline Partial use & Selective use & $\begin{array}{l}\text { The guideline is used when it is considered to be especially } \\
\text { useful, e.g. when the consultation is not going well. }\end{array}$ \\
\hline Partial use & Fragmented use & $\begin{array}{l}\text { Only some of the recommendations in the guideline are used. } \\
\text { Which recommendations are used depends on: doctor } \\
\text { characteristics (personal style, experience, goals), perceived } \\
\text { patient characteristics (clarity, assertiveness), type of } \\
\text { consultation (first consultation, follow-up visit), and type of } \\
\text { complaint (somatic, psychosocial). }\end{array}$ \\
\hline Partial use & Modified use & $\begin{array}{l}\text { Most of the recommendations in the guideline are used, with } \\
\text { some deliberate additions and/or omissions. }\end{array}$ \\
\hline Integral use & Dispersed use & $\begin{array}{l}\text { All recommendations in the guideline are used, dispersed over } \\
\text { several consultations }\end{array}$ \\
\hline Integral use & Implicit use & $\begin{array}{l}\text { All recommendations in the guideline are used, but less } \\
\text { explicitly and with more non-verbal communication than is } \\
\text { recommended. }\end{array}$ \\
\hline Integral use & Full use & $\begin{array}{l}\text { All the recommendations in the guideline are used in a single } \\
\text { consultation, mostly in the recommended order. }\end{array}$ \\
\hline
\end{tabular}

Experienced GPs and GP trainers generally used only parts of the guideline, i.e. only those recommendations they thought were appropriate for a particular situation. 
It's just my toolkit. For a nail you use a hammer and when a screw turns up you start looking for a screwdriver.

GP trainee/UVA

It's some sort of theoretical schema for a consultation from which you use what you need at the time. What you don't need you simply leave out.

GP trainer/VU

It's a framework in your mind which you use to structure the interview and it depends on the person sitting opposite you and their wishes and needs how you proceed.

Behavioural scientist/UVA

The desirability of using only parts of a guideline was debated. Some argued that using only those recommendations that help doctors achieve their objective in a particular consultation is the most professional usage of communication guidelines. Other participants doubted whether doctors are capable of making the right choices when using only parts of a guideline. They cautioned against inaccurate assumptions and incomplete information.

The fact that a GP conducts a consultation in a purposeful manner. That he can change his goal because the patient suddenly changes his appeal for help. Noticing that and acting upon it, changing your goal and then working towards it. All that is part of professionalism.

Behavioural scientist/Rotterdam

\section{Facilitating and impeding guideline characteristics}

The greater part of the discussions was devoted to guideline characteristics that impeded guideline use. When invited to discuss facilitating characteristics, participants frequently digressed and turned the discussion to impeding characteristics instead. Two central themes emerged from these discussions. The first one was 'Guideline development'. Within this theme, two sub-themes can be distinguished: 'Procedural development flaws' and 'Assumptive flaws'. The second central theme was 'Impact of guideline use' with the sub-themes: 'Impact on consultation process' and 'Other impact'. Table 3.2 categories the impeding and facilitating guideline characteristics in accordance with these themes. We will discuss them in the following section. 
Table 3.2 Facilitating factors and barriers to guideline use, by theme.

\begin{tabular}{|c|c|}
\hline Theme & Guideline characteristics \\
\hline Procedural development flaws & $\begin{array}{l}\text { - Supporting evidence is not convincing } \\
\text { - Lack of instructions for use } \\
\text { - Guideline developers are not representative of the target group }\end{array}$ \\
\hline Assumptive flaws & $\begin{array}{l}\text { Erroneous assumptions about patients } \\
\text { - Not all patients are equal negotiating partners. } \\
\text { - Not all patients have a background in Western culture. } \\
\text { - Not all patients present with a new, well defined medical } \\
\text { complaint. } \\
\text { - Not all patients come by themselves. } \\
\text { Erroneous assumptions about doctors } \\
\text { - Not all communication is verbal. } \\
\text { - Doctors need to be in charge. } \\
\text { - Experienced doctors communicate differently. } \\
\text { - Doctors want to have the opportunity to express a personal } \\
\text { interest in their patients. } \\
\text { - Using the guideline is too energy consuming } \\
\text { Erroneous assumptions about the situation } \\
\text { - Different situations need different approaches. } \\
\text { - The guideline does not support long-term patient management } \\
\text { strategies. }\end{array}$ \\
\hline Impact on the consultation process & $\begin{array}{l}\text { + More grip on the consultation; } \\
\text { + More clarity for patients; } \\
\text { - Less focus on the 'here and now'. }\end{array}$ \\
\hline Other impact & $\begin{array}{l}\text { + Higher quality of consultations; } \\
\text { + Does justice to both patient and doctor; } \\
\text { + Less chance of jumping to conclusions; } \\
\text { + Fewer unreasonable patients; } \\
\text { - Loss of time; } \\
\text { - Loss of natural interaction and personal style; } \\
\text { - Creating anxiety in patients. }\end{array}$ \\
\hline
\end{tabular}

\section{Guideline development}

\section{Procedural development flaws}

The users were of the opinion that procedural errors made during guideline development compromised the quality of the guidelines. Three types of development flaws were distinguished.

The supporting evidence is not convincing

The users thought that the recommendations were consensus based rather than evidence based. Moreover, the effectiveness of the guideline had not been tested in general practice and the underlying assumptions and beliefs were not described. 
Lack of instructions for use

The users noted a lack of information as to how and in which situations the recommendations were to be used or which of the recommendations were expected to be used in any case, regardless of the situation.

You could even say that the models need good instructions about how to use the model. And we don't really have those. For instance, instructions telling you what's important, in such a way that you can recognise which phase of the model or the consultation you're at. And when you're struggling with a certain phase, those are the parts you can look at to get through it. And which parts you should always include and which parts are optional.

GP/UM

Guideline developers are not representative of the target group

The users thought that social scientists were overrepresented among guideline developers and GPs underrepresented. The GPs felt that guideline developers had priorities that were different to theirs'.

Assumptive flaws

Users felt that the guidelines were somewhat artificial and reflected assumptions with little relevance to day-to-day practice. They felt that using the complete guideline was not helpful or that the guideline was of no use at all in many situations.

Well, what I wanted to say is that the problem here is that it's a very general schema and it is also just bristling with assumptions. And because of that funnily enough again it's not a general schema. And a lot of the problems you see in general practice they just don't fit into the schema.

GP trainer/VU

Participants said that some of the assumptions about patients, doctors and the situation in a consultation were incorrect.

Erroneous assumptions about patients Not all patients are equal negotiating partners

The users mentioned that for patients to be equal negotiating partners, as assumed in the guideline, they should be intelligent, knowledgeable about health and health care organisation, mentally sane, have good self-knowledge, be assertive and act responsibly. Experience has taught doctors that many patients are unable to fully verbalise their requests for help, are claiming or unwilling to take responsibility for their own health. Patients are often surprised when their GP explores their request for help. Some patients do not appreciate it when the GP explores their emotions or beliefs, others do not want to participate in decision making. 
I think that for a perfect exploration of the request for help you need a perfect patient, they just don't exist.

GP trainee/Nijmegen

Sometimes I hear people say, people without medical training: When I go and see my GP he asks me what I think about it. I think that 's just a lot of nonsense!

GP trainee/Nijmegen

Not all patients have backgrounds in Western culture

Patient responsibility is a central feature in Western perspectives on health care, whereas non-Westerners often expect a more authoritarian doctor and have higher expectations of the medical interventions they are being offered.

Language is not the problem, but those people have such a different attitude towards doctors. They want you to give a clear message, just tell me what has to be done.

GP trainee/UVA

Not all patients present with a new, well-defined medical complaint Some complaints may be clear, but not readily identifiable as medical problems. Patients with chronic disease frequently do not have new complaints but only longstanding ones. Some patients have are not able to communicate clearly what their complaint actually is.

No, I find with somatic complaints it's easier to use than when a person has some sort of relationship problem for instance.

GP trainee/Nijmegen

Not all patients come by themselves

Patients are often accompanied by relatives or partners, who need to be attended to as well.

\section{Erroneous assumptions about doctors}

Not all doctor patient communication is verbal communication

Many things are checked or communicated non-verbally, for example by a questioning look or by remaining silent instead of a verbal exploration of the reason for the visit.

Doctors need to be in charge, sometimes

The guidelines are patient centred. Doctors sometimes feel that as a result they do not have sufficient opportunity to structure consultations when patients' stories are very long-winded and unstructured, support anxious or indecisive patients or set boundaries when patients behave inappropriately. 
You also get very dominant people who refuse to be guided. So then you can keep returning to the MAAS-Global but they will always go back to their own story. And well, then it's really of no use whatsoever.

GP trainee/Nijmegen

Wouldn't you just like it now and again to say to a person who is being very rude and claiming: no, you may come back when you can behave properly. Without exploring what this person really wants.

GP trainee/VU

\section{Experienced doctors communicate differently}

Their long-standing relationships with patients help experienced doctors to understand their patients' requests for help.

Well, doctors do actually very much go on their first impressions, especially when you have had a patient in your practice for many years, so yes, it's only logical that you will pay more attention to those aspects in deciding what to do and what not to do.

GP trainer/VU

Doctors want to express a personal interest in their patients

The users said they wanted to be able to express their personal interest in their patients' lives and welfare, beyond the scope of the medical reason for the consultation.

Too energy consuming

It takes too much energy for a doctor to explore the emotional welfare of all his patients in depth.

Besides it's also true, I think that's actually even more of a problem, when I look at the 2650 people on my list and I'm truly interested in what's going on for all of them emotionally, then I'm putting myself in God's place, I think. That is impossible.

GP trainer/Nijmegen

Erroneous assumptions about the situation

Different situations need different approaches

Doctors modify their communication patterns according to their goals within a specific consultation, actual or perceived patient characteristics and type of complaint. This leads to communication strategies that are tailored to the consultation at hand. Doctors feel that most of the recommendations in guidelines are not suitable for every situation and that the sequence advocated by the recommendations is often not appropriate for a particular consultation. They feel that the guidelines do not afford them sufficient flexibility to achieve efficient and 
effective communication. This barrier is mentioned specifically when participants explain why they do not adhere to communication guidelines.

I think that the model can be very helpful for a classic or complicated consultation comprising a lot of different aspects, but whenever you're dealing with only a part of a problem you won't do that.

GP trainer/Nijmegen

The guideline does not support long-term patient management strategies

The guidelines offer recommendations for a single consultation, not for a series of consultations about a single problem. They do not support long-term follow-up strategies.

Impact of guideline use

Impact on the consultation process

The consultation process is the most strongly affected by the structure that the guideline offers. Structure is the most appreciated guideline feature. The users say they appreciate the presentation of the consultation phases in chronological order and even more so the fact that the phases are conceptually different.

The phased structure enables doctors to keep a firm grip on a consultation The phased structure gives doctors a better overview of the consultation. This enables them to improve structure and management of consultations, especially more complex ones.

Sometimes everything is going smoothly but there are also very difficult consultations and then I take a step back, then I see that model before me and then I know where I am in the consultation.

GP trainee/UVA

When you structure the interview like that then it becomes very easy to manage time, whereas when things are becoming just one big mess, it's really hard to finish within 10 minutes.

GP/VU

More clarity for patients

Both the structure and the recommended summarisations help to create more clarity for patients. They help organise the patient's story and stimulate the patient's feeling of being understood. 
Of course as a doctor you want something from your patient, but you also have to give something back. Some sort of assurance that you really understand what that person wants from you.

Student/VU

Less focus on the 'here and now'

There is less focus on the 'here and now', because so much attention goes to structure, and the structure is not flexible. It is tempting to move from one recommendation to the next, without paying attention to clues provided by the patient.

\section{Other impact: positive effects}

Higher quality of consultations

The users think that guideline use improves doctor patient communication in many cases. Exploring the request for help in particular is considered to result in betterhelped patients. Exploring emotions and giving feedback on them to patients is believed to reduce somatisation.

Whenever I feel that the interview did not go very well, that's usually the problem. Then I think well it was not clear after all why she really came to see me. You have talked with someone for ten minutes and you didn't discuss what it really was all about.

GP trainee/Nijmegen

\section{The guideline does justice to both patient and doctor}

Both patients' wishes and doctors' needs are being attended to. Responsibility for the consultation is shared and deliberation about the course of action is stimulated.

What I like is the dynamic of it, there's a sort of dynamic in first actively listening and then taking action and using your expertise and then looking at the situation together like well is this what's going on. And I think that's, well I'm very comfortable doing things this way that you're actually sharing, the responsibility for the consultation and to me that's the main thing.

GP/VU 


\section{Less chance of doctors jumping to conclusions}

The guideline helps to prevent doctors from jumping to conclusions, because it forces them to explicitly check hypotheses about the disease or the request for help.

\section{Fewer unreasonable patients}

Once they have started to use the guideline, doctors find that they come to see fewer patients as unreasonable.

Since I started using the consultation model, I haven't encountered that sort of problem and I see hardly any unreasonable patients. And when a patient is unreasonable I know exactly what the matter is.

GP trainee/UVA

\section{Other impact - negative effects}

Loss of time

This barrier is specifically mentioned when participants explain why they do not adhere to communication guidelines, mostly in combination with the statement that different situations need a different approach. Doctors feel that the guidelines pay little heed to efficiency. Due to the absence of clearly stated priorities, all of the recommendations seem equally important in every situation. Doctors tend to think, however, that the relevance of the recommendations varies among consultations. Using all of the recommendations takes more time than doctors feel they have available for a consultation. This barrier is counterbalanced by the opinion that using the guideline structure saves time and promotes time management, especially in complex consultations. The users also say that it saves time to work on the patient's request for help. However, all things considered, most doctors feel that using the guideline takes more time than it saves.

When you have ten minutes per patient and every time you have to ask about course, reaction, reaction to the diagnosis. Well, what do you think? I will give you some eardrops, is that alright with you? Then I think, that's going to take far too much time. GP trainee/Nijmegen

\section{Loss of natural interaction and personal style}

This is due to the strong focus on structure and having to ask very focused questions and repeat them to check whether the patient has understood what was said. This leaves little room for experiment. 
I'm not a very structured person myself. When I see that I think well that's not my way of treating people. There's no fun left in my consultations this way.

GP trainee/UVA

All normal interaction disappears. For that's not something you would normally do, when you say A I think you mean A and I'm not going to ask you well do you really mean A? It's as if you're running off a list.

GP trainee/Nijmegen

\section{Creating anxiety}

The guideline stimulates doctors to explore patients' emotions, but in some cases exploration of anxiety causes unrest in patients.

Sometimes people say, should I be afraid or is there something I should be worried about? Then I think, oh dear, now l've really frightened them. So sometimes patients just don't get it at all.

GP trainee/Nijmegen

\section{Suggestions for improvement}

\section{Suggestions for additions or deletions}

For one of the guidelines a addition and a deletion were suggested. It was suggested to add reflection on previous consultations about the same problem in order to emphasise continuity of care. The suggested deletion involved shortening the 'agenda setting phase' to merely listing the items on the agenda of the consultation, because negotiating over the consultation agenda was considered to be necessary in very rare cases only.

\section{Suggestions for improvement of the development procedure}

The smallest recommended change was to update the supporting literature. A more drastic suggestion was to develop guidelines that are evidence based instead of consensus based. The evidence should preferably be derived from general practice. There should be evidence of the effectiveness of communication guidelines with regard to patient outcomes, cost effectiveness and patient and doctor satisfaction.

I would be very happy when models were designed that are really derived from theory, based on empirical studies of consultations in general practice, so not laboratory conditions, but based on GPs' practice routine. What has been developed so far, was generally developed in the laboratory.

GP trainer/VU 


\section{Suggestions to develop different types of guideline}

One suggestion was to develop a guideline for long-term patient management strategies. All the other suggestions relate to the development of guidelines that offer more flexibility in the use of communication strategies. It was also suggested to develop different guidelines for different types of patients, a guideline not intended for integral use, a guideline with different courses of action depending on the situation and a guideline showing the consequences of non-adherence, which was thought to help doctors in making considered decisions.

This is a model of a first consultation, you want to have models for different consultations, or types of consultation. Or a model especially suitable for a long-term doctor patient relationship, a chronic disease or something like that.

GP trainer/VU

I would rather like a model that would reveal why ... for instance when you forget to explicitly pursue a certain line of questioning ... that it would reveal whether that is really bad for the patient's follow-up.

Student/VU

\section{Discussion}

In this focus group study, we interviewed users of communication guidelines in order to explore facilitating and impeding characteristics of guidelines in respect of the actual utilisation of these guidelines. The aim was to identify ways of making guidelines more user centred and thereby promote guideline adherence.

Our participants spent more time discussing impeding than facilitating guideline characteristics. The most frequently mentioned impeding characteristics are the assumptions underlying guideline development, which are thought not to correspond with routine day-to-day practice. As a result doctors feel that there are many situations in which the guideline is difficult to apply. The rigidity of guidelines is specifically mentioned as a reason for non-adherence to communication guidelines, because it runs counter to the individualised communication approach that GPs commonly use. The users indicated that this rigidity makes guideline usage inefficient and time consuming. Less frequently mentioned impeding characteristics are flaws in the development procedure, such as lack of proof of effectiveness in general practice. The facilitating characteristic that was mentioned most frequently is the phased structure, which helps GPs manage the consultation. Positive effects of using the guideline such as better consultations or doing justice to both doctor and patient were also mentioned, albeit less often. 
Most suggestions for improvement concern ways to change the main impeding characteristics: developing flexible guidelines that are applicable in many situations and that have proven effectiveness for the settings in which they are to be used.

The similarity of the results for the different guidelines suggests that, despite differences, all the guidelines have the same strengths and weaknesses, i.e. supporting structure but limited applicability.

We will look at these results in light of the literature. The most common complaint uttered by the focus group participants concerned incorrect assumptions underpinning guideline development and flaws in the development process. An instrument to assess the quality of the dutch communication guidelines indicated poor guideline quality, especially as regards development rigour, user involvement and applicability ${ }^{16}$. This suggests that guideline users are probably right in complaining about lack of evidence base. Lack of user involvement and attention for applicability in guideline development increase the likelihood of erroneous assumptions underpinning guidelines, with detrimental effects on the applicability of guidelines.

We will now take a closer look at the two most frequently mentioned complaints regarding inaccurate assumptions. The first complaint is that guidelines that advocate shared decision making are not equally appropriate for all patients, because not all patients can be equal and willing negotiation partners. There is indeed evidence that not all patients are comfortable with shared decision making 47,48 . There is also evidence that it is difficult to explain concepts regarding risks related to treatment or non-treatment of their disease to patients in such a way that they can really grasp it49-51. This may contribute to the participants' perceptions that some patients are not really capable of involvement in decisions. The communication guidelines discussed by the focus groups provide no recommendations as to how to act when the patient does not want to take decisions or does not seem to understand information about risks involved. This may cause doctors go to abandon patient centred guidelines in these situations. However, this may compromise patients' autonomy, because doctors have reported to have difficulty discerning which patients want to take part in decision making and which patients prefer to let the doctor take the decisions for them [52]. Generally, the results of the focus groups seem to show that doctors are rather ambivalent as regards shared decision making. Doctors prefer guidelines that take account of both the patient's and the doctor's interests. They acknowledge that it is important to explore the patient's request for help and to share decisions, but at the same time they want to remain in charge of the consultation. In assessments of doctor patient communication in daily practice, scores on items reflecting patient centredness or shared decision making tend to be low $29,53,54$. The percentages of consultations with low scores on shared decision making seem to be higher than 
the number of patients unwilling to take part in decision making29,47,48. In order to further shared decision making doctors' ambivalence towards it should be examined more extensively.

The second complaint of the focus group participants was that different situations demand different communication strategies, whereas the guidelines are generic. This view seems to be in line with the current literature. There is a wealth of communication guidelines for specific situations, such as breaking bad news, anti smoking counselling, patients with a chronic disease, and conflict situations ${ }^{14,16}$. The Dutch GP training centres use four guidelines for specific situations in addition to the generic ones (see appendix 1). However, neither these guidelines nor the literature offer a framework to determine which guideline to use in which situation. There are communication guidelines for different types of patients, different types of diseases and different goals of the doctor ${ }^{14,16}$. However, there appears to be no consensus about which characteristics of a situation determine which type of communication is most appropriate.

The facilitating factor of the guidelines that is most frequently mentioned by the participants is the structure of the consultation which is divided into conceptually different phases. Participants say that this structure gives them more grip on the consultation. This aspect of the guidelines has been little studied. However, Cegala et al. suggest that a chronological order of recommendations, following the course of the consultation, would be helpful55. Silverman et al. advocate organising the recommendations in a conceptual framework comprising the main tasks of a doctor in a consultation ${ }^{6}$. The latter proposal seems to be supported by our results, with the main tasks being similar to the 'conceptual difference' in the phases of our guidelines.

\section{Strengths and weaknesses}

Our results are based on discussions of communication guidelines used by all but one of the Dutch medical schools in general practice settings. The fact that the results are similar for four different guidelines suggests that they may be at least partly generalisable to other communication guidelines, especially if they have a phased structure and recommend a single course of action. Doctor patient communication is argued to be essentially similar in different health care settings (for example primary or secondary care $)^{6}$, which suggests that our results should be generalisable to other health care settings. However, as our results stress the effect of the context of a consultation on the usefulness and applicability of recommendations for communication, we think it is important to explore facilitating and impeding characteristics of communication guidelines in the context of different health care settings.

In this study we made use of the expertise of different groups of guideline users, which enhanced the richness of the results. Participation was high: seven of the eight Dutch medical schools participated. 
The discussions of the guidelines in the focus groups reflect users' interpretations of the guidelines. Many of the participants in the study are communication trainers. Although their interpretations may be assumed to be largely accurate, misconceptions cannot be ruled out completely.

The nature of focus group discussions implies that only those barriers and facilitating factors were discussed that the participating users were aware of. An observational study in clinical practice might reveal additional impeding or facilitating guideline characteristics.

We were interested in barriers and facilitators experienced by doctors that try to use communication guidelines. For this reason, we have not included patients in our study, in this stage. However, patients are the most important stakeholders of doctor patient communication. It is therefore important that their opinions and preferences are taken into account during development of communication guidelines.

If we want to develop communication guidelines that are user centred, applicable and evidence based, we need to resolve two problems. The first one is how to develop a set of guidelines that offers a strong and supporting structure yet at the same time allows sufficient flexibility to support communication strategies that can be tailored to individual situations. The second problem is how to develop a flexible set of guidelines to tailor communication strategies to individual consultations and support the use of evidence based communication strategies. Should we develop guidelines for different types of patients, different types of diseases, or different goals of the doctor? An answer to this question might be found in the notion that communication serves to address the goals of its participants 56,57 , in our case those of doctors and patients. In order to support doctors in using effective communication strategies, we might consider developing guidelines with a conceptual structure consisting of different consultation phases, but with evidencebased recommendations within these phases that vary depending on the goal the doctor is trying to accomplish in a particular consultation. This offers three advantages: 1 . The main facilitating factors of the present structure are preserved. 2. Doctors can adapt their communication strategies to the goals they think relevant for a specific consultation 3 . The guidelines can incorporate evidencebased overviews of the best way to pursue specific goals. Another advantage of goal orientated communication strategies is that the effectiveness of the communication can be evaluated by checking if the goals have been achieved ${ }^{56}$. If these guidelines focus on goals that are specific for certain diseases, they could serve as an addition to existing medical technical guidelines.

This solution is in keeping with the participants' view that goal-directed communication is an important component of medical professionalism. 


\section{Conclusions}

Although communication guidelines are considered useful, especially for structuring consultations, their feasibility is strongly impaired by lack of flexibility and applicability to practice routines. As feasible communication guidelines are an important tool for the improvement of doctor patient communication, the development of guidelines that combine a supportive structure with flexibility to tailor communication strategies to specific situations should be considered. Further research might address first how this combination of a supportive structure and flexibility can be realised best. This would allow testing whether flexible communication guidelines indeed have a higher adherence then the existing communication guidelines. 


\section{Literature}

1. Bensing J. Doctor-patient communication and the quality of care. Social Science and Medicine 1991, 32:1301-10.

2. Matthews DA, Suchman AL, Branch WT Jr. Making "connexions": enhancing the therapeutic potential of patient-clinician relationships. Annuals of Internal Medicine 1993, 118:973-7.

3. Ong LM, de Haes JC, Hoos AM, Lammes FB. Doctor-patient communication: a review of the literature. Social Science and Medicine 1995, 40:903-18.

4. Stewart MA. Effective physician-patient communication and health outcomes: a review. Canadian Medical Association Journal 1995, 152:1423-33.

5. Stewart MA, Brown JB, Donner A, McWhinney IR, Oates J, Weston W. Final report: the impact of patient-centred care on patient outcomes on family practice: Thames Valley Practice Research Unit; 1996.

6. Silverman J, Kurtz S, Draper J. Skills for communicating with patients. Oxford - San Francisco: Radcliffe; 2005.

7. Beck RS, Daughtridge R, Sloane PD. Physician-patient communication in the primary care office: a systematic review. J Am Board Fam Pract 2002, 15:25-38.

8. Di Blasi Z, Harkness E, Ernst E, Georgiou A, Kleijnen J. Influence of context effects on health outcomes: a systematic review. Lancet 2001, 357:757-62.

9. Gysels M, Richardson A, Higginson IJ. Communication training for health professionals who care for patients with cancer: a systematic review of effectiveness. Support Care Cancer 2004, 12:692-700.

10. Rowe RE, Garcia J, Macfarlane AJ, Davidson LL. Does poor communication contribute to stillbirths and infant deaths? A review. J Public Health Med 2001, 23:23-34.

11. Rowe RE, Garcia J, Macfarlane AJ, Davidson LL. Improving communication between health professionals and women in maternity care: a structured review. Health Expect 2002, 5:63-83.

12. Stevenson FA, Cox K, Britten N, Dundar Y. A systematic review of the research on communication between patients and health care professionals about medicines: the consequences for concordance. Health Expect 2004, 7:235-45.

13. Thorne SE, Bultz BD, Baile WF. Is there a cost to poor communication in cancer care?: a critical review of the literature. Psychooncology 2005, 14:875-84; discussion 885-6.

14. Lewin SA, Skea ZC, Entwistle V, Zwarenstein M, Dick J. Interventions for providers to promote a patient-centred approach in clinical consultations. Cochrane Database Syst Rev 2001:CD003267.

15. Makoul G. Essential elements of communication in medical encounters: the Kalamazoo consensus statement. Acad Med 2001, 76:390-3.

16. Veldhuijzen W, Ram PM, van der Weijden T, Wassink MR, van der Vleuten CPM. Much variety and little evidence: a description of guidelines for doctor patient communication in vocational training for general practice. Medical Education, In press.

17. Makoul G.Communication research in medical education. In: Health Communication Research: A Guide to Developments and Directions. Edited by L Jackson, BK Duffy. pp. 17-35. Westport: Greenwood Press; 1998: 17-35.

18. Rowan KE, Sparks L, Pecchioni L, Villagran MM. The CAUSE model: a researchsupported aid for physicians communicating with patients about cancer risk. Health Commun 2003, 15:235-48.

19. Hantho A, Jensen L, Malterud K. Mutual understanding: a communication model for general practice. Scand J Prim Health Care 2002, 20:244-51. 
20. Levenstein JH, McCracken EC, McWhinney IR, Stewart MA, Brown JB. The patientcentred clinical method. 1. A model for the doctor-patient interaction in family medicine. Fam Pract 1986, 3:24-30.

21. Burgers JS, Van Everdingen JJE. Beyond the evidence in clinical guidelines. Lancet 2004, 364:392-393.

22. Burgers J. Quality of clinical practice guidelines. Nijmegen: Katholieke Universiteit Nijmegen; 2002.

23. Grol R, Wensing M, Eccles M. Improving patient care; the implementation of change in clinical practice: Elsevier limited; 2005.

24. Grol R, Grimshaw J. From best evidence to best practice: effective implementation of change in patients' care. Lancet 2003, 362:1225-30.

25. Grol R. Successes and failures in the implementation of evidence-based guidelines for clinical practice. Medical Care 2001, 39:|146-54.

26. Malacco E, Ferri C, Grandi AM, Kilama MO, Soglian AG, Vigna L. Treatment of hypertension and adherence to treatment guidelines in clinical practice: an Italian study. Advances in therapy 2005, 22:96-106.

27. Kaiser R. Antiemetic guidelines: are they being used? Lancet oncology 2005, 6:622-5.

28. Hulsman RL, Ros WJ, Winnubst JA, Bensing JM. Teaching clinically experienced physicians communication skills. A review of evaluation studies. Medical Education 1999, 33:655-68.

29. Kramer AW, Dusman H, Tan LH, Jansen JJ, Grol RP, van der Vleuten CP. Acquisition of communication skills in postgraduate training for general practice. Medical Education 2004, 38:158-67.

30. Haidet P, Paterniti DA. "Building" a history rather than "taking" one: A perspective on information sharing during the medical interview. Archives of Internal Medicine 2003, 163:1134-1140.

31. Libert Y, Conradt S, Reynaert C, Janne P, Tordeurs D, Delvaux N, Fontaine O, Razavi D. [Improving doctor's communication skills in oncology: review and future perspectives]. Bull Cancer 2001, 88:1167-76.

32. Kennelly C, Bowling A. Suffering in deference: a focus group study of older cardiac patients' preferences for treatment and perceptions of risk. Qual Health Care 2001, 10 Suppl 1:i23-8.

33. Davis DA, Taylor-Vaisey A. Translating guidelines into practice. A systematic review of theoretic concepts, practical experience and research evidence in the adoption of clinical practice guidelines. Canadian Medical Association Journal 1997, 157:408-16.

34. Fallowfield L, Jenkins V. Communicating sad, bad, and difficult news in medicine. Lancet 2004, 363:312-319.

35. Gysels M, Richardson A, Higginson IJ. Communication training for health professionals who care for patients with cancer: a systematic review of training methods. Support Care Cancer 2005, 13:356-66.

36. Kurtz S, Silverman J, Draper J. Teaching and learning communication skills in medicine. Oxford - San Franscisco: Radcliffe Publishing; 2005.

37. van Dalen J, Kerkhofs E, van Knippenberg-Van Den Berg BW, van Den Hout HA, Scherpbier AJ, van der Vleuten CP. Longitudinal and concentrated communication skills programmes: two dutch medical schools compared. Adv Health Sci Educ Theory Pract 2002, 7:29-40.

38. Aspegren K. BEME Guide No. 2: Teaching and learning communication skills in medicine-a review with quality grading of articles. Medical Teacher 1999, 21:563 570. 
39. Howells RJ, Davies HA, Silverman JD. Teaching and learning consultation skills for paediatric practice. Arch Dis Child 2006, 91:367-70.

40. Draper J, Silverman J, Hibble A, Berrington RM, Kurtz SM. The East Anglia Deanery Communication Skills Teaching Project-six years on. Med Teach 2002, 24:294-8.

41. van Thiel J, Ram P, J van Dalen J. MAAS-global manuel. Maastricht: Maastricht University; 2000.

42. Silverman J, Kurtz S, Draper J. Skills for communicating with patients. Oxon: Radcliffe Medical Press; 1998.

43. Dosanjh S, Barnes J, Bhandari M. Barriers to breaking bad news among medical and surgical residents. Medical Education 2001, 35:197-205.

44. Elwyn G, Edwards A, Gwyn R, Grol R. Towards a feasible model for shared decision making: focus group study with general practice registrars. British Medical Journal 1999, 319:753-6.

45. Beckman HB, Frankel RM. Training practitioners to communicate effectively in cancer care: It is the relationship that counts. Patient Education and Counseling 2003, 50:8589.

46. Guideline development at the Dutch Institute for Healthcare improvement. User guide for working group members. In: Book Guideline development at the Dutch Institute for Healthcare improvement. User guide for working group members. City: Utrecht, Dutch Institute for Healthcare improvement; 2000.

47. Robinson A, Thomson R. Variability in patient preferences for participating in medical decision making: implication for the use of decision support tools. Qual Health Care 2001, 10 Suppl 1:i34-8.

48. van den Brink-Muinen A, van Dulmen SM, de Haes HC, Visser AP, Schellevis FG, Bensing JM. Has patients' involvement in the decision-making process changed over time? Health Expect 2006, 9:333-42.

49. Edwards AG, Evans R, Dundon J, Haigh S, Hood K, Elwyn GJ. Personalised risk communication for informed decision making about taking screening tests. Cochrane Database Syst Rev 2006:CD001865.

50. Dillard AJ, McCaul KD, Kelso PD, Klein WM. Resisting good news: reactions to breast cancer risk communication. Health Commun 2006, 19:115-23.

51. Lobb EA, Butow PN, Barratt A, Meiser B, Gaff C, Young MA, Haan E, Suthers G, Gattas $\mathrm{M}$, Tucker $\mathrm{K}$. Communication and information-giving in high-risk breast cancer consultations: influence on patient outcomes. Br J Cancer 2004, 90:321-7.

52. Edwards A, Elwyn G, Wood F, Atwell C, Prior L, Houston H. Shared decision making and risk communication in practice: a qualitative study of GPs' experiences. Br J Gen Pract 2005, 55:6-13.

53. Loh A, Simon D, Hennig K, Hennig B, Harter M, Elwyn G. The assessment of depressive patients' involvement in decision making in audio-taped primary care consultations. Patient Educ Couns 2006, 63:314-8.

54. Elwyn G, Hutchings H, Edwards A, Rapport F, Wensing M, Cheung WY, Grol R. The OPTION scale: measuring the extent that clinicians involve patients in decision-making tasks. Health Expect 2005, 8:34-42.

55. Cegala DJ, Lenzmeier Broz S. Physician communication skills training: a review of theoretical backgrounds, objectives and skills. Med Educ 2002, 36:1004-16.

56. Feldman-Stewart D, Brundage MD, Tishelman C. A conceptual framework for patientprofessional communication: an application to the cancer context. Psychooncology 2005, 14:801-9; discussion 810-1.

57. Bensing J, van Dulmen S, Tates K: Communication in context: new directions in communication research. Patient Education and Counseling 2003, 50:27-32. 


\section{Appendix 1}

The guidelines for doctor patient communication, as used in the universities that participated. The guideline that was used most was topic of our discussion and is printed in bold.

\begin{tabular}{ll}
\hline University & Guidelines* \\
\hline Erasmus University Rotterdam & MAAS-global manual $2000^{14,27}$ \\
Radboud University Medical Centre & Syllabus consultations in general practice \\
Nijmegen & The five-consultations model \\
& MAAS-global manual $2000^{14,27}$ \\
& NHG-cahier 1: How may I help you? Why patients visit their \\
& GP. \\
& MAAS-global manual $2000^{14,27}$ \\
Leiden University & MAAS-global manual $2000^{14,27}$ \\
Maastricht University & A model for the structure of a consultation \\
& Calgary-Cambridge guides ${ }^{25}$ \\
& 6 step conflict management model \\
University of Amsterdam & The consultation model \\
& Phasing of a bad news conversation \\
& Talking about errors \\
& Counselling conversation model \\
Utrecht University & No title, 176 pages, Syllabus year 1 \\
& Laconto \\
& A bad news model \\
Managing medically unexplained complaints & Syllabus: consultations in general practice \\
Free university of Amsterdam & MAAS-global manual $2000^{14,27}$ \\
& Model for the bad news conversation \\
\hline
\end{tabular}

* The titles of the guidelines have been translated from Dutch into English. 


\section{Appendix 2}

List of guidelines discussed in this study, with short descriptions of the guideline

1. Laconto. J.C.M. Bloemen, L.H.C. Tan. Utrecht: SVUH. 1994

Theoretical background: not described, content appears to be patient centred Content: Combines recommendations for a focused and systematic consultation with those for doctor patient communication.

Structure: There are three chronological consultation phases, with six to seven recommendations for good GP-patient communication within each phase.

Situation: the guideline is meant for all consultations in general practice.

2. MAAS-global manual (Dutch version). Jacques van Thiel, Paul Ram, Jan van Dalen Maastricht: Maastricht University. 2000. http://www.hag.unimaas.nl/ Maas-Global_2000/index.htm

Theoretical background: not described, content appears to be patient centred. Good doctor patient communication is defined as the situation in which both parties are seeking to align their mutual goals and are aware of the meaning of the information exchanged.

Content: Combines recommendations for doctor patient communication with recommendations for medical technical skills.

Structure: There are recommendations for separate consultation phases (seven phases), general communication (six items) and medical technical skills (4 items).

Situation: The guideline is meant for consultations that are relatively complete and uncomplicated, such as when the patient presents with only one complaint and the consultation comprises all phases.

3. Syllabus: consultations in general practice. Marion Schmitz, Chris Claus. Amsterdam: Free University of Amsterdam. 2000.

Theoretical background: not described, content appears to be patient centred. Content: Recommendations for doctor patient communication.

Structure: There are recommendations for four separate consultation phases. The goals that should preferably be achieved by following these recommendations are described for each phase.

Situation: Not described, the guideline seams to be meant for GP-patient consultations in general.

4. The consultation model. Amsterdam: University of Amsterdam. Author and date not mentioned.

Theoretical background: not described, content appears to be patient centred. 
Content: Recommendations for doctor patient communication and recommendations regarding medical problem solving.

Structure: There are recommendations for three separate consultation phases. For each phase the appropriate attitude towards the patient is described.

Situation: Not described, the guideline seams to be meant for GP-patient consultations in general.

\section{Appendix 3}

\section{Interview scheme}

The chairman made sure the following topics were discussed, with regard to the use of the guideline in clinical practice and with regard to the guideline as a teaching instrument.*

1. The manner in which the guideline is used (this topic was added after it had been discussed spontaneously in the first three interviews)

2. The strengths of the guideline

3. The weaknesses of the guideline

4. Ways to improve guidelines for DPC

To stimulate discussion the chairman could offer the following questions:

- How does the guideline help you?

- In which situations does the guideline not provide enough help? What help could you use in that situation?

- Are there situations in which it is hard to apply the guideline? Why is that difficult?

- How can this guideline be improved?

- What would a better guideline look like?

\footnotetext{
${ }^{*}$ In this paper the results that consider the use of the guideline in clinical practice have been described only.
} 


\section{Chapter 4}

Exploring characteristics of communication guidelines that enhance training and learning communication

W Veldhuijzen, PM Ram, T van der Weijden, CPM van der Vleuten 


\section{Abstract}

\section{Background}

Skills for doctor patient communication are essential for doctors and ineffective communication patterns have proven hard to change. Because communication skills training is preferably underpinned by guidelines based on communication theory, it is important to explore how these guidelines are best presented.

\section{Objective}

To explore characteristics of written communication guidelines that enhance the success of training aimed at the application of the recommendations in the guidelines.

\section{Methods}

Seven mixed focus groups were held consisting of communication skill teachers (GPs, behavioural scientists) and communication skill learners (GP trainees and medical students) and three groups with only trainees. Analyses was done in line with principles of grounded theory.

\section{Results}

According to the participants in the focus groups there are five key attributes of guidelines for communication skill training: complexity, level of detail, format and organisation, type of information, and trustworthiness/validity. The desired use of these attributes is related to specific educational purposes and learners' expertise. The low complexity of current communication guidelines is appreciated, but seems ad odds with the wish for more valid communication guidelines.

\section{Conclusions}

Communication guidelines can be improved by modifying the key attributes. Ideally, they should to be in line with specific educational functions and tailored to specific groups of learners. The current communication guidelines, for example such as in use in GP training in the Netherlands, seem to offer an oversimplified model of doctor patient communication. This model may be suited for undergraduate learning, but does not meet the validity demands of postgraduate learners that have already received basic communication skills training and who have need of recommendations which they can apply in the diverse environment of regular clinical practice. 


\section{Introduction}

Learning new patterns of behaviour is not easy for doctors ${ }^{1}$. Therefore methods to influence doctors' behaviour have been researched in medical education and in clinical settings. Medical education researchers investigated skills training methods $^{2-4}$ and quality of care researchers investigated strategies for implementation of clinical guidelines 5 . Findings from both research areas may be triangulated for effective training in new behaviour. This may be particularly relevant for communication training, as despite extensive research in effective didactics 5 and the existence of many state of the art training programmes ${ }^{6}$, there seems to be little evidence that medical education has improved doctors communication in everyday clinical practice ${ }^{6-9}$.

Quality of care research showed that the quality of the description of the behaviour that is desired from doctors, also influences the extent to which doctors behaviour is improved ${ }^{10}$. Most quality criteria for these descriptions refer to the quality of the content of guidelines, and are not the domain of educational research ${ }^{11-13}$. However, the criterion that recommendations should be clear, simple, brief and easy to follow is relevant and challenging for educationalists, especially when recommendations address complex behaviour, such as doctor patient communication. Neither quality of care research nor the educational literature provide much direction on how to write guidelines that are perceived as clear, simple, brief and easy to follow for behaviour as complex as doctor-patient communication.

The existing 'models', 'frameworks', 'guides' and 'guidelines' that describe desired communicative behaviour of doctors are a multiform set ${ }^{14-20}$. These documents, from hereon referred to as 'communication guidelines' vary considerably in length, number of recommendations, structure and extent to which underpinning evidence is described, without it being clear why these different choices were made ${ }^{21}$.

Some authors have made suggestions for optimizing the structure of communication guidelines. Cegala et al. argue that it is helpful to present recommendations in a chronological sequence reflecting the normal course of a

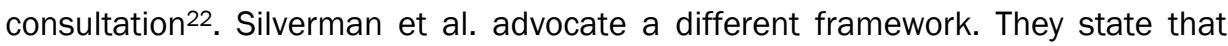
their framework is organised following the physicians' principal tasks during a consultation but does not describe their sequence. Their underlying assumption is that these tasks will be performed at varying moments in different consultations ${ }^{15}$. There are no theoretical or empirical data, however, to support the validity of either of these approaches. 
Besides guideline structure there may be other guideline characteristics that influence the extent to which guidelines are perceived as 'easy to use'. In order to better understand how the presentation of recommendations for doctor patient communication in theoretical texts can support the quality of communication skill training, we wanted to know which guideline characteristics might have a positive impact on teaching and learning. Therefore we explored the experiences of general practice (GP) trainees and their teachers with the communication guidelines used during training.

\section{Methods}

\section{Participants}

We sought the opinions of different groups of guideline users to promote diversity of data. GP supervisors (GPs supervising GP trainees in their own practice), communication skill trainers (GPs and behavioural scientists) and communication skill learners (GP trainees and medical students). The eight Dutch GP training centres were invited to take part and invite participants for a focus group held at their own institution.

To elicit unbiased opinions from the participants of lower status (learners), we asked three institutions to organise a session for GP trainees only in addition to the mixed group session. The three trainee-only groups consisted of first-year GP trainees, final-year (Year 3) GP trainees and GP trainees in both these years of training, respectively. All participants were received written and verbal information about the purpose of the focus groups and gave consent.

\section{Data collection}

The focus groups were moderated by an experienced chair. Each group discussed the guideline used primarily in their GP training centre. The participants were invited to consider which characteristics of the guideline, in their opinion, facilitated or impeded their learning of the theory underlying the guideline and to discuss the guideline's strengths and weaknesses as an instrument to support communication skill training. The findings of the first three focus group sessions led to a modification of the structure of the interview because the participants mentioned different strengths and weaknesses depending on the different functions of the guideline. So, after session 3, the participants were explicitly invited to discuss the functions of the guideline before focusing on the related strengths and weaknesses. 


\section{Data analysis}

The focus group discussions were audiotaped and transcribed and all transcriptions were analysed by the first author using specialised software (Atlas-ti). An iterative process of analysis and reflection was used in accordance with the principles of grounded theory. ${ }^{23}$ All text fragments pertaining to the research questions were coded. Next, the codes were organised in networks of interrelated codes to facilitate the identification of concepts, categories and hypotheses. To incorporate different views in the interpretation model the first six interviews were analysed independently: one by an experienced GP communication skill trainer; three by a researcher specialised in quality of care; and one by an educational researcher. After the analyses differences of interpretation were discussed until agreement was reached.

\section{Results}

\section{Participation}

One GP training centre was unable to participate due to time constraints. In each of the seven remaining centres, one mixed focus group was held. In these mixed groups participated six GP supervisors, nineteen communication skill trainers (eight experienced GPs, eleven behavioural scientists), seven GP trainees and four students. Twenty-seven GP trainees attended the trainee-only groups. Four of the training centres used the same communication guideline and the remaining three centres used a different one each, bringing the total to four different guidelines that were discussed. A description of these guidelines can be found in Box 4.1. The mean duration of the focus group sessions was 90 minutes.

\section{Box 4.1 Description of the communication guidelines}

\footnotetext{
The communication guidelines discussed in our focus groups all pertained to general GP consultations and not to specific situations, such as breaking bad news or dealing with psychosocial problems. In each guideline, the recommendations for communication were organised along the lines of the consecutive phases of a consultation, with specific recommendations being provided for each phase. One guideline also contained general recommendations for communication for the consultation as a whole. The guidelines differed somewhat in content and in the quality of their development, shown for example by the quality of referencing and the involvement of users (doctors) in development of the guideline. They also differed in number and nature of consultation phases and in the related recommendations. Another difference was that of function. Two of the guidelines were developed specifically as assessment instruments while the other two described a theoretical communication model. With each of these two descriptive guidelines an assessment instrument was provided mirroring the content of the communication model in question. More detailed descriptions of the guidelines can be found in the appendix.
} 


\section{Facilitating characteristics, attributes and functions of the guidelines}

The analysis revealed facilitating characteristics relating to the following five attributes: complexity, specificity, structure, type of information, and trustworthiness/validity. As we mentioned earlier in the methods section, the analysis of the first three interviews yielded seemingly conflicting facilitating characteristics. For example, 'guidelines should be easy to use by everyone' alongside 'only teachers need to be able to use the guideline'. Further analysis showed that this arose from the fact that different facilitating characteristics were associated with different functions of the guideline. In other words, both teachers and students should find the guideline easy to use for learning and teaching but only teachers need to be able to use it to assess student performance. In order to prevent this type of confusion, we changed the focus group scheme. Henceforward we started the interview by asking the participants which specific function or functions the guideline fulfilled and which guideline characteristics contributed the most to these functions. The analysis revealed different functions of a guideline that support learning and teaching communication skills (Box 4.2). The five attributes and related facilitating characteristics will be discussed in relation to these functions (Table 4.1).

Box 4.2 Description of the functions of communication guidelines that support teaching and learning communication skills.

Functions that support individual learning

- Learning model: integrated set with recommendations on how to communicate.

- Comprehensive textbook: description of the available knowledge on doctor patient communication, providing background information for the learning model.

- $\quad$ Checklist: short list of recommendations on which learners can see at a glance what needs to be done.

Functions that support teaching

- Theoretical framework and common language: theoretical description naming the main concepts in doctor patient communication and describing their role in the theory that is used.

- Basis for training programme: shows which skills or competences should be targeted in the communication training programme.

- $\quad$ Feedback instrument: helps users give feedback on communication performance.

- Assessment instrument: assesses the quality of learners' communication performance 
Table 4.1 Preferred guideline characteristics for all guideline functions.

\begin{tabular}{|c|c|c|c|}
\hline Attributes & Support function & Preferred characteristics for the functions & $\begin{array}{c}\text { Current fit for } \\
\text { function } \\
\end{array}$ \\
\hline \multirow[t]{3}{*}{ Complexity } & Learning model & $\begin{array}{l}\text { The skills to apply the learning model can be acquired } \\
\text { by the learners with acceptable effort. }\end{array}$ & + \\
\hline & Feedback instrument & $\begin{array}{l}\text { The instrument is easy to use for both teachers and } \\
\text { learners. Observers observe only one type of skill at the } \\
\text { same time, i.e. either general communication skills or } \\
\text { phase specific consultation skills. }\end{array}$ & $+/-$ \\
\hline & Assessment instrument & $\begin{array}{l}\text { A teacher can learn to use the instrument confidently } \\
\text { with some training. }\end{array}$ & $+/-$ \\
\hline \multirow[t]{3}{*}{ Level of detail } & Learning model & $\begin{array}{l}\text { Focus on the main issues not on the details, leaving } \\
\text { room for professional autonomy }\end{array}$ & $+/-$ \\
\hline & Checklist & $\begin{array}{l}\text { Short formulations, all recommendations fit on one } \\
\text { page and can be taken in at a glance. }\end{array}$ & + \\
\hline & Feedback instrument & Focus on the main issues & + \\
\hline \multirow[t]{3}{*}{$\begin{array}{l}\text { Format and } \\
\text { structure }\end{array}$} & Learning model & $\begin{array}{l}\text { Clear organisation distinguishing between main themes } \\
\text { and more detailed recommendations }\end{array}$ & ++ \\
\hline & $\begin{array}{l}\text { Common language and } \\
\text { conceptual framework }\end{array}$ & $\begin{array}{l}\text { A structure that divides a consultation into conceptually } \\
\text { different parts with different tasks. }\end{array}$ & ++ \\
\hline & $\begin{array}{l}\text { Basis for the programme } \\
\text { of the communication } \\
\text { course }\end{array}$ & $\begin{array}{l}\text { A phased structure to enable learners and teachers to } \\
\text { focus on a specific phase and its relevant skills. }\end{array}$ & ++ \\
\hline \multirow[t]{3}{*}{$\begin{array}{l}\text { Type of } \\
\text { information }\end{array}$} & Comprehensive textbook & $\begin{array}{l}\text { Contains an explanation of how to use the learning } \\
\text { model. The theory is illustrated by several examples. }\end{array}$ & $+/-$ \\
\hline & Feedback instrument & $\begin{array}{l}\text { Feedback stimulates discussions of communication } \\
\text { skills. }\end{array}$ & + \\
\hline & Assessment instrument & $\begin{array}{l}\text { Feedback stimulates learning by giving narrative as well } \\
\text { as normative information and by limiting the amount of } \\
\text { negative feedback. }\end{array}$ & -- \\
\hline \multirow[t]{3}{*}{$\begin{array}{l}\text { Trustworthiness } \\
\text { and validity }\end{array}$} & $\begin{array}{l}\text { Common language and } \\
\text { conceptual framework }\end{array}$ & Precise and unambiguous wording & + \\
\hline & Learning model & $\begin{array}{l}\text { Application of the model results in good doctor patient } \\
\text { communication }\end{array}$ & - \\
\hline & Assessment instrument & $\begin{array}{l}\text { The score should reflect the quality of the } \\
\text { communication. It should not depend on the observer } \\
\text { or on whether the assessee has jumped through all the } \\
\text { hoops. This could be promoted by increased attention } \\
\text { for interactions, nonverbal communication and the } \\
\text { motives underlying the doctor's communication. }\end{array}$ & -- \\
\hline
\end{tabular}

Attributes and their preferred characteristics for different support functions of the guideline and the extent to which users feel that these guideline characteristics are currently optimised for the required function.

++ Users tend to consider this characteristic of the guideline as fit for this function; strong positive opinions are common;

$+\quad$ Users tend to consider this characteristic of the guideline as fit for this function;

+/- Users differ in their opinion, either because of differences in personal preferences, or because users are consider this characteristic as fit for function in some guidelines but as unfit in other guidelines;

- $\quad$ Users tend to consider this characteristic of the guideline as unfit for this function;

- $\quad$ Users tend to consider this characteristic of the guideline as unfit for this function; strong negative opinions are common. 
Satisfaction with guideline characteristics

Overall our participants considered the characteristics of their guideline more often as fit for their function than not, although there were differences in opinion for several characteristics. Users considered a small minority of the characteristics as unfit for function. They were particularly negative over the fitness of the guidelines for assessment purposes and over the trustworthiness and validity of the guidelines. They were very positive over the structure of the guidelines that supports several functions, over the fitness of the guideline as a common language and conceptual framework and as a basis for a training programme.

\section{Complexity}

Optimal complexity of a guideline is related to its suitability for the intended function and to users' experience and expertise. Obviously, les complex guidelines are more easy to use. However, too much simplicity may harm other important attributes such as the validity of the guideline. The acceptable level of complexity depends on the function of the guideline: a learning model for students should offer recommendations that students can apply after some training, a feedback instrument should be easy to use for teachers and students alike, but only teachers need to be able to use an assessment instrument appropriately after some instruction. Furthermore, users suggested that recommendations for medical students should pertain to basic communication skills, whereas recommendations for GP trainees should focus on which communication skill to use in which situation.

Learning skills, well it is really always guided by external directions. There is always a teacher who tells you what is good for you. The interesting thing is that eventually you will have to leave that track because professionals who continue along those lines in their work are not professionals. In my opinion it is an essential component of becoming a professional, the transition from conditioned learning, as in skills training, versus selective use of certain skills you have learned in situations where they are appropriate and useful, that should be the focal point of postgraduate training.

GP-trainer Free University of Amsterdam

\section{Specificity}

Specificity refers to the focus of the recommendations: are there many, highly detailed recommendations for specific aspects or situations or are the recommendations more broadly applicable. Generally participants prefer a low level of detail. For a learning model or a feedback instrument, the participants 
indicated that detailed instructions were difficult to remember and apply and argued that a more general approach would leave room for professional autonomy when filling in the details. When the guideline provided an abstract that could be used as a checklist, short descriptions are preferred which can be taken in at a glance when support is needed during a consultation. Some situations were mentioned to require a high level of detail. For example, the participants set great store by precise and unambiguous descriptions and definitions to ensure the validity of a conceptual framework.

I think such a list is easier to use when it has less information. There is just too much in it. It is just one sheet but when you put it on your desk to look at now and then you see nothing because there is just too much in it.

GP-trainee Nijmegen university

You also have that other list with 71 categories [Calgary-Cambridge guides], before you have memorised those and performed each detail .....

Behavioural scientist-trainer Rotterdam University

\section{Structure}

The participants prefer guidelines that are structured according to conceptually different phases of the consultation, with different recommendations for each phase. This type of structure shows the focus of the communication in different moments in a consultation (important for a conceptual framework), distinguishes main themes from detailed recommendations (learning model) and distinguishes different components, thereby enabling learners and teachers to focus on a certain phase and its specific recommendations (basis of the programme of the communication course). The current structure was the most appreciated aspect of current communication guidelines.

'Didactically, I think that dividing it into phases offers a sort of overview and makes it easier to look at reality according to the model.

GP-supervisor Amsterdam University

When you say you want to master it in one year and every week or every month you add a part that you want to study in depth, then I think it is easy to learn. If you say, from the first consultation I want to follow the MAAS-global, then I think it will be a real struggle.

GP-trainee Nijmegen University 


\section{Type of information}

This refers to the sort of information supplied by a guideline to facilitate its use and desired effects. The participants said they wish a comprehensive textbook to explain how to use the learning model it presents, with examples to illustrate and clarify the recommendations and show how to translate the recommendations to practice. A feedback instrument should produce the type of feedback that stimulates discussion about communication. As for feedback resulting from the outcomes of the assessment instrument, the participants were of the opinion that it should motivate learners to improve themselves. Users feel currently often demotivated because of an overwhelming amount of negative feedback and a lack of narrative feedback. To motivate learners feedback should be narrative as well as normative with an appropriate balance of positive and negative feedback.

I think if it, if there would be a substantial series of examples in it, then you can look for yourself what is right for you (...) I think you can get something from it, that you see examples and you think, yes, that's what is meant by that. For I think like exploration, yes, well I still don't really know what to do there. At a certain point it gets clearer when you read some illustrative sentences like, oh so that is what they mean.

GP-trainee Nijmegen University

I find that the feedback I get from watching the videotapes is very good. Together with my GP trainers or in group, but the assessment by the institute is not very useful. It is a bit like, yes, it is just not looked at, it is just that our score is returned to us. That doesn't help me much. You do not know why something goes wrong. There is no explanation. At least not enough.

GP-trainee Nijmegen University

\section{Trustworthiness and validity}

These concepts are used in the same sense as they are used in relation to assessment. The participants want validity and trustworthiness to apply not only to the assessment function of the guideline but to other functions as well. Trustworthiness and validity of the conceptual framework should be based on precise and unambiguous definitions of concepts and recommendations. Participants emphasised that for a guideline to offer a valid model of good doctor patient communication, there should be proof that the recommendations do indeed enhance the quality of communication. Similarly, a good assessment outcome should reflect a high quality of communication and not an observer's idiosyncratic personal preferences or the fact that the assessee has managed to jump through all the required hoops. Student, trainers and even many of the 
teachters tended to be negative about the trustworthiness and validity of the guidelines as learning model of assessment instrument.

... you may score low on all points and still have a good consultation. This is that strange discrepancy that you feel there is between the consultation and the checklist or the other way round. Terrible consultation but you covered all the items. You have just worked your way down the list.'

GP-trainee Maastricht University

\section{Discussion}

This study shows that there are five key attributes of communication guidelines that influence their usefulness for learning and teaching communication guidelines: complexity, specificity, format and structure, type of information, and trustworthiness and validity. These attributes do not represent single set of ideal guideline characteristics, because the guideline characteristics that support learning or teaching depend on the function of the guideline in the training programme and the level of the trainees, i.e. the ideal characteristics of a learning model for medical students are different from those of a feedback instrument for GP trainees. Overall learners and teachers tend to be positive over the suitability of the guidelines for their functions. However, there is still considerable room for improvement, especially in relation to the use of guidelines as assessment instruments and in the trustworthiness and validity of the guidelines.

The five attributes of communication guidelines we identified as influencing the effectiveness of communication training are in line with the literature on implementation of clinical guidelines. High complexity is known to have a negative impact on implementation ${ }^{10}$. Doctors state that they prefer briefness, i.e. a low level of detail in clinical guidelines ${ }^{12}$. Which type of information a guideline should give, for example in which detail scientific underpinnings should be presented, is topic of discussion in guideline development ${ }^{13}$. Marriot et al. and Tunis et al. confirmed the relevance of trustworthiness and validity: guidelines originating from a trusted source whose recommendations are believed to actually promote the quality of health care have a greater chance of being implemented ${ }^{24,25}$. The literature on implementation of guidelines does not offer much advise on guideline structures, but within education research Mayer ${ }^{26}$, and Bannert ${ }^{27}$, have shown that a text with a clear structure is easier memorised than an unstructured text. Our analysis revealed a preference for a chronological structure based on conceptually different phases of the consultation each with different tasks, which combines the conceptual framework advocated by Silverman et al. ${ }^{15}$ with a preference for a 
structure based on the consecutive phases of the consultation as suggested by Cegala et al.22.

In the attributes of the guidelines there seems to be a tension between complexity and validity. Learners and teachers prefer guidelines with a low complexity and a high validity, but feel that currently guidelines are not sufficiently valid. We interviewed the same groups of participants on guideline characteristics that support applicability of the guideline in clinical practice. Both learners and teachers were much more negative about the fitness of the guidelines for clinical practice than about the characteristics that influence how difficult it is to learn the behaviours described in the guideline ${ }^{28}$. The criticisms regarding fitness for practice were strongly related to their criticisms on the validity of the guidelines. Suggestions that were made to improve these, would all increase the complexity of guidelines. Participants suggested several ways to developing situation specific guidelines for example by paying attention to differences between patients, or by describing several courses of actions depending on the content of the consultation. Participants would also prefer guidelines to pay more attention to nonverbal communication 28 .

Currently, communication guidelines describe GP communication tasks in detail, but generally ignore interactions between the doctor's and the patient's communication and between communication and the content of the consultation ${ }^{21}$. Also, non-verbal communication is mostly ignored, despite its potentially strong impact on the quality of a consultation $21,29,30$. In addition little attention is paid to the different endpoint one may want to achieve with communication ${ }^{31}$. Addressing these issues is likely to lead to more valid communication guidelines. It might also lead to a highly complex set of differentiated guidelines, that is to difficult to master. The challenge therefore is to find an appropriate balance between simplifying communication theory into recommendations for behaviour that are sufficiently easy to use and at the same time fit in with the complexity of real practice consultations. Solutions for this problem should probably be sought in by focussing on main themes instead of detail -the Calgary cambridge guides ${ }^{15}$, pay more attention to non-verbal communication than most guidelines, but was disliked by our participants, because it contains 71 steps to be performed in a consultation- and by using a clear organising principle.

\section{Strengths and weaknesses}

We collected data from a rich sample, including different learners and teachers, and different guidelines, which resulted in a variety of facilitating characteristics. A limitation of this study is that the results reflect the participants' opinions instead of objectively measured effects on training. The attributes that we identified appear to be generic and applicable to different settings, whereas the facilitating characteristics are more likely to depend on specific training contexts. For example, 
Kurz et al. reported that their interns preferred a small checklist which they could carry from room to room in their white coats, whereas our trainees, who have their own consultation rooms, prefer larger sheets, which they can put at a corner of their desk 32 .

\section{Implications for educational practice}

Developers of communication guidelines and accompanying educational materials should take account of the attributes of complexity, specificity, format and structure, type of information, and trustworthiness and validity. They should ascertain which type of support for learning and teaching is required for a particular communication skill course and develop educational materials to fit that course. The guideline by Silverman et al. is illustrative of this. It consists of an integrated comprehensive textbook, an assessment instrument and a checklist ${ }^{15,32}$. Which characteristics are most likely to enhance the usefulness of a guideline in a specific training setting can be gathered from conversations with learners and teachers. It is very important to determine learners' levels of expertise and adapt materials accordingly. This may seem very labour intensive but in the end the benefits will make it worth the effort.

The many functions of communication guidelines in learning and teaching show the importance of written educational materials. When learners are provided with good materials that present, explain and underpin recommendations of communication guidelines which can be used for training sessions and teacher-independent learning, there is every reason to assume that the investment in the development of these educational materials will prove to be cost effective.

\section{Recommendations for further research}

The recommendations made on the basis of the results of this study are derived from focus group discussions and the literature and have not been tested in communication skill training. Such empirical tests could be performed in studies using a design-based approach 33 to validate our findings. The results of this study suggest that the communication guidelines currently in use in GP training in the Netherlands may be more appropriate for undergraduate training than for postgraduate training. There is an extensive body of research into communication training for students and doctors who have had no previous exposure to communication skill training. Today, however, there is a growing group of doctors who have had basic communication skill training in medical school. In consequence, research should focus on ways to advance doctors' communication skills to a higher level during postgraduate and further training. The results of this study raise doubt about the suitability for this of the communication guidelines that are currently in use in GP training. 


\section{Literature}

1. Grol R, Wensing M, Eccles M. Improving patient care; the implementation of change in clinical practice: Elsevier limited, 2005.

2. Byrne AJ, Pugsley L, Hashem MA. Review of comparative studies of clinical skills training. Med Teach 2008;30:764-7.

3. Cheraghi-Sohi S, Bower P. Can the feedback of patient assessments, brief training, or their combination, improve the interpersonal skills of primary care physicians? A systematic review. BMC Health Serv Res 2008;8:179.

4. Scalese RJ, Obeso VT, Issenberg SB. Simulation technology for skills training and competency assessment in medical education. J Gen Intern Med 2008;23 Suppl 1: 46-9.

5. Kurtz S, Silverman J, Draper J. Teaching and learning communication skills in medicine. Oxford - San Franscisco: Radcliffe Publishing, 2005.

6. Kramer AW, Dusman H, Tan LH, Jansen JJ, Grol RP, van der Vleuten CP. Acquisition of communication skills in postgraduate training for general practice. Medical Education 2004;38:158-67.

7. Bensing JM, Tromp F, van Dulmen S, van den Brink-Muinen A, Verheul W, Schellevis FG. Shifts in doctor-patient communication between 1986 and 2002: a study of videotaped general practice consultations with hypertension patients. BMC Fam Pract 2006;7:62.

8. Marvel MK, Epstein RM, Flowers K, Beckman HB. Soliciting the patient's agenda: have we improved? Jama 1999;281:283-7.

9. Hulsman RL, Ros WJ, Winnubst JA, Bensing JM. Teaching clinically experienced physicians communication skills. A review of evaluation studies. Medical Education 1999;33:655-68.

10. Burgers J, Grol R, Eccles M. Clinical guidelines as a tool for implementing change in patient care. In: Grol R, Wensing M, Eccles M, editors. Improving patient care; the implementation of change in clinical practice: Elsevier, 2005.

11. Group. TAcW, Cluzeau FA, Burgers JS, Brouwers M, Grol R, Mäkelä M, et al. Development and validation of an international appraisal instrument for assessing the quality of clinical practice guidelines: the AGREE project. Qual Saf Health Care 2003;12:18-23.

12. Watkins C, Harvey I, Langley C, Gray S, Faulkner A. General practitioners' use of guidelines in the consultation and their attitudes to them. Br J Gen Pract 1999;49: 11-5.

13. Grol R, Wensing M. Characteristics of succesvol innovations. In: Grol R, Wensing M, Eccles $\mathrm{M}$, editors. Improving patient care; the implementation of change in clinical practice: Elsevier, 2005.

14. Makoul G. Essential elements of communication in medical encounters: the Kalamazoo consensus statement. Acad Med 2001;76:390-3.

15. Silverman J, Kurtz S, Draper J. Skills for communicating with patients. Oxford - San Francisco: Radcliffe, 2005.

16. Veldhuijzen W, Ram PM, van der Weijden T, Wassink MR, van der Vleuten CPM. Much variety and little evidence: a description of guidelines for doctor patient communication in vocational training for general practice. Medical Education;In press.

17. Makoul G. Communication research in medical education. In: Jackson L, Duffy BK, editors. Health Communication Research: A Guide to Developments and Directions. Westport: Greenwood Press, 1998:17-35. 
18. Rowan KE, Sparks L, Pecchioni L, Villagran MM. The CAUSE model: a researchsupported aid for physicians communicating with patients about cancer risk. Health Commun 2003;15:235-48.

19. Hantho A, Jensen L, Malterud K. Mutual understanding: a communication model for general practice. Scand J Prim Health Care 2002;20:244-51.

20. Levenstein JH, McCracken EC, McWhinney IR, Stewart MA, Brown JB. The patientcentred clinical method. 1. A model for the doctor-patient interaction in family medicine. Fam Pract 1986;3:24-30.

21. Veldhuijzen W, Ram P, van der Weijden T, Wassink M, van der Vleuten C. Much variety and little evidence: a description of guidelines for doctor-patient communication. Med Educ 2007;41:138-45.

22. Cegala DJ, Lenzmeier Broz S. Physician communication skills training: a review of theoretical backgrounds, objectives and skills. Med Educ 2002;36:1004-16.

23. Glaser BG, Strauss A. The discovery of grounded theory; Strategies for qualitative research. Chicago: Aldine Transaction, 1976.

24. Marriott S, Palmer C, Lelliott P. Disseminating healthcare information: getting the message across. Qual Health Care 2000;9:58-62.

25. Tunis SR, Hayward RS, Wilson MC, Rubin HR, Bass EB, Johnston M, Steinberg EP. Internists' attitudes about clinical practice guidelines. Ann Intern Med 1994;120: 956-63.

26. Mayer R. Learning and instruction. Upper Saddle River, NJ: Prentice Hall, 2003.

27. Bannert M. Managing cognitive load-recent trends in cognitive load theory. Learning and Instruction 2002;12:139-46.

28. Veldhuijzen W, Ram PM, van der Weijden T, Niemantsverdriet S, van der Vleuten CP. Characteristics of communication guidelines that facilitate or impede guideline use: a focus group study. BMC Fam Pract 2007;8:31.

29. Griffith $\mathrm{CH}$, 3rd, Wilson JF, Langer S, Haist SA. House staff nonverbal communication skills and standardized patient satisfaction. J Gen Intern Med 2003;18:170-4.

30. Ambady N, Laplante D, Nguyen T, Rosenthal R, Chaumeton N, Levinson W. Surgeons' tone of voice: a clue to malpractice history. Surgery 2002;132:5-9.

31. de Haes $\mathrm{H}$, Bensing J. Endpoints in medical communication research, proposing a framework of functions and outcomes. Patient Educ Couns 2009;74:287-94.

32. Kurtz S, Silverman J, Benson J, Draper J. Marrying content and process in clinical method teaching: enhancing the Calgary-Cambridge guides. Acad Med 2003;78:802-9.

33. Collins A, Joseph D, Bielaczyc K. Design research: theoretical and methodological issues. The Journal of the Learning Sciences 2004;13:15-42.

34. van Thiel J, Ram P, van Dalen J. MAAS-global manual. Maastricht: Maastricht University, 2000. http://www.hag.unimaas.nl/Maas-Global_2000/index.htm. 


\section{Appendix}

List of guidelines discussed in this study, with short descriptions of the guideline

1. Laconto. J.C.M. Bloemen, L.H.C. Tan. Utrecht: SVUH. 1994

Theoretical background: not described, content appears to be patient centred Content: Combines recommendations for a focused and systematic consultation with those for doctor patient communication.

Structure: There are three chronological consultation phases, with six to seven recommendations for good GP-patient communication within each phase.

Situation: the guideline is meant for all consultations in general practice.

2. MAAS-global manual (Dutch version). Jacques van Thiel, Paul Ram, Jan van Dalen Maastricht: Maastricht University. 2000. http://www.hag.unimaas.nl/ Maas-Global_2000/index.htm

Theoretical background: not described, content appears to be patient centred. Good doctor patient communication is defined as the situation in which both parties are seeking to align their mutual goals and are aware of the meaning of the information exchanged.

Content: Combines recommendations for doctor patient communication with recommendations for medical technical skills.

Structure: There are recommendations for separate consultation phases (seven phases), general communication (six items) and medical technical skills (4 items).

Situation: The guideline is meant for consultations that are relatively complete and uncomplicated, such as when the patient presents with only one complaint and the consultation comprises all phases.

3. Syllabus: consultations in general practice. Marion Schmitz, Chris Claus. Amsterdam: Free University of Amsterdam. 2000.

Theoretical background: not described, content appears to be patient centred. Content: Recommendations for doctor patient communication.

Structure: There are recommendations for four separate consultation phases. The goals that should preferably be achieved by following these recommendations are described for each phase.

Situation: Not described, the guideline seams to be meant for GP-patient consultations in general.

4. The consultation model. Amsterdam: University of Amsterdam. Author and date not mentioned.

Theoretical background: not described, content appears to be patient centred. 
Content: Recommendations for doctor patient communication and recommendations regarding medical problem solving.

Structure: There are recommendations for three separate consultation phases. For each phase the appropriate attitude towards the patient is described.

Situation: Not described, the guideline seams to be meant for GP-patient consultations in general. 



\section{Chapter 5}

\section{How doctors move from generic goals to specific communicative behaviour in real practice consultations}

W Veldhuijzen, K Moogendorf, PM Ram, T van der Weijden, G Elwyn, 


\section{Abstract}

\section{Background}

Communication training has been shown to have little impact on how doctors communicate with their patients, despite extensive efforts to improve the quality of teaching methods. A potential cause is the generic nature of recommendations for good communication, which doctors perceive as impractical for clinical practice. In order to understand which type of recommendations for communication would be in alignment with clinical routines, we explored how doctors select communicative actions during patient encounters.

\section{Methods}

We conducted stimulated recall interviews with 15 general practitioners, asking them to comment on recordings of two of their recent consultations. The data analysis was based on the principles of grounded theory.

\section{Results}

A model describing how doctors select communicative actions during patient encounters was developed, the goal-directed communicative action model. This model illustrates how GPs' communicative actions stem from a complex process in which GPs constantly adapt their selection of communicative actions to their evaluation of the situation. These evaluations culminate in the selection of situation-specific goals for individual consultations. The impact of GPs' consultation goals on the selection of communicative actions outweighs all other influences. These multiple and often dynamic goals require constant revision and adaptation of the discourse during consultations. GPs go to considerable length to tailor their actions to individual patients. When selecting consultation goals GPs weigh patients' needs and preferences as well as the medical situation and its consequences. In the final selection of communicative actions GPs attempt to tailor their communication to individual patients.

\section{Conclusions}

Doctors' selection of communicative actions during patient encounters is situational and goal driven. Goal-specific communication guidelines seem therefore better suited to the needs of clinical practice. To help doctors develop communicative competence tailored to the specific situation of each patient encounter, holistic communication training courses, which pay attention to the selection of consultation goals and communicative actions that serve these goals besides training specific communication skills, seem preferable to current generic communication skills training. 


\section{Introduction}

Although medical curricula pay considerable attention to patient-centred communication, training appears to have little impact on doctor-patient communication in clinical practice. This is especially worrisome in light of repeated reports during the past forty years of doctors failing to meet expectations with respect to exploring their patients' beliefs, preferences, and emotions ${ }^{1-6}$, giving information ${ }^{6-8}$, and engaging in shared decision making with their patients ${ }^{7-9}$.

The effectiveness of communication training methods has been extensively studied $^{10}$. Studies of state-of-the-art training methods, such as small group learning, learner-centred methods, and hands-on training in using communication skills, have shown that medical students can be taught to show patient-centred communicative behaviour in practice situations ${ }^{10-12}$. Regrettably, studies have also shown that positive effects of communication training tend to decline after students start clinical training, while training courses for doctors appear to have little effect ${ }^{13-16}$. The negative impact of exposure to clinical practice on the quality of patient-centred communication has been interpreted as the corrupting effect of clinical practice, with studies focussing on the 'hidden curriculum' in clinical education showing negative attitudes of doctors towards patient-centeredness ${ }^{17-19}$. However, a different, more constructive take on the problem of declining communication skills appears to be offered by implementation theory, which proposes discrepancies between the change one wants to implement with training and the requirements of clinical practice as an explanation for implementation problems. Support for the relevance of this explanation for communication training can be found in various sources. While the majority of communication guidelines that are currently in use are generic and designed for use in all types of consultations ${ }^{20-23}$, there are signs that these guidelines are not in alignment with the needs and requirements of clinical practice. Indeed communication guidelines have scored very low on 'user involvement' and 'applicability'24. GPs involved in communication training have suggested that doctors are underrepresented among developers of communication guidelines and qualified guidelines as 'somewhat artificial' and based on assumptions with 'little relevance to day-to-day practice'20. The main concern of these GPs was that the guidelines were too generic to be useful in specific situations. Hence, they applied only parts of the guidelines and adjusted their communication strategies to the specifics of encounters ${ }^{20}$. In a similar vein, De Haes claimed that effective communication differs from situation to situation, describing situations where patient-centred communication was not helpful and even detrimental ${ }^{25}$, and Bensing et al. ${ }^{26}$ argued that communicative actions intended to foster a positive therapeutic relationship can be counterproductive in situations where the emphasis is on promoting adherence to treatment. Support for situation-specific communication strategies is also provided 
by broader communication theories, which state that a competent communicator has the ability to tailor communication to the situation at hand ${ }^{27}$. It is therefore not surprising that it has been suggested to develop specific guidelines, tailored to specific diseases or specific goals ${ }^{28,29}$. This plea for goal-specific guidelines is in line with communication theory on the selection of communicative actions, such as goals-plans-action theory and message assembly theory, which emphasise that communication is goal driven ${ }^{27}$.

Although it seems clear that the current generic communication guidelines are not satisfactory, any change should be underpinned by research that examines which types of communication guidelines are best suited to clinical practice. As a preliminary step we need to gain insight into the communication routines that are commonly used by doctors and how doctors select communicative actions during patient encounters. Therefore we explored which factors determine doctors' communicative behaviour. For this purpose we addressed the following two research questions: Which factors' influence doctors' selections of communicative actions; and what is the role of these factors, i.e. what are the underlying mechanisms. Considering the paucity of information from studies on this topic we conducted an exploratory study combining stimulated recall interviews and a grounded theory approach.

\section{Methods}

\section{General design}

Using a grounded theory approach, we recorded and selected GP consultations, which were then used as stimuli for stimulated recall interviews[30] with the GPs (appendix 1). We used a cyclical process of data collection-analysis-reflection, based on constant comparative methods and progressive focus. In order to facilitate further exploration of topics that emerged from the interviews, we first analyzed each interview before proceeding to the next one.

\section{Data sample}

We purposively recruited GPs who varied in age, number of working years and practice settings (urban or rural). GPs who supervised GPs in training or who were university teachers were excluded to ensure that the participants were not involved in the teaching of existing communication guidelines. A call for participation was published in the newsletter of the academic department of general practice, which is disseminated in the southern part of the Netherlands. Additionally, a convenience sample of fifty GPs in the same region were approached by means of a personal letter followed by a telephone call. Female GPs were strongly 
encouraged to respond in order to ensure diversity of the sample. Recruitment was stopped when data saturation had been reached. Usually, for stimulated recall interviews a sample of between 10 and 15 participants is considered sufficient ${ }^{31}$. Of all the participating GPs a clinic was observed by one of two researchers (WV or $\mathrm{JU})$. After the clinic, the researcher selected two consultations to be used for a stimulated recall interview. The selection was intended to achieve maximum variation sampling regarding patients' age and gender, type of consultation (new complaint, repeat visit, chronic disease), type of complaint (ICPC classification) and the GP's use of communication techniques, which was assessed with the MAASglobal ${ }^{32}$.

\section{Interview}

The interviews were held immediately after the recorded clinics. During the interviews the GPs watched the recordings of the two selected consultations. They were asked to reflect on their thoughts, intentions and actions during the consultation and stop the videotape any time they wanted to comment on these. The interviewer then prompted them to explain how their thoughts or intentions had influenced a specific communicative action. Whenever the interviewer suspected a change in the communication process but the doctor did not stop the tape, the interviewer could decide to stop the tape and ask the GP to reflect on his/her communicative action. All interviews were video recorded and transcribed verbatim.

\section{Informed consent procedure}

This study was exempted from approval by the medical ethical commission, by the executive committee of the medical ethics board, because the participating patients were not part of an intervention and no patient related medical information was used. The participating GPs received written information on the procedure and the purpose of the study. The practice assistants of the participating GPs were asked to invite patients who made an appointment for the day of practice visit to take part in the study. Except for the patients who declined to participate at this point, all patients received written information on the study from the office assistant on arrival at the practice and were asked to give informed consent to the office assistant or the GP. Before the start of each consultation the GPs asked patients whether they had received and understood the information about the study and were willing to participate. All verbatims were anonymised.

\section{Data analysis}

Coding of all the transcripts was done by attaching keywords ('codes') to all text fragments that were considered relevant to one of the research questions. Subsequently, we developed code networks that symbolized the connections 
between codes. Additionally, we identified each occasion when a communicative action was discussed during an interview. For each communicative action, factors influencing its selection were examined and positioned in a scheme representing the selection process of that action. Based on the set of these schemes and the code networks the research questions were answered.

\section{Validation of results}

All the transcripts were analyzed independently by two of the authors with different backgrounds (WV (GP) and KM (anthropologist)), who discussed any differences in codes and selection schemes until consensus was reached. The developed model was discussed in depth by all the authors. Member checking was conducting through in-depth discussions of the model and the results on which it was based with three academic GPs who were experienced researchers and/or teachers of doctor patient communication.

\section{Results}

Fifteen GPs took part in stimulated recall interviews about two of their consultations. In all, thirty consultations were explored. The participating GPS represented a wide range of age (33 to 59), work experience (2 to 27 years) and practice settings (urban and rural, solo, duo and group practices). Eight of the GPS were male, seven female. The patients age ranged, from 2 to 86 . They presented one to four complaints related to a total of nine different organ systems with musculoskeletal problems being the most common. Data exhaustion occurred after eleven interviews, with further interviews showing repetitions of the observed phenomena, thereby confirming the results without adding new topics. After fifteen interviews data saturation was reached and we therefore stopped collecting data.

\section{The interviews}

Average interview time was 60 to 90 minutes. Per interview, between 10 and 24 communicative actions were discussed. Most of the communicative actions were verbal, for instance various types of questions on different topics; some of the actions were nonverbal, such as nodding, smiling, or standing up to end the consultation. Besides form and content of communicative actions, the timing in the consultation (for example asking questions during physical examination) was also a frequent interview topic.

\section{Agreement}

Agreement between the two researchers ( $\mathrm{WV}$ and $\mathrm{KM}$ ) on what constituted a communicative action was easily reached, but the transition from one action to the 
next one was occasionally subject of discussion. Generally, a new communicative action was considered to start when the topic of the conversation changed or a GP employed a different communication technique (for example changed from asking questions to making statements). It was easy for the researchers to agree on the factors that had a direct impact on the selection of a communication technique by a GP. Factors with an indirect impact, which influenced important mediators such as GPs' goals in a consultation, were more difficult to identify. Reaching consensus took more time in these cases and in some cases the researchers had to conclude that it was impossible to identify all the relevant factors.

\section{Factors influencing the selection of communication techniques}

\section{Participants' reflections}

It appeared to be difficult for the GPs to reflect on how personal factors, like thoughts and feelings, influenced their communicative actions. Although they described what they thought and felt at a certain point in a consultation, they had difficulty reflecting on how this impacted on their communication. When they were prompted to reflect on a particular communicative action by the interviewer, things went more smoothly, and the GPs were able to reflect on the causes and reasons for their behaviour. This suggests that selecting communicative actions is not so much a deliberate process as the result of an automated process, parts of which can be made explicit by probing.

\section{Factors influencing the selection of communicative actions}

We identified several factors that influenced the selection of communicative actions by the GPs: consultation goals, generic goals, assumptions about the patient as an individual and about his or her medical condition, the time available for a consultation, the GP's state of mind during a consultation, i.e. emotions and energy levels, and the GP's competence. An overview is given in box 5.1. These factors are described below and illustrated by citations from the interviews.

\section{Consultation goals}

The GPs described a variety of goals they pursued during consultations: examples of which are medical goals, such as diagnosis and treatment, and relational goals, such as meeting patients' preferences and needs and building a trusting relationship. Goals varied from consultation to consultation and usually several goals were pursued in one consultation. Goals sometimes conflicted, for example when a GP wanted to meet a patient's preference for a certain treatment, but at the same time aimed to avoid overprescribing. The following quotes are examples of GP comments on relationship building goals and diagnostic goals. 
There it is, that "stupid" question: 'What do you like about playing korfball'. (...) I think remarks like that always serve two purposes: obviously I want them to like me as a doctor and I also think it helps when a patient feels there is an open climate, it will be easier for him to talk about things.

GP 3

Now I am considering the diagnosis. When I started to ask focused questions, I thought: pneumonia, airway hyper-reactivity or a common airway infection. Based on the focused questions I am almost certain that my diagnosis will be airway hyperreactivity.

GP 8

Box 1: Summary of the results

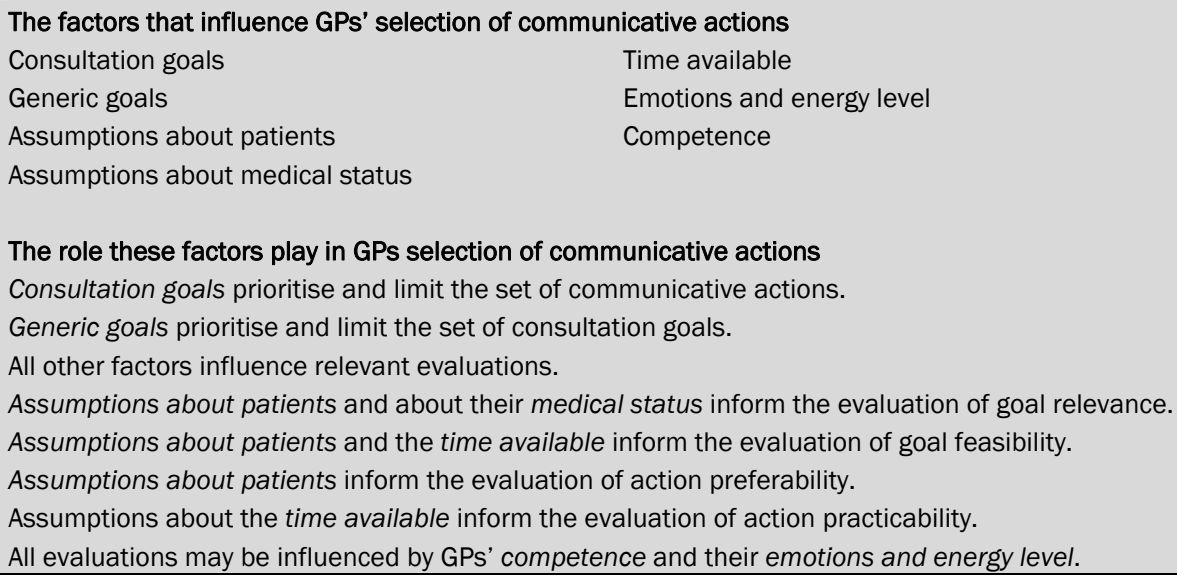

\section{Generic goals}

Goals were often described by the GPs as part of their tasks as a doctor as part of a shared professional identity, 'it is the task of a GP to ...', and also as part of their personal professional identity, 'as a GP it is important for me to ....' Apparently, the goals that directly impact on the selection of communication techniques are subordinate goals from a set of generic goals that represent the way GPS conceptualize their role as a doctor. Doctors' beliefs, norms, values, and social context are factors that influence these generic goals.

I like to use expressions like the ones I use here: 'that we will look at it together' and that we will 'talk about what we will do next'. It is important for me that the patient does not feel that I am the only one who decides what is going to happen, but that we do that together. I can imagine that this makes a patient feel better. It makes me feel better too. (...) My main goal is to ensure that patients a) receive good medical 
technical care and b) at the same time go home with a good feeling about the consultation.

GP 7

\section{GPs' assumptions about patients' medical condition}

The GPs said they made assumptions about different aspects of a patient's medical condition, such as the diagnosis of the presented complaints, the prognosis, the aetiology, and how certain they were that their assumptions were accurate. These assumptions influenced how important medical goals were to the GPs: for example the importance of a detailed diagnosis, whether they should address a patient's life-style, or convince a patient of the necessity of a certain treatment.

\section{GPs' assumptions about patients as individuals}

The GPs made a lot of assumptions about patients' personal characteristics. They had preconceptions about stable attributes, such as intelligence, tendency to worry, and general preferences for certain treatments. These assumptions were mainly based on earlier experiences with patients or their families.

He is not very intelligent and that is relevant as well. I have often noticed with him that he doesn't really understand what you mean.

GP 1

Yes, I know that with this boy, that's the advantage of having been in practice for 27 years, I know this family is unlikely to be difficult anyway. I know they are not childish and not likely to complain.

GP 3

Based on patients' verbal and nonverbal communication, the GPs made assumptions about patient characteristics that played a specific role in specific consultations, such as patients' requests for help, beliefs about complaints, and emotions. Assumptions concerning patient attributes and situational patient characteristics, based on previous experiences with patients or similar patient groups, influenced the GPs' assumptions about how a particular patient would behave during a consultation and be affected by communicative actions.

The time available for a consultation

Time was an important factor. Many GPs felt that the constant demand to stay on schedule occasionally forced them to choose a communication technique that would limit the duration of a consultation. The GPs' perceptions of the available 
time depended on the amount of time scheduled for a consultation and their ability to stay on schedule.

It was also because I was considerably behind schedule. That probably also explains why I became more pragmatic and did not lean back and ask: how is the pregnancy going and did you catch cold?

GP 2

\section{GPs' state of mind: emotions and energy level}

The use of communication techniques was also influenced by GPs' state of mind and energy levels. GPs said that low energy levels, for instance at the end of an exhausting day, limited their ability to apply communication techniques. Negative emotions, such as irritation, were associated with more directive and less exploratory communicative actions, whereas positive emotions, like happiness, were associated with non-directive behaviour.

When one hasn't slept well and one's energy is getting low, that can be a pitfall for me, for then I tend to become very directive and less likely to take time to listen to the other person.

GP 13

Most of the statements GPs made about the effects of their state of mind were general and non-specific. Emotions and energy levels were mentioned only rarely in relation to specific communicative actions. An explanation for this was proposed during the discussions with the academic GPs, where the possibility was raised that GPs think it is unprofessional to allow their behaviour towards patients to be influenced by their state of mind and consequently give socially acceptable answers or show a lack of awareness of concrete effects of emotions and energy levels.

\section{GPs' competence}

GPs do not have similar levels of skills for each communicative action. One GP may be good at using humour, others less so, either because they lack the ability or because they are unaware of its usefulness as a strategy. Familiarity with an action enhances its use.

\section{The role of the influencing factors.}

\section{The central role of consultation goals}

Central to the process of selecting communicative actions were consultationspecific goals. Generally, consultation-specific goals were mentioned as the main 
influence in the selection of communicative actions. They determined the general direction of the communication, thereby substantially limiting the set of communicative actions that were considered.

\section{Generic goals as a framework for consultation goals}

The framework for the selection of consultation-specific goals was formed by generic goals, which determined which goals were regarded as falling within the professional scope of a GP. The priority given by GPs to different generic goals determined which consultation-specific goals they were most likely to pursue.

\section{Fine-tuning of selection based on evaluations}

While the general direction of the selection of consultation-specific goals was determined by generic goals, the selection was fine-tuned by GPs' evaluations. Most of the factors that affect the selection of communicative actions are a part of these evaluations. When selecting a consultation goal, GPs evaluate the relevance of possible consultation goals and their feasibility. They evaluate the expected effectiveness and practicability of a communicative action, also. All evaluations are affected by GPs' emotions, energy levels, and competence. Which other factors are included in the evaluation depends on what is being evaluated.

In evaluating a goal preference, GPs considered a patient's medical condition as well as their assumptions about that patient's personal characteristics, paying specific attention for the patient's needs and preferences. For the evaluation of the feasibility of goals the amount of time available was considered together with assumptions about patients' characteristics, for example willingness and ability to change behaviour. For example, it was an important goal for GP5 to help a patient who was an alcoholic to stop drinking, but the GP decided not to act on this goal, because earlier attempts to do so had failed and she believed this was not a feasible goal.

This lady has an alcohol problem, depression and relationship problems. In the past we have made plans to use anti-depressants and things have gone well for some time. But then she stays away for a long time. (...) My feelings about this are somewhat ambivalent. On the one hand I want to help her, on the other hand I am hesitant because she may want things but she is unlikely to stick with them. That's why at this point I do not go into the causes for her relapse. That is probably also due to our shared history. I am not going to offer her help.

GP 6

To evaluate whether a communicative action is likely to be effective, the GPs tried to predict how patients would behave in a consultation and how they would respond to different communicative actions, based on their assumptions about 
patients' personal characteristics. GP2, for example, said he deliberately used strong words because he presumed that a more subtle approach would not succeed in convincing this sceptical patient that an antibiotic was not necessary.

If someone else made the same request, I would say that 'in itself it is of little use to do this'. But in this case I really feel I have to go one step further one way or the other. And just make it very clear to him. 'Absolutely not' is a statement I do not use often. But in this case I feel I have to be very firm. If I leave any room for doubt, I will definitely fail [to convince him]. And then he will go somewhere else to get his antibiotics.

GP2

To judge if a preferred action is feasible, the GPs evaluated whether they would be able to stay within the available time considering how much time their action and the patient's response were likely to take.

I think that at that point I was thinking we'll also get there this way. Let her have her say, ask all her questions and I know that she will get to her reason for coming to see me. I know she is like that. I was not worried that I had got it totally wrong here. If I just give her some space... then it [the request for help] will become clear anyway. GP 14

\section{Synthesis of the results}

\section{The goal-directed communicative action model}

Based on the synthesis of our results we propose a provisional model that describes the intrapersonal processes that take place when GPs select communicative actions, the goal-directed communicative action model (Figure 5.1). The generic goals, which are listed on the left-hand side of the model are already present before the patient encounter and are not affected by the specifics of a consultation. Early in the consultation and sometimes even before the consultation, GPs start to evaluate their preferences for and feasibility of specific gaols that are congruent with their generic goals. They base these evaluations on what they know at that moment about a patient's medical condition and the patient's personal characteristics. This leads to the selection of situation-specific goals that determine the general direction of the communication in a particular consultation. The selection of further communicative actions is informed by GPs' evaluations of the expected effectiveness and feasibility of their communicative actions. All evaluations can be affected by GPs' emotions and energy levels as well as their competence. After the execution of the selected communicative actions, new information may emerge and lead to adjustments of the consultation goals and communicative actions. GPs are generally not conscious of these selection 
processes, which seem to be automated and only come into GPs' awareness when things get difficult or in response to external probing, like the questions during the interviews.

\section{Validation of the model: member check}

According to the academic GPs the model offers an accurate representation of how GPs select communication techniques and provides useful handles for the development of effective educational interventions. They did not suggest any modifications of the model, but their reactions elucidated the influence of GPs' competence, emotions, and energy levels. Although competence did arise as a topic in the analysis, its role was not very clear. It was implied in several interviews but never explicitly mentioned. The academic GPs observed that this was probably due to the GPs' lack of awareness of their competence level and thus of its effect. As for GPs emotions and energy levels, they were mentioned several times as very influential factors when doctor patient communication was discussed in general, but only rarely within the context of specific consultations. In the discussions with the academic GPs this was attributed to the norm that it is unprofessional for doctors to allow their clinical actions to be influenced by their emotions or energy levels. As a result GPs may know that these factors have an impact on communication in general while being unaware of their effects on specific consultations.

\section{Validation of the model: relation to theory}

We compared our model to communication theories and general theories on how behaviour originates. The field of communication theory that describes how communicative actions come about, i.e. message production theory, is relevant to our model. The dominant theories on message production stipulate that communicators pursue frequently changing goals and that their selection of communicative actions is guided by their strategies to reach these goals 33 . According to goals-plans-actions theory, competent communicators typically have elaborate but flexible communication plans ${ }^{27}$. Our goal-directed communicative action model is in line with the dominant role of goals in the selection of communicative actions as stipulated in message production theories. The model also shows that GPs are flexible in their communication. The results of our study show little evidence of the presence of communication plans, however, and the GPs did not seem to be conscious of selection processes. 


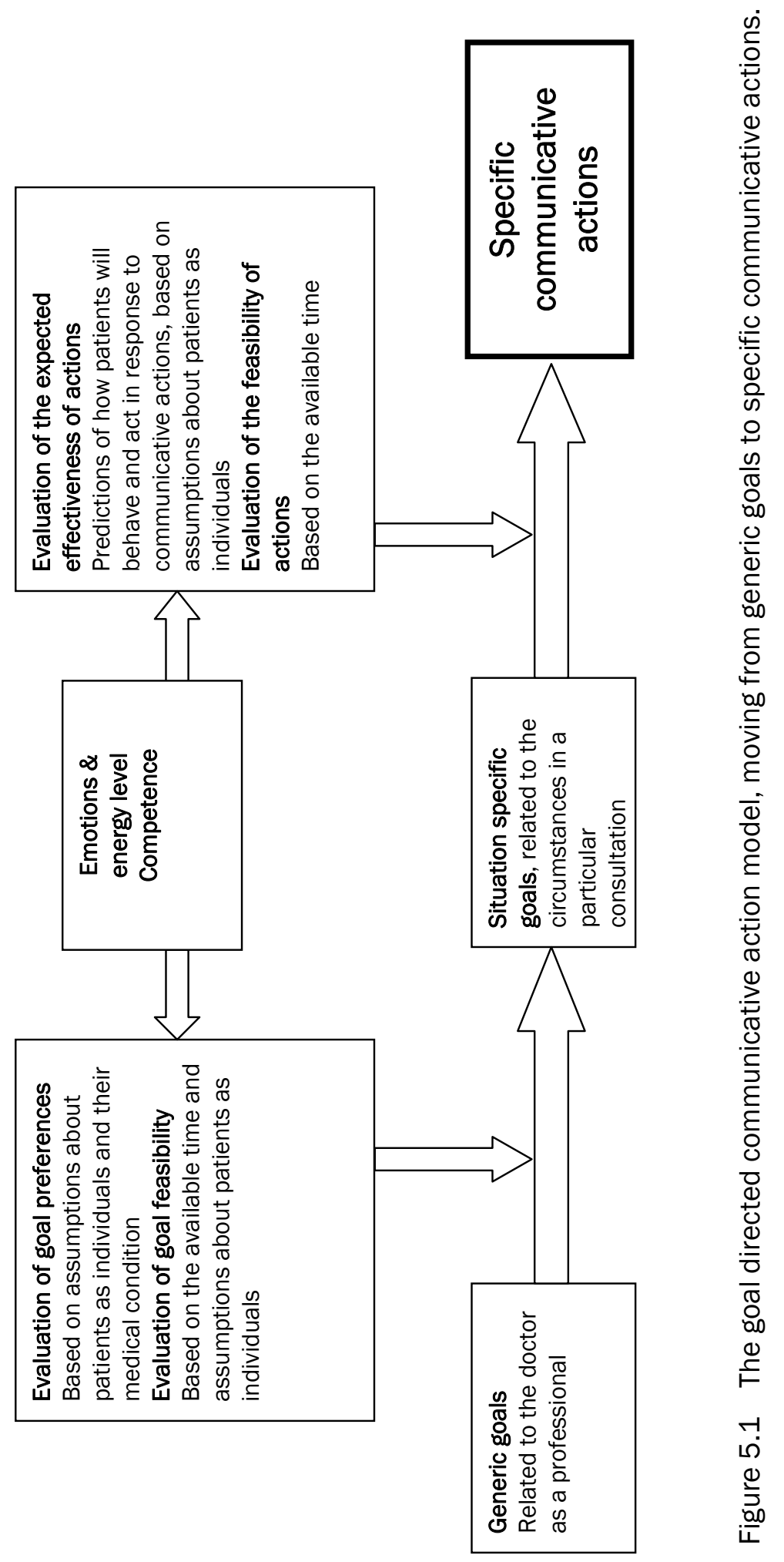


We also compared our model to the theory of planned behaviour (TPB), because this is one of the best validated theories on the establishment of behaviour ${ }^{34}$. According to TPB, attitudes toward a certain behaviour, subjective norms, and perceived behavioural control together produce an intention to enact a behaviour. Given sufficient behavioural control, people are expected to carry out their intentions when the opportunity arises ${ }^{35}$. In the case of doctor patient communication opportunities to carry out intended behaviours probably occur shortly after the intention is formed or not at all. The need for rapid selection of communicative actions - due to the need to respond to the communication partner and to new information that arises during the consultation - may explain why we were unable to identify behavioural intentions; they were probably enacted immediately and then forgotten. The factors that influence behavioural intentions according to TPB are represented in our model. In the model the selection of GPs' generic goals is based on attitudes toward behaviours and on subjective norms. Evaluations of goal relevance and the expected effectiveness of actions can be interpreted as evaluations of behavioural beliefs and subjective norms. Similarly, evaluations of goal feasibility and action practicability can be interpreted as perceived behavioural control. Like our model, TPB acknowledges that competence can influence perceived behavioural control but our model differs from TPB in the inclusion of the influence of emotions, which do not feature in TPB ${ }^{35}$. However, other studies have reported that emotions can explain behaviour independently of intentions and suggestions have been made to expand TPB with the influence of emotions ${ }^{36}$.

\section{Discussion}

This study is a first attempt to describe how GPs select their communicative actions during patient encounters. It shows that GP-patient communication is goaldirected and that GPs constantly adapt their selection of communicative actions to their evaluations of characteristics of individual patients and medical aspects of the consultation. The empirically informed model of the selection process of communicative actions we build in this study is for the most part in line with theories that describe the establishment of behaviour, communicative behaviour in particular, such as the theory of planned behaviour and message production theories $27,33,35$. Discrepancies between our model and theory seem to be associated with the nature of consultations where communicative actions have to be selected very quickly due to time pressure and the need to tailor the communication to individual patients and their medical needs as new information arises during a consultation. 
In this study we built an empirically informed model of the selection process of communicative actions. We interviewed GPs about carefully sampled recently recorded consultations. This data collection method is suited to chart in detail what doctors are thinking during patient encounters. In order to validate the results the data were analyzed by two independent researchers from different backgrounds and the results were submitted to academic GPs who were able to judge the model based on their extensive teaching and research experience.

The main limitation of our study is that the interviews did not capture the parts of the selection process that take place outside GPs conscious awareness. Thus it cannot be excluded that we missed information of which the GPs were not aware, although the GPs did reflect on the selection process when asked to do so. It is therefore important that the model should be verified in further observational studies of actual doctor-patient communication. Another limitation is that the participating GPs were volunteers, who are likely to be more interested in doctor patient communication than the average GP.

The field of doctor-patient communication is sometimes accused of being 'little evidence based' and it is said that it is 'generally accepted that there is limited theoretical basis to explain its mechanisms'25,37,38. With this study we aimed to contribute to the development of a theoretical foundation for the development of communication guidelines by providing a provisional model that explains how doctors select their communicative actions. The goal-directed communicative action model shows that situation-specific factors play a dominant role in the selection of communicative actions. Based on this insight, it seems likely that situation-specific communication guidelines will be more acceptable to doctors than generic ones and thus may have a stronger impact on care. This notion is supported by recent provisional review data on communicative interventions, which showed that, compared to generic recommendations, situation-specific communication training is associated with more changes in doctors' behaviour and more improvement of patient parameters ${ }^{39-41}$. Consequently, the introduction of goal-specific communication guidelines can be expected to improve the quality of care, an idea that is in line with Brown and Byley's theory-based proposal to develop guidelines consisting of sets of communication strategies that together promote the realization of the goal of a consultation 28 . The goals that emerged during the interviews appear to support the development of various distinct goalrelated guidelines, such as a guideline for effective information gathering, a guideline for exploring and responding to a request for help, a guideline for comforting patients, etc. Additional support for the notion that doctor patient communication is goal driven is found in studies by Kellerman, who showed that people tend to act goal driven, even if they may not actually be aware of doing $\mathrm{so}^{42}$. 
In addition to suggestions for communication guidelines, implications for communication skill training can be derived from our model. Currently, the main focus is general skill training, i.e. training doctors to perform sets of communicative actions $^{10,43}$. Our model indicates that this type of training is likely to have a limited impact. Indeed, exclusive emphasis on training doctors to perform sets of communicative actions may even be counterproductive, because it hampers the flexibility needed to tailor the communication to individual patients and to the specific medical requirements of a consultation. Current communication skills training ignores many components that make doctors good communicators. For communication training to be effective it probably needs to take a more holistic approach to communicative competencies, including knowledge, beliefs and even ethical considerations, besides skills. Our model offers suggestions for various aspects of the processes underlying doctors' communication which can be education targets:

- The ability to pick up and interpret patients' clues.

- Having a correct set of beliefs about individual and groups of patients which supports understanding and prediction of patients' needs, preferences, and behaviour.

- The ability to choose goals that fit a consultation and to handle goal conflicts.

- The ability to select communicative actions that best fit the pursued goals for a particular patient.

- The ability to recognize and take account of the effects of one's own emotions and fatigue on patient care.

The choice to develop goal-related communication guidelines still leaves guideline developers with some important puzzles to solve when building new communication guidelines. The two most important ones are:

1. How to develop guidelines that can be combined when a GP has to meet more than one goal in a consultation.

2. How to develop guidelines that are not only tailored to GPs' goals, but also to patient characteristics.

But first and foremost, we need to a better understanding of the goals of doctors in consultations, in order to decide which goals require guidelines. Furthermore, there is the big challenge to develop and synthesize a body of evidence that can be used in literature studies and consensus discussions that will have to be conducted to provide a solid foundation for the development of goal-oriented communication guidelines. Little evidence is available at the moment, because communication research focuses neither on specific communication techniques nor on specific goals or outcomes measures, nor on the relationships between goals and techniques $\left.{ }^{44,4}\right]$. Therefore, communication research should investigate the effects of well-described interventions, testing combinations of small numbers of 
communication techniques, or even individual techniques, in relation to welldescribed goals or outcome measures.

\section{Conclusions}

The study indicates that doctors' communication is situational and goal driven. Doctors consider both characteristics of individual patients and medical aspects of a consultation when selecting communicative actions. This points to a need to reconsider the use of generic communication guidelines and turn to goal-related communication guidelines, which are likely to be of more use for clinical practice. To help doctors achieve communicative competence tailored to the specific situation of each patient encounter, holistic communication training courses seem preferable to conventional communication skills training. To develop an evidence base to underpin the development of goal-related communication guidelines, studies are needed that research the effects of goal-related communication strategies. 


\section{Literature}

1. Marvel MK, Epstein RM, Flowers K, Beckman HB. Soliciting the patient's agenda: have we improved? JAMA 1999;281:283-7.

2. Rhoades DR, McFarland KF, Finch WH, Johnson AO. Speaking and interruptions during primary care office visits. Fam Med 2001;33:528-32.

3. Levinson W, Gorawara-Bhat R, Lamb J. A study of patient clues and physician responses in primary care and surgical settings. JAMA 2000;284:1021-7.

4. Rogers MS, Todd CJ. The 'right kind' of pain: talking about symptoms in outpatient oncology consultations. Palliat Med 2000;14:299-307.

5. Maguire P, Faulkner A, Booth K, Elliott C, Hillier V. Helping cancer patients disclose their concerns. Eur J Cancer 1996;32A:78-81.

6. Britten N, Stevenson FA, Barry CA, Barber N, Bradley CP. Misunderstandings in prescribing decisions in general practice: qualitative study. BMJ 2000;320:484-8.

7. Kennelly C, Bowling A. Suffering in deference: a focus group study of older cardiac patients' preferences for treatment and perceptions of risk. Qual Health Care 2001;10 Suppl 1:i23-8.

8. Campion P, Foulkes J, Neighbour R, Tate P. Patient centredness in the MRCGP video examination: analysis of large cohort. Membership of the Royal College of General Practitioners. BMJ 2002;325:691-2.

9. Elwyn G, Hutchings H, Edwards A, Rapport F, Wensing M, Cheung WY, Grol R. The OPTION scale: measuring the extent that clinicians involve patients in decision-making tasks. Health Expect 2005;8:34-42.

10. Kurtz S, Silverman J, Draper J. Teaching and learning communication skills in medicine. Oxford - San Franscisco: Radcliffe Publishing; 2005.

11. Gysels M, Richardson A, Higginson IJ. Communication training for health professionals who care for patients with cancer: a systematic review of training methods. Support Care Cancer 2005;13:356-66.

12. Aspegren K. BEME Guide No. 2: Teaching and learning communication skills in medicine-a review with quality grading of articles. Medical Teacher 1999;21:563-70.

13. Pfeiffer $\mathrm{C}$, Madray $\mathrm{H}$, Ardolino A, Willms $\mathrm{J}$. The rise and fall of students' skill in obtaining a medical history. Med Educ 1998;32:283-8.

14. Craig JL. Retention of interviewing skills learned by first-year medical students: a longitudinal study. Med Educ 1992;26:276-81.

15. van Dalen J, Kerkhofs E, van Knippenberg-Van Den Berg BW, van Den Hout HA, Scherpbier AJ, van der Vleuten CP. Longitudinal and concentrated communication skills programmes: two dutch medical schools compared. Adv Health Sci Educ Theory Pract 2002;7:29-40.

16. Hulsman RL, Ros WJ, Winnubst JA, Bensing JM. Teaching clinically experienced physicians communication skills. A review of evaluation studies. Medical Education 1999;33:655-68.

17. Cote L, Leclere H. How clinical teachers perceive the doctor-patient relationship and themselves as role models. Acad Med 2000;75:1117-24.

18. Haidet P, Dains JE, Paterniti DA, Hechtel L, Chang T, Tseng E, Rogers JC. Medical student attitudes toward the doctor-patient relationship. Med Educ 2002;36:568-74.

19. Jaye, C Egan T, Parker S. 'Do as I say, not as I do': Medical Education and Foucault's Normalizing Technologies of Self. Anthropology \& Medicine 2006;13:141-55.

20. Veldhuijzen W, Ram PM, van der Weijden T, Niemantsverdriet S, van der Vleuten CP. Characteristics of communication guidelines that facilitate or impede guideline use: a focus group study. BMC Fam Pract 2007;8:31. 
21. Silverman J, Kurtz S, Draper J. Skills for communicating with patients. Oxford - San Francisco: Radcliffe; 2005.

22. Makoul G. Essential elements of communication in medical encounters: the Kalamazoo consensus statement. Acad Med 2001;76:390-3.

23. Van Dalen J, Bartholomeus P, Kerkhofs E, Lulofs R, Van Thiel J, Rethans JJ, Scherpbier AJ, Van Der Vleuten CP. Teaching and assessing communication skills in Maastricht: the first twenty years. Med Teach 2001;23:245-251.

24. Veldhuijzen W, Ram P, van der Weijden T, Wassink M, van der Vleuten C. Much variety and little evidence: a description of guidelines for doctor-patient communication. Med Educ 2007;41:138-45.

25. de Haes H. Dilemmas in patient centeredness and shared decision making: a case for vulnerability. Patient Educ Couns 2006;62:291-8.

26. Bensing J, van Dulmen S, Tates $\mathrm{K}$. Communication in context: new directions in communication research. Patient Education and Counseling 2003;50:27-32.

27. Wilson SR, Sabee CM. Explicating communicative competence as a theoretical term. In: Handbook of communication and social interaction skills Edited by JO Greene, BR Burleson. Mahwah, New Jersey: Lawrence Erlbaum Associates; 2003.

28. Brown RF, Bylund CL. Communication skills training: describing a new conceptual model. Acad Med 2008;83:37-44.

29. Maassen $\mathrm{H}$. Interview met Jozien Bensing: gezond communiceren. Medisch contact 2006;61:1924-27.

30. Lyle J. Stimulated recall: a report on its use in naturalistic research. British Educational Research Journal 2010;29:861-78.

31. Schepens A, Aeltermana A, van Keer H. Studying learning processes of student teachers with stimulated recall interviews through changes in interactive cognitions. Teaching and Teacher Education 2010;23:457-72.

32. van Thiel J, Ram P, van Dalen J. MAAS-global manual. Maastricht: Maastricht University; 2000. http://www.hag.unimaas.nl/Maas-Global_2000/index.htm.

33. Green JO. Message production; advances in communication theory. Mahwah, New Jersey: Lawrence Erlbaum Associates; 1997.

34. Armitage CJ, Conner M. Efficacy of the Theory of Planned Behaviour: a meta-analytic review. Br J Soc Psychol 2001;40:471-99.

35. Ajzen I, Albarracín D, Hornik R. Prediction and change of health behavior: applying the reasoned action approach: Psychology Press; 2007.

36. Cappella JN. The role of discrete emotions in the theory of reasoned action and its successors: quitting smoking in young adults. In: Prediction and change of health behavior: applying the reasoned action approach Edited by I Ajzen, D Albarracín, R Hornik: Psychology Press; 2007.

37. Bensing J. Bridging the gap. The separate worlds of evidence-based medicine and patient-centered medicine. Patient Educ Couns 2000;39:17-25.

38. Epstein RM, Franks P, Fiscella K, Shields CG, Meldrum SC, Kravitz RL, Duberstein PR. Measuring patient-centered communication in patient-physician consultations: theoretical and practical issues. Soc Sci Med 2005;61:1516-28.

39. Dwamena FC, Gaulden C, Lewin S, Smith RC, Holmes-Rovner M, et al.: A systematic review for providers to promote a patient-centered approach. In: International conference on communication in health care; 2008; Oslo.

40. van Nuland M, Hannes K, Aertgeerts B, Goedhuys J. Educational interventions for improving the communication skills of general practice trainees in the clinical consultation. Cochrane Database of Systematic Reviews 2005, Protocols 2005. 
41. van Nuland M, Goedhuys J. Effective educational interventions for improving the communication skills of general practice trainees. In: International conference on communication in health care; 2004; Brugge.

42. Kellermann K. Communication: Inherently strategic and primarily automatic. Communication monographs 1992;59:288-300.

43. Duffy FD, Gordon GH, Whelan G, Cole-Kelly K, Frankel R, Buffone N, Lofton S, Wallace $M$, Goode L, Langdon L. Assessing competence in communication and interpersonal skills: the Kalamazoo II report. Acad Med 2004;79:495-507.

44. Cegala DJ, Lenzmeier Broz S. Physician communication skills training: a review of theoretical backgrounds, objectives and skills. Med Educ 2002;36:1004-16.

45. de Haes $\mathrm{H}$, Bensing J. Endpoints in medical communication research, proposing a framework of functions and outcomes. Patient Educ Couns 2009;74:287-94. 



\section{Chapter 6}

\section{Beyond patient centeredness: the multitude of competing goals that doctors pursue in}

consultations

W Veldhuijzen, G Elwyn, PM Ram, T van der Weijden, Y van Leeuwen,

CPM van der Vleuten 


\section{Abstract}

\section{Objective}

Doctors tend to be little patient centred in their communication. In order to established whether this is caused by a lack of commitment to the ideals underlying the concept of patient centred communication, we explored the goals GPs pursue in consultations.

\section{Design}

A qualitative study in which we triangulated three different qualitative datasets, obtained from focus groups, stimulated recall interviews, and think aloud interviews.

\section{Participants}

Focus group participants: 63 communication teachers (GPs and behavioural scientists) and learners (GP trainees and medical students).

Participants in the stimulated recall and think aloud interviews: fifteen and sixteen non-academic GPs.

\section{Results}

In the majority of consultations, the GPs pursued multiple goals. Moreover, many of these goals competed with each other for time allocation or they were even in direct conflict with each other.

Thirty different goals were identified, most of them with several sub goals. The goals were related to different aspects of persons or organisations, i.e. maintaining the health of the patient, the patient's well-being, work satisfaction of the GP, the organisation of care, and public health agendas. The most frequently mentioned goal (reassuring the patient) was present in about one third of the consultations. Although being patient centred was only specifically mentioned as a goal in a minority of cases, GPs referred to the delivery of patient centred care as an everpresent goal, which they considered central to their work as a GP.

\section{Conclusions}

Our results show that GPs consider no single goal so important that they report pursuing it in every consultation. Besides patient centeredness, GPs discern many other different aspects of high quality health care. As high quality care takes time and time is scarce, GPs set priorities in every new consultation. The need to choose between different aspects of quality of care explains why GPs do not communicate in accordance with a single model, like the patient centred one. 


\section{Introduction}

For decades, patient centred communication has been advocated as the preferred approach for doctor-patient communication in clinical consultations ${ }^{1-4}$. Yet, study after empirical study reveals that during routine practice professionals do not follow the guidance that is at the core of this type of communication - to examine the patient's agenda and to put their ideas, expectations and concerns at the heart of interactions ${ }^{5-10}$. This gap is often attributed to either pressure of time, clinician attitude or lack of communication skills ${ }^{11-14}$, but we think these explanations may be too simplistic. Few studies have gone beyond these assumptions and we think it is time to investigate in more depth which factors underlie the gap between the promoted models and the reality of day to day encounters.

Doctors' communicative behaviour in clinical practice seems mainly driven by the goals doctors pursue in specific consultations ${ }^{15}$. This is in line with two major theories on the production of communicative actions, goals-plans-actions theory and message assembly theory, which state that communicative actions are determined by the goals of the communicator ${ }^{16,17}$. The notion that doctors' communication is goal driven suggests two explanations for the lack of patient centred communication:

1. The goals doctors try to achieve in consultations do not include delivery of patient centred care, either due to unfavourable attitudes or for practical reasons.

2. Doctors try to achieve patient centred communication, but they do not use the recommended communication techniques, either because they lack the ability to use them, or because they do not consider these techniques the methods of choice.

In line with the first hypothesis, doctors' failure to achieve patient-centred communication has been attributed to unfavourable attitudes towards it ${ }^{12-14}$. Knowing whether this is caused by a lack of commitment, by incompetence, or by disagreement on how patient centred communication is to be achieved has important consequences for the implementation of patient centred communication. In an attempt to unravel the scarce usage of patient centred communication techniques, we have tested the first hypothesis by exploring the goals doctors pursue in real practice consultations.

\section{Methods}

\section{General design}

In this observational study we triangulated qualitative data sets obtained by three research methods: 1 . focus groups, 2 . stimulated recall interviews, and 3 . thinkaloud interviews. 


\section{Data collection}

Focus groups

We used an existing dataset ${ }^{18}$ from focus groups conducted at seven of the eight Dutch GP training centres involving GP supervisors (GPs supervising GP trainees in their practice), communication skill trainers (GPs and behavioural scientists), GP trainees, and medical students with experience in general practice. Additionally, trainee-only focus groups were organised in three of the GP training centres. The interviews were guided by an experienced facilitator, who used a topic guide focused on factors with a potential effect on communication guidelines used for training and on adherence to these guidelines. Consultation goals were explored as potential reasons for applying or ignoring recommendations on communication. All focus group interviews were recorded and transcribed.

\section{Stimulated recall interviews}

GPs were recruited to participate in stimulated recall interviews ${ }^{19}$ via an advert in the newsletter of the Department of General Practice of Maastricht University. A convenience sample of fifty GPs in the Maastricht region was recruited by personal invitation. Female GPs were specifically urged to take part to ensure diversity of the sample. We excluded GP supervisors and GP trainers because their views had been explored in the focus groups. A researcher (WV or JU) observed the participating GPs during consultations in their clinics. They then selected two consultations per GP to create a maximum variation sample with regard to patients' gender and age, type of complaint, and communication techniques used by the GP, and used these as a stimulus for stimulated recall interviews in which the GPs were asked to reflect on their communicative actions, specifically the reasons for specific actions. Each GP was observed and interviewed by the researcher that had observed the clinic and all interviews were recorded and transcribed.

\section{Think-aloud interviews}

After the stimulated recall interviews, WV or JU again visited the participating GPS in their practice, observed consultations, and interviewed the GPs immediately after each consultation, asking them to think aloud and reflect on the goals pursued during that consultation ("Can you tell me what you tried to achieve in this consultation? Please, mention anything that comes to mind.") ${ }^{19}$. All the interviews were recorded and transcribed.

\section{Informed consent procedures}

This study was exempted from approval by the medical ethical commission, by the executive committee of the medical ethics board, because the participating patients were not part of an intervention and no patient related medical 
information was used. The centres organising the focus group interviews and the GPs who participated in the individual interviews received written information on the procedure and the purpose of the study. The practice assistants of the participating GPs were asked to invite patients who made an appointment during the study period to take part in the study. Except for the patients who declined to participate at this point, all patients received written information on the study from the office assistant and were asked to give informed consent to the office assistant or the GP. Before the start of each consultation the GPs asked patients whether they had received and understood the information about the study and were willing to participate. The transcriptions of the focus groups and the interviews were anonymised.

\section{Data analysis}

Focus groups: the development of a provisional framework of goals

A qualitative thematic analysis of the focus group transcripts was performed by the first author, using qualitative software (atlas-ti) ${ }^{20}$. All consultation goals mentioned by the participants were coded and organised in code networks, which were visualised to identify other nested goals. Based on the similarity of themes, goals were assigned to code families. Goals that were pursued to achieve other goals were labelled as sub goals. Five of the ten focus groups were analysed independently by the third author (YvL), for whom the material was completely new (see appendix 1, for an overview of all analysts). The interpretation and coding of the goals was compared and discussed until consensus was reached, as were the relations in the code networks and the categorisation of code families. Based on the outcome of these discussions a provisional framework of communication goals was developed. The main categories of this framework were based on the code families.

Stimulated recall and think aloud interviews: refining and validating the framework of goals

Using the set of codes derived from the focus group data, WV and JU conducted a thematic analysis of the stimulated recall and think aloud interviews simultaneously. Whenever possible the goals mentioned by the GPs were assigned to an existing category. If this was not possible, the goals were added on to the framework, thereby extending and refining it. Having established the final framework, WV and JU independently analysed the content of the think aloud interviews scoring the goals pursued for each consultation. Differences in interpretation were discussed until agreement was reached. In this way, a tentative impression of the frequency of the occurrence of the goals was obtained. The goal categories and other themes will be described in depth when we synthesise the results of the focus groups and those of the other interviews. 


\section{Results}

\section{Participation}

Focus groups

A total of fourteen experienced GPs, eleven behavioural scientists, 34 GP trainees and four medical students participated in seven mixed focus group sessions and three trainee-only sessions. The focus groups lasted approximately 90 minutes.

\section{Stimulated recall and think aloud interviews}

A total of sixteen GPs participated. Of the ten GPs who responded to the advert, three were excluded because they supervised a GP trainee. Nine GPs accepted a personal invitation to participate. The majority of patients (96\%) consented to the presence of the researcher and the recording of the consultation. Each GP took part in an average of fifteen think aloud interviews (246 in total). One GP did not participate in the stimulated recall interview due to time constraints, thus fifteen stimulated recall interviews were held in which thirty consultations were discussed.

\section{Goals framework}

The final goals framework consists of five goal categories (see Box 6.1) and thirty different goals (see Table 6.1). Table 6.1 also shows the frequency of sub goals. Below we describe the evolution of the framework and the goal categories.

\section{Box 6.1 Goal categories.}

1. Maintaining patients' health

2. Maintaining patients' well-being

3. Maintaining work satisfaction

4. Maintaining organisation of care

5. Maintaining public health agendas

\section{Evolution of the framework}

Based on the analysis of the focus group interviews a provisional framework of goals was developed. Being the most discriminating feature of the goals, the person or the group that benefited from the realisation of a goal was used as the organising principle in developing categories. For each category a series of goals was identified, most of which included sub goals. 


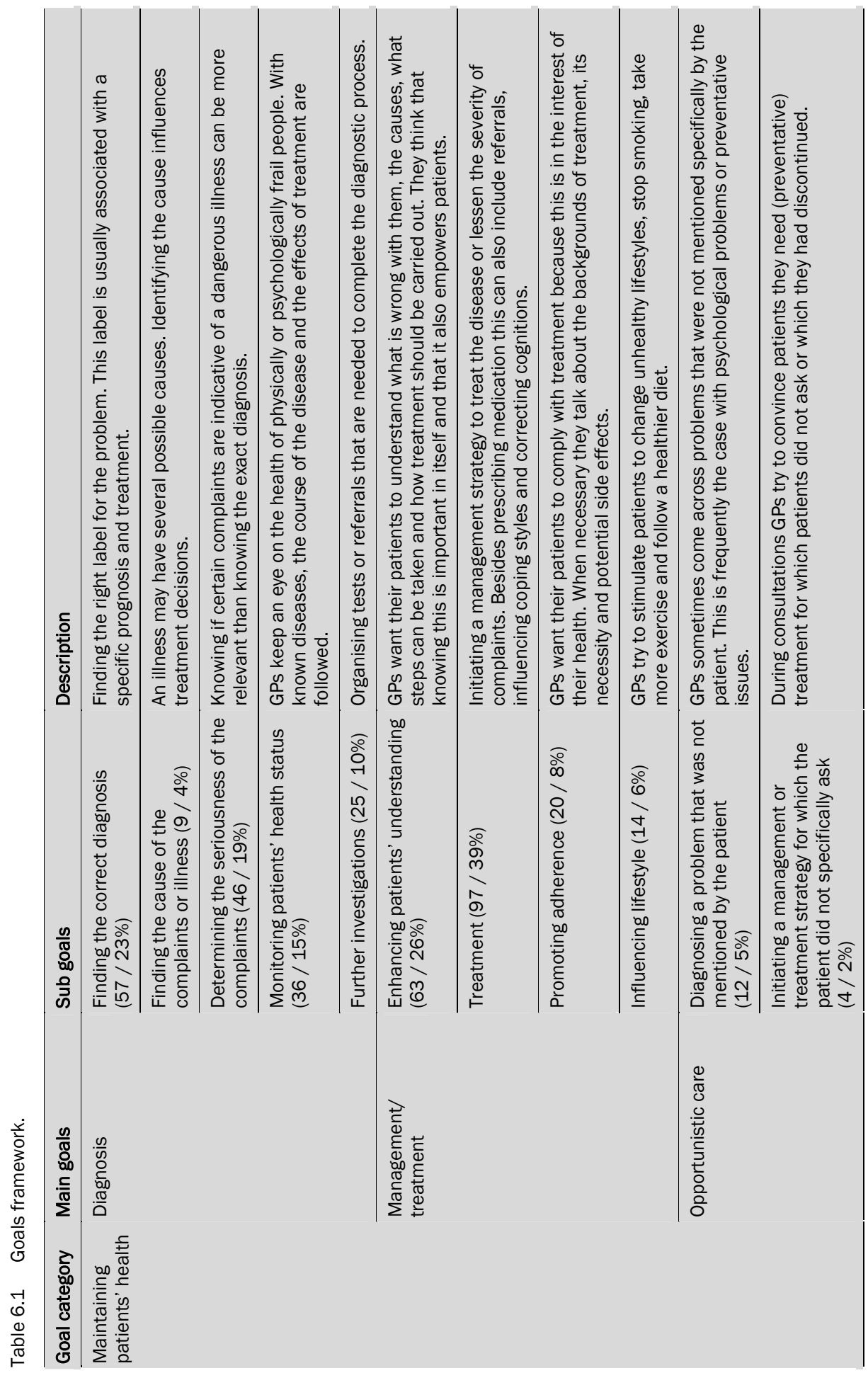




\begin{tabular}{|c|c|c|c|c|c|c|c|c|c|c|c|}
\hline $\begin{array}{l}\frac{\infty}{0} \\
\frac{0}{0} \\
0 \\
\text { o } \\
\text { क }\end{array}$ & 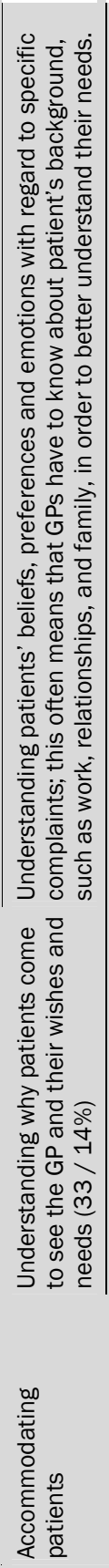 & 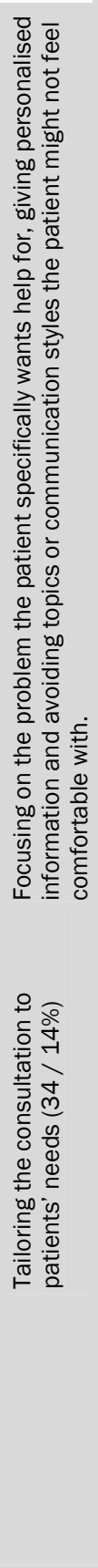 & 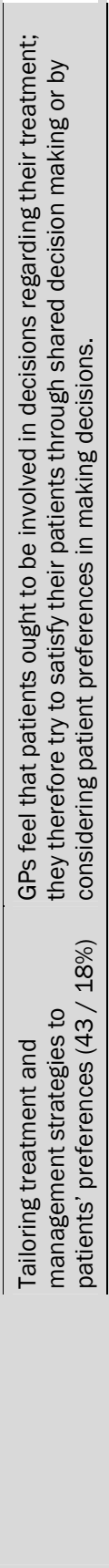 & 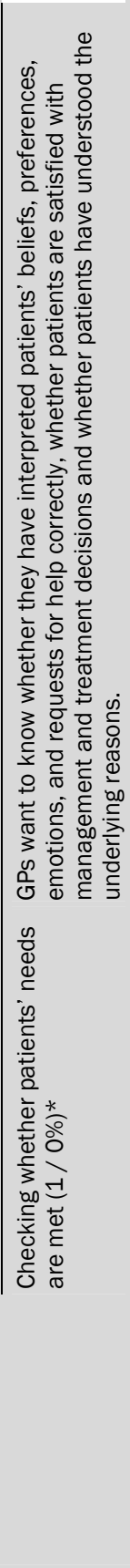 & 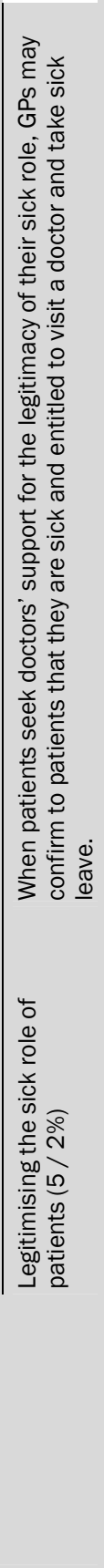 & 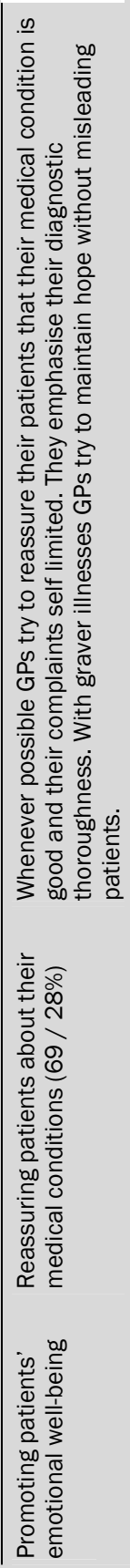 & 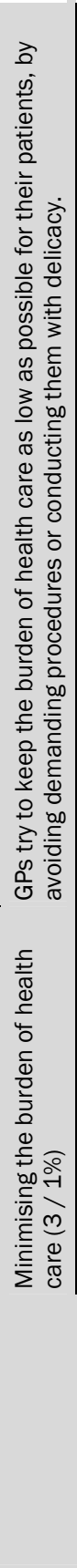 & 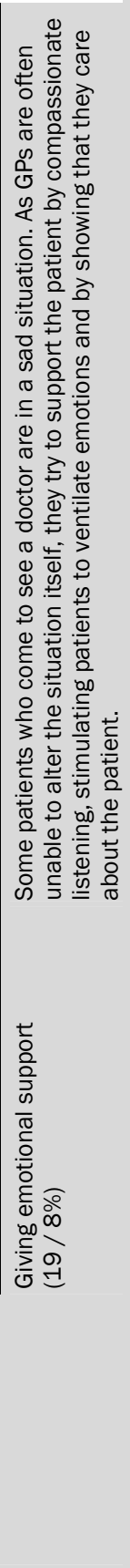 & 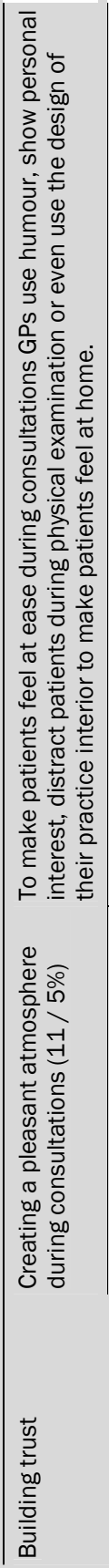 & 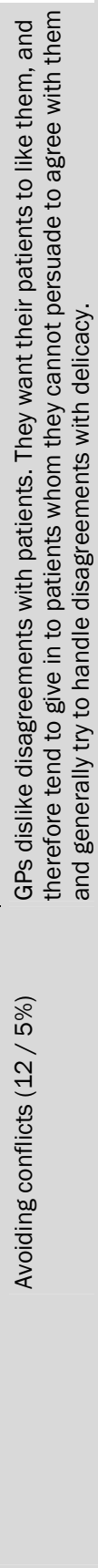 & 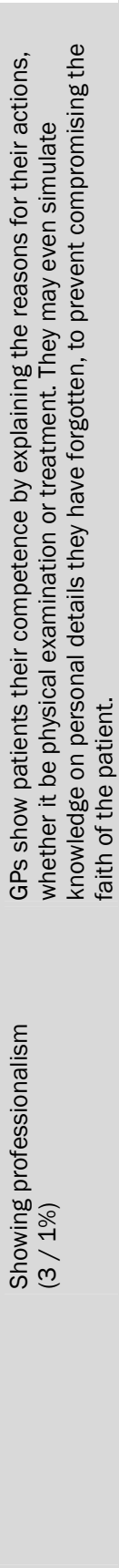 \\
\hline & 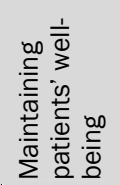 & & & & & & & & & & \\
\hline
\end{tabular}




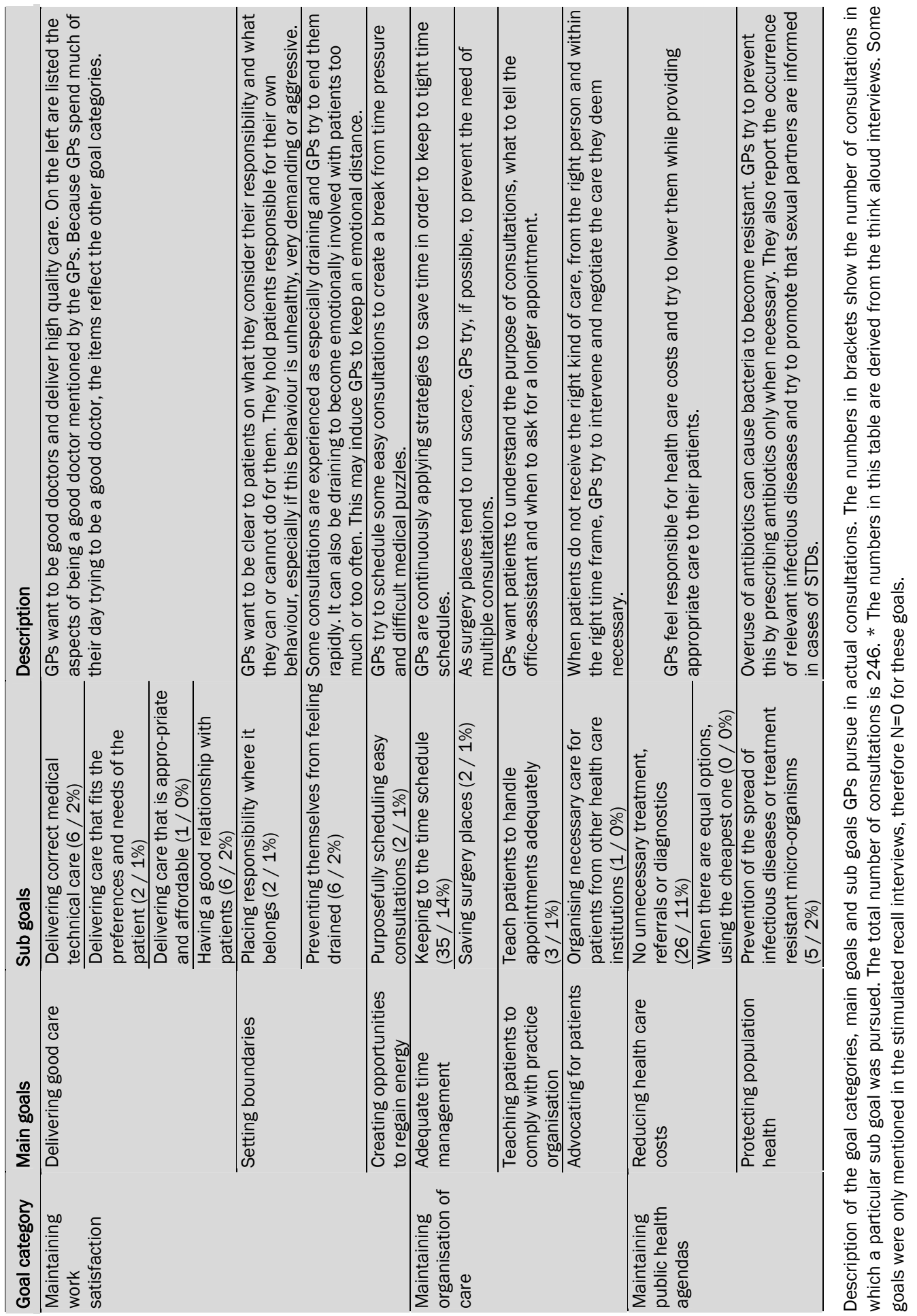


The analysis of the stimulated recall and think aloud interviews confirmed most of the categories of the provisional framework and led to some minor redefinitions. One provisional category was removed, because it contained process goals that were useful for the consultation process but had no function beyond that. For example, maintaining a clear structure in the consultation was an enabling goal for diagnosis and staying on schedule. We removed the process goal category, because our research questions focused on doctors goals not on the means to accomplish them. Furthermore, we added a goal category focusing on the organisation of care. The list of sub goals was expanded considerably. The main goal categories are described below.

\section{Maintaining patients' health}

Most of the participants consider healing patients, or at least striving to do so, as the core task of doctors. Goals that serve the health of individual patients, such as making a diagnosis, initialising treatment and monitoring and managing complex health problems, are the most frequently mentioned goals in this study.

These are the really good things, not this endless nattering about nothing. To me this is just a medical technical problem, a ganglion, clearly. For once you know something, that is good for the ego. She has a lump she wants to get rid of it and I think I can help her.

GP 3, think aloud interviews

\section{Maintaining patients' well-being}

Because they are often unable to influence their patients' health, doctors look for other ways to help their patients. They try to promote their patients' well-being and relieve anxiety and suffering by comforting them, giving emotional support, and developing supporting doctor-patient relationships, which are built on trust. Doctors consider it important to accommodate their patients by focussing on patients' needs and requests for help and by adjusting management and treatment to (perceived) patient preferences.

\section{Maintaining work satisfaction}

Although most of the goals are targeted at promoting the health of others, doctors basically want to go home feeling satisfied they have done a good job. Doctors' work satisfaction is strongly based on the extent to which they succeed in meeting their own standards of being a good doctor. They try to prevent themselves from feeling drained by setting boundaries to their responsibilities and by sometimes creating a necessary distance from their work, or by introducing breaks from their heavy workload. 
Satisfaction for a doctor, well, that is just delivering good health care. So, efficient and cost effective care, but also good care. I mean that it is actually diagnosed when something is really wrong.

GP 4, think aloud interviews

\section{Promoting the organisation of care}

Doctors want to deliver health care effectively and efficiently. This means that certain actions need to be performed at certain moments and that the right person should see the right patient at the right moment. This implies that doctors have to manage themselves, but sometimes also their patients or (members of) other health care institutions. Trying to gain time in order to keep within the time limits of the clinic schedule is an ever-present goal, which can be a burden, because it limits what can be done to achieve other goals.

\section{Meeting public health agendas}

Most doctors aim to benefit individuals, but they also feel responsible for public health and may even go against the wishes of individual patients to benefit society, as is exemplified by reluctance to prescribe antibiotics in cases where benefits are likely to be minor, while overuse can give rise to resistant strains. Being aware of the high demands that are made of health care, doctors try to promote adequate use of scarce resources. They also try to maintain public health by preventing the spread of infectious diseases or overuse of interventions that have side effects which are a risk for the whole community, such as antibiotics.

\section{The nature of consultation goals}

Besides the content of goals, the nature of goals is an important theme. The potentially conflicting nature of goals was observed in the analysis of the first dataset and confirmed when the second and third data sets were analysed. Additionally, the priority and time span of goals emerged as relevant themes.

\section{Goal priority}

One might think of goals as binary, i.e. as being present or not. However, in practice goals tends to be more like a continuum. There are several indications for this. The first one is the difference between two of the interview sets. In the stimulated recall interviews the GPs commented on two consultations and had ample time to recall every goal they had pursued, however unimportant it might seem. These interviews yielded many more goals than the think aloud interviews where the GPs were specifically and often repeatedly prompted to talk about their goals but without mnemonic stimulus. This suggests that in the think aloud interviews only the most salient goals were reported. The second indication is that some GPs said that some goals were always present, such as accommodating the patient, time 
management, and health related goals, although these goals were not mentioned in all the think-aloud interviews. What this suggests is that goals can be present even though they may not spring to mind when GPs are recalling the goals of a consultation. The third indication is that doctors prioritise in cases of competing or conflicting goals, which suggests that some goals are more important than others, depending on the situation. We therefore assume that the goals table describes all goals our participants pursue in their consultations, but that the frequencies of goal occurrence do not so much accurately reflect the presence of all the goals but rather reflect the presence of goals that were most salient in a consultation.

\section{Goal competition and goal conflicts}

Goals often compete for time allocation. Dutch GPs usually have ten minutes for a consultation, and this is often not sufficient to pursue all goals adequately. Sometimes goals are even in direct conflict. This is most evident when goals are related to different groups. For example, goals serving the organisation of health care or society often conflict with goals that serve individual patients. And the latter goals may also clash, such as when interests dictated by a patient's health run counter to a patient's personal wishes. For example, being dependent on medication may not be compatible with the patient's desire to be in control. Doctors often struggle to balance such competing or conflicting goals and try to make the most appropriate choice.

And then one always has to decide whom am I going to talk to, the mother or the daughter? How well can I meet the daughter's needs and attend to what she wants to ask and feels and why? That is a dilemma, on the one hand I want her to talk but on the other hand I want to get to the right information quickly, so that is really a dilemma.

GP 9, stimulated recall interview

I make the referral somewhat reluctantly [...] I think the climate of the doctor-patient encounter, I think that it is just very important. It is very important to me that people have a good feeling about coming here and are still feeling good or preferably even better when they leave. And I think that is sometimes a case of give and take. And it is possible that because of that I may sometimes indulge patients.

GP 5, think aloud interview

Goal time span

Doctors mention short-term goals, which can be realised completely in one consultation, such as finishing on schedule, intermediate goals, of which the effect lasts for some time after the consultation, such as comforting a patient, and longterm goals, whose effects hopefully will last for years, but may need further 
attention in that period, such as promoting patients' health. Often the shorter term goals are facilitators for longer term goals. One might even consider categorising them as means to achieve a goal. However, many of the short-term goals were not only mentioned as facilitators but also as end goals in themselves.

\section{Discussion}

Our results show that in practice clinicians do not follow one single ideal such as patient centeredness. Their behaviour appears to be guided by the need to accomplish a variety of competing and sometimes conflicting goals, some of which are orientated to patients as persons, but most of which are orientated by medical, organisational, societal or even personal preservation or profit. We identified five high level goal categories and thirty different nested sub goals which GPs pursue in consultations, most of them with several subordinate goals, aimed at benefiting different aspects of persons or organisations. Because GPs discern many different aspects of high quality health care and often consider several of them as relevant in a consultation, they tend to pursue multiple goals. Those goals support maintaining the health and the well-being of their patients, maintaining their own work satisfaction, maintaining the organisation of care, and maintaining public health agendas. Goals of different goal categories may compete and sometimes conflict within a single consultation. To make optimal use of consultation time, GPs estimate which aspects of the quality of care are dominant in a consultation and invest less in others.

An interesting finding is the paradoxical observation that GPs regard the patient centred goal 'accommodating patients' as such an important means to maintain the well-being of their patients that they describe it as a goal that is always present, however they mention it as a specific goal in only a small number of consultations. In contrast, 'reassuring patients', another goal that is considered to be a means to maintain the well-being of patients, is the most frequently pursued goal in this study. Apparently, GPs weigh the value of patient centeredness against the urgency of other goals.

In this study we used three interview methods to explore the goals GPs pursue during consultations. These different methods offered both complementary and confirmatory data, thereby strengthening the results ${ }^{19}$. Because the focus groups were not directly linked to specific consultations they provided more general reflections on consultation goals, which could be used to guide the subsequent focused interviews. Additionally, being a group process, they fostered the growth of new insights. The stimulated recall interviews yielded detailed descriptions of doctors' thoughts and motivations during consultations. In the think-aloud interviews the possible bias by the effects of reflection and reinterpretation were 
diminished because of the short time between the actual event and the interview. Therefore they provided data to gauge the interpretation of the other types of interviews. This combination of methods also made it possible to study a large and diverse sample of both participants and consultations.

A potential risk of all interview methods is that participants give socially desirable answers $^{21}$. It has been demonstrated that GPs are less likely to give socially desirable answers and are more likely to show vulnerability and reflect on attitudes and emotions when interviewed by another $\mathrm{GP}^{22}$, as was the case in our study, but they still may have tried to please or impress the interviewer. However, our results show no indication of this. The socially desirable goals that are part of the advocated communication models were only mentioned in a minority of consultations. The GPs did mention goals aimed at protecting themselves which might thwart the interests of the patient. As these are not socially desirable goals this suggests that our participants felt safe enough to give true statements. However, it is not unlikely that goals aimed at protecting professional functioning and wellbeing are underrepresented because doctors do not like to admit to others or perhaps even to themselves that they pursue goals that benefit themselves.

Another risk of our methodology is the possibility of interpretation bias in the analysis, in particular because the researcher who did all the first analyses is a GP herself and may have had trouble in keeping a professional distance. To prevent this she frequently discussed findings during data collection and analysis with supervisors and colleagues, using these moments as peer debriefing. Additionally the researchers doing the independent second analysis were chosen for their different backgrounds, to add the richness of different viewpoints and thereby heighten the quality of the analysis.

The frequency numbers given for the goals should be considered as no more than a very rough indication of the occurrence of goals, as the sample of participating GPs was too small to guarantee reliable numerical data.

Patient centeredness has been described as a method to guide consultations, as a moral philosophy ${ }^{2}$ and even as an ideology ${ }^{3}$. It is also frequently described as the ideal for every type of consultation ${ }^{4,11}$. In line with this, good communication is described as a generic set of behaviours that is uniformly desirable in any kind of consultation ${ }^{11,23,24}$. This generic approach contrasts with the diversity of goals that emerged when we asked doctors about the goals they pursued when trying to meet the demands of everyday practice.

Similar discrepancies between prescribed behaviour and actual practice have been noticed and explored throughout the whole range of public services ${ }^{25,26}$. Public servants that have direct interactions with people such as the police, teachers and healthcare workers, work in an environment that is too complex to reduce to prescribed responses, despite pressure to do $\mathrm{so}^{25}$. To meet the unpredictable and variable needs of the people they serve, they evolve their own strategies to manage 
dilemmas caused by insufficient resources and unrealistically high expectations of what can be done. They work out practical versions of public policy that often diverge from officially pronounced policy, which has led to discussions on the pros and cons of professional autonomy ${ }^{25,26}$. The introduction of evidence based medicine and clinical practice guidelines raised similar discussions on autonomy in health care. ${ }^{27}$ Clinical practice guidelines as a phenomenon have been accused of compromising professional autonomy and ignoring relevant aspects of the individual by applying evidence of groups to individual cases ${ }^{3,28}$. Patient centeredness instead focuses on the individual patient but neglects medical circumstances and societal needs ${ }^{3}$. The goals of the doctors in our study show that they do not blindly follow prescriptions from either, but have developed situation specific notions of quality of care.

Our study has implications for clinicians, policy makers, and for researchers. It shows that the idealised notion of communication that is advocated by the patient centred model does not fit practice and may therefore be a burden to clinicians. One of the central aims of patient centeredness is to support patient autonomy ${ }^{1,4}$. But although patient autonomy is an important value in health care, it is not the only value, nor is it always the most important one. Delivering high quality medical technical care, caring for populations, or caring for persons may be as important 29 30. Doctors should perhaps not feel remiss when they do not follow the idealised notions of patient centred communication models, if they sincerely feel that other goals take precedence. But they might want to keep in mind that many of the communicative actions described in these models can be useful for the realisation of other goals, for example for information gathering or giving reassurance ${ }^{11}$. Similar to clinicians, policy makers in health care may need to balance the importance of patient autonomy and that of other values. Too much emphasis on one particular value may lead to negligence in other areas. There are indications that too much emphasis on patient autonomy as the right of self-determination may result in less caring for patients ${ }^{1,31,32}$. For communication research and training our results show the importance of studying and teaching effective communication strategies related to the whole gamut of doctors' goals instead of focussing on one subdivision. 


\section{Literature}

1. Marvel MK, Epstein RM, Flowers K, Beckman HB. Soliciting the patient's agenda: have we improved? JAMA 1999;281:283-7.

2. Rhoades DR, McFarland KF, Finch WH, Johnson AO. Speaking and interruptions during primary care office visits. Fam Med 2001;33:528-32.

3. Levinson W, Gorawara-Bhat R, Lamb J. A study of patient clues and physician responses in primary care and surgical settings. JAMA 2000;284:1021-7.

4. Rogers MS, Todd CJ. The 'right kind' of pain: talking about symptoms in outpatient oncology consultations. Palliat Med 2000;14:299-307.

5. Maguire P, Faulkner A, Booth K, Elliott C, Hillier V. Helping cancer patients disclose their concerns. Eur J Cancer 1996;32A:78-81.

6. Britten N, Stevenson FA, Barry CA, Barber N, Bradley CP. Misunderstandings in prescribing decisions in general practice: qualitative study. BMJ 2000;320:484-8.

7. Kennelly C, Bowling A. Suffering in deference: a focus group study of older cardiac patients' preferences for treatment and perceptions of risk. Qual Health Care 2001;10 Suppl 1:i23-8.

8. Campion P, Foulkes J, Neighbour R, Tate P. Patient centredness in the MRCGP video examination: analysis of large cohort. Membership of the Royal College of General Practitioners. BMJ 2002;325:691-2.

9. Elwyn G, Hutchings H, Edwards A, Rapport F, Wensing M, Cheung WY, Grol R. The OPTION scale: measuring the extent that clinicians involve patients in decision-making tasks. Health Expect 2005;8:34-42.

10. Kurtz S, Silverman J, Draper J. Teaching and learning communication skills in medicine. Oxford - San Franscisco: Radcliffe Publishing; 2005.

11. Gysels M, Richardson A, Higginson IJ. Communication training for health professionals who care for patients with cancer: a systematic review of training methods. Support Care Cancer 2005;13:356-66.

12. Aspegren K. BEME Guide No. 2: Teaching and learning communication skills in medicine-a review with quality grading of articles. Medical Teacher 1999;21:563-70.

13. Pfeiffer $\mathrm{C}$, Madray $\mathrm{H}$, Ardolino A, Willms $\mathrm{J}$. The rise and fall of students' skill in obtaining a medical history. Med Educ 1998;32:283-8.

14. Craig JL. Retention of interviewing skills learned by first-year medical students: a longitudinal study. Med Educ 1992;26:276-81.

15. Dalen van J, Kerkhofs E, van Knippenberg-van den Berg BW, van den Hout HA, Scherpbier AJ, van der Vleuten CP. Longitudinal and concentrated communication skills programmes: two dutch medical schools compared. Adv Health Sci Educ Theory Pract 2002;7:29-40.

16. Hulsman RL, Ros WJ, Winnubst JA, Bensing JM. Teaching clinically experienced physicians communication skills. A review of evaluation studies. Medical Education 1999;33:655-68.

17. Cote L, Leclere $\mathrm{H}$. How clinical teachers perceive the doctor-patient relationship and themselves as role models. Acad Med 2000;75:1117-24.

18. Haidet P, Dains JE, Paterniti DA, Hechtel L, Chang T, Tseng E, Rogers JC. Medical student attitudes toward the doctor-patient relationship. Med Educ 2002;36:568-74.

19. Jaye C, Egan T, Parker S. 'Do as I say, not as I do': Medical Education and Foucault's Normalizing Technologies of Self. Anthropology \& Medicine 2006;13:141-155.

20. Veldhuijzen W, Ram PM, van der Weijden T, Niemantsverdriet S, van der Vleuten CP. Characteristics of communication guidelines that facilitate or impede guideline use: a focus group study. BMC Fam Pract 2007;8:31. 
21. Silverman J, Kurtz S, Draper J. Skills for communicating with patients. Oxford - San Francisco: Radcliffe; 2005.

22. Makoul G. Essential elements of communication in medical encounters: the Kalamazoo consensus statement. Acad Med 2001;76:390-3.

23. Dalen van J, Bartholomeus P, Kerkhofs E, Lulofs R, Van Thiel J, Rethans JJ, Scherpbier $\mathrm{AJ}$, van der Vleuten CP. Teaching and assessing communication skills in Maastricht: the first twenty years. Med Teach 2001;23:245-51.

24. Veldhuijzen W, Ram P, van der Weijden T, Wassink M, van der Vleuten C. Much variety and little evidence: a description of guidelines for doctor-patient communication. Med Educ 2007;41:138-45.

25. Haes de H. Dilemmas in patient centeredness and shared decision making: a case for vulnerability. Patient Educ Couns 2006;62:291-8.

26. Bensing J, van Dulmen S, Tates $\mathrm{K}$. Communication in context: new directions in communication research. Patient Education and Counseling 2003;50:27-32.

27. Wilson SR, Sabee CM. Explicating communicative competence as a theoretical term. In: Handbook of communication and social interaction skills Edited by JO Greene, BR Burleson. Mahwah, New Jersey: Lawrence Erlbaum Associates; 2003.

28. Brown RF, Bylund CL. Communication skills training: describing a new conceptual model. Acad Med 2008;83:37-44.

29. Maassen $\mathrm{H}$. Interview met Jozien Bensing: gezond communiceren. Medisch contact 2006;61:1924-27.

30. Lyle J. Stimulated recall: a report on its use in naturalistic research. British Educational Research Journal 2010, 29:861-78.

31. Schepens A, Aeltermana A, van Keer H. Studying learning processes of student teachers with stimulated recall interviews through changes in interactive cognitions. Teaching and Teacher Education 2010;23:457-72.

32. Thiel van J, Ram P, van Dalen J. MAAS-global manual. Maastricht: Maastricht University; 2000. http://www.hag.unimaas.nl/Maas-Global_2000/index.htm.

33. Green JO. Message production; advances in communication theory. Mahwah, New Jersey: Lawrence Erlbaum Associates; 1997.

34. Armitage CJ, Conner M. Efficacy of the Theory of Planned Behaviour: a meta-analytic review. Br J Soc Psychol 2001;40:471-99.

35. Ajzen I, Albarracín D, Hornik R. Prediction and change of health behavior: applying the reasoned action approach: Psychology Press; 2007.

36. Cappella JN. The role of discrete emotions in the theory of reasoned action and its successors: quitting smoking in young adults. In: Prediction and change of health behavior: applying the reasoned action approach Edited by I Ajzen, D Albarracín, R Hornik: Psychology Press; 2007.

37. Bensing $\mathrm{j}$. Bridging the gap. The separate worlds of evidence-based medicine and patient-centered medicine. Patient Educ Couns 2000;39:17-25.

38. Epstein RM, Franks P, Fiscella K, Shields CG, Meldrum SC, Kravitz RL, Duberstein PR. Measuring patient-centered communication in patient-physician consultations: theoretical and practical issues. Soc Sci Med 2005;61:1516-28.

39. Dwamena FC, Gaulden C, Lewin S, Smith RC, Holmes-Rovner M, et al. A systematic review for providers to promote a patient-centered approach. In: International conference on communication in health care; 2008; Oslo.

40. Nuland van M, Hannes K, Aertgeerts B, Goedhuys J. Educational interventions for improving the communication skills of general practice trainees in the clinical consultation. Cochrane Database of Systematic Reviews 2005, Protocols 2005. 
41. Nuland van M, Goedhuys J. Effective educational interventions for improving the communication skills of general practice trainees. In: International conference on communication in health care; 2004; Brugge.

42. Kellermann K. Communication: Inherently strategic and primarily automatic. Communication monographs 1992;59:288-300.

43. Duffy FD, Gordon GH, Whelan G, Cole-Kelly K, Frankel R, Buffone N, Lofton S, Wallace $M$, Goode L, Langdon L. Assessing competence in communication and interpersonal skills: the Kalamazoo II report. Acad Med 2004;79:495-507.

44. Cegala DJ, Lenzmeier Broz S. Physician communication skills training: a review of theoretical backgrounds, objectives and skills. Med Educ 2002;36:1004-16.

45. Haes de $\mathrm{H}$, Bensing J. Endpoints in medical communication research, proposing a framework of functions and outcomes. Patient Educ Couns 2009;74:287-94. 


\section{Chapter}

\section{The goal driven nature of doctor-patient communication in primary care encounters}

W Veldhuijzen, J Urlings, P Portegijs, T van der Weijden, A Muijtjens, G Elwyn, CPM van der Vleuten 


\section{Abstract}

\section{Objective}

To investigate whether the communication of general practitioners (GPS) with their patients is led by what doctors want to achieve, by exploring if the goals GPs say to pursue predict their communicative behaviour.

\section{Design}

Cross-sectional observational study comparing GPs' consultation goals elicited by think-aloud interviews with ratings of the communication during the same consultations by observers using a validated instrument to measure communicative behaviour. We used a hypothesis testing and an exploratory approach.

\section{Setting}

General practice

\section{Participants}

16 GPs and 246 patients who gave informed consent.

\section{Main outcome measures}

Consultation goals identified by content analysis of think-aloud interviews, guided by a predefined list of goals, containing items such as making a diagnosis or reassuring the patient. GP communication scores on the MAAS-global, a validated observational instrument for doctor patient communication. Test results of nine hypotheses concerning the effects of consultation goals on communicative behaviour.

\section{Results}

Six hypotheses were confirmed, with effect sizes between 0.33 and 1.10 . The other three hypotheses showed a (non-significant) difference in the direction predicted. Patient-centred goals led to higher scores on patient-centred communication items, while health-related goals led to lower scores on these items.

\section{Conclusions}

The communicative behaviour of GPs appears to depend on the situation and to be guided by what doctors want to achieve. It is recommended that communication training programmes be adapted accordingly. 


\section{Introduction}

In recent decades doctors' communicative behaviour has received considerable attention, with many studies supporting the benefits of good doctor-patient communication 1-13. The importance of communicative competence for doctors is recognised by medical boards worldwide ${ }^{14,15}$ and effective training and assessment of doctor patient communication is a major research theme ${ }^{16-20}$.

However, despite the strong interest in improving doctors' communication skills, no studies have examined what determines the processes of doctor-patient communication. And while an entire research area is devoted to the exploration of mechanisms underlying doctors' diagnostic and therapeutic behaviours - and their relevance for medical training 21 - far less attention is devoted to how doctors select their communicative behaviours from a potentially wide-open set of possibilities. It seems odd that the drivers of specific communicative behaviours during doctorpatient encounters are apparently not considered to merit serious attention. Although doctors' attitudes towards communication styles, such as holistic or patient-centred communication, are well researched, based on the assumption that they influence communicative behaviour22-24, the mechanisms by which these attitudes influence doctors' selection of communication strategies remain to be investigated.

In an earlier study we demonstrated that doctors pursue multiple goals in a single consultation ${ }^{25}$, such as accurate diagnosis, adequate referral, tailoring treatment to the patient's preferences, building a trusting relationship and preventing the spread of infectious diseases. Consultation goals can relate to the medical technical quality of care, the patient as a person, the doctor's own well-being, the organisation of health care and society at large ${ }^{25}$. In another study we found that doctors regard their own communicative behaviours as situation specific, with consultation goals determining which communicative actions they use ${ }^{26}$.

In contrast with the doctors' reported notion of goal-directed and situation-specific communication, medical education training programmes are guided by a generic concept of communicative competence. Generally, programmes define communication skills as the ability to perform a set of pre-specified communicative behaviours, representing a broad conception of good doctor-patient communication. In the same vein, descriptions of good communication used in medical education tend to disregard the type of consultation, the medical context and patient characteristics $5,27,28$. Nevertheless, communication trainers who are also practising clinicians have characterized the prevailing generic underpinnings of communication training as "somewhat artificial" and too simplistic to meet the needs of doctors in training 29 . 
If we want to improve communication training in postgraduate medical education, we need to understand how doctors' communicative behaviour is shaped. As we pointed out earlier, doctors have been found to describe their communication as goal directed ${ }^{26}$, but self-reports are vulnerable to bias due to flawed self-knowledge and socially desirable answers ${ }^{30,31}$, Hence, the hypothesis that doctors' communication is goal directed needs to be tested against observational data. That is why we investigated the relation between doctors' communication goals and behaviours during consultations by testing whether specific consultation goals predict doctors' actual communicative behaviours.

\section{Methods}

\section{Design}

Cross-sectional observational design to correlate observed communicative actions with doctor-reported communication goals.

\section{Data collection}

\section{Participants}

We recruited GPs in the south of the Netherlands via an advertisement in a local newsletter that is sent to doctors in the region and by letters to a selected sample of GPs, emphasising our wish to also recruit female GPs. GPs who were involved in communication training for GP trainees and medical students at the local university were excluded from participation.

\section{Procedure}

Each participant was observed during a routine surgery. We only excluded consultations in which we could not obtain informed consent, because we wanted to include as wide a range of communication goals as possible. Data were collected on patients' age, gender and reason for visit. The doctors' communicative behaviour was rated by trained assessors (WV and JU), using the MAAS-global, a validated instrument for measuring communication ${ }^{32-34}$. Each consultation was video recorded to enable a second, independent, rating at a later time. After each consultation, the assessors conducted short think-aloud interview, in which they asked GPs which goals they had pursued during the consultation ("Can you tell me what you wanted to achieve in this consultation? Please describe anything that comes to mind.") ${ }^{35}$. The interviews were video recorded and transcribed verbatim. 


\section{Instruments}

\section{Communicative behaviour}

The MAAS-global requires rating, on a scale from 0-6, of thirteen items, relating to different skills for doctor-patient communication. The items are broadly defined but anchored in detailed criteria (appendix 1) ${ }^{32}$. The assessors (WV and JU) rated all the consultations independently, with one assessor rating while observing the consultation in real time and the other assessor rating the video recording. Both were blinded to the GPs' self-reported consultation goals during the assessment, which were obviously unknown during the actual consultation and not communicated to the assessors until after they had rated the consultation.

\section{GPs' consultation goals}

All the interviews were recorded and transcribed verbatim. After completing the rating of the consultations, the same researchers (WV and JU) analysed the content of the transcripts to identify the GPs' consultation goals, based on a predefined list. As the literature provided no suitable list, a list was developed for this study based on grounded theory analysis of the interview transcripts and other qualitative data 25 . The list contained 41 goals in five categories: maintaining the health of the patient, the patient's well-being, the GP's work satisfaction, the organisation of care and public health agendas (appendix 2). Differences in rating were resolved by discussion. It was noted for each goal whether or not discussion was needed to reach consensus.

\section{Analysis}

We started with a hypothesis-driven analysis. The hypothesis regarded effects of consultations goals of GPs and their communication scores on the MAAS-global. The hypothesis were based on the literature knowledge and clinical experience of WV and JU. After consultation of PR, who is co-author of the MAAS-global and an experienced communication trainer, one hypothesis was revised. In addition we were also prepared to do an exploratory analysis on the relations between consultation goals and communicative behaviour, if our hypothesis would be confirmed. For both analysis we used means of the two assessors' MAAS-global ratings as dependent variable or, if no video recording was available, the scores of the direct observation only. The consultation goals resulting from the analysis of the interviews were the independent variables. Interrater reliability was established by calculating Interrater Class Correlations (ICC) for the MAAS-global ratings. 


\section{Hypothesis-driven analysis}

In the hypothesis-driven analysis, we used multilevel models to test the predictive value of the following nine hypotheses:

1. If doctors aim at making patients understand the diagnosis and its implications, their ratings on the MAAS-global item 'diagnosis' will be higher.

2. If doctors aim at making patients understand treatment options and/or how to handle their complaints themselves, their ratings on the MAAS-global item 'management' will be higher.

3. If doctors aim at monitoring the status and progression of chronic illness, their ratings on the MAAS-global item 'introduction' will be lower.

4. If doctors aim at comforting patients, their ratings on the MAAS-global item 'diagnosis' will be higher.

5. If doctors aim at understanding why a patient has come to see them and what he/she wants or needs, their ratings on exploration of the patient's perspective, i.e. the mean of the MAAS-global items 'request for help', 'exploration' and 'emotions,' will be higher.

6. If doctors aim at giving emotional support to patients, their ratings on empathy, i.e. the mean of the MAAS-global items 'exploration', 'emotions' and 'empathy,' will be higher.

7. If doctors aim at avoiding needless investigations or treatment, their ratings on the MAAS-global item 'management' will be higher.

8. If doctors only pursue goals relating to diagnosis and management, their ratings on exploration of the patient's perspective, i.e. the mean of the MAASglobal items 'request for help', 'exploration' and 'emotions,' will be lower.

9. If doctors pursue more than three goals, their overall rating on the MAAS-global (the mean item rating) will be higher.

For each hypothesis a multilevel model was built with consultations nested within GPs. We used the 'mixed' procedure in SPSS 16.0 with a maximum likelihood method. For hypotheses relating to a combination of multiple MAAS-global items, we used the mean of these items to enable expressing the results on the original seven-point scale. Additionally, we calculated Cohen's d (difference/standard deviation) as standardised effect size. An effect size $\approx 20$ is considered small, $\approx 50$ medium and $\approx 80$ large $^{36}$.

\section{Exploratory analysis}

In the exploratory analysis we related consultation goals to all MAAS-global items. Because most goals occurred infrequently, we aggregated the goals into groups that were assumed to be associated with similar communicative behaviours (appendix 2), based on the researchers' clinical experience and the literature. Single goals with high frequency and goal groups with a frequency of $>7 \%$ were analysed (for a frequency list see appendix 2). As this resulted in 130 associations 
to be analysed, we considered a normal multi-level approach unfeasible, and instead used a cluster corrected single level analysis, the 'aggregate' approach ${ }^{37}$. This method is more robust than a multilevel approach because it requires no model building decisions or tests of assumptions, which is especially relevant with small samples on a 'nested' level as in this study. The main disadvantage of this method is that more cases are needed for significant results ${ }^{37}$.

In this analysis, we devided the consultations of each GP in consultations in which the GP did, and did not, pursue a given goal. We computed mean Maas Global ratings over each subset. Using paired t-tests we tested whether MAAS global ratings were affected by GPs having pursued the goal or not. We repeated this for all ten goals/goal groups. To illustrate the analysis, let us consider the goal group 'diagnosis'. After clustering, for one GP, the consultations with a diagnosis-related goal and the consultations with no such goal, we computed GP's mean scores on each item of the MAAS-global. This procedure was repeated for all the GPs. Next we tested for each item whether the mean scores differed significantly between consultations with and without a diagnostic goal. The reliability of this method was examined by applying it to reanalyse the hypotheses and comparing the results of the multi-level analysis with those of the aggregated analysis.

\section{Results}

The sixteen participated. They were fairly representative of Dutch GPs with regard to demographics and type of practice: eight men, mean age 47 years (range 33-59 years), mean professional experience as a GP 15 years. Seven GPs worked fulltime, the others an average of 0.6 full time equivalents (range 0.4-0.9). Group practices were somewhat overrepresented, with five GPs working single-handed, five in a duo practice (within a larger group practice) and six in a group practice ${ }^{38}$. Of the 259 patients invited to participate, three were excluded because of hearing (2) and language (1) problems and ten refused to participate, mostly because their visit concerned a sensitive issue (private conversation, genital or sexually transmitted disease, $n=5$ ). Of the total of 246 consultations that were analysed, 234 were video recorded for scoring by the second assessor. Twelve consultations were not recorded due to technical problems (8) and patient refusal (4). The patients were representative of the patients in Dutch general practice ${ }^{39}$. Most of the patients were women (62\%) and all age groups were represented (median 47 years, interquartile range 30 - 60 years, range 0-89 years). The most frequent reasons for the encounter were respiratory (ICPC chapter R, 17\%), musculoskeletal (15\%) or skin (14\%) problems. 


\section{Interrater reliability}

The total number of GP goals in one consultation ranged from one to seven with a mean of three. The content analysis of the interviews resulted in immediate complete agreement between the two researchers on the goals of $61 \%$ of the consultations. For the remaining consultations there was always agreement on some of the goals and consensus was generally easily reached through discussion. The reliability of the MAAS-global ratings was acceptable, with ICC between the raters 0.77 for the total score. Rater ICCs for single items ranged from 0.61 to 0.83 , except for item 13 'empathy', with ICC 0.52.

\section{Communicative behaviour}

The ratings of items 7 'evaluation of consultation' and 3 'request for help' were lowest and the highest ratings were those of items 4 'physical examination' and 13 'empathy'. The average ratings on items and item combinations targeted by our hypotheses ranged from 1.2 to 3.4 (see Table 7.1). For most of these we found substantial differences between GPs, necessitating multilevel or aggregate analysis. ICCs for the GPs ranged from 0.042 (item 6, 'treatment') to 0.23 (total score).

\section{Hypotheses testing}

A multilevel model with random intercept showed the best fit for all the hypotheses, except for hypotheses 1 and 4, with the MAAS-global item 'diagnosis' as dependent variable (see Table 7.2), which had a fairly low ICC of 0.058 , most of which could also be explained by the influence of goals. As the SPSS 'mixed' procedure yielded no definite results, we conducted ANOVA for these hypotheses.

The goals of the nine hypotheses were pursued in $5 \%$ to $36 \%$ of the consultations (see Table 7.2). In six of the nine hypotheses we demonstrated goal-directed communication. They were confirmed, with effect sizes ranging from 0.33 to 1.10 . For the other three hypotheses there was a non-significant difference in the predicted direction. The largest effects were the positive influence of the goal "understanding the patient's agenda" on the ratings of the MAAS-global items concerning exploration of the patient's perspective, and the positive influence of the goal "giving emotional support" on the ratings of the MAAS-global items relating to exploration, emotions and empathy (0.98 and 0.94 respectively, with effect sizes of 0.79 and 1.1). The score variance ranged from 0.82 to 2.38 for individual Maasglobal items and was 0.34 for the total score. Depending on the item, between $4.2 \%$ and $17.0 \%$ of the variance could be ascribed to the influence of the doctor, with a mean variance of $12 \%$. The hypotheses that were confirmed explained between $2.1 \%$ and $7.6 \%$ of the additional variance, with a mean variance of $3 \%$ being explained by each of the tested goals (all hypotheses included). 


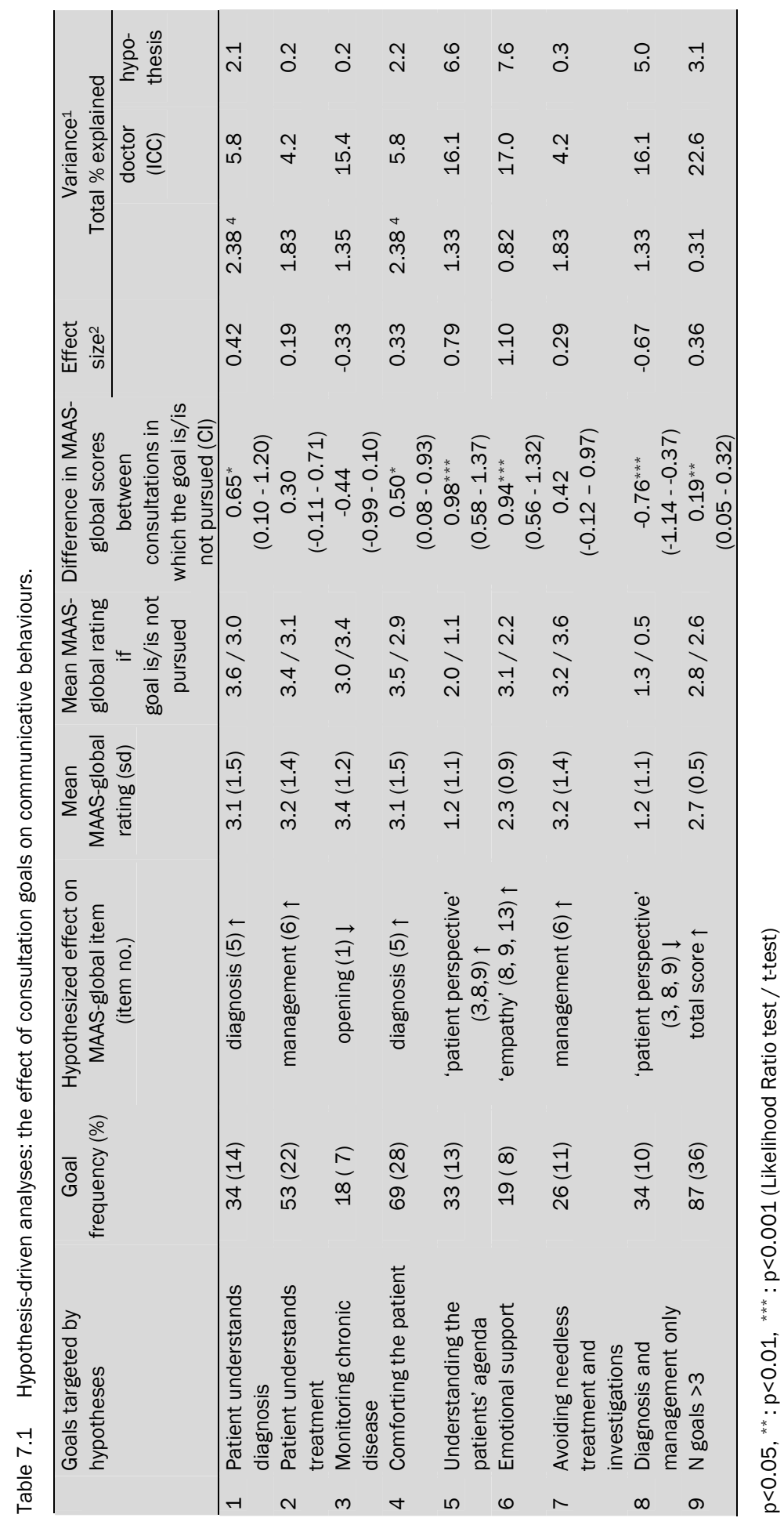




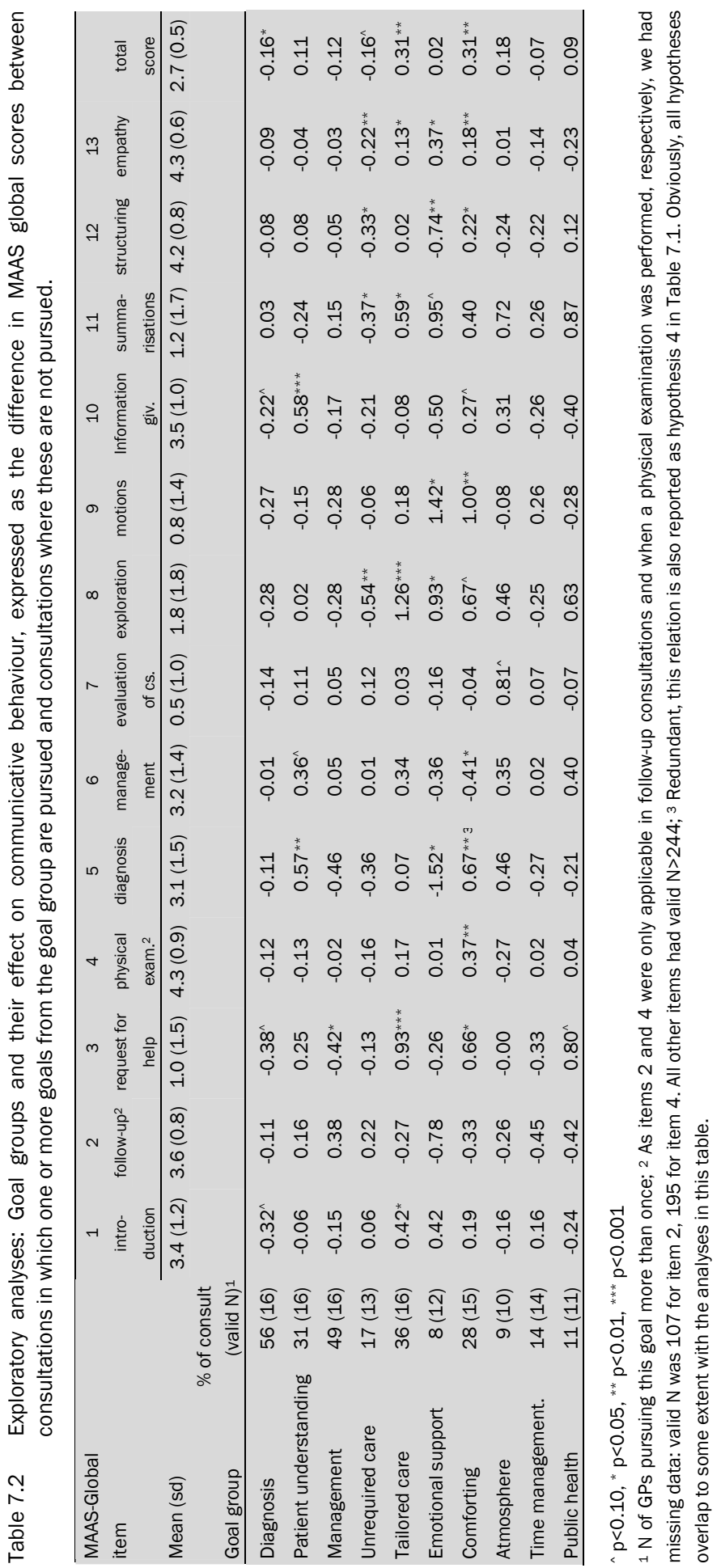




\section{Exploratory analyses}

The ample support for a relation between consultation goals and communicative behaviour encouraged us to do an exploratory analysis on which goals affect which aspects of communicative behaviour. Because the results of our aggregate analyses corresponded well with those of the multilevel analyses, with only slightly more conservative significance values for the aggregate analyses (appendix 3 ), we concluded that this was a reliable method to analyse the goal groups.

Table 7.2 shows the difference in communication scores between consultations during which the GP did or did not pursue goals of the specified goal groups. The goal groups 'reassuring the patient' and 'understanding and adjusting to the patient' had the largest impact on the GPs communication. The presence of goals had the strongest influence on the two consultation phase-related items 'request for help' and 'diagnosis' and on not phase-related aspects of communication (MAAS-global items 8-13) and. Generally, patient-centred goals and goal groups, such as 'understanding and adjusting to the patient', 'reassuring' and 'giving emotional support,' tended to be associated with higher scores on patient centred MAAS-global items, such as introduction (1), exploring the request for help (3), exploration (8) and emotions (9), and on the total score, whereas health-related goals, such as goals in the goal groups 'diagnosing' and 'management' tended to be associated with lower scores on patient-centred items and with the total score.

\section{Discussion}

In this study, we examined whether the communicative behaviours displayed by GPs during specific consultations are indeed in alignment with the GPs' selfreported goals for these consultations. The results do indeed reveal a substantial effect of goals on GPs' communicative behaviour. Of the nine hypotheses we tested, six are confirmed, with effects sizes ranging from moderate to large, while the remaining three show a (non-significant) difference in the predicted direction. That the hypothesis-related variance is rather low in comparison with the effect sizes can be explained by the low frequencies of some goals. The goals described in the hypotheses were pursued in only a small number of the consultations, which explains how a large effect can be combined with a relatively small impact on the overall variance of the consultations. The variation that is attributable to the consultation goals included in the hypotheses is smaller than the variance attributable to the person of the doctor. It should be noted, however, that the doctor-related variance reflects the overall influence that can be ascribed to the doctor, whereas the hypothesis-related variance is limited to the variance related to one goal. Estimating the total influence of the consultation goals would require 
taking account of 41 different goals. The average doctor-explained variance of $12 \%$ illustrates that most of the variance is related to situational factors other than the doctor, such as goals. The aggregate analyses further support the goal directedness of doctor patient communication. For these analyses we performed 130 statistical tests and, assuming independence, we could expect about 7 'significant' results (at $\alpha=0.05$ ) based on chance alone. We found 24 significant results, however. The pattern in the aggregate analysis shows that goals in patientcentred goal groups lead to higher scores on patient centred communication items, whereas health-related goals lead to lower scores on these items. Both the high number of statistically relevant correlations and the theory-related pattern we found support the conclusion that doctors' communication is goal-directed.

This study has some limitations. For reasons of feasibility we kept the sample size relatively small. This means, however, that we cannot rule out that we may have missed some smaller effects, even though the effects we did find are robust. An unavoidable weakness of this study is the timing of the think-aloud interviews. Ideally participants in this type of interview are asked to reflect during action ${ }^{35}$. In this study this would have meant asking the GPs to state their goals as soon as these arose, necessitating repeated interruption of the consultations for moments of reflection. This was not feasible as it would have disturbed the natural course of the consultations. Instead we interviewed the GPs immediately after each consultation. However, the time lag between the decision to pursue a goal and the interview may have influenced the content of the reported goals and thus caused under-representation of goals that were not achieved or only pursued during the early part of the consultation.

Comparison to other studies indicates that the effects of the goals are highly relevant. Studies which also used the MAAS global to explore effects of communication training reported absolute effects that were considerably smaller (evaluation of GP vocational training) 40 or in the same range (CME training for GPs with voluntary participation) ${ }^{41}$. The notion that doctor patient communication is situation specific is in line with reports relating to other clinical competencies, such as clinical reasoning21. Initially, clinical reasoning was taught as a generic skill, but when evidence emerged that the clinical reasoning processes of experienced clinicians are situation specific, training courses were redesigned to include relevant aspects of situations, such as disease groups, similar groups of complaints or patient age groups ${ }^{21}$. Currently, doctor patient communication is mainly taught as a generic, non-situational, set of skills $5,27,28$. If this was in alignment with what actually happens in clinical practice, the variance in our study would have been strongly associated with doctors' communication styles/levels of competence and not with situational factors. The low levels of doctor-related variance in this study can be interpreted as a falsification of a generic concept of 
doctor-patient communication. The notion that communicative competence is not generic would also explain the preliminary results of two reviews showing that situation-specific communication training is more effective than generic training ${ }^{42-44}$. In this study, we focused exclusively on the impact of consultation goals and not on other situation-specific aspects. In an earlier study doctors identified their consultation goals as the main influence on their communicative behaviour, but they also mentioned other relevant situational factors, such as assumptions about the patient based on present patient behaviour and experience, time available and emotions and energy levels of the doctor ${ }^{26}$.

\section{Conclusion and recommendations}

The results of this study warrant the conclusion that doctor patient communication is situational and goal-driven. To redesign communication training and change the focus to situational and goal-specific communicational competence, we need to better understand the mechanisms of communicative behaviour. Further studies should examine in greater depth which factors influence doctors' communication and how these factors determine the effectiveness of different communication techniques. 


\section{Literature}

1. Bensing J. Doctor-patient communication and the quality of care. Social Science and Medicine 1991;32:1301-10.

2. Ong LM, de Haes JC, Hoos AM, Lammes FB. Doctor-patient communication: a review of the literature. Social Science and Medicine 1995;40:903-18.

3. Stewart MA. Effective physician-patient communication and health outcomes: a review. Canadian Medical Association Journal 1995;152:1423-33.

4. Stewart MA, Brown JB, Donner A, McWhinney IR, Oates J, Weston W. Final report: the impact of patient-centred care on patient outcomes on family practice: Thames Valley Practice Research Unit; 1996.

5. Silverman J, Kurtz S, Draper J. Skills for communicating with patients. Oxford - San Francisco: Radcliffe; 2005.

6. Beck RS, Daughtridge R, Sloane PD. Physician-patient communication in the primary care office: a systematic review. J Am Board Fam Pract 2002;15:25-38.

7. Di Blasi Z, Harkness E, Ernst E, Georgiou A, Kleijnen J. Influence of context effects on health outcomes: a systematic review. Lancet 2001;357:757-62.

8. Gysels M, Richardson A, Higginson IJ. Communication training for health professionals who care for patients with cancer: a systematic review of effectiveness. Support Care Cancer 2004;12:692-700.

9. Rowe RE, Garcia J, Macfarlane AJ, Davidson LL. Does poor communication contribute to stillbirths and infant deaths? A review. J Public Health Med 2001;23:23-34.

10. Rowe RE, Garcia J, Macfarlane AJ, Davidson LL. Improving communication between health professionals and women in maternity care: a structured review. Health Expect 2002;5:63-83.

11. Stevenson FA, Cox K, Britten N, Dundar Y. A systematic review of the research on communication between patients and health care professionals about medicines: the consequences for concordance. Health Expect 2004;7:235-45.

12. Thorne SE, Bultz BD, Baile WF. Is there a cost to poor communication in cancer care?: a critical review of the literature. Psychooncology 2005;14:875-84; discussion 885-6.

13. Lewin SA, Skea ZC, Entwistle V, Zwarenstein M, Dick J. Interventions for providers to promote a patient-centred approach in clinical consultations. Cochrane Database Syst Rev 2001:CD003267.

14. Miller SH. ABMS' Maintenance of Certification: the challenge of continuing competence. Clin Orthop Relat Res 2006;449:155-8.

15. WONCA_europe: The european definition of family medicine / general practice. 2005.

16. Gysels M, Richardson A, Higginson IJ. Communication training for health professionals who care for patients with cancer: a systematic review of training methods. Support Care Cancer 2005;13:356-66.

17. Kurtz S, Silverman J, Draper J. Teaching and learning communication skills in medicine. Oxford - San Franscisco: Radcliffe Publishing; 2005.

18. van Dalen J, Kerkhofs E, van Knippenberg-Van Den Berg BW, van Den Hout HA, Scherpbier AJ, van der Vleuten CP. Longitudinal and concentrated communication skills programmes: two dutch medical schools compared. Adv Health Sci Educ Theory Pract 2002;7:29-40.

19. Aspegren K. BEME Guide No. 2: Teaching and learning communication skills in medicine-a review with quality grading of articles. Medical Teacher 1999;21:563-570.

20. Duffy FD, Gordon GH, Whelan G, Cole-Kelly K, Frankel R, Buffone N, Lofton S, Wallace M, Goode L, Langdon L. Assessing competence in communication and interpersonal skills: the Kalamazoo II report. Acad Med 2004;79:495-507. 
21. Eva KW. What every teacher needs to know about clinical reasoning. Med Educ 2005; 39:98-106.

22. Haidet P, Dains JE, Paterniti DA, Chang T, Tseng E, Rogers JC. Medical students' attitudes toward patient-centered care and standardized patients' perceptions of humanism: a link between attitudes and outcomes. Acad Med 2001;76:S42-4.

23. Haidet P, Dains JE, Paterniti DA, Hechtel L, Chang T, Tseng E, Rogers JC. Medical student attitudes toward the doctor-patient relationship. Med Educ 2002;36:568-74.

24. Tsimtsiou Z, Kerasidou O, Efstathiou N, Papaharitou S, Hatzimouratidis K, Hatzichristou D. Medical students' attitudes toward patient-centred care: a longitudinal survey. Med Educ 2007;41:146-53.

25. Veldhuijzen W, Elwyn G, Ram PM, Leeuwen Y, van der Weijden T, van der VleutenCPM. Beyond patient centeredness: the multitude of competing goals that doctors pursue in consultations. In preparation.

26. Veldhuijzen W, Moogendorf K, Ram PM, van der Weijden T, Elwyn G, van der Vleuten CP. How doctors move from generic goals to specific communicative behaviour in real practice consultations. In preparation.

27. Van Dalen J, Bartholomeus P, Kerkhofs E, Lulofs R, Van Thiel J, Rethans JJ, Scherpbier AJ, Van Der Vleuten CP. Teaching and assessing communication skills in Maastricht: the first twenty years. Med Teach 2001;23:245-251.

28. Veldhuijzen W, Ram PM, van der Weijden T, Niemantsverdriet S, van der Vleuten CP. Characteristics of communication guidelines that facilitate or impede guideline use: a focus group study. BMC Fam Pract 2007;8:31.

29. Veldhuijzen W, van der Weijden T, Ram P, van Leeuwen $Y$, van der Vleuten CP. Communication guideline characteristics that enhance communication skill training: a focus group study. Submitted.

30. Lyle J. Stimulated recall: a report on its use in naturalistic research. British Educational Research Journal 2010;29:861-78.

31. Checkland K, Harrison S, Marshall M. Is the metaphor of 'barriers to change' useful in understanding implementation? Evidence from general medical practice. J Health Serv Res Policy 2007;12:95-100.

32. van Thiel J, Ram P, van Dalen J. MAAS-global manual. Maastricht: Maastricht University; 2000. http://www.hag.unimaas.nl/Maas-Global_2000/index.htm.

33. Ram P, Grol R, Rethans J-J, Schouten B, van-der-Vleuten C, Kester A. Assessment of general practitioners by video observation of communicative and medical performance in daily practice: issues of validity, reliability and feasibility. Med Educ 1999;33:447-54.

34. Hobma SO, Ram PM, Muijtjens AM, Grol RP, van der Vleuten CP. Setting a standard for performance assessment of doctor-patient communication in general practice. Med Educ 2004;38:1244-52.

35. Cotton D, Gresty K. Reflecting on the think-aloud method for evaluating e-learning. British Journal of Educational Technology 2006;37:45-54.

36. Hojat M, Xu G. A visitor's guide to effect sizes: statistical significance versus practical (clinical) importance of research findings. Adv Health Sci Educ Theory Pract 2004; 9:241-9.

37. Twisk JWR. Applied multilevel analysis: A practical guide. Cambridge: Cambridge University Press; 2006.

38. van den Berg MJ, Kolthof ED, de Bakker DH, van der Zee J. Tweede Nationale Studie naar ziekten en verrichtingen in de huisartspraktijk. De werkbelasting van huisartsen. Utrecht: NIVEL; 2004. 
39. van der Linden MW, Westert GP, de Bakker DH, Schellevis FG. Tweede Nationale Studie naar ziekten en verrichtingen in de huisartspraktijk. Klachten en aandoeningen in de bevolking en in de huisartspraktijk. Utrecht/Bilthoven: NIVEL/RIVM; 2004.

40. Kramer AW, Dusman H, Tan LH, Jansen JJ, Grol RP, van der Vleuten CP. Acquisition of communication skills in postgraduate training for general practice. Medical Education 2004;38:158-67.

41. Hobma S, Ram P, Muijtjens A, van der Vleuten C, Grol R. Effective improvement of doctor-patient communication: a randomised controlled trial. $\mathrm{Br} J$ Gen Pract 2006; 56:580-6.

42. Dwamena FC, Gaulden C, Lewin S, Smith RC, Holmes-Rovner M, e al.: A systematic review for providers to promote a patient-centered approach. In: International conference on communication in health care; 2008; Oslo.

43. van Nuland $M$, Goedhuys J. Effective educational interventions for improving the communication skills of general practice trainees. In: International conference on communication in health care; 2004; Brugge.

44. van Nuland M, Hannes K, Aertgeerts B, Goedhuys J. Educational interventions for improving the communication skills of general practice trainees in the clinical consultation. Cochrane Database of Systematic Reviews 2005, Protocols 2005. 


\section{Appendix 1: MAAS-Global rating list}

\section{MAAS-Global Rating List for Consultation Skills of Doctors}

Jacques van Thiel, Paul Ram, Jan van Dalen Mastricht University, Netherlands

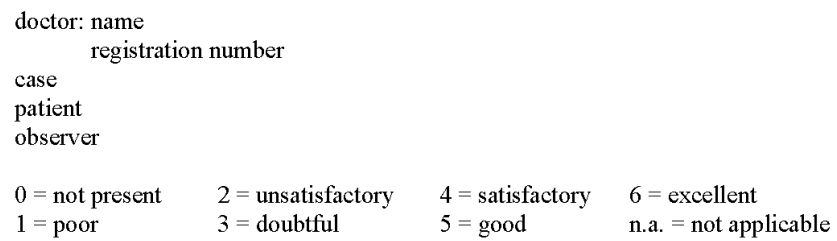

\section{SECTION 1: COMMUNICATION SKILLS FOR EACH SEPARATE PHASE}

\section{INTRODUCTION}

giving the patient room to tell his story general orientation on the reason for visit asking about other reasons for visit

2. FOLLOW-UP CONSULTATION naming previous complaints,

requests for help and management plan asking about adherence to management plan asking about the course of the complaint

\section{REQUEST FOR HELP}

naming requests for help, wishes or expectations naming reasons that prompted

the patient to come now completing exploring request for help

4. PHYSICAL EXAMINATION instructions to the patient explanation of what is being done treating the patient with care and respect

\section{DIAGNOSIS}

naming findings and diagnosis/hypothesis naming causes or the relation

between findings and diagnosis naming prognosis or expected course asking for patient's response

6. MANAGEMENT

shared decision-making, discussing alternatives, risks and benefits discussing feasibility and adherence determining who will do what and when asking for patient's response

\section{EVALUATION OF CONSULTATION} general question responding to requests for help perspective for the time being $\begin{array}{llllllll}0 & 1 & 2 & 3 & 4 & 5 & 6\end{array}$

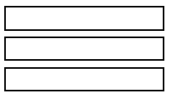

n. $\begin{array}{lllllll}0 & 1 & 2 & 3 & 4 & 5 & 6\end{array}$
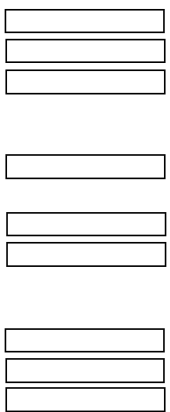

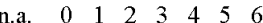

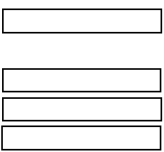

$\begin{array}{lllllll}0 & 1 & 2 & 3 & 4 & 5 & 6\end{array}$

$\begin{array}{lllllll}0 & 1 & 2 & 3 & 4 & 5 & 6\end{array}$
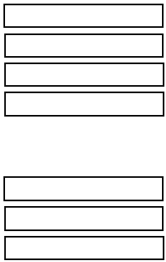


\section{SECTION 2: GENERAL COMMUNICATION SKILLS}

8. EXPLORATION

$\begin{array}{lllllll}0 & 1 & 2 & 3 & 4 & 5 & 6\end{array}$

exploring requests for help,

wishes or expectations

exploring patient's response to information given

within patient's frame of reference

responding to nonverbal behavior and cues

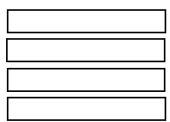

9. EMOTIONS

asking about/ exploring feelings

reflecting feelings (including nature and intensity) sufficiently throughout the entire consultation

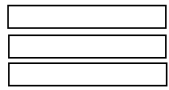

$\begin{array}{lllllll}0 & 1 & 2 & 3 & 4 & 5 & 6\end{array}$

10. INFORMATION GIVING

announcing, categorizing

in small quantities, concrete explanations

understandable language

asking whether the patient understands

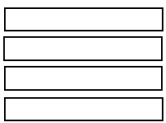

$\begin{array}{lllllll}0 & 1 & 2 & 3 & 4 & 5 & 6\end{array}$

11. SUMMARIZATIONS

content is correct, complete

concise, rephrased

checking

sufficiently throughout the entire consultation

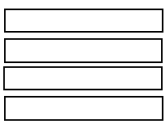

$\begin{array}{lllllll}0 & 1 & 2 & 3 & 4 & 5 & 6\end{array}$

12. STRUCTURING

logical sequence of phases

balanced division of time

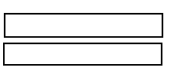

$\begin{array}{lllllll}0 & 1 & 2 & 3 & 4 & 5 & 6\end{array}$

announcing (history taking,

examination, other phases)

13. EMPATHY

concerned, inviting and sincerely empathetic

in intonation, gesture and eye contact

expressing empathy in brief verbal responses

SECTION 3: MEDICAL ASPECTS

Rate according to professional guidelines if they are available.

Otherwise rate to the best of your ability.

14. HISTORY TAKING

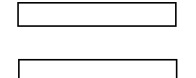

$\begin{array}{lllllll}0 & 1 & 2 & 3 & 4 & 5 & 6\end{array}$

15. PHYSICAL EXAMINATION

$\begin{array}{llllllll}\text { n.a. } & 0 & 1 & 2 & 3 & 4 & 5 & 6\end{array}$

16. DIAGNOSIS

$\begin{array}{lllllll}0 & 1 & 2 & 3 & 4 & 5 & 6\end{array}$

17. MANAGEMENT

$\begin{array}{lllllll}0 & 1 & 2 & 3 & 4 & 5 & 6\end{array}$

OTHER FEEDBACK 


\section{Appendix 2: overview of the goals GPs pursue in consultations}

\begin{tabular}{|c|c|c|}
\hline $\begin{array}{l}\text { Goal } \\
\text { categories }\end{array}$ & Goal groups & Goals (N / percentage of consultations) \\
\hline \multirow{16}{*}{$\begin{array}{l}\text { Maintaining } \\
\text { patients' } \\
\text { health }\end{array}$} & \multirow[t]{5}{*}{ Diagnosing } & Finding the right diagnosis (57/23\%) \\
\hline & & Finding the cause of the complaints or illness $(9 / 4 \%)$ \\
\hline & & Estimating the graveness of the complaint ( $46 / 19 \%)$ \\
\hline & & Monitoring health status $(20 / 8 \%)$ \\
\hline & & Monitoring the progress of chronic disease $(18 / 7 \%)$ \\
\hline & \multirow{3}{*}{$\begin{array}{l}\text { Enhancing patients' } \\
\text { understanding }\end{array}$} & Enhancing patients understanding about the diagnosis (34 / 14\%) \\
\hline & & Enhancing patients understanding about treatment (28/11\%) \\
\hline & & Enhancing patients understanding about self-management (30 / 12\%) \\
\hline & \multirow[t]{4}{*}{ Management } & Starting further diagnostics (25 / 10\%) \\
\hline & & Treatment with medication ( $53 / 22 \%)$ \\
\hline & & Referral to other health care worker $(16 / 7 \%)$ \\
\hline & & Other treatment $(15 / 6 \%)$ \\
\hline & \multirow{4}{*}{$\begin{array}{l}\text { Initiating unrequired } \\
\text { care }\end{array}$} & Stimulating adherence $(20 / 8 \%)$ \\
\hline & & Influencing lifestyle (14 / 6\%) \\
\hline & & Diagnosing a problem the patient did not ask help for (12/5\%) \\
\hline & & Starting a policy not asked for (4 / $2 \%)$ \\
\hline \multirow{11}{*}{$\begin{array}{l}\text { Maintaining } \\
\text { patients' } \\
\text { wellbeing }\end{array}$} & \multirow[t]{3}{*}{ Tailoring to the patient } & $\begin{array}{l}\text { Understanding why the patient has come and what he wants or needs. ( } 33 \text { / } \\
14 \%)\end{array}$ \\
\hline & & Tailoring the consultation itself to the needs of the patient. (34 / 14\%) \\
\hline & & Tailoring the medical policy to the patient's preferences. (43/18\%) \\
\hline & \multirow[t]{3}{*}{ Service } & Evaluating if the attempts to adjust to the patient were successful. $(1 / 0 \%)$ \\
\hline & & Legitimizing the sick role of the patient. $(5 / 2 \%)$ \\
\hline & & Making health care as little burdening as possible. ( $3 / 1 \%)$ \\
\hline & Comforting the patient & Comforting the patient about his/her medical condition. (69 / 28\%) \\
\hline & $\begin{array}{l}\text { Emotionally supporting } \\
\text { the patient }\end{array}$ & Emotional supporting the patient. (19/8\%) \\
\hline & \multirow{2}{*}{$\begin{array}{l}\text { Creating a good } \\
\text { atmosphere }\end{array}$} & Creating a pleasant atmosphere during the consultations $(11 / 5 \%)$ \\
\hline & & Avoidance of conflicts (12/5\%) \\
\hline & Creating trust & Showing professionalism (3/1\%) \\
\hline \multirow{7}{*}{$\begin{array}{l}\text { Maintaining } \\
\text { work } \\
\text { satisfaction }\end{array}$} & \multirow[t]{4}{*}{ Delivering good care } & Delivering medical technical correct care $(6 / 2 \%)$ \\
\hline & & Delivering care that fits the preferences and needs of the patient $(2 / 1 \%)$ \\
\hline & & Delivering care that is appropriate and affordable $(1 / 0 \%)$ \\
\hline & & Having a good relationship with patients $(6 / 2 \%)$ \\
\hline & \multirow[t]{2}{*}{ Setting boundaries } & Placing responsibility where it belongs $(2 / 1 \%)$ \\
\hline & & Prevent being drained $(6 / 2 \%)$ \\
\hline & $\begin{array}{l}\text { Creating opportunities } \\
\text { to regain energy. }\end{array}$ & Purposefully scheduling easy consultations (2/1\%) \\
\hline \multirow{4}{*}{$\begin{array}{l}\text { Maintaining } \\
\text { organization } \\
\text { of care }\end{array}$} & Staying on time & Keeping in line with the time-schedule of the surgery $(35 / 14 \%)$ \\
\hline & Saving surgery places & Saving surgery places $(2 / 1 \%)$ \\
\hline & $\begin{array}{l}\text { Learning the patient to } \\
\text { comply with practice } \\
\text { organization }\end{array}$ & Teach patients to handle appointments adequately $(3 / 1 \%)$ \\
\hline & $\begin{array}{l}\text { Advocating for the } \\
\text { patient }\end{array}$ & $\begin{array}{l}\text { Organizing that the patient gets the care needed from other health care } \\
\text { institutions }(1 / 0 \%)\end{array}$ \\
\hline \multirow{3}{*}{$\begin{array}{l}\text { Maintain } \\
\text { public health } \\
\text { agenda's }\end{array}$} & \multirow{3}{*}{$\begin{array}{l}\text { Impeding medicalisation, } \\
\text { reducing costs and } \\
\text { supporting public health }\end{array}$} & No unnecessary treatment, referrals or diagnostics (26 / 11\%) \\
\hline & & When there are equal options, using the cheapest one $(0 / 0 \%)$ \\
\hline & & $\begin{array}{l}\text { Prevention of the spread of infectious diseases or treatment resistant } \\
\text { micro-organisms }(5 / 2 \%)\end{array}$ \\
\hline
\end{tabular}




\section{Appendix: 3}

Supplement to Table 7.1: comparison of multilevel and aggregate analysis (hypotheses)

\begin{tabular}{|c|c|c|c|c|c|}
\hline \multirow{3}{*}{\multicolumn{2}{|c|}{$\begin{array}{l}\text { Hypothesis } \\
\text { Consultation goal }\end{array}$}} & \multirow[b]{3}{*}{ Freq $(\%)$} & \multirow{3}{*}{$\begin{array}{l}\text { MAAS-global } \\
\text { Item (item no.) }\end{array}$} & \multirow{3}{*}{$\begin{array}{l}\text { Difference } \\
\qquad(\mathrm{Cl})\end{array}$} & \multirow{3}{*}{$\begin{array}{c}\text { aggregate analysis } \\
\text { diff. }(\mathrm{Cl})\end{array}$} \\
\hline & & & & & \\
\hline & & & & & \\
\hline \multirow[t]{2}{*}{1} & Explain diagnosis & 34 (14) & diagnosis (5) $\uparrow$ & $0.65^{*}$ & $0.67^{*}$ \\
\hline & & & & $(0.10-1.20)$ & $(0.19-1.16)$ \\
\hline \multirow[t]{2}{*}{2} & Explain treatment & $53(22)$ & treatment $(6) \uparrow$ & 0.30 & 0.21 \\
\hline & & & & $(-0.11-0.71)$ & $(-0.38-0.79)$ \\
\hline \multirow[t]{2}{*}{3} & Monitoring chronic & $18(7)$ & opening (1) $\downarrow$ & -0.44 & -0.54 \\
\hline & disease & & & $(-0.99-0.10)$ & $(-1.71-0.63)$ \\
\hline \multirow[t]{2}{*}{4} & Comforting the & $69(28)$ & diagnosis $(5) \uparrow$ & $0.50^{*}$ & $0.67^{*}$ \\
\hline & patient & & & $(0.08-0.93)$ & $(0.29-1.05)$ \\
\hline \multirow[t]{2}{*}{5} & Understanding & 33 (13) & 'patient perspective' & $0.98^{* * *}$ & $1.12^{* *}$ \\
\hline & request for help & & $(3,8,9) \uparrow$ & $(0.58-1.37)$ & $(0.51-1.74)$ \\
\hline \multirow[t]{2}{*}{6} & Emotional support & 19 (8) & 'empathy' $(8,9,13) \uparrow$ & $0.94^{* * *}$ & $0.91^{* *}$ \\
\hline & & & & $(0.56-1.32)$ & $(0.32-1.49)$ \\
\hline \multirow[t]{2}{*}{7} & Avoid needless & $26(11)$ & treatment (6) $\uparrow$ & 0.42 & 0.27 \\
\hline & & & & $(-0.12-0.97)$ & $(-0.40-0.94)$ \\
\hline \multirow[t]{2}{*}{8} & Diagnosis and & $13(5)$ & 'patient perspective' $(3,8,9) \downarrow$ & $-0.73^{* *}$ & $-0.76^{*}$ \\
\hline & management only & & & $(-1.18--0.28)$ & $(-1.31--0.22)$ \\
\hline \multirow[t]{2}{*}{9} & $N$ goals $>3$ & 87 (36) & total score $\uparrow$ & $0.19^{* *}$ & $0.16^{\wedge}$ \\
\hline & & & & $(0.05-0.32)$ & $(-0.00-0.33)$ \\
\hline
\end{tabular}

${ }^{\wedge}: p<0.10,{ }^{*}: p<0.05,{ }^{* *}: p<0.01,{ }^{* * *}: p<0.001$ (Likelihood Ratio test $/ \mathrm{t}$-test) 


\section{Chapter 8}

\section{An exploration of the extent to which doctors modify their goals to those of their patients and its effect on goal achievement by patients}

W Veldhuijzen, P Portegijs, T van der Weijden, PM Ram, L Kruisifix, G Elwyn, CPM van der Vleuten 


\section{Abstract}

\section{Objective}

To explore the extent to which doctors' and patients' consultation goals match and test acceptability and validity of a measurement procedure for this purpose.

\section{Methods}

We obtained data on patients' goals and patient satisfaction from a preconsultation questionnaire and a post-consultation questionnaire, respectively. Data on doctors' goals were derived from think aloud interviews directly after consultations. Two raters independently rated three aspects of goal match on a five-point scale.

\section{Results}

The methodology seemed acceptable to doctors and patients. High inter-rater variation necessitated consensus discussions between raters. The validity of the goal match construct was supported by a positive association of goal match with several aspects of patient satisfaction. The mean ratings of goal match were: presence of patient-only goals 2.1 , presence of doctor-only goals 2.3 , presence of goal conflict 1.2 .

\section{Conclusions}

Our study confirmed that interactive problem solving in consultations is a highly complex process. Inter-rater reliability might be enhanced by rater training and more detailed exploration during the interviews with doctors. The results for goal match were better than the predominantly negative reports in the literature had led us to expect. Further studies are needed to verify our results. Confirmation of our results would warrant exploration of how doctors achieve goal match. 


\section{Introduction}

Patient-centred care is the central paradigm for Western health care ${ }^{1}$. It requires that doctors deliver care that is 'closely congruent with and responsive to patients' wants, needs and preferences" 2 . To do so, doctors need to bridge differences between themselves and their patients with regard to roles (user or provider of care), medical knowledge and knowledge about the impact of symptoms. Time and again this has been shown to be a tall order. Doctors tend to underestimate patients' need for information and overestimate patients' medical knowledge. ${ }^{3-6}$ Other areas of discordance are the interpretation of the patient's reason for attendance, the evaluation of subjective morbidity and the impact of symptoms, perceptions of treatment risks, side effects and efficacy, and evaluations of doctor patient communication ${ }^{7-12}$. Some scholars go so far as to say that doctors and patients seem to be from different worlds ${ }^{10,13}$. Consequently, there appears to be good reason to doubt whether doctors are successful in adjusting their agenda for a consultation to that of their patients.

The efforts to raise doctors' awareness of patients' agendas, i.e. patients' concerns and the goals they pursue in the consultation, have taken different forms. Doctors have been trained to explore patients' beliefs, preferences and emotions, ${ }^{14,15}$ patients have been asked to complete agenda forms, to be used by the doctor as a starter for the consultation ${ }^{16}$, and patients have been taught to communicate their agendas more clearly ${ }^{17,18}$. However, no studies have examined to what extent doctors actually adapt their agendas to match those of their patients or the consequences of ill-matched agendas of doctor and patient.

Matching doctors' and patients' agendas involves a complex two-step process of interactive problem solving. The doctor and the patient have to agree first on the topic of the consultation and then on the goals for these topics. In the study reported in this paper, attention was concentrated on the second step by eliciting and comparing doctors' and patients' consultation goals. Additionally, we tested the acceptability and construct validity of our method. Because goal mismatch was expected to diminish patient satisfaction, especially with regard to the achievement of consultation goals, a negative correlation between goal mismatch and patient satisfaction was interpreted as confirmation of the construct validity of our instruments. 


\section{Methods}

\section{Design}

In a cross-sectional observational study we examined the match of doctors' and patients' goals in consultations in general practice. We collected data on patients' goals using a standardised pre-consultation questionnaire and data on doctors' goals by think aloud interviews directly after each consultation. We measured patient satisfaction immediately following the consultation using a second questionnaire. The consultation, including doctor and patient data, was the unit of analysis.

\section{Participants}

GPs were recruited by a call for participation in the newsletter of the department of general practice of the local university and through personal letters, followed by phone contact, to a convenience sample of fifty GPs in the local region. Female GPs in particular were requested to respond to ensure gender diversity of the sample. GPs involved in GP training were excluded from participation, because their experience with communication training might be associated with better goal matching and therefore hamper the generalisability of the results. Data were gathered during clinics of the participating GPs. All patients attending a clinic on the day of the practice visit were invited to participate unless severe language problems prevented informed consent or when the GP asked us not to approach the patient.

\section{Data collection}

\section{Think aloud interviews}

Data were collected during one regular clinic of each of the participating GPs. Following each consultation, the interviewer, who was present at all the consultations, asked the GP to think aloud and reflect on the goals pursued ("Can you tell me what you tried to achieve in this consultation? Mention anything that comes to mind."). The interviewer also recorded the type of consultation (new complaint / follow-up / chronic illness), the number of reasons for attendance presented by the patient, and the main reason (ICPC-code). All the interviews were video recorded and transcribed.

\section{Patient questionnaires}

All participating patients were asked to complete two short questionnaires, one before the consultation and another one immediately afterwards. Patients who had no time or wished to complete the questionnaire at home, were allowed to return the questionnaires to the practice at a later date. Patients were asked to state their 
age and gender and to indicate their consultation goal(s) by checking one or more boxes in a list consisting of 17 patient goals including the options 'I do not know' and 'other' (see appendix 1). The goals were derived from literature on patient expectations and agendas ${ }^{19-22}$ and the authors' clinical and research experience. The post-consultation questionnaire asked patients to express their general satisfaction with the consultation on a ten-point scale, to answer four questions exploring different aspects of satisfaction (five-point Likert scale) taken from the Consultation Satisfaction Questionnaire ${ }^{23}$ and one added question on the extent to which they were satisfied that they had achieved their goals in the consultation.

\section{Analysis}

Evaluating the match between the goals of doctors and patients

In the absence of an existing instrument to examine the match of patients' and doctors' goals, we devised our own method. We started by creating, for each consultation, a dyadic data set, containing the verbatim from the interview and the patient goals from the pre-consultation questionnaire. Based on these sets, two researchers independently rated the applicability of the following three statements, derived from the literature and the researchers' clinical experience:

1. The patient pursues goals that the doctor does not pursue.

2. The doctor pursues goals that the patient does not pursue.

3. The goals of the patient and the doctor are conflicting.

These three statements probed the presence of patient-only goals, doctor-only goals and goal conflict, respectively. Rating was on a five point Likert scale from $1=$ not present to $5=$ present.(see text box) Goals were considered to be conflicting if they were (almost) opposite, for example if the patient wanted a prescription and the doctor deemed this unnecessary or even harmful.

The researchers had different backgrounds. Rater 1 (LK) was a movement scientist and rater $2(\mathrm{WV})$, the principal researcher, was a GP. They used written instructions and, by way of rater training, discussed their independent ratings of twenty consultations from seven different GPs. After all independent ratings had been completed a consensus meeting was held in which all consultations were discussed of which the ratings for one of the statements differed by more than one Likert scale point.

\section{Statistical analysis}

Intraclass correlations (SPSS 16.0 procedure 'mixed') of the independent ratings were determined in order to assess inter-rater reliability. All further analyses were based on consensus ratings or, if these were not available, the mean of two 
independent ratings. We used non-parametric tests to analyse associations between the quality of goal match and other parameters: Mann-Whitney for the dichotomous independent variable patient gender and Kruskall-Wallis for the polytomous variable nature of the presented problem. We used Spearman rank correlation to analyse the interdependence of the goal match variables and the association of goal match with the continuous variables patient age, number of problems presented and patient satisfaction. Despite the use of non-parametric tests we report means instead of medians, because the median of a variable with only five possible values can hide important differences. We determined intraclass correlations to identify any clustering of goal mismatch on the level of individual GPS.

\section{Results}

\section{Population}

The sixteen participating GPs were fairly representative of Dutch GPs with regard to demographics and type of practice: eight men, mean age 47 years (range 33-59 years), mean professional experience as a GP 15 years. Seven GPs worked fulltime, the others an average of 0.6 full time equivalents (range 0.4-0.9). Female GPs and group practices were somewhat overrepresented, with five GPs working in solo practice, five in a duo practice (within a larger group practice) and six in group practice $^{24}$.

Of 259 patients invited to participate, three were excluded (two for a hearing problem, one for a language problem) and ten refused to have a researcher present during the consultation, mostly because of the sensitive nature of the reason for attendance (private conversation, genital or sexually transmitted disease, $n=5)$. Of the patients attending the 246 consultations included in the study, 179 returned both the pre-consultation and post-consultation questionnaires. Several of the patients who had allowed the researcher to be present at the consultation explained that they had not completed the questionnaire because they had left their reading glasses at home.

The patients were representative of the patient population in Dutch general practice. ${ }^{25}$ The majority were women (62\%) and all age groups were represented (median 47 years, interquartile range 32-59 years, range 0-89 years). The most common consultation type was 'new episode' (55\%), followed by 'follow-up consultation' (35\%) and 'chronic care consultation' (10\%). Seventy per cent of patients presented a single reason for attendance, 20\% presented two reasons and $10 \%$ presented three or more reasons. The most frequent main reasons for attendance were musculoskeletal (ICPC chapter L, 17\%), respiratory $(\mathrm{R}, 15 \%)$ or 
skin related (S, 15\%). Patients indicated 0 to 12 goals (mean 2.9) per consultation. Diagnostic and treatment goals were the most common ones, occurring in $74 \%$ and $72 \%$ of consultations, respectively (appendix 2 ).

\section{Reliability of the ratings of goal match}

Inter-rater reliability before the consensus meetings was low (Table 8.1), although the ratings of both raters were in the same range and the differences showed no consistent pattern. Of 178 consultations, 57 showed a difference in rating of more than one Likert scale points for one or more of the three rated statements. For these consultations consensus discussions on ratings were held. In most cases, agreement was easily reached through discussion. Rating problems were most frequent in consultations involving one of the following three situations:

1. GPs reported different goals for different topics in consultations where the patient presented with several reasons for attendance. However, the patient questionnaire did not ask patients to relate their goals to specific topics. This led to differences in goal match depending on the topic selected by the GP.

2. GPs used terms to label the goals that differed from the goal categories in the patient questionnaire. So where the patient questionnaire distinguished between advice on how to manage problems, treatment with medication, and referrals, some doctors uniformly used 'treatment' to denote these consultation aspects.

3. In some interviews GPs said they aimed to meet their patients' goals but did not define these goals. As a result the researchers could not ascertain whether a GP had interpreted the goals correctly, which precluded adequate evaluation of goal match.

\section{The quality of the match between doctors' and patients' goals}

There was considerable similarity between patient and doctor goals (Table 8.1). The mean rating (Likert scale: $1=$ not present; $5=$ present) for patient-only goals was 2.1 , for doctor-only goals it was 2.3 , and for goal conflict 1.2 . In order to clarify the implications of these ratings, we recalculated the Likert ratings of patient-only and doctor-only goals as percentages of all patient goals and all doctor goals, respectively, assuming that the ratings represented continuous variables with 1 equalling $0 \%$ and 5 equalling 100\% (text box). According to our raters, approximately $28 \%$ of patient goals were patient-only goals and $33 \%$ of the doctor goals were doctor-only goals, which means that $72 \%$ of patient goals and $67 \%$ of doctor goals were shared by both parties. The absence of goal conflict in $87 \%$ of the consultations (both raters scoring 1; no conflict present) implies that our raters judged that some goal conflict was present in $13 \%$ of the consultations. 
Table 8.1 Comparison of the ratings of goal match by the two raters.

\begin{tabular}{lcccc}
\hline & Mean ${ }^{1}$ R1 (sd) & Mean ${ }^{1}$ R2 (sd) & Rater ICCs & $\begin{array}{c}\text { Mean }{ }^{1} \text { after } \\
\text { consensus (sd) }\end{array}$ \\
\hline Presence of patient-only goals & $1.92(1.18)$ & $2.02(1.11)$ & 0.46 & $2.12(1.19)$ \\
Presence of GP-only goals & $2.38(1.17)$ & $2.25(1.19)$ & 0.46 & $2.30(1.12)$ \\
Goal conflict & $1.25(0.70)$ & $1.11(0.46)$ & 0.51 & $1.18(0.58)$ \\
\hline
\end{tabular}

1 Likert-type scale from 1 'not present' to 5 'present'

Table 8.2 shows that there was no association between goal match on the one hand and type of consultation (new episode, follow-up consultation, chronic care consultation), the main reasons for attendance and age or gender of the patient on the other hand. There was a significant positive relationship between the number of reasons for attendance presented and goal conflict. The GPs do not seem to differ in degree of goal match, but perhaps for goal conflict were a slight clustering of GPs was found.

Table 8.2 Relations between consultation characteristics and goal match.

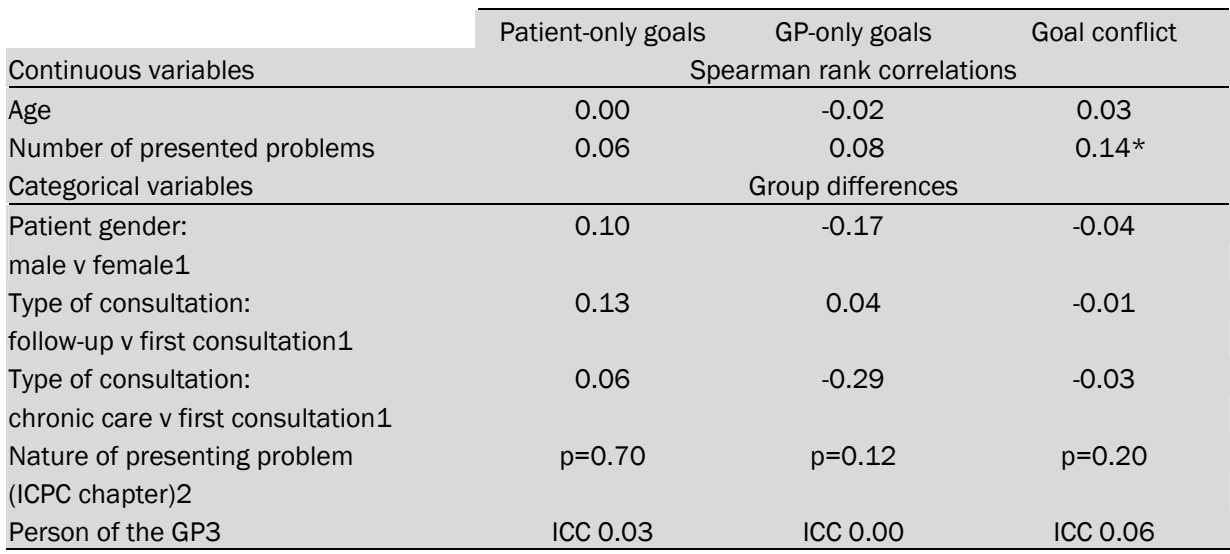

${ }^{\wedge} \mathrm{p}<0.10,{ }^{*} \mathrm{p}<0.05,{ }^{*} \mathrm{p}<0.01 ;{ }^{1}$ Mann Whitney test; ${ }^{2}$ Kruskall-Wallis test; ${ }^{3}$ Intra-class correlations

\section{The construct of goal match}

In this study we focused on three aspects of the match of patient and doctor goals in consultations: the presence of patient-only goals, the presence of GP-only goals and the presence of goal conflict. These three aspects showed positive interrelationships (Table 8.3), the strongest of which was that between the presence of GP-only goals and goal conflict. As for the relationships between goal match and patient satisfaction (Table 8.4), the presence of patient-only goals appeared to be related to lower patient satisfaction with regard to goal 
achievement, personal trust, intention to adhere to advice and overall satisfaction, and a tendency toward lower satisfaction with attentive listening $(p=0.057)$. There was a tendency for goal conflict to be associated with patients not intending to adhere to their doctor's advice $(p=0.058)$. No relationship was found between the presence of GP-only goals and patient satisfaction.

Table 8.3 Mutual correlations between goal match variables.

\begin{tabular}{|c|c|c|c|}
\hline Variable & Patient only goals & GP only goals & Goal conflict \\
\hline Patient only goals & & $0.21 * *$ & $0.21 * *$ \\
\hline GP only goals & & & $0.28 * * *$ \\
\hline Goal conflict & & & \\
\hline
\end{tabular}

Spearman rank correlations. ${ }^{*} p<0.05, * * p<0.01, * * * p<0.001$

Tabel 8.4 Relation between goal match and patient satisfaction.

\begin{tabular}{|c|c|c|c|c|}
\hline & Mean (sd) & Patient only goals & GP only goals & Goal conflict \\
\hline Goals fully achieved ${ }^{1}$ & $4.1(1.01)$ & $-0.25 * *$ & 0.03 & -0.11 \\
\hline GP listened attentively ${ }^{1}$ & $4.7(0.58)$ & $-0.16^{\wedge}$ & 0.01 & 0.02 \\
\hline Could discuss personal matters ${ }^{1}$ & $4.4(0.89)$ & -0.18 * & 0.07 & -0.10 \\
\hline Enough time available ${ }^{1}$ & $3.3(1.67)$ & -0.00 & -0.01 & 0.03 \\
\hline Will comply, GP is right ${ }^{1}$ & $4.4(0.81)$ & -0.21 * & 0.05 & $-0.16^{\wedge}$ \\
\hline Overall satisfaction ${ }^{2}$ & $8.3(1.02)$ & $-0.17 *$ & 0.01 & -0.06 \\
\hline
\end{tabular}

Spearman rank correlations: ${ }^{\wedge}: p<0.10, *: p<0.05, * *: p<0.01$

${ }^{1}$ Likert-type scale from $1=$ strongly disagree to $5=$ strongly agree

2Scale 1-10 (standard grading in Dutch schools)

\section{Discussion}

\section{Main results}

This study suggests a better match between patients' goals and doctors' goals than initially expected based on the predominantly negative reports about congruence between doctors and patients in the literature. Our findings suggest that most goals were pursued by doctors and patients alike. The rarity of goal conflict also points toward good goal match. Apparently, this match becomes harder to attain as more topics have to be dealt with in the same consultation, as was manifested in 
the positive relationship of goal conflict and multiple reasons for attendance. The importance of good goal match was underlined by the negative association we found between goal mismatch and patient satisfaction, particularly if the latter was caused by doctors not sharing patient goals.

The acceptability of our measurement methods to both doctors and patients appears to be confirmed by the fact that we had little trouble recruiting doctors and patients. Patients' willingness to have a researcher present during the consultation was high and the response to the questionnaires acceptable. Despite low interrater reliability, the validity of the goal match construct appears to be supported by the positive relationship of goal match and patient satisfaction as regards goal achievement and the negative relationship of goal match and the number of reasons for attendance presented by the patient.

\section{Strengths and weaknesses}

It is a strength of this study that, as far as we know, it is the first attempt to exploratory the match of doctors' and patients' goals. The results have to be interpreted with caution, because of several weaknesses, such as the disbalance of patient data and doctor data and the rather low inter-rater reliability.

In the absence of validated instruments to determine goal match, we developed our own procedure, using questionnaires and interviews to elicit patient goals and doctor goals, respectively. The differences in the way these data sets were obtained complicated the comparison between doctor and patient goals, a problem we tried to resolve by having researchers interpret the data and judge goal match. The interviews to investigate doctors' goals were conducted after each consultation, for the obvious reason that collecting data during consultations would severely disrupt the consultation process. It should be noted, however, that this method introduces the possibility of post-hoc rationalisation of goals. In other words, it cannot be ruled out that the goals reported by the doctors in retrospect matched the patient goals more closely than the goals the doctors actually pursued during the consultation.

Another weakness is low inter-rater reliability. Although this was resolved through consensus discussions, rating might have been more reliable with more intensive training and instruction of the raters. Rating might also have been facilitated by the use of video recordings of consultations to give a better idea of what happened during the consultation. On the other hand, however, video recording might contaminate the results, for instance good doctor patient communication characterised by easy flowing conversation, a positive atmosphere and a friendly, empathetic doctor - could cause rating bias towards good goal match.

\section{Conclusions}

We have to be cautious in interpreting the findings, because we used surrogate measures such as questionnaires and think aloud interviews to identify goals while 
what we really wanted to do was read the minds of doctors and patients during consultations. That interactive problem solving, operationalised as goal matching during consultations, is a very complex object of study was illustrated by our rating problems.

Still, the quality of the match of doctor and patient goals seems to be better than might have been expected in the light of the substantial discordance between doctor and patient described in the literature ${ }^{7,8,10-12}$ and reports that doctors show few of the behaviours that are supposed to help them understand patients' perspectives ${ }^{26-31}$. When the results are interpreted in terms of the quality of goal match it should be considered that unmatched patient goals do not necessarily indicate that the doctor was not aware of a certain goal or unwilling to attend to it. Unmatched goals may be a reflection of unrealistic patient goals, for example a patient may want a prescription for a disease for which there is no cure. Goal conflict may arise when patient goals are not commensurate with goals motivated by the doctor's other responsibilities, such as having to meet public health agendas.

\section{Implications for practice}

\section{Implications for further research}

Our unexpectedly low degree of goal mismatch invites more in depth study of doctor and patient goals, preferably in larger populations, to confirm our results. This would also enable more detailed exploration of causes of goal mismatch and relations between goal mismatch and specific goals of doctors and patients. In such studies, inter-rater reliability might be enhanced by more extensive rater training, by using more raters or by using raters from similar backgrounds, such as only clinicians or only non-clinicians. It would also be interesting to involve patients in the rating process, because their interpretations may differ from those of professionals. Both validity and trustworthiness of the measurement might be enhanced by more detailed exploration during the interviews with the GPs to clarify doctor goals and bridge differences in formulation between the patient questionnaires and the GPs' statements. Validity and trustworthiness would probably be enhanced considerably if patients were to list their goals for each of their reasons for attendance separately. However, such an approach might make the questionnaire overly complex and consequently impair response rates and the validity of patients' answers. Alternatively, patient interviews could replace the preconsultation questionnaire, although this might have other undesirable side effects, such as a greater burden on patients and, more importantly, more insight into their own goals on the part of patients, which might affect their behaviour during the consultation and thus affect the goal match. On a more practical note, response rates might be enhanced by supplying reading glasses for patients and help with the questionnaire. 
Implications for medical education

If further studies confirm our results and show positive results on the quality of goal match, we might want to rethink aspects of our communication training programmes for doctors. If goal match is achieved to considerable extent despite doctors general failure to display the type of communicative behaviour they have been taught, one might conclude that doctors have found effective alternatives to the recommended communicative behaviours. Studying these alternatives and exploring causes of goal mismatch may inform communication training and help to reach transfer of skills learned in medical school to doctor behaviour in clinical practice. 


\section{Literature}

1. de Haes H. Dilemmas in patient centeredness and shared decision making: a case for vulnerability. Patient Educ Couns 2006;62:291-8.

2. Laine C, Davidof F. Patient-centered medicine: a professional evolution. Journal of the American Medical Association 1996(275):152-6.

3. Beisecker $\mathrm{AE}$, Beisecker TD. Patient information-seeking behaviors when communicating with doctors. Med Care 1990;28:19-28.

4. Kindelana K, Kenta G. Concordance between patients' information preferences and general practitioners' perceptions. PsychologyHhealth 1987;1:399-409.

5. Williams MV, Davis T, Parker RM, Weiss BD. The role of health literacy in patientphysician communication. Fam Med 2002;34:383-9.

6. Rogers ES, Wallace LS, Weiss BD. Misperceptions of medical understanding in lowliteracy patients: implications for cancer prevention. Cancer Control 2006;13:225-9.

7. Scheuer E, Steurer J, Buddeberg C. Predictors of differences in symptom perception of older patients and their doctors. Fam Pract 2002;19:357-61.

8. Geest TA, Engberg M, Lauritzen T. Discordance between self-evaluated health and doctor-evaluated health in relation to general health promotion. Scand J Prim Health Care 2004;22:146-51.

9. Cegala DJ, Gade C, Lenzmeier Broz S, McClure L. Physicians' and patients' perceptions of patients' communication competence in a primary care medical interview. Health Commun 2004;16:289-304.

10. Kenny DA, Veldhuijzen W, Weijden T, Leblanc A, Lockyer J, Legare F, et al. Interpersonal perception in the context of doctor-patient relationships: a dyadic analysis of doctorpatient communication. Soc Sci Med 2010;70:763-8.

11. Lapane KL, Dube CE, Schneider KL, Quilliam BJ. Misperceptions of patients vs providers regarding medication-related communication issues. Am J Manag Care 2007;13:613-8.

12. Sewitch MJ, Abrahamowicz M, Dobkin PL, Tamblyn R. Measuring differences between patients' and physicians' health perceptions: the patient-physician discordance scale. J Behav Med 2003;26:245-64.

13. Mishler EG. The discourse of medicine: Dialectics of medical interviews. New Yersey: Ablex Publishing Corporation, 1984.

14. Van Dalen J, Bartholomeus P, Kerkhofs E, Lulofs R, Van Thiel J, Rethans JJ, et al. Teaching and assessing communication skills in Maastricht: the first twenty years. Med Teach 2001;23:245-51.

15. Kurtz S, Silverman J, Draper J. Teaching and learning communication skills in medicine. Oxford - San Franscisco: Radcliffe Publishing, 2005.

16. Middleton JF, McKinley RK, Gillies CL. Effect of patient completed agenda forms and doctors' education about the agenda on the outcome of consultations: randomised controlled trial. BMJ 2006;332:1238-42.

17. Cegala DJ. Emerging trends and future directions in patient communication skills training. Health Commun 2006;20:123-9.

18. Dwamena FC, Mavis B, Holmes-Rovner M, Walsh KB, Loyson AC. Teaching medical interviewing to patients: the other side of the encounter. Patient Educ Couns 2009;76:380-4.

19. Keitz SA, Stechuchak KM, Grambow SC, Koropchak CM, Tulsky JA. Behind closed doors: management of patient expectations in primary care practices. Arch Intern Med 2007;167:445-52. 
20. Wensing M. Patients' expectations of treatment. In: Jones R, Britten N, Gulpepper L, Gass D, Grol R, Mant D, et al., editors. Oxford textbook of primary medical care. Oxford, New York: Oxford University Press, 2004.

21. McKinley RK, Middleton JF. What do patients want from doctors? Content analysis of written patient agendas for the consultation. Br J Gen Pract 1999;49:796-800.

22. Peck BM, Ubel PA, Roter DL, Goold SD, Asch DA, Jeffreys AS, et al. Do unmet expectations for specific tests, referrals, and new medications reduce patients' satisfaction? J Gen Intern Med 2004;19:1080-7.

23. Poulton BC. Use of the consultation satisfaction questionnaire to examine patients' satisfaction with general practitioners and community nurses: reliability, replicability and discriminant validity. Br J Gen Pract 1996;46:26-31.

24. van den Berg MJ, Kolthof ED, de Bakker DH, van der Zee J. Tweede Nationale Studie naar ziekten en verrichtingen in de huisartspraktijk. De werkbelasting van huisartsen. Utrecht: NIVEL, 2004.

25. van der Linden MW, Westert GP, de Bakker DH, Schellevis FG. Tweede Nationale Studie naar ziekten en verrichtingen in de huisartspraktijk. Klachten en aandoeningen in de bevolking en in de huisartspraktijk. Utrecht/Bilthoven: NIVEL/RIVM, 2004.

26. Campion P, Foulkes J, Neighbour R, Tate P. Patient centredness in the MRCGP video examination: analysis of large cohort. Membership of the Royal College of General Practitioners. Bmj 2002;325:691-2.

27. Levinson W, Gorawara-Bhat R, Lamb J. A study of patient clues and physician responses in primary care and surgical settings. JAMA 2000;284:1021-7.

28. Marvel MK, Epstein RM, Flowers K, Beckman HB. Soliciting the patient's agenda: have we improved? JAMA 1999;281:283-7.

29. Kennelly C, Bowling A. Suffering in deference: a focus group study of older cardiac patients' preferences for treatment and perceptions of risk. Qual Health Care 2001;10 Suppl 1:i23-8.

30. Rhoades DR, McFarland KF, Finch WH, Johnson AO. Speaking and interruptions during primary care office visits. Fam Med 2001;33:528-32.

31. Matthys J, Elwyn G, Van Nuland M, Van Maele G, De Sutter A, De Meyere M, et al. Patients' ideas, concerns, and expectations (ICE) in general practice: impact on prescribing. Br J Gen Pract 2009;59:29-36. 


\section{Appendix 1: Checklist of patient goals in pre-consultation questionnaire}

\section{GP initiated}

The GP asked me to come back

- I was asked to come back for a check-up.

a I was asked to come back if the symptoms did not diminish.

\section{Unknown}

I do not know exactly what the reasons for my visit are.

a I do not quite know what I want from this consultation.

a Others said I should go to the doctor.

\section{Diagnostic}

I have a question I want to ask my GP, it is about an examination.

口 I have a complaint and I want to know precisely what I have.

- I have a complaint, I do not think it is something serious, but I want to make sure.

a I have a complaint and I want to know whether it is serious.

- I have a complaint and I want to be referred for further investigation.

- I have no complaint, but I want a check-up.

a I have no complaint, but I want a preventive examination.

\section{Treatment}

a I want to know what I can do myself to get rid of my complaints.

口 I want a treatment for my complaints.

․ I want to be referred for further treatment.

\section{Information}

- I want to ask something about my complaints / illness (only check this item if your question is not addressed in one of the above items).

- I have a question about my treatment / medication.

a I want to talk about my private situation.

Other

을 $\quad$ being ... 


\section{Appendix 2: Frequency of patient goals}

\begin{tabular}{llc}
\hline \multirow{3}{*}{ GP-initiated consultation } & Nepeat visit requested & 41 \\
& & 38 \\
Goals unknown & Repeat visit if symptoms persist & 79 \\
& Don't know & 8 \\
& Others suggested consultation & 24 \\
Diagnosis & Diagnosis? & 32 \\
& Confirmation of self-limiting cause & 80 \\
& Serious diagnosis? & 27 \\
& Referral for diagnostics & 24 \\
& Physical examination (for..) & 23 \\
& Preventive examination & 0 \\
Treatment & & 4 \\
& Information self-management & 158 \\
& Treatment & 80 \\
Talk / information & Referral for treatment & 57 \\
& & 18 \\
& Information about my symptom/disease & 155 \\
& Information about my medication & 35 \\
Other & Talk about my personal situation & 34 \\
Total & & 6 \\
\hline
\end{tabular}




\section{Chapter 9}

\section{Interpersonal perception in the context of doctor-patient relationships: A dyadic analysis of doctor-patient communication}

DA Kenny, W Veldhuijzen, T van der Weijden, A LeBlanc, J Lockyer, F Le gare, C Campbell 


\section{Abstract}

Doctor-patient communication is an interpersonal process and essential to relationship-centered care. However, in many studies, doctors and patients are studied as if living in separate worlds. This study assessed whether: 1) doctors' perception of their communication skills is congruent with their patients' perception; and 2) patients of a specific doctor agree with each other about their doctor's communication skills. A cross-sectional study was conducted in three provinces in Canada with 91 doctors and their 1749 patients. Doctors and patients independently completed questions on the doctor's communication skills (content and process) after a consultation. Multilevel modeling provided an estimate of the patient and doctor variance components at both the dyad-level and the doctorlevel. We computed correlations between patients' and doctors' perceptions at both levels to assess how congruent they were. Consensus among patients of a specific doctor was assessed using intraclass correlation coefficient (ICC). The mean score of the rating of doctor's skills according to patients was 4.58 , and according to doctors was 4.37. The dyad-level variance for the patient was 0.38 and for the doctor was .06. The doctor-level variance for the patient ratings was 0.01 and for the doctor ratings, 0.18 . The correlation between both the patients' and the doctors' skills' ratings scores at the dyad-level was weak. At the doctorlevel, the correlation was not statistically significant. The ICC for patients' ratings was 0.03 and for the doctors' ratings 0.76 . Overall, this study suggests that doctors and their patients have a very different perspective of the doctors' communication skills occurring during routine clinical encounters. 


\section{Introduction}

If the focus of the 21st-century health care system is to be the patient, then the value of the doctor-patient relationship must be promoted ${ }^{1}$. In this context doctorpatient communication is regaining interest because it is expected to lead to improved patient outcomes ${ }^{2}$ and fewer complaints from patients regarding medical practice $^{3}$. However, researchers are still exploring both what makes communication effective and the underlying mechanisms by which patients' and providers' outcomes are affected ${ }^{4}$. Although doctor-patient communication is considered an interpersonal process ${ }^{5}$ and an essential component of relationship-centered care, ${ }^{6}$ it tends to be operationalized as a set of behaviors enacted by only one member of the dyad 7,8 . If indeed doctor-patient communication is a process by which a transmitter and a receiver of messages interact in a defined social context, then gaining more insight into this interpersonal process would be desirable ${ }^{9}$. In the last decade, a vast body of research has advanced our understanding of how individuals influence each other in the context of relationships. ${ }^{10}$ Even when the meeting is brief, as in medical consultations, individuals involved in such relationships have the potential to influence each other's cognitions, emotions and behaviors in a reciprocal way11-13. Nonetheless, many doctor-patient communication studies have assessed patients or doctors separately but not the interpersonal dynamics. If the doctor-patient interaction is an interpersonal system $^{5,14}$, then the two participants need to be considered simultaneously ${ }^{15}$. Consequently, this paper addresses the value of using a dyadic data analysis approach to the study of doctor-patient communication. ${ }^{16}$

\section{Interpersonal perception in the context of doctor-patient relationships}

In recent years, there has been increased interest in addressing gaps in mutual understanding of knowledge and values between physicians and their patients ${ }^{17,18}$. An examination of agreement between the patient perspective and the provider perspective identifies these gaps. This is important because a shared perspective is positively associated with resolution of problems and symptoms, ${ }^{19-22}$ satisfaction with physician ${ }^{23}$ and with the clinical encounter, ${ }^{24}$ trust in and endorsement of the physician's recommendations, ${ }^{25}$ adherence to treatment, ${ }^{26}$ and the patient's assessment of selfmanagement and self-efficacy when faced with a chronic disease 27 . Some factors influencing patient-provider agreement have been identified as modifiable, some of which could be the target of intervention. These include: the number and nature of problems assessed during the clinical encounter, ${ }^{28}$ education of patient, ${ }^{29}$ number of prescription medications, ${ }^{28}$ ordering of tests, ${ }^{28}$ and type of medication ${ }^{30}$. In addition, a lack of trust and agreement between patients and physicians contributes to frustrating visits from the physicians' perspective and thus could hamper the quality of care they provide ${ }^{31}$. This potential for disagreement is consistent with data from a study in general 
internal medicine suggesting that patients and physicians form their opinion about a consultation in different ways ${ }^{32}$.

Nonetheless, there are several challenges in advancing knowledge in this area. Conceptualization and operationalization of effective communication as an interpersonal and interdependent process (i.e., when those involved influence each other) between doctors and patients have important consequences. First, it emphasizes the need for concept definitions that are congruent with an interpersonal and interdependent process. In particular, consensus among individuals refers to whether two or more individuals agree on their assessment of a common target. For example, do two patients who are treated by the same physician agree with each other about their interactions with the physician? If there is strong consensus in patients' perceptions, then interventions need to be targeted at doctors who have poor outcomes. If there is little or no consensus, then we need to understand what leads a doctor to sometimes have good outcomes and sometimes have poor outcomes. Alternatively, self-other agreement ${ }^{15}$ refers to the correspondence between how a person sees him or herself in interaction with another and how others see that person. For example, if a doctor thinks he or she has good communication skills with a given patient, does the patient agree with that assessment? Particularly important here would be determining whether a doctor thought he or she had skills, but in fact his or her patients disagreed with this assessment. This distinction is important because it suggests that different underlying relationship processes are operating to form these two different perspectives. From a methodological point of view, the measurement of effective communication as an interpersonal and interdependent process requires dyadic measurements and analytical methods. Both patients and physicians would be required to assess the same consultation or skills. In a review of instruments that assess the perception of physicians on decision making in specific clinical encounters, eleven instruments were identified ${ }^{33}$. Five of the six most recently developed instruments measured both doctors' and patients' perceptions of the same phenomenon, suggesting that a dyadic approach to the clinical encounter is gaining in popularity. Interestingly, two of the dyadic instruments addressed communication skills ${ }^{34,35}$.

\section{Research questions}

Using data from a previous study that had evaluated the psychometrics of a dyadic assessment tool of doctors' communication skills, we examined the level of consensus between doctors and their patients in routine clinical encounters and among patients of the same doctor ${ }^{34}$. More specifically, our research questions were: 1) Do patients of a specific doctor agree on this doctor's communication skills? 2) Are doctors' self-perception of their communication skills congruent with patients' perceptions of them? 


\section{Methods}

\section{Data source and participants}

Data originated from a cross-sectional study carried out between January and May 2005 and for which the overall goal was to develop, test and psychometrically assess a dyadic instrument on the process and the content of communication from the perspectives of both doctors and patients ${ }^{34}$. Briefly, family doctors and specialists $(n=91)$ from three provinces in Canada and their patients $(n=1749)$ completed a post-consultation questionnaire that included the Matched-Pair Instrument (MPI). Doctors were recruited through an invitation letter from the College of Family Physicians of Canada and the Royal College of Physicians and Surgeons of Canada. Patients were then recruited by their own participating physician. Both doctors and patients participated voluntarily and did not receive any financial incentives. The number of patients per doctor was a little more than 19 , ranging from 2 to 25 . Ethical approval was provided by the University of Ottawa Ethics Board.

\section{Data collected}

Basic socio-demographic characteristics were collected for both doctors (i.e., gender andmedical specialty) and patients (i.e., gender). Doctors' and patients' perceptions on doctors' communication skills were measured using the MPI, a dyadic instrument that was developed based on several existing instruments and expertise of developers in communication skills ${ }^{34}$. The MPI is comprised of 19 items that assess both the content (4 items) and the process (15 items) of doctors' communication skills. A copy of the MPI is included in Appendix 1. The doctor's version assesses selfperception while the patient's version assesses his or her perception of the doctor's communication skills. Each item of the MPI is scored on a 5 -point Likert scale ( 1 = strongly disagree -5 = strongly agree). The overall score for the $\mathrm{MPI}$ is the mean of the 19 ratings. Higher scores refer to higher communication skills (i.e., the physician was perceived or perceived him or herself as more competent in communication). Internal consistency coefficients (Cronbach alpha) for the MPI are .69 for the patient version and .70 for the doctor version ${ }^{34}$. Both doctors and patients completed their own version of the MPI immediately after a consultation and were blinded to each other's answers. Therefore, doctors rated many consultations (i.e., for each patient) but patients only rated one consultation, their own. (There was no audiotape of the consultation.) Detailed information regarding the original study may be found elsewhere ${ }^{34}$.

\section{Data analysis}

The existing dataset was by nature dyadic and, more specifically, represented a one-with-many (i.e., many patients nested within one doctor), reciprocal design (i.e., 
doctors and patients are measured) with distinguishable members (i.e., members of the dyad can be distinguished as patient and doctor). ${ }^{16} \mathrm{~A}$ multilevel modeling framework was used to estimate the different variance components. ${ }^{16}$ This framework partitions variance into two levels: 1) dyadic-level (within variance), also known as the relationship-level; and 2) the doctor-level (between variance). Therefore, to answer our first and second research questions, the variance components were estimated from the dyad-level (within variance) and the doctorlevel (between variance) for both doctor and patient ratings. At the dyad-level, the two variance components (patient and doctor) represent the assessment of the communication skills as seen by patients or doctors removing the mean for doctors. At this level, the patient variance represents how much variability there is on the MPI scores of patients nested within doctors (i.e., higher values indicate that patients' MPI scores vary considerably from one patient to another patient for one doctor). Likewise, the variance in doctor ratings represents how much variability there is on the MPI score of a doctor with their patients (i.e., higher values indicate that doctors' MPI scores vary considerably from one patient to another patient within one doctor). At the doctor-level, the variance of patient ratings represents how much variability there is on the MPI scores of patients between doctors, that is, from one doctor to another doctor (i.e., higher values indicate that patients' MPI scores vary considerably from one doctor to another doctor and so indicate patient consensus about their doctors). At this level, the variance in doctor ratings represents how much variability there is on the MPI score of doctors from one doctor to another doctor (i.e., higher values indicate that doctors' MPI scores vary considerably from one doctor to another doctor). From the multilevel modeling, we computed two intraclass correlation coefficients (ICC): one for the patient data and one for the doctor data. The ICC for the patient represents the proportion of the variance due to doctor on the MPI score of patients. A higher value indicates high consistency among the patients of a doctor, i.e., the within doctor variation is relatively smaller than the between doctor variation on the MPI score of patients; thus, there is less variability on the patients' MPI score from one patient to another patient of the same doctor than from one patient of one doctor to another patient of another doctor. The ICC for the doctor represents the proportion of the variance due to doctor for the doctors' MPI score. A higher value indicates that there is more variability from one doctor to another doctor on the MPI scores than from one MPI score of one doctor to another MPI score of the same doctor. To answer question 2 we correlated each of the components across doctors and patients. We could then determine if doctors who generally felt they had good communication skill were rated as such by patients who felt the same way. We could also assess whether a doctor who felt he or she had good communication with one patient and not with another was rated as such by the patients. We conducted analyses on different factors of the MPI, and we found essentially the same results; thus, only the composite score is analyzed here. Also, in the dataset that was used, there was 
minimal information in the dataset about patient and doctor characteristics. One variable was whether physicians were general practitioners or specialists. However, we found only small differences between the two.

\section{Results}

\section{Characteristics of participants}

Ninety-one physicians contributed 1749 patients of whom 1059 were female and 594 male. There were 58 general practitioners ( 28 females and 17 males) and 43 medical specialists ( 8 females and 29 males). The mean score of the MPI for patients was $4.58(\mathrm{Cl} 95 \%$ 4.54-4.61) and for physicians, 4.37 (Cl 95\% 4.284.46), thus suggesting that overall patients tended to rate doctors higher than doctors rated themselves. Details regarding means for individual items may be found elsewhere. ${ }^{34}$

\section{Do patients of a specific doctor reach a consensus on this doctor' communication skills?}

Table 9.1 shows the different variance components that were computed at both the dyad-level and the doctor-level. The first two dyad-level variance terms refer to relationship variance and represent the assessment of the communication skills as seen by the patient or doctor, removing the average rating of that doctor. Note that there is substantially more relationship variance for the patient than for the doctor (0.382 versus 0.056$)$, which implies that patients' MPI scores vary considerably from one patient to another patient within doctors. In contrast, the doctors' MPI scores do not vary much from one patient to another patient within doctors. In other words, doctors perceived themselves to be more consistent from one patient to another patient than patients perceived doctors to be.

Next we consider variation in the mean perception of doctors. The variance in these means for patients' MPI is much smaller than the variance for doctors $(0.014$ versus 0.180 ). This implies that patients' MPI scores do not vary much from one doctor to another doctor. In contrast, doctors' MPI scores vary considerably from one doctor to another doctor. In other words, some doctors think that they are generally good at communicating with their patients and other doctors think that they are generally quite poor. The ICC for patients is only 0.034 . Thus, patients of the same doctor do not agree very much with each other about the level of communication skills of their physician as revealed during the consultation. The ICC for the doctor is very large: 0.763 . This means that overall doctors perceive their level of communication skills to be the same with all of their patients. 
Table 9.1 Estimates of variance and correlation parameters.

\begin{tabular}{|c|c|c|c|c|}
\hline $\begin{array}{l}\text { Parameter } \\
\text { level }\end{array}$ & Definition & Estimate & $\begin{array}{l}\text { Standard } \\
\text { Error }\end{array}$ & $p$ value \\
\hline \multirow[t]{3}{*}{$\begin{array}{l}\text { Dyad } \\
\text { (within } \\
\text { variance) }\end{array}$} & $\begin{array}{l}\text { How much variability there is on the MPI scores of } \\
\text { patients within doctors (i.e., higher values } \\
\text { indicate that patients MPI scores vary } \\
\text { considerably from one patient to another patient } \\
\text { within one doctor). }\end{array}$ & 0.382 & 0.013 & $<0.001$ \\
\hline & $\begin{array}{l}\text { How much variability there is on the MPI score of } \\
\text { doctors within doctors (i.e., higher values indicate } \\
\text { that doctors MPI scores do vary considerably from } \\
\text { one patient to another patient within one doctor). }\end{array}$ & 0.056 & 0.002 & $<0.001$ \\
\hline & $\begin{array}{l}\text { Dyadic reciprocity: Whether doctors' MPI scores } \\
\text { predict patients' MPI scores. }\end{array}$ & 0.131 & 0.024 & $<0.001$ \\
\hline \multirow[t]{3}{*}{$\begin{array}{l}\text { Person } \\
\text { (between } \\
\text { variance) }\end{array}$} & $\begin{array}{l}\text { How much variability there is on the MPI scores of } \\
\text { patients between doctors that is from one doctor } \\
\text { to another doctor (i.e., higher values indicate that } \\
\text { patients MPI scores do vary considerably from } \\
\text { one doctor to another doctor). }\end{array}$ & 0.014 & 0.005 & $<0.001$ \\
\hline & $\begin{array}{l}\text { How much variability there is on the MPI score of } \\
\text { doctor from one doctor to another doctor (i.e., } \\
\text { higher values indicate that doctors MPI scores } \\
\text { vary considerably from one doctor to another } \\
\text { doctor). }\end{array}$ & 0.180 & 0.027 & $<0.001$ \\
\hline & $\begin{array}{l}\text { General reciprocity: Whether a doctor MPI scores } \\
\text { predict his/her own patients MPI }\end{array}$ & 0.123 & 0.167 & 0.460 \\
\hline
\end{tabular}

\section{Are doctors' self-perceptions of their communication skills congruent with how their patients perceive them?}

If we remove the effect of the doctor (i.e., examine the relationship-level), the correlations between the patient MPI score and the doctor MPI score is weak $(r=0.13, p<0.001)$. Thus, despite some agreement, patients and doctors have different views about doctors' communication skills during their interaction. The correlation between the patient MPI score and the doctor MPI score at the doctorlevel is also weak and not significantly different from zero $(r=0.123, p=0.460)$. Therefore given these small correlations, we found physicians did not agree with their patients about the level of their own communication skills. For example, providers who think they are especially good at communicating with their patients are not necessarily seen that way by their patients. The same held true when providers' perceptions were negative. 


\section{Discussion}

This study measured and analyzed the interpersonal perceptions and the interdependent processes that occur between doctors and patients during routine clinical encounters. Overall, they suggest that doctors' self-perceptions of their communication skills are not congruent with how their patients perceive them. More specifically, they suggest that: 1 ) doctors tend to perceive themselves to be more alike from one patient to another patient than patients perceive doctors to be; 2) from one doctor to another doctor, doctors see themselves quite differently but patients do not see them so differently; 3) patients of the same doctor do not agree very much with each other about the level of communication skills of their doctors; and 4) some doctors' scores did not correlate better with their patients' scores of their communication skills than with scores received by other doctors. There are several explanations that can help interpret what has been observed in this study. Doctors' and patients' perceptions of the medical encounter have been characterized as being so different that they appear to be from different worlds ${ }^{36}$. During a consultation neither the doctor nor patient are likely to focus on doctors' communication skills. The patient is likely to be concerned about presenting his or her complaints, the nature of his or her diagnosis, the treatment options that may be available and the prognosis of his or her condition. The doctor is likely to be concerned about making the right diagnosis, finding the right treatment and explaining the course of action to the patient. As pointed out by Hall e.a., “monitoring one's own nonverbal behavior may be a difficult task because a person is simultaneously a sender and a receiver, and therefore has to plan and execute his or her nonverbal and verbal behavior, process the other person's nonverbal and verbal behavior, and engage in metacognitive activity such as asking oneself how the interaction is going" (Hall et al., 2007, p.1675) ${ }^{37}$. Therefore, the perception of both doctors and patients about the doctor's communication skills are likely to diverge ${ }^{38}$ or to be limited to issues such as establishing whether the doctor has been able to clarify information or to reassure a patient. This may raise some concern because a shared perspective between doctors and patients has been said to be positively associated with patient outcomes $22,23,25,26$. The results of this study are consistent with what has been reported in the literature. Although doctors and patients agree on the core competencies regarding the physicians' communication skills, they usually do not agree on the actual presence of these skills in consultations ${ }^{39}$. Moreover, patients' assessment of doctors' communication skills differ from assessments made by experts. More importantly, both patients' assessment and experts' assessment of doctors' communication skills differ from assessments made by other doctors. This is worrisome because patient-centered communication appears to influence patients' outcomes through patients' perceptions and not through perceptions of others, including that of a third observer ${ }^{40}$. Therefore, it would be important to keep 
monitoring the experience of patients regarding their consultation with a doctor. We also found that there was little agreement across patients from the same physician on the level of communication skills of their doctor, although doctors themselves estimate their level of communication skills to be almost similar for every patient. Patients of the same doctor showed little agreement with other patients of that doctor about his or her level of communication skills. Few factors combine to determine consensus among a group of individuals ${ }^{15}$. One of these is observation of the same consultation. In this study, each patient had assessed his or her doctor following his or her own specific consultation. Another potential factor that might have contributed to low consensus is similarity of meaning systems or the extent to which different patients understand the interaction. Low consistency (i.e., the degree to which the doctor exhibited very different communicative behaviors between his/her patients) might have also contributed since physicians may adapt their behavior to patients' specificities. In contrast, we observed that doctors' self-ratings were quite consistent across a number of consultations with different patients.

As reported by Kenny,15 "(S)elf-ratings carry a great deal of excess baggage; that is, they measure other things besides how the person truly is" (p. 202). In this study, although doctors in general rated themselves more severely than did their patients, they may have overestimated the consistency of their communication from one patient to another one. This would be in line with a review of ICCs from several datasets of primary and secondary care studies in the UK. ${ }^{41}$ This review reported that overall, ICCS at the level of the doctors for process variables in primary care as observed by a third observer were of the order of $0.05-0.15$, whilst those in secondary care were of the order of 0.30 and thus much lower than the observed 0.76 in this study. Also, patients may have "missed" some of the consistency in the doctor's behavior because they were too focused on their own needs 37,38 . Lastly, we also observed that some doctors' scores did not correlate with their patients' scores of their communication skills. This suggests that the misperception that we have found is chronic and endemic in doctor-patient interactions. This is of some concern because the doctor-patient relationship is one of the pillars of patient-centered care. ${ }^{2}$ Because a relationship would imply a minimum of interdependence between doctors and their patients, it is somehow surprising that in this study, all doctors have little overlap with their patients' perceptions. As discussed above, it is possible that this "relationship" is present in other components of the consultation or, in the worstcase scenario, non-existent. This study has some limitations. First, this is a secondary analysis of an existing dataset from a cross-sectional study for which the overall goal was to develop, test and psychometrically assess a dyadic instrument on the communication skills of doctors ${ }^{34}$. However, given the paucity of large dyadic reciprocal datasets in the field of doctor-patient communication, we believe that this study sheds some interesting light that will help in the design of future studies. Second, the means of 
the MPI scores of the doctors and the patients are quite high, being close to the maximum possible value which may have affected our results. However, high scores have been reported before in doctor-patient communication research. ${ }^{42}$ Third, physicians recruited patients and might have been more inclined to do so with patients they felt most comfortable with. Therefore, the results from this study would be an overestimation of the real agreement found in clinical encounters. However, our results are quite consistent with those reported in a previous study in which patients were recruited by the office staff ${ }^{42}$. Another limitation of this study might reside in the diversity of the items of the MPI. For example, the item "Discussed treatment options with the patient (doctor)/Discussed treatment options with me (patient)" seems to measure agreement on the occurrence of an event. Deficiencies in memory of events, similar to those described by witnesses, might account for dissimilarities here even though the questionnaire was administered immediately after the consultation. Also, the consultation was not audiotaped, thus hampering our ability to assess how the patients' and the physicians' perspectives correlated with a third observer perspective ${ }^{43}$. Overall, this study suggests that doctors and their patients have a very different perspective of doctors' communication skills occurring during routine clinical encounters. Moreover, we found very little or no interdependence between doctors and their patients on these aspects. Given the importance of the doctor-patient relationship in patient-centered care, future studies will need to assess if mutuality is present or not on other components of the consultation. 


\section{Literature}

1. Frist WH. Shattuck Lecture: health care in the 21st century. N Engl J Med 2005;352: 267-72.

2. Stewart MA. Effective physician-patient communication and health outcomes: a review. CMAJ1995;152:1423-33.

3. Tamblyn R, Abrahamowicz M, Dauphinee D, Wenghofer E, Jacques A, Klass D, et al. Physician scores on a national clinical skills examination as predictors of complaints to medical regulatory authorities. JAMA 2007;298:993-1001.

4. Street RL, Jr., Makoul G, Arora NK, Epstein RM. How does communication heal? Pathways linking clinician-patient communication to health outcomes. Patient Educ Couns 2009; 74:295-301.

5. Street RL, Jr., O'Malley KJ, Cooper LA, Haidet P. Understanding concordance in patientphysician relationships: personal and ethnic dimensions of shared identity. Ann Fam Med 2008;6:198-205.

6. Pew-Fetzer Task Force on Advancing Psychosocial Health Education. In: Tresolini C, editor. Health professions education and relationship-Centered care. San Francisco, CA: Pew-Health Professions Commission Fetzer Institute, 1994.

7. Bensing JM, Dronkers J. Instrumental and affective aspects of physician behavior. Med Care 1992;30:283-98.

8. Street RL. Communicative styles and adaptations in physician-parent consultations. Soc Sci Med 1992;34:1155-63.

9. Bennett AEE. Communication between doctors and patients. New York: Oxford University Press., 1976.

10. Roter D, Hall J. Doctors talking with patients/patients talking with doctors: Improving communication in medical visits. Westport, CT: Praeger Publishers, 2006.

11. Kenny DA, Cook W. Partner effects in relationship research: Conceptual issues, analytic difficulties, and illustrations. Personal Relationships 1999;6:433-48.

12. LeBlanc A, Kenny DA, O'Connor AM, Legare F. Decisional conflict in patients and their physicians: a dyadic approach to shared decision making. Med Decis Making 2009;29:61-8.

13. Legare F, Elwyn G, Fishbein M, Fremont P, Frosch D, Gagnon MP, et al. Translating shared decision-making into health care clinical practices: proof of concepts. Implement Sci 2008;3:2.

14. Street RL, Jr., Gordon H, Haidet P. Physicians' communication and perceptions of patients: is it how they look, how they talk, or is it just the doctor? Soc Sci Med 2007;65:586-98.

15. Kenny DA. Interpersonal perception: A social relations analysis. New York: Guilford Press, 1994.

16. Kenny DA, Kashy DA, Cook W. Dyadic data analysis. New York: Guilford Press, 2006.

17. O'Connor AM, Tugwell P, Wells GA, Elmslie T, Jolly E, Hollingworth G, et al. A decision aid for women considering hormone therapy after menopause: decision support framework and evaluation. Patient Educ Couns 1998;33:267-79.

18. Towle A, Godolphin W. Framework for teaching and learning informed shared decision making. Bmj 1999;319:766-71.

19. Bass MJ, Buck C, Turner L, Dickie G, Pratt G, Robinson HC. The physician's actions and the outcome of illness in family practice. J Fam Pract 1986;23:43-7.

20. Cedraschi C, Robert J, Perrin E, Fischer W, Goerg D, Vischer TL. The role of congruence between patient and therapist in chronic low back pain patients. J Manipulative Physiol Ther 1996;19:244-9. 
21. Gabbay M, Shiels C, Bower P, Sibbald B, King M, Ward E. Patient-practitioner agreement: does it matter? Psychol Med 2003;33:241-51.

22. Starfield B, Wray C, Hess K, Gross R, Birk PS, D'Lugoff BC. The influence of patientpractitioner agreement on outcome of care. Am J Public Health 1981;71:127-31.

23. Krupat E, Rosenkranz SL, Yeager CM, Barnard K, Putnam SM, Inui TS. The practice orientations of physicians and patients: the effect of doctor-patient congruence on satisfaction. Patient Educ Couns 2000;39:49-59.

24. Fagerberg CR, Kragstrup J, Stovring $\mathrm{H}$, Rasmussen NK. How well do patient and general practitioner agree about the content of consultations? Scand J Prim Health Care 1999;17:149-52.

25. Krupat E, Bell RA, Kravitz RL, Thom D, Azari R. When physicians and patients think alike: patient-centered beliefs and their impact on satisfaction and trust. J Fam Pract 2001;50:1057-62.

26. Sewitch MJ, Abrahamowicz M, Dobkin PL, Tamblyn R. Measuring differences between patients' and physicians' health perceptions: the patient-physician discordance scale. J Behav Med 2003;26:245-64.

27. Heisler M, Vijan S, Anderson RM, Ubel PA, Bernstein SJ, Hofer TP. When do patients and their physicians agree on diabetes treatment goals and strategies, and what difference does it make? J Gen Intern Med 2003;18:893-902.

28. Freidin RB, Goldman L, Cecil RR. Patient-physician concordance in problem identification in the primary care setting. Ann Intern Med 1980;93:490-3.

29. Taylor RB, Burdette JA, Camp L, Edwards J. Purpose of the medical encounter: identification and influence on process and outcome in 200 encounters in a model family practice center. J Fam Pract 1980;10:495-500.

30. Bikowski RM, Ripsin CM, Lorraine VL. Physician-patient congruence regarding medication regimens. J Am Geriatr Soc 2001;49:1353-7.

31. Levinson W, Stiles WB, Inui TS, Engle R. Physician frustration in communicating with patients. Med Care 1993;31:285-95.

32. Zandbelt LC, Smets EM, Oort FJ, Godfried MH, de Haes HC. Satisfaction with the outpatient encounter: a comparison of patients' and physicians' views. J Gen Intern Med 2004;19:1088-95.

33. Legare F, Moher D, Elwyn G, LeBlanc A, Gravel K. Instruments to assess the perception of physicians in the decision-making process of specific clinical encounters: a systematic review. BMC Med Inform Decis Mak 2007;7:30.

34. Campbell C, Lockyer J, Laidlaw T, Macleod H. Assessment of a matched-pair instrument to examine doctor-patient communication skills in practising doctors. Med Educ 2007;41:123-9.

35. Cegala DJ, Coleman MT, Turner JW. The development and partial assessment of the medical communication competence scale. Health Commun 1998;10:261-88.

36. Mishler EG. The discourse of medicine: Dialectics of medical interviews. New Yersey: Ablex Publishing Corporation, 1984.

37. Hall JA, Murphy NA, Mast MS. Nonverbal Self-Accuracy in Interpersonal Interaction. Personality and Social Psychology Bulletin 2007;33:1675-85.

38. DePaulo BM, Kenny DA, Hoover CW, Webb W, Oliver PV. Accuracy of Person Perception: Do People Know What Kinds of Impressions They Convey? Journal of Personality and Social Psychology 1987;52:303-15.

39. Cegala DJ, McNeilis KS, McGee DS. A Study of Doctors' and Patients' Perceptions of Information Processing and Communication Competence During the Medical Interview. Health Communication 1995;7:179-203. 
40. Stewart M, Brown JB, Donner A, McWhinney IR, Oates J, Weston WW, et al. The impact of patient-centered care on outcomes. J Fam Pract 2000;49:796-804.

41. Campbell M, Grimshaw J, Steen N. Sample size calculations for cluster randomised trials. Changing Professional Practice in Europe Group (EU BIOMED II Concerted Action). J Health Serv Res Policy 2000;5:12-6.

42. Makoul G, Krupat $\mathrm{E}$, Chang $\mathrm{CH}$. Measuring patient views of physician communication skills: development and testing of the Communication Assessment Tool. Patient Educ Couns 2007;67:333-42.

43. Saba GW, Wong ST, Schillinger D, Fernandez A, Somkin CP, Wilson CC, et al. Shared decision making and the experience of partnership in primary care. Ann Fam Med 2006;4:54-62. 


\section{Appendix 1. Patients' and physicians' questionnaires.}

\begin{tabular}{|c|c|}
\hline Patients' items & octors' items \\
\hline This doctor: & $\mathrm{I}:$ \\
\hline $\begin{array}{l}\text { Greeted me in a way that made me feel } \\
\text { comfortable }\end{array}$ & $\begin{array}{l}\text { the patient in a way that made them feel } \\
\text { ble }\end{array}$ \\
\hline Discussed my reason(s) for coming today. & Discussed the patients reason(s) for coming today. \\
\hline $\begin{array}{l}\text { Encouraged me to express my thoughts } \\
\text { concerning my health problems. }\end{array}$ & $\begin{array}{l}\text { Encouraged the patient to express their thoughts } \\
\text { concerning their health problem. }\end{array}$ \\
\hline Listened carefully to what I had to say. & Listened carefully to what the patient had to say. \\
\hline $\begin{array}{l}\text { Understood what I had to say. } \\
\text { If a physician examination was required for } \\
\text { your health concerns, the doctor fully } \\
\text { explained what was done and why. }\end{array}$ & $\begin{array}{l}\text { Understood what the patient had to say. } \\
\text { If a physical examination was required, explained } \\
\text { what was done and why. }\end{array}$ \\
\hline $\begin{array}{l}\text { he lab tests needed (e.g., Blood, X- } \\
\text { ound, etc). }\end{array}$ & $\begin{array}{l}\text { Explained the lab tests needed (e.g., Blood, X-rays, } \\
\text { ultrasound, etc.) to explore the patient's problem's. }\end{array}$ \\
\hline tions with me & Discussed treatment options with patient. \\
\hline Gave me as much information as I wanted. & $\begin{array}{l}\text { Gave the patient as much information as they } \\
\text { wanted. }\end{array}$ \\
\hline $\begin{array}{l}\text { ee if the treatment plan(s) was } \\
\text { me. }\end{array}$ & $\begin{array}{l}\text { Checked with patient to see if the treatment } \\
\text { plan(s) was acceptable. }\end{array}$ \\
\hline $\begin{array}{l}\text { Explained medications, if any, including } \\
\text { possible side effects. }\end{array}$ & $\begin{array}{l}\text { Explained medications, if any, including possible } \\
\text { side effects. }\end{array}$ \\
\hline ask questions. & Encouraged the patient to ask questions. \\
\hline Responded to my questions and concerns. & $\begin{array}{l}\text { Responded to the patient's questions and } \\
\text { concerns. }\end{array}$ \\
\hline Involved me in decisions as much as I wanted. & $\begin{array}{l}\text { Involved the patient in decisions as much as they } \\
\text { wanted. }\end{array}$ \\
\hline $\begin{array}{l}\text { Discussed next steps including any follow-up } \\
\text { plans. }\end{array}$ & Discussed next steps including any follow-up plans. \\
\hline Checked to be sure I understood everything. & $\begin{array}{l}\text { Checked to be sure the patient understood } \\
\text { everything. }\end{array}$ \\
\hline $\begin{array}{l}\text { Showed care and concern about me as a } \\
\text { person }\end{array}$ & $\begin{array}{l}\text { Showed care and concern about the patient as a } \\
\text { person. }\end{array}$ \\
\hline Spent the right amount of time with me. & Spent the right amount of time with the patient. \\
\hline $\begin{array}{l}\text { Overall, I was satisfied with my visit to the } \\
\text { doctor today. }\end{array}$ & Overall, I was satisfied with this consultation today. \\
\hline
\end{tabular}



Chapter 10

General discussion 



\section{General discussion}

The research of this thesis project investigated the usefulness and feasibility of the recommendations for doctor patient communication that are commonly used in medical education. The underlying goals were to determine how recommendations for doctor patient communication can be improved and to stimulate adherence to the recommendations in order to promote good doctor patient communication in clinical practice. Using the perspective and vocabulary of the clinical guideline movement, we conducted exploratory and investigative studies in clinical and educational practice aimed at answering three research questions:

1. What are the objective and experienced strengths and weaknesses of the current guidelines for doctor patient communication?

2. What drives doctors' communicative behaviour in clinical practice?

3. To what extent are the opinions and goals of doctors congruent with those of their patients during consultations?

In this chapter we summarise the answers to these three questions and discuss the strengths and weaknesses of the research by evaluating the theoretical perspective, the setting and the methods. Next we review the meaning of the studies and compare the results with the wider literature. We use the results to modify and fill in some of the gaps in the framework of factors relevant to the implementation of communication guidelines, which we presented in the introduction. Finally, we present recommendations for practice and further research.

\section{Main results}

Research question 1: The strengths and weaknesses of communication guidelines

\section{Strengths}

Structure is mentioned most frequently as one of the strengths of the generic communication guidelines that are generally used in communication training. These guidelines are all structured along the lines of consecutive, conceptually different consultation phases, each with specific recommendations for communication. Doctors experience this structure as a useful organising principle for consultations, saying it helps them come to grips with the consultation process (chapter 3). A division into different consultation phases is also useful because it enables sequential training and evaluation (chapter 4).

Most of the other strengths of communication guidelines are related to education and training. The guidelines provide concepts and terminology for discussing and analysing communicative processes and, most of them being short, they are usually easy to understand and remember. Nevertheless, trainees generally 
appreciate the additional mnemonic aids, such as short checklists, which are handy during consultations (chapter 4).

\section{Weaknesses}

The absence of a clear and comprehensive plan for the development of communication guidelines can be regarded as a weakness. Recommendations for communication are spread over a variety of documents and although all Dutch universities use one or more general guidelines, there is no uniformity in the guidelines used for specific situations. Although all guidelines share a patient centred orientation, they differ in content, even when they are intended for the same situation.

The quality of the procedures used in developing the communication guidelines was low; the quality of communication guidelines is rated at least $50 \%$ below that of medical technical guidelines. The scores for user centeredness and applicability are very low and those for developmental rigour are lower yet (chapter 2).

These developmental problems are reflected in the opinions of GPs and GP trainees based on their experiences as guideline users. Both groups are not convinced that the recommendations of the communication guidelines are evidence based. They additionally feel that the guidelines are artificial, often based on incorrect assumptions, and that doctors are underrepresented in guideline development (chapter 3).

A central problem is the generic nature of the most widely used communication guidelines, because this conflicts with the situation in practice where GPs tailor their communication to consultations, i.e. to individual patients and their medical conditions. With this approach, it is more efficient and effective to use situation specific than generic recommendations (chapter 3 ).

In summary, the main strength of communication guidelines appears to be as an aid in structuring and simplifying consultations. However, GPS also claim that communication guidelines have limited utility in clinical practice and no proven effectiveness. These notions are also shared by GPs involved in communication training who admit that they make sparse usage of the communication guidelines in their own medical practice.

\section{Question 2. What drives doctors' communicative behaviour?}

Doctor patient communication was found to be to be highly situational and doctors' communicative behaviour is determined more strongly by situational factors than by individual differences (chapter $5 \& 7$ ).

Doctors' communicative behaviour appears to be strongly determined by the goals of a consultation. Furthermore, doctors' decisions to use a certain communication strategy are guided by their judgement of the practicability of a particular strategy, which depends on the effect it is expected to have on the patient in question and 
the time available for the consultation. This process is also influenced by doctors' competence and contingent on their emotions and energy levels (chapter 5).

GPs pursue a multitude of different consultation goals, with the underlying aim to support the patient's health and well-being, good organisation of care, public health goals and personal work satisfaction (chapter 6).

Which goals are singled out in a particular patient encounter depends on GPs' generic goals as well as contextual aspects. Furthermore, the prioritisation of consultation goals reflects GPs' priorities with regard to the broadly defined generic goals which GPs deem to be at the core of their profession. Nevertheless, the final selection of consultation goals depends on the situational evaluation of the relevance and feasibility of specific goals, based on the GP's assumptions about the patient as an individual (needs, preferences), the patient's medical situation and the time available for the consultation. As with the selection of communicative actions, these evaluations are also influenced by GPs' competence and their emotions and energy levels (chapter 5).

These results show that GPs go to considerable length to adjust their communication to the specifics of individual consultations. As a result their day-today practice is far removed from the generic recommendations of the prevailing communication guidelines.

\section{Question 3. Matching goals and opinions}

The literature on doctor patient communication reveals considerable differences between doctors' and patients' needs and perceptions of communication. Surprisingly, our exploratory study of doctors' and patients' goals revealed a better match than the literature had led us to expect. Confirmation of these results by further studies would suggest that doctors have found a way to match their goals to those of their patients without using the recommendations in the communication guidelines. That the match of the goals of doctor and patient is in fact relevant to the quality of care is supported by the positive relationship between a good match and several aspects of patient satisfaction (paper 7). The encouraging results with regard to the match of doctor and patient goals are somewhat counterbalanced, however, by our finding of a weak relationship between patients' and doctors' evaluation of their communication in the same consultations (paper 8). Experience 


\section{Strengths and weaknesses of the study}

\section{Evaluation of the usefulness of the theoretical perspective}

Benefits

The perspective of clinical guideline development offers ways to assess and compare the quality of communication guidelines ${ }^{1}$. It also suggests procedures for analysing possible causes of implementation problems, such as surveying users' opinions and attitudes towards a guideline, observing current practice and how it fits with guidelines and identifying the preferences of the patients who are supposed to benefit from guideline use ${ }^{2}$. These procedures yielded information that clarifies the problems encountered in the implementation of recommendations for doctor patient communication. The results of the studies provide new ideas, which could make communication guidelines more effective tools for directing communicative strategies during consultations.

\section{Drawbacks / Risks}

Based on quality criteria for clinical guidelines, we assessed the recommendations for doctor-patient communication. This meant that we compared materials that might not have been designated or developed as a guideline with materials developed explicitly for use as a guideline, albeit for a different type of behaviour, such as medical technical decisions and actions. The result of this comparison was unfavourable for the communication guidelines. An explanation for this may be that many recommendations for doctor patient communication were developed not as a guideline but as a model of optimal doctor patient communication that was to be valid in all circumstances. Of one of the guidelines we were told that the developers gave precedence to an accurate and detailed description of that communication ideal for doctors and trainees and paid less attention to practical applicability. It was left to doctors to decide how to modify their communicative behaviours in suboptimal circumstances, for example with time constraints. [Jan van Dalen; personal communication]

Another risk of the guideline perspective is that it assumes that quality can be standardised without having to make unacceptable compromises. This assumption may be incorrect in the case of communication. The studies in this thesis show that, in practice, doctors go to considerable length to adjust their communication to individual patients and situations by considering not only the consultation goals but also the personal characteristics of individual patients. For example, doctors may use different techniques with different patients, such as when reassuring a child, or an anxious male patient with a tendency to dependent behaviour, or a female patient with a university education and strong values regarding autonomy. 


\section{Evaluation of the setting}

\section{Benefits}

This thesis focuses on doctor patient communication in general practice. We concentrated our attention on this one setting, because we deemed it more useful to examine in depth the problems encountered in implementing communication guidelines in one setting than to conduct a more superficial investigation of generic problems in a variety of settings. General practice was chosen because it has a long history of investment in communication training and thus enabled us to make use of the experience of practising doctors who know and understand the recommendations for communication and can be expected to be motivated to implement them in practice, because of their involvement in teaching.

\section{Generalisability of the results}

Restricting research to one single setting can diminish the generalisability of the results to other health care settings. However, the key attributes that determine the suitability of a communication guideline for training and learning (chapter 4) are probably similar across specialties and Western countries, because basic processes, such as how doctors learn to communicate with patients and how communication techniques are selected, are unlikely to be affected by small differences between cultures or health care systems. For similar reasons, the model for the selection of communicative actions (chapter 5 and 6) is probably valid for other specialities and other countries as well. On the other hand, in so far as the results relate to specific circumstances in patient contacts and communication training or to doctors' views of their work there are likely to be some differences between specialties. Therefore it cannot be ruled out that some of the strengths and weaknesses of communication guidelines (chapters 3 and 4) may differ between countries and specialties. The goal categories pursued by GPs, such as maintaining patients' health and well-being, work satisfaction, the organisation of care and public health agendas, are probably generalisable because they appear to be related to universal responsibilities of doctors ${ }^{3-5}$. However, specific goals, their perceived importance and frequency in particular, are likely to show some variation across health care settings.

The quality of the match between doctors' and patients' goals and opinions appears to be dependent on the extent to which doctors are attuned to their patients. This is probably related to both personal and cultural factors. Canadian data on the match of doctors' and patients' opinions regarding doctors' communicative competence (chapter 9) were gathered for three specialties, general practice, internal medicine and surgery. Subgroup analysis showed no difference between these specialties, suggesting that the results can be generalised over specialties. 


\section{Evaluation of the methods}

The mixed methods approach

In this thesis we used a mixed methods approach, which enabled in-depth exploration of processes in qualitative studies as well as quantitative verification of the findings. It is a limitation that we used the same group of sixteen GPs for both the qualitative and the quantitative studies. This sample was large enough to achieve data saturation and therefore acceptable for the qualitative studies. For the quantitative studies, however, we used consultation data from a sample of 150-220 consultations. Although the size of the consultation sample was quite large, the number of GPs in the sample was relatively small. This may impair the generalisability of the results even though the sample can be considered to be representative of the Dutch situation. We evaded this problem when we studied the match of doctors' and patients' opinions by analysing an existing Canadian dataset representing a large sample of doctors and an even larger sample of consultations.

\section{Influence of research process on the investigated practice}

The methodologies used in this thesis were selected for their potential to elucidate processes in routine practice. Because the aim of the research was to study natural situations in medical practice, no intervention studies were conducted and the methods were selected so as to minimise the impact on the doctors' office routine. Nevertheless, when the research was being conducted, the researcher and the instruments became part of the practice routine and therefore, inevitably, exerted some influence. So an impact on the results cannot be ruled out.

We used focus groups because of the limited role of the interviewer and the reduced risk of socially desirable answers ${ }^{6}$. We used mixed focus groups, because they stimulate dialogue between different groups and thus enable different parties to learn from each other and to form more nuanced opinions ${ }^{7}$. However, a mixed group environment can be less safe than a peer group, for lower status participants in particular ${ }^{7}$. Therefore we organised additional interviews for trainee-only groups. Unfortunately, it can also not be ruled out that the higher status participants gave socially desirable answers in the mixed groups.

It has been shown that GPs are more likely to reflect on their emotions and show vulnerability when they are interviewed by a colleague, especially if that colleague is not perceived as an expert ${ }^{8}$. The fact that our interviews were carried out by a 'junior colleague' may have enhanced openness. Still, there will always be a risk of socially desirable answers with interviews like the ones in our studies that tap into processes that are very personal and require considerable effort to make them the focus of conscious attention. 
Qualitative analyses

All the qualitative data were analysed by the author of this thesis, who is a GP. To avoid bias due to her personal involvement with the research topic and to maximise the richness of interpretation, independent analyses were carried out by other researchers from different backgrounds. In all the qualitative studies, a part or all of the data were also analysed independently by another, non-medical, researcher.

\section{Dyadic analysis}

For the last two studies we collected dyadic data, that is, data on the same consultations obtained from doctors and patients. Studying the degree of agreement between doctors' and patients' opinions and goals created new insights into doctor patient interactions. However, identifying a difference between doctors and patients is not the same as understanding it. Qualitative dyadic studies might yield more insight into the causes and consequences of and potential remedies for the incongruence of opinions between doctors and patients.

\section{The meaning of the research}

After discussing the findings of the thesis in the light of the broader literature, we discuss to what extent the results offer explanations for the limited implementation of the recommendations for doctor patient communication in clinical practice. The results of the thesis are used to complement the framework of factors relevant to the implementation of communication guidelines, which was presented in the introduction.

\section{Comparisons with the published literature}

The main finding of this thesis is the exposure of fundamental differences between practising doctors' beliefs and routines with regard to doctor patient communication and the recommendations as documented in the prevailing communication guidelines. What is fundamental about this difference is that most communication guidelines offer generic descriptions of good communication and disregard differences between individual consultations, whereas, for practising doctors, the situational specificity of communication is the key concept. Another difference is that, to doctors, communication is primarily a tool which is to be used effectively and efficiently, while the guidelines pay little attention to concrete consultation goals or to evidence of the effectiveness, feasibility or efficiency of the recommendations. They mainly emphasise the primacy of patient centredness. The centrality of the ideal of patient-centred communication suggest that communication guidelines represent an ethical ideal rather than a practical tool. 
There are two ways in which the validity of research results can be tested from the perspective of the wider literature. The results of other studies can confirm and thus support their trustworthiness or they can explain them, thereby offering theoretical validation. We will look at these two aspects consecutively.

\section{Confirmation}

Time and again research has shown that doctors' communication is not optimally aligned with the principles of patient-centred communication ${ }^{9-11}$ and hence with the communication guidelines. So the real question is not whether the results of this thesis confirm these differences, but whether they add to our insight into the nature and causes of the discrepancies. In other words, what this thesis adds to the literature is not the finding that medical practice diverges from the communication guidelines, but the interpretation of the differences between medical practice and the communication guidelines as: 1.) the discrepancy between the advocacy of a generic ideal of good communication and the conviction that good communication is essentially situation and patient specific and 2.) the discrepancy between the concepts of communication as a tool and as an ethical ideal.

The view that good communication is situation specific and the view of communication as a tool are both supported by communication theory. In the handbook of interpersonal communication, Wilson et al. describe communication from different theoretical perspectives. In all these perspectives good communicators adjust their communication to the situation. How to do that and which aspects of the situation are to be considered differs depending on the theory ${ }^{12}$. Theories focusing on the production of communication, such as goalsplans-actions theory and message assembly theory, emphasise the importance of the goals of the communicators and see all communication as goal driven ${ }^{12,13}$.

On the other hand, the belief that good communication can be defined generically is in keeping with the common assumption in medicine that there is a generic definition of good medical care. This view informs the notion, which is also at the basis of evidence-based medicine, that conclusions based on group level analyses of intervention outcomes can be applied to the treatment of individual patients ${ }^{14}$. Protocols and guidelines reflect a generic conception of best practice and leave it to individual health care workers to interpret them for specific situations, health care settings and individual patients ${ }^{1}$. Generic communication guidelines are in line with this concept.

\section{Explanation}

In this section we discuss three conditions that may explain the differences between practitioners' beliefs and routines concerning communication and the instructions given in guidelines and recommendations. The first is the origin of the guidelines, the second the differing benefits from standardisation versus 
idiosyncrasy, and the third is the changes in the spirit of the times between the period in which the recommendations were developed and the present time.

\section{The origin of the communication guidelines}

The developers of the first patient-centred communication guidelines relied heavily on developments in psychotherapy, where patient (client) centredness had its origin ${ }^{15}$. Rogers described desired communicative behaviours for client-centred therapy and measured the quality of therapists' behaviour using observation instruments that are similar to those used today to assess doctors' communication. However, the implementation of patient-centred communication guidelines appears to have been much less problematic in client-centred psychotherapy than in medicine, probably because the recommendations are more congenial to that domain 15 .

Eliciting the patient's concerns, preferences and request for help is at the core of patient centred psychotherapy. In medicine, however, doctors are dealing with many competing goals and, as a result, goal competition or goal conflicts between patient-centred goals and medical goals seem unavoidable. In order to diagnose a patient, doctors do not necessarily need to know the patient's concerns and preferences but they do also need a lot of information that may seem of little relevance to the patient. In addition, patients' preferences may conflict with doctors' societal responsibility to limit the use of scarce resources, as there is a lot of over- and underuse of resources in medicine. This may explain why doctors are reluctant to embrace the recommendations for communication despite their good applicability in client-centred therapy.

\section{The advantages of standardisation versus the advantages of idiosyncrasy}

Standardisation, in this case the use of generic recommendations for doctor patient communication, has a number of advantages. A generic description of preferred behaviours facilitates the formulation of training goals, qualification requirements and behavioural targets for clinicians. Being relatively easy to teach, learn and measure, standardised behaviour can facilitate training and assessment. It also enables research comparing the communicative behaviour of different groups of students and doctors and investigating the influence of interventions and trained behaviours.

When desired behaviour is conceptualised as primarily situation-specific, however, the description of that behaviour inevitably becomes more variegated and complex. This complicates the formulation of goals as well as training and assessment. A potential effect of this phenomenon is to give teachers, policy makers and researchers a reason for keeping recommendations for doctor patient communication as generic as possible.

Patients, however, are never standard. One of the implications of this is that small differences can have far-reaching consequences for a patient's prognosis and the 
effectiveness of management options. The more characteristics of patients and their situation a doctor can take into account, the greater the chance of maximum benefit. In an ideal situation, the evidence is completely idiosyncratic, predicting accurately the consequences of different interventions for individual patients, so that informed patients can choose the management options with the consequences they prefer the most or dislike the least. Thus doctors and patients have an interest in promoting that patient management should be as idiosyncratic as possible, both with regard to treatment and to communication. However, in the absence of idiosyncratic medical evidence, doctors combine information gathered at group level with their own experience and translate that to the case at hand ${ }^{16}$. Doctors have been shown to do so with regard to treatment strategies and the results of this thesis suggest they do something similar with regard to communication. With communication they seem to rely more heavily on personal experience and less on scientific evidence though.

In conclusion, generic recommendations for doctor patient communication offer advantages, for teachers, policy makers and researchers in particular, but so does the tailoring of communication to the specifics of individual situations, the advantages of which apply to doctors and patients in particular. The competing advantages of standardisation and idiosyncrasy provide another explanation of the difference between recommendations for doctor patient communication and doctors' beliefs and routines regarding communication.

\section{Changes in the spirit of the time}

Recommendations for doctor patient communication stem from the ideals of patient autonomy that were embraced in the nineteen sixties, a period of decreasing respect for established authority figures, such as the police, politicians, doctors and teachers, combined with an increasing emphasis on individual freedom and autonomy ${ }^{17}$. So while the unassailable position of the doctor as an authority figure came under attack, the notions of patient emancipation and patient empowerment rose in popularity. In the Netherlands in those days, many people lived their whole life in the same village where the local GP - usually running his practice single-handedly and being on call 24 hours a day - was responsible for first line medical care and looked after many of his patients from cradle to grave.

Since that time, there has been a dramatic explosion of technical possibilities as well as other changes in society and medicine. However, as the limits of technical possibilities became clear, attention shifted to preventative care. Today's combination of ever increasing medical possibilities and an ageing population is making increasing demands on health care, resulting in a shift from secondary to primary care, where doctors have to contend with heavier workloads but substantial, easy to objectify, effects on patients' health. The above-mentioned fall in status of authority figures, including doctors, has also fuelled calls from the public for 'transparency' and 'accountability'18. Together with a growing body of 
empirical evidence underpinning best medical practices, this has favoured the emergence of a health care system that is more and more protocol based. ${ }^{19}$ In other words, medicine has become less value driven and more target driven, a trend eagerly supported not only by governments eager to promote free market mechanisms in health care but also by health insurance companies using targetrelated financial incentives ${ }^{20}$.

Goal-driven communication seems to be more in keeping with a target driven than with a value-driven medical system and the opposite can be said for patientcentred communication. Thus it can be argued that the difference between the recommendations for doctor patient communication and the beliefs and routines in clinical practice is a sign of the changing times.

Another important chain of events since the development of the first communication guidelines is the pivotal role that has come to be accorded to evidence-based medicine exemplified in clinical practice guidelines underpinned by the results of scientific research ${ }^{21}$. When the first communication guidelines were written, there was considerably less attention for the difficulties of implementing the results of scientific research while health care was not changing at today's relentless pace. The developers of the first communication guidelines were more interested in promoting a new ethical perspective than in developing evidencebased, easily applicable recommendations. ${ }^{22}$ This is not surprising, since evidence on effective doctor-patient communication was largely non-existent at the time ${ }^{21}$. Thus a third explanation for the differences between communication guidelines and clinical practice may be found in the spirit of the present time, which favours a shift from value-driven medicine to target-driven medicine, with emphasis on the usefulness of recommendations for health care workers, i.e. their proven effectiveness and applicability.

From the above it can be concluded that the trustworthiness and validity of the findings of this thesis are supported by the wider literature. The findings are congruent with the results of other relevant literature and they seem plausible in the light of broader historical and societal developments.

\section{An extended framework for the implementation of communication guidelines}

The framework for the implementation of communication guidelines that was described in the introduction (Figure 10.1) can now be updated based on the results of the studies. The updated framework (Figure 10.2) adds further details to the description of several factors as well as evidence regarding the type of influence (stimulating or impeding) they exert. The impact of some of the factors is further clarified, while the direction of the effect of some other factors is reversed. 


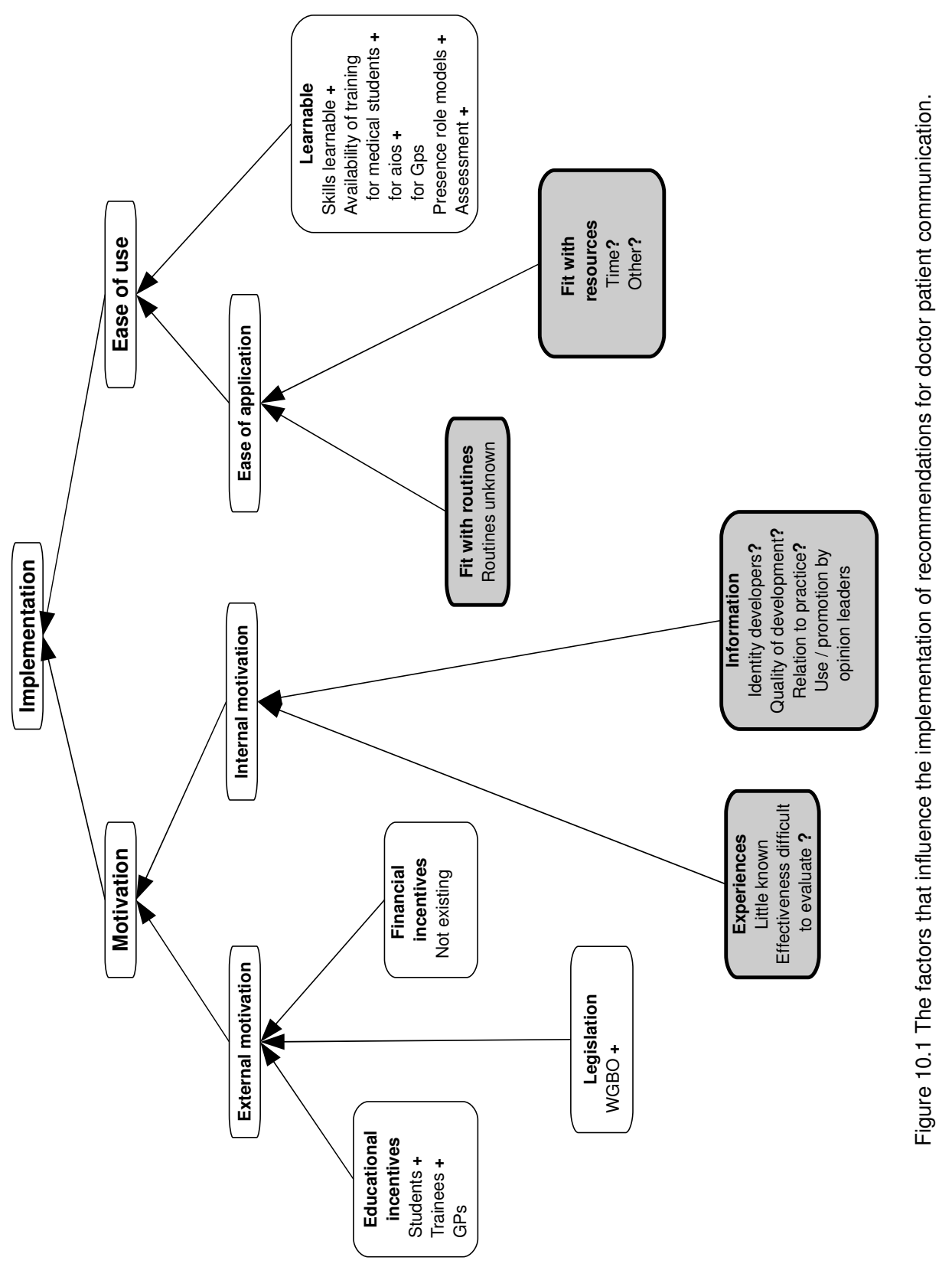




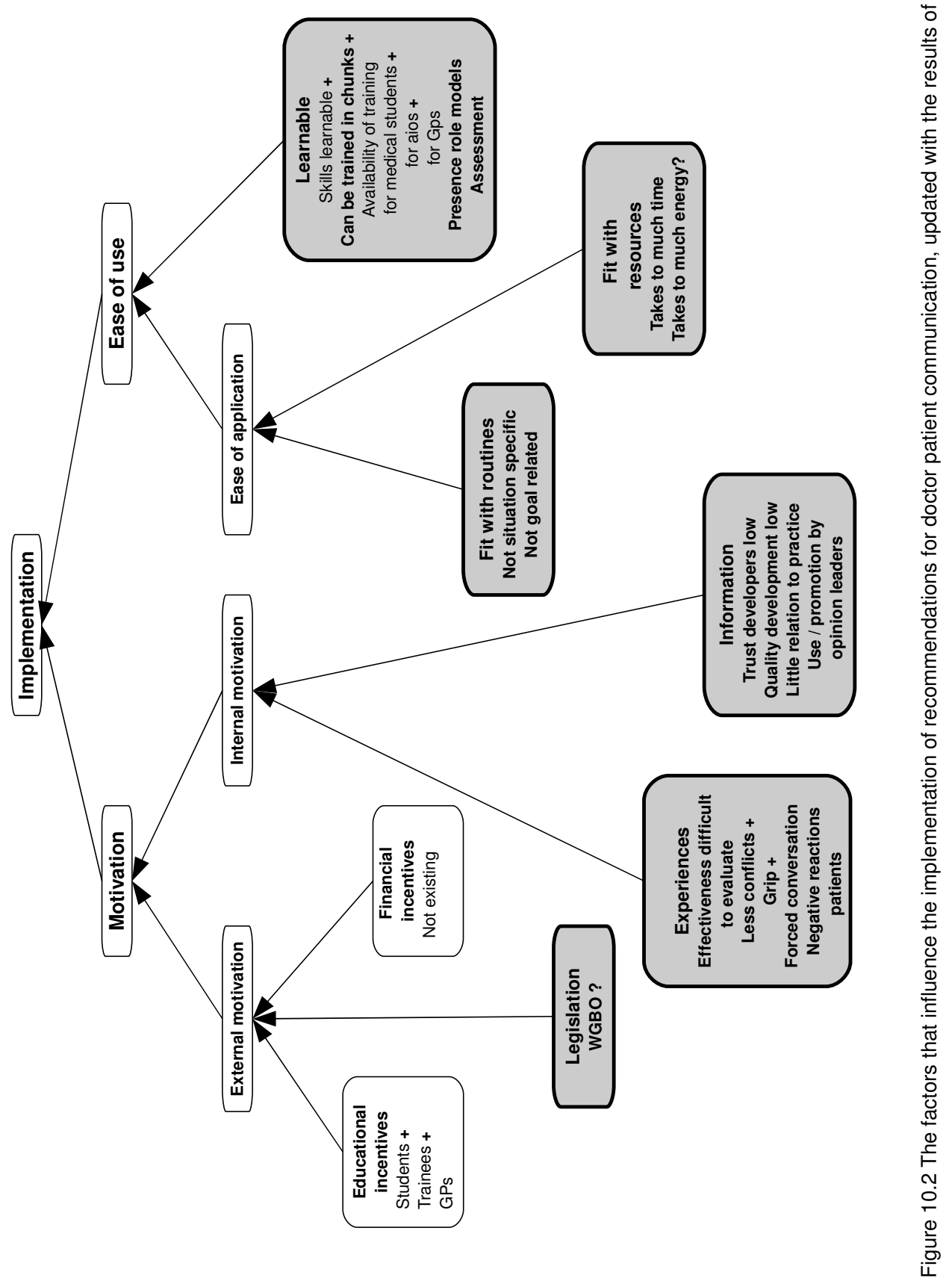




\section{Alterations of the framework}

Based on the thesis results, three alterations were made to the framework. Two factors, the availability of supportive role models and validated assessment instruments, which were labelled in the first framework as having a positive impact on the implementation of the guidelines, because they were assumed to stimulate effective training, are now labelled as impediments to the implementation of communication guidelines.

In the first model, GP communication trainers and GP supervisors, in their role as role models for medical students and GP trainees, were considered supportive of the implementation of communication guidelines. The results in chapter three, however, show that GP communication trainers and GP supervisors generally do not aim for integral implementation of the communication guidelines in their own work as doctors, but tend to apply only a selection from the guidelines depending on their appraisal of the situation at hand. Their use of communication guidelines seems to be considerably more fragmented than is prescribed by the guidelines. Therefore the example they set is more likely to inhibit than to stimulate the implementation of communication guidelines as a generic tool. In summary, they seem to be advocates not of the generic but of the situation specific use of communication guidelines.

The assessment instruments used in Dutch communication training have been validated by evidence that medical students' communicative performance improves as a result of training. ${ }^{23}$ This same evidence also proves that the instruments can discriminate between different levels of mastery of communication skills. Indeed, communication trainers and trainees confirm that the instruments can measure the ability to perform the actions described in the instrument (often referred to as 'tricks' by both groups). Nonetheless, many trainers and trainees consider the instruments unsuitable for discriminating between good and poor communication with patients (chapter 3). Moreover, GP trainers and GP trainees indicate that the type of feedback they receive from the instruments does not motivate them to change their behaviour (chapter 3 ). This implies that there are currently no instruments available to assess the quality of the communication of doctors that are accepted by users. This impairs the effectiveness of communication training.

The third alteration to the framework relates to external motivation. In the first version of the framework the Dutch law on informed consent (WGBO) is considered an external motivator of the implementation of communication guidelines. This was based on Van de Brink-Muiren et al.'s claim that one of the reasons why GPs' communication became slightly more patient-centred between 1987 and 2001 is that the WGBO came into effect in that period. ${ }^{24}$ However, the results of this thesis contradict WGBO's effect on GPs' communication, although there may have been an impact in other specialties. Legislation was not mentioned in any of the focus groups as a reason to adhere to communication guidelines, nor was it mentioned 
as a factor influencing communicative behaviour in any of the stimulated recall interviews with GPs (chapters 3 and 5). As a result of these findings and the realisation that we only have indirect evidence of the influence of the WGBO, this influence is now marked as 'unknown' in the framework.

\section{Additions to the framework}

The results of this thesis suggest that several additions should be made to the framework. Of the factors that determine the internal motivation of users we now know considerably more about the information on communication guidelines that is available to guideline users. For one thing, the quality of guideline development is questionable, due to unsound theoretical underpinnings, users' lack of trust in the developers and underrepresentation of guideline users in the development process. Furthermore, there is a mismatch with practice, because doctors' pursue a large range of competing goals in their communication and it is often not clear which goals can be achieved by applying the guidelines apart from delivering patient centred care. Moreover, the goal congruence between doctors and patients was higher than expected in our exploratory study, despite the usual pattern of low scores on items regarding exploration of the patients perspective shown in the doctors communication scores. A confirmation of these results would suggests that doctors use other methods to deliver patient centred care than to apply the recommendations of communication guidelines.

The results of the thesis also provide insight into another factor that influences internal motivation; doctors' experiences in applying communication guidelines. The hypothesis that patients view the consultation process differently than doctors do is confirmed by doctors' and patients' different ratings of communication during consultations. This difference of interpretation may impede the assessment of the effectiveness of communication by doctors, because it requires interpretation of the patient's reactions, something at which doctors do not appear to be very successful. The strongest positive experience with the application of the guidelines is that it gives doctors more grip on the consultation. In addition some doctors experience fewer conflicts with patients when applying the guidelines. Negative experiences are that the conversation becomes forced and lacking in natural fluency, while some patients react negatively when doctors apply guidelines, especially when this involves the exploration of emotions, preferences or the request for help.

This thesis reveals a poor fit of communication guidelines with routines in clinical practice. Communication in clinical practice is situation specific and goal directed something which communication guidelines are not. With regard to the fit with available resources, lack of time was mentioned most frequently. Some users appreciate that the application of communication guidelines may save time in the long run by reducing the number of consultations. However, most doctors' immediate, most pressing concern is to stay on schedule and finish the 
consultation within set time limits. Doctors feel that the application of communication guidelines usually extends consultation time. Some remarks by users suggest that GPs may also sometimes be inclined to avoid patient-centred communication to maintain an emotional distance from their patients and prevent becoming emotionally drained (GP-trainer focus group VU, GP 6 stimulated recall interviews). The high burn-out rate among GPS $^{25}$ highlights the urgency for GPs to develop strategies to deal with the burden of emotional pressure and emotional exhaustion. However, too little was said on this particular topic to draw any definite conclusions.

A relevant result with regard to the learning of the communication guidelines is that the current communication guidelines seem to have simplified communication to trainable skills which can be learned in separate chunks. According to current educational theory, however, the strategy of dividing competencies into separate skills for training purposes is outdated, because it hampers the learning of whole task-performance. ${ }^{26}$

\section{Conclusions}

The application of communication guidelines in clinical practice is not very widespread. Even communication trainers say they make only fragmented use of the guidelines. In this thesis, this lack of adherence was investigated from the perspective of implementation research. As is shown in Figure 10.3, this thesis and the related literature identified considerably more factors impeding the implementation of the guidelines than factors that facilitate their use, despite the attention devoted to communication training in medical school and in specialty training in general practice. The main problems are:

1. Lack of trust in the usefulness of the communication guidelines due to flaws in the development process.

The quality of communication guidelines is low, due to poor developmental rigour, little involvement of users and little attention to applicability. This creates doubt as to the reliability and usefulness of communication guidelines.

2. Lack of applicability due to a mismatch with clinical practice.

Communication guidelines do not fit with existing routines in clinical practice and, according to users, make too strong a demand on the available resources. Both problems point to a conflict between the generic nature of communication guidelines and the situation specific goal-directed communication of doctors, who make real-time decisions on communicative behaviour in fluid, complex consultations in which many, often competing, goals have to be achieved.

3. Lack of experienced usefulness

Users' experiences with the application of communication guidelines do not stimulate more than fragmented use of recommendations. The paucity of 
positive experiences is likely connected with the two preceding problems, the flaws in the development procedure and the lack of applicability of the guidelines. Another probable cause is the difficulty for doctors of evaluating the effects of communication on the patient due to doctors' and patients' discordant perceptions of communication during consultations.

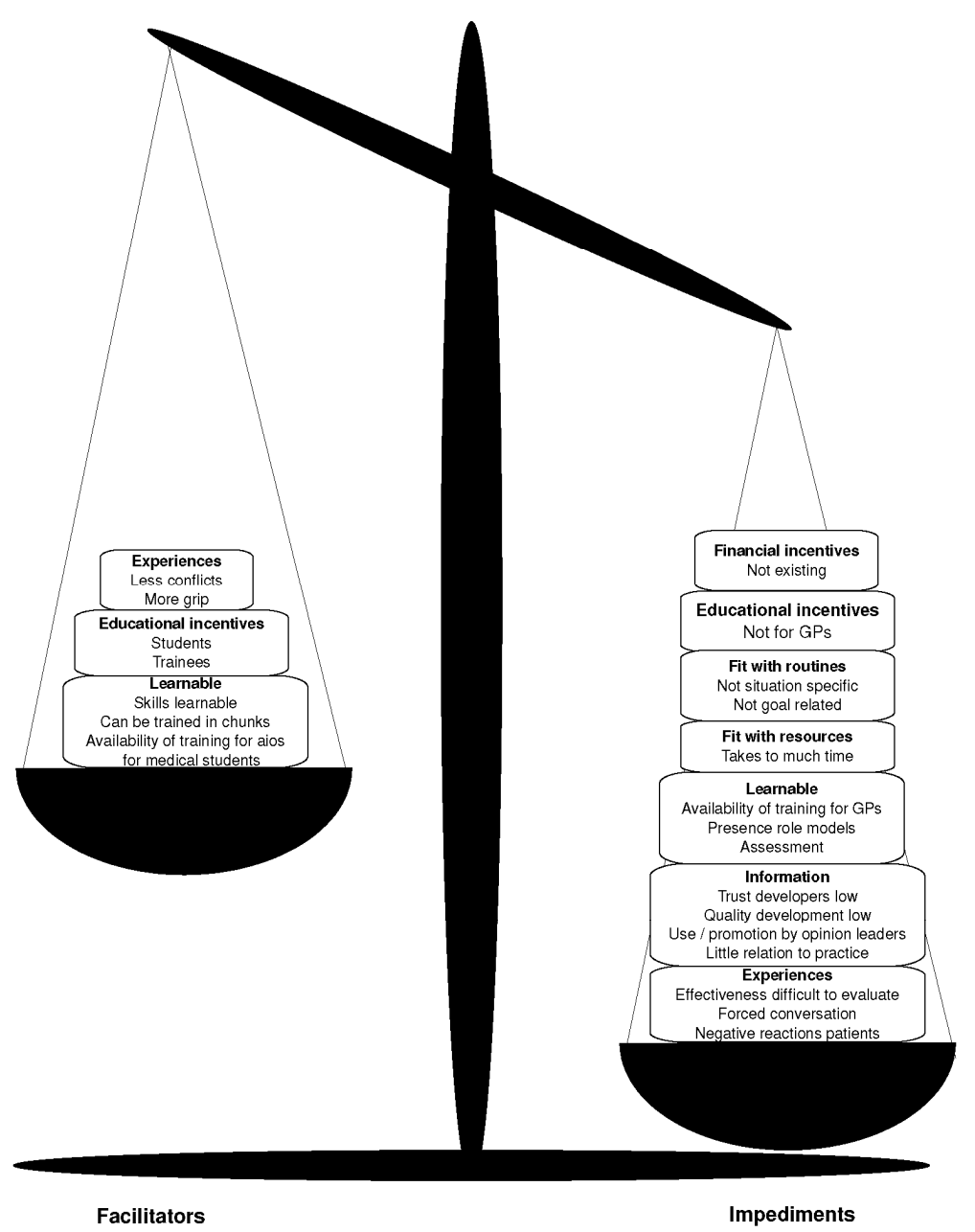

Figure 10.3 Facillitators and impediments: proportions 


\section{Recommendations to practitioners}

Based on this thesis I want to make two broad recommendations, which concern not only the development of communication guidelines, but also communication training and communication research in general. After presenting these recommendations, I will elaborate them and present recommendations for specific groups. Next, I will describe in greater detail what I believe to be the best method to develop communication guidelines, based on current knowledge and the findings of the thesis. I will finish this section by making recommendations for further research. My two broad recommendations are:

1. Focus on giving support to doctors to help them deliver high quality health care, not on changing doctors' communicative behaviour.

2. Doctors should take responsibility for doctor patient communication.

Recommendations to the developers of communication guidelines

- Align recommendations where possible with the established communicative behaviour of doctors in clinical practice, i.e. develop situationally relevant communication guidelines.

- Make it clear to doctors how the recommended communicative behaviour can help them achieve their goals, i.e. tailor recommendations to consultation goals that are important to doctors.

- Set quality standards for the development of communication guidelines. The standards for medical technical guidelines, as formulated in AGREE, could serve as a template for this, although some divergence will be inevitable due to differences in the available evidence and the amount of conscious attention paid to communication decisions compared to medical technical decisions.

- Explain the status of communication guidelines clearly. If communicative competence is defined and measured as the extent to which the recommendations are followed, the recommendations are accorded protocol status, i.e. they must be followed, unless there are good reasons not to do so. If this is indeed the case, that status must be made clear to guideline users. The use of protocols, however, is only defensible if the gains of standardisation outweigh the drawbacks. To what extent standardisation is 'safe,' in the case of doctor patient communication, is a topic for further research. Doctors say they adjust their communication to medical and societal needs, but also to patients' individual characteristics. This flexibility seems something that is worth fostering. Therefore I would suggest that communication guidelines should be given the status of recommendations and not of protocols. They should enlighten doctors about the effects of different strategies and leave it to individual doctors to decide which strategies to use. 


\section{Recommendations to communication trainers}

- Respect doctors' need to achieve other goals than patient-centred care.

- Divide communication competence in the following three subcompetences

- $\quad$ selecting appropriate goals and handling goal competition and goal conflict in consultations;

- $\quad$ selecting effective communication techniques to achieve the selected goals

- $\quad$ skilful performing the selected communication techniques

- Pay attention to the quality of the choice of consultation goals and the assumptions underlying those choices.

- Pay attention to how competing goals and goal conflict are handled during consultations.

- Emphasise the benefits and risks of desired and actual communicative behaviour in relation to the goals pursued during specific consultations. consultations.

- Take the situation specific nature of doctor patient communication into account when assessing communication. Develop assessment programmes related to the subcompetences mentioned above, that identify which subcompetence is insufficient when communication performance is inadequate.

\section{Recommendations to communication researchers}

- $\quad$ Collect evidence to enable evidence-based doctor patient communication, i.e. focus on how specific goals are best achieved when specific communicative strategies are used.

- When making recommendations for practice, it is important to realise that proof of benefit from a certain type of behaviour does not automatically warrant changes in practice. One should only recommend changes if the benefits of change are larger than the potential benefits of a different use of the resources that have to be invested in the new behaviour (time, energy).

- Make more use of dyadic data collection and analysis, as this may enhance insight into how doctors and patients interact and influence each other during consultations.

\section{Recommendations to doctors}

With regard to doctor patient communication, doctors have relied heavily on the expertise of behavioural scientists, who have played an important role in the development of communication guidelines and in education and research in relation to doctor patient communication. Regrettably, doctors use this as an excuse not to commit to the guidelines, saying that the guidelines are developed by persons who do not carry medical responsibility and do not understand the needs 
and limitations of clinical practice. A similar excuse is used to disparage training by non-clinician communication trainers. However, doctor patient communication impacts strongly on the quality and outcome of health care, for which doctors are responsible. Consequently, doctors have no choice but to take responsibility for the quality of doctor patient communication, both as individuals and as a group. It is the doctors who should take the lead in the development of communication guidelines to which they can commit and which can be used successfully to teach appropriate communicative behaviour to novice doctors. Doctors should also propose topics for research that may help to optimise their communication. Doing so is part of the responsibility of the medical community for the delivery of good health care.

\section{Recommendations for the development of communication guidelines}

Although these recommendations are intended for guidelines for doctors in all domains of medicine, I will occasionally specify them with reference to the setting in which this thesis was executed, i.e. Dutch general practice.

\section{A. Developers}

1. Communication guidelines should be developed primarily by their users (doctors in the specialty for which the guidelines are intended), supported by experts in doctor patient communication from other disciplines.

2. Developers should include doctors with and doctors without specific affinity with doctor patient communication in order to ensure that the recommendations are achievable by all doctors.

3. Guidelines should be developed by the same institution that develops medical technical guidelines. In the Netherlands this is the CBO or, for GPs, the Dutch College of General Practitioners (NHG). Preferably the centres for vocational training in general practice should also take part, because of their expertise and their role in the implementation of communication guidelines.

4. There is a movement towards patient involvement in the development of medical technical guidelines. Possibilities in this area should also be explored for communication guidelines in order to benefit from the experiences of this group of stakeholders.

\section{B. Situation specificity of communication guidelines}

1. Communication guidelines should be situation specific in order to fit the practice routines of doctors. Consultation goals seem the best organising principle for situation specific communication guidelines, as doctors use goalrelated strategies to tailor their communication to the medical context of the consultation and to the individual needs and preferences of patients (text box 1: 'situation specific communication guidelines'). 
2. It has been suggested to add communication guidelines to disease-related medical technical guidelines. This seems a useful way to stimulate the implementation of communication guidelines as it underscores their importance for patients' health. Recommendations for communication could be incorporated into medical technical guidelines that are associated with specific consultation goals (such as lifestyle advice in guidelines on cardiovascular disease or COPD).

3. For exceptional cases, such as patient groups with special communication needs for almost all situations, group-related communication guidelines could be developed. An example of this would be guidelines for communication with intellectually disabled patients.

\section{Topics}

In the selection of guideline topics several things are important.

1. Topics should be important to doctors. This means that goal-related communication guidelines should be directed at goals which doctors pursue frequently and consider important, such as collecting diagnostic information and reassuring patients.

2. It should also be evident that goal achievement will be enhanced considerably by good communication, i.e. the application of the guidelines should offer considerable benefit. For example, techniques of motivational interviewing might be included in a guideline on promoting lifestyle changes, as this communication approach has been shown to contribute substantially to lifestyle improvement.

3. There should be room for improvement. In other words guidelines should address topics on which doctors' communication tends to be suboptimal or shows considerable variation. An example of this is a guideline on risk communication, because doctors are known to have difficulty explaining to patients the risks related to their health status or to different treatment options, while effective communication strategies for this are available.

4. Efficiency of communication is extremely important to doctors. As this applies to almost all patient encounters, it seems less suited as a topic for a single guideline, but should be included in all guidelines. Doctors need to know the immediate time gain or cost associated with the application of a recommendation in a specific patient encounter and also the longer term implications as regards the number and duration of follow-up consultations.

\section{Scientific underpinnings}

1. Because guidelines should be based on evidence whenever possible, the same development procedures that are used for medical technical guidelines could be adopted. This procedure could be adjusted when needed, for instance because less 'hard' evidence may be available on communication topics 
compared to disease-related topics. One adjustment might be to broaden the sources of evidence to communication research outside health care.

2. Recommendations should be developed in consensus procedures, as is done in the development of medical technical guidelines.

3. For each recommendation the strength of the evidence, the setting where it originated and the underlying mechanisms should be made clear. This can help doctors to make informed choices with regard to the application of recommendations.

\section{E. Guideline structure}

1. Guidelines are probably best structured according to tasks related to consecutive consultation phases to help doctors keep track of the consultation. A division into an opening phase, a diagnostic phase and a management phase seems appropriate as this is a natural distinction for doctors. It should be noted, however, that this structure is merely an aid to guideline use and not a mandatory procedure. Consultation tasks should be executed as and when they fit into the interaction, which is not necessarily always in the same phase of the consultation.

2. For each task the communicative actions that can help to perform that task should be described. An example of a communicative action is 'summarising the information given,' an action that might be part of the task 'informing the patient'.

3. The communicative actions that are a part of different communication tasks can be described generically. For example the task 'informing the patient' will require the same set of actions whether it is part of a guideline on reassuring patients or shared decision making.

F. Recommendations to facilitate the implementation and use of guidelines in communication training

In order to facilitate the implementation of communication guidelines they should be integrated into existing training programmes and in planned programmes. Although the development of training modules lies outside the scope of guideline development, some educational materials could be developed concurrently with new guidelines to help learners implement the new recommendations.

1. Examples can be given to clarify and concretise communicative actions, although it should be emphasised that they are purely illustrative and not prescriptive. Examples do not necessarily have to be presented in well-turned sentences; they can also consist of (very) brief utterances, which may suffice when supported by non-verbal communication. The following examples refer to 'checking whether the patient has understood the information'. 
- l've just described to you the four treatment options for shoulder complaints: awaiting their natural course, physiotherapy, pills or a shoulder injection. Are these options and their pros and cons clear to you?

- You look puzzled, was anything in my explanation not clear?

- Clear?

2. Mnemonic aids to be used by trainees during patient encounters could be developed, such as sheets containing a summary of all communication tasks related to a certain goal-related guideline, or summaries of all communicative actions related to a certain task.

\section{Recommendations for further research}

- Explore the generalisability of the results of this thesis to other countries and specialties.

- Explore the growth of competence: How does communicative competence develop and what are the implications of learners' competence levels for training?

- Explore in more detail how doctors' communicative behaviour comes about, for instance by looking at the relation with the theory on action scripts /event schemas.

- $\quad$ Explore how to create situation-specific recommendations without creating cognitive overload: How to integrate recommendations for communication with specific types of patients with recommendations for specific goals, without causing information overload for doctors?

- Assess whether situation specific communication guidelines are indeed easier to implement than generic communication guidelines.

- Assess the appropriateness of different levels of idiosyncrasy/protocolisation of recommended communicative behaviours.

- $\quad$ Further explore the match between doctors' and patients' goals in consultations and investigate doctors' communication strategies and other factors that influence this match. 


\section{Literature}

1. Burgers J, Grol R, Eccles M. Clinical guidelines as a tool for implementing change in patient care. In: Improving patient care; the implementation of change in clinical practice Edited by R Grol, M Wensing, M Eccles: Elsevier; 2005.

2. Wensing M, Grol R. Methods to identify implementation problems. In: Improving patient care; the implementation of change in clinical practice Edited by R Grol, M Wensing, M Eccles: Elsevier; 2005.

3. WONCA_europe. The european definition of family medicine / general practice. 2005.

4. MSMW. The Aim of American Medicine Within the Constraints of Today's Society. The Western Journal of Medicine 1986;145:181.

5. Doelen van gezondheidszorg. In: Medische ethiek Edited by HAMJ ten Have, RHJ ter Meulen, E van Leeuwen: Bohn Stafleu van Loghum; 2009.

6. Kitzinger J. Qualitative research. Introducing focus groups. BMJ 1995;311:299-302.

7. Abma TA. The Practice and Politics of Responsive Evaluation. American Journal of Evaluation 2006;27:31-43.

8. Chew-Graham CA, May CR, Perry MS. Qualitative research and the problem of judgement: lessons from interviewing fellow professionals. Fam Pract 2002;19:285-9.

9. Matthys J, Elwyn G, Van Nuland M, Van Maele G, De Sutter A, De Meyere M, Deveugele M. Patients' ideas, concerns, and expectations (ICE) in general practice: impact on prescribing. Br J Gen Pract 2009;59:29-36.

10. Campion P, Foulkes J, Neighbour R, Tate P. Patient centredness in the MRCGP video examination: analysis of large cohort. Membership of the Royal College of General Practitioners. BMJ 2002;325:691-2.

11. Elwyn G, Hutchings H, Edwards A, Rapport F, Wensing M, Cheung WY, Grol R. The OPTION scale: measuring the extent that clinicians involve patients in decision-making tasks. Health Expect 2005;8:34-42.

12. Wilson SR, Sabee CM. Explicating communicative competence as a theoretical term. In: Handbook of communication and social interaction skills Edited by JO Greene, BR Burleson. Mahwah, New Jersey: Lawrence Erlbaum Associates; 2003.

13. Green JO. Message production; advances in communication theory. Mahwah, New Jersey: Lawrence Erlbaum Associates; 1997.

14. Straus SE, McAlister FA. Evidence-based medicine: a commentary on common criticisms. CMAJ 2000;163:837-841.

15. de Haes $\mathrm{H}$, J Bensing J. Endpoints in medical communication research, proposing a framework of functions and outcomes. Patient Educ Couns 2009;74:287-94.

16. Watkins C, Harvey I, Langley C, Gray S, Faulkner A. General practitioners' use of guidelines in the consultation and their attitudes to them. Br J Gen Pract 1999;49: 11-5.

17. Righart H. De eindeloze jaren zestig. Geschiedenis van een generatieconflict. Amsterdam Antwerpen: De Arbeiderspers; 1995.

18. Armstrong E. Integrity, Transparency and Accountability in Public Administration: Recent Trends, Regional and International Developments and Emerging Issues: UN Economic \& Social Affairs; 2005.

19. Rycroft-Malone J, Fontenla M, Bick D, Seers K. A realistic evaluation: the case of protocol-based care. Implementation Science 2010;5:38.

20. Dudley RA, Miller RH, Korenbrot TY, Luft HS. The impact of financial incentives on quality of health care. Milbank Q 1998;76:649-86, 511.

21. Bensing J. Bridging the gap. The separate worlds of evidence-based medicine and patient-centered medicine. Patient Educ Couns 2000;39:17-25. 
22. de Haes H. Dilemmas in patient centeredness and shared decision making: a case for vulnerability. Patient Educ Couns 2006;62:291-8.

23. van Dalen J, Kerkhofs E, van Knippenberg-Van Den Berg BW, van Den Hout HA, Scherpbier AJ, van der Vleuten CP. Longitudinal and concentrated communication skills programmes: two dutch medical schools compared. Adv Health Sci Educ Theory Pract 2002;7:29-40.

24. van den Brink-Muinen A, van Dulmen SM, de Haes HC, Visser AP, Schellevis FG, Bensing JM. Has patients' involvement in the decision-making process changed over time? Health Expect 2006;9:333-42.

25. Nielsen HG, Tulinius C. Preventing burnout among general practitioners: is there a possible route? Educ Prim Care 2009;20:353-9.

26. Van Merriënboer JJG, Clark RE, De Croock MBM. Blueprints for complex learning: The 4C/ID-model. Educational Technology, Research and Development 2002;50:39-64. 



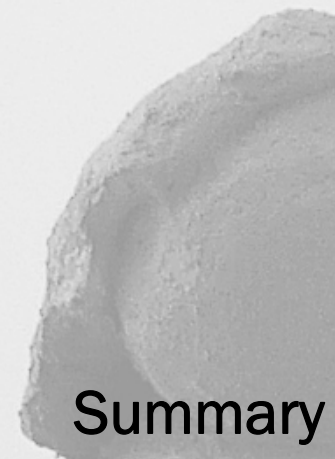

Summary

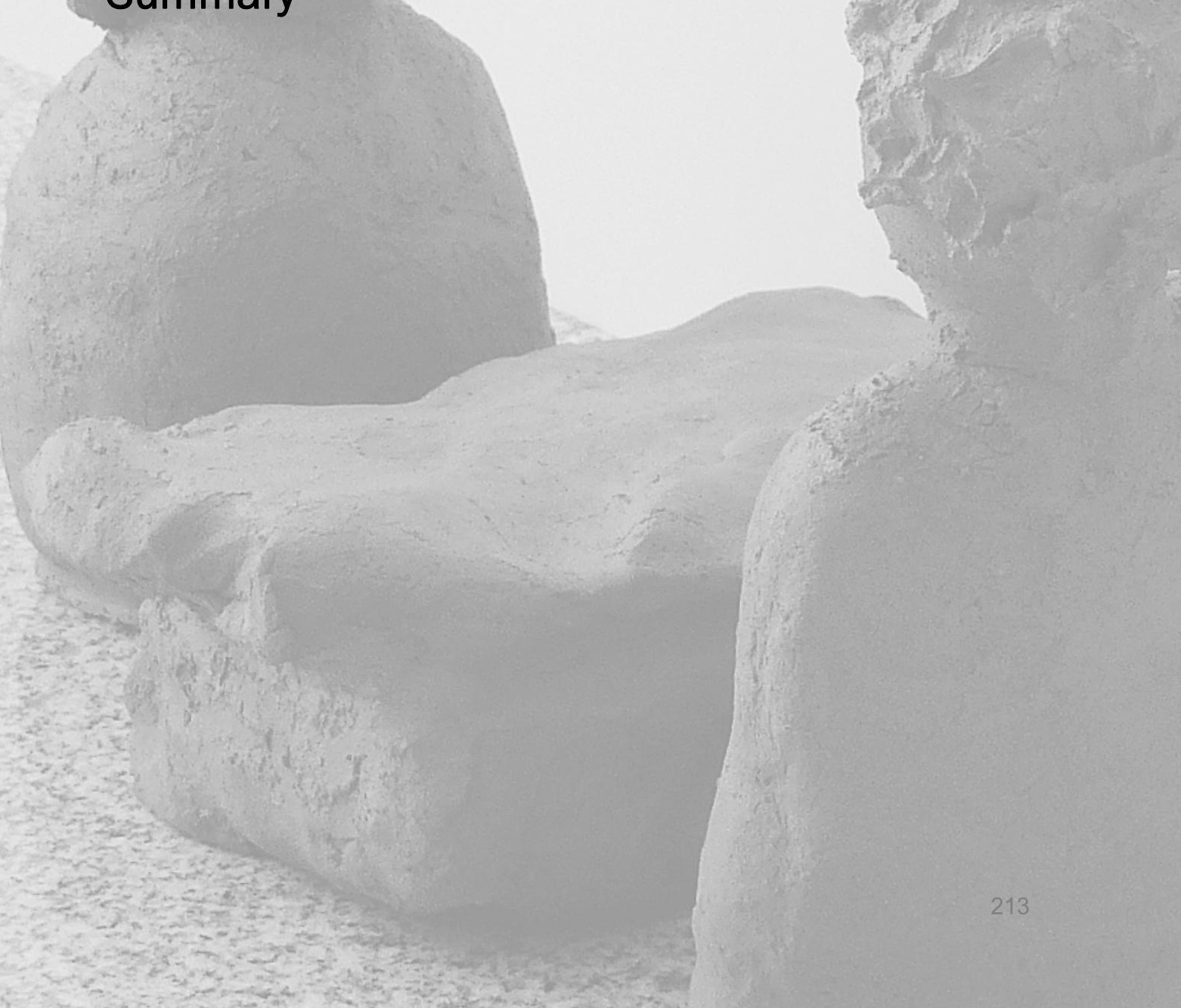





\section{Summary}

\section{Chapter 1}

This introductory chapter starts with a description of the historical background and the effectiveness of attempts to change the way doctors communicate with their patients. After an analysis of possible causes of the general lack of impact of these attempts, it is concluded that one of the probable causes is that recommendations for doctor patient communication lack feasibility or usefulness for clinical practice. This leads to the aim of this thesis: to gather information on the feasibility and usefulness of recommendations for doctor patient communication, which are the basis for efforts to influence doctors' communication. The underlying aim is to gain knowledge that can be used to develop recommendations for doctor patient communication that can be successful in enhancing doctor patient communication in clinical practice.

Next, the theoretical perspective used in this thesis is described. Documents containing recommendations, guidance or instructions concerning doctor-patient communication are considered communication guidelines. This interpretation allows for the use of the literature on the implementation of clinical practice guidelines to explore and explain problems in efforts to influence doctor-patient communication. A framework derived from this literature describes factors that can influence the implementation of recommendations for doctor patient communication and identifies gaps in the literature. The framework illustrates that little is known about the quality of communication guidelines, what drives doctors' communicative behaviour during patient encounters and the congruence of doctors' and patients' experiences during consultations. This gives rise to the following research questions:

1. What are the objective and experienced strengths and weaknesses of the current guidelines for doctor patient communication?

2. What drives doctors' communicative behaviour in clinical practice?

3. To what extent are the opinions and goals of doctors congruent with those of their patients during consultations?

\section{Chapter 2}

The aim of the study reported in this chapter was to describe the guidelines for doctor patient communication used in communication training for GP trainees. It was also the first of three studies that explored the quality of communication guidelines. The guidelines were extracted from educational materials supplied by the eight Dutch university centres for vocational training in general practice. The analysis of the guidelines was guided by four themes: content, type of contact, format and structure, and status. The quality of the guidelines was assessed with 
the AGREE instrument, a validated measurement instrument for the assessment of the quality of clinical guidelines.

It proved difficult to extract guidelines for doctor patient communication from the materials of the GP training courses due to variety in terminology and lack of clarity concerning the status of documents. Nevertheless, eighteen guidelines were identified. Nine of them related to general consultations and nine related to specific situations such as breaking bad news or handling conflicts. Depending on the university, guideline content covered $64 \%-100 \%$ of the GP qualification requirements. Format, structure and number of recommendations differed widely between guidelines. There were no indications that guideline use was obligatory. The AGREE scores were low.

It was concluded that the Dutch communication guidelines for GPs are of low quality, hardly based on evidence and developed with a lack of attention to applicability and user involvement. Additionally, there was considerable difference between individual guidelines in subjects, content and format, and between universities in the use of different guidelines. It was not clear what caused these differences.

\section{Chapter 3}

This chapter describes a study exploring the strengths and weaknesses of communication guidelines as experienced by users. Seven mixed focus groups, consisting of experienced GPs, communication trainers (GPS and behavioural scientists) and communication learners (GP trainees and medical students), and three focus groups consisting of GP trainees only discussed the main communication guidelines in use during GP training in one of the seven participating universities. These guidelines were a subset of the generic communication guidelines described in chapter 2.

The groups reported considerably more weaknesses than strengths of the communication guidelines. The main problem was that the guidelines did not fit well into GPs' day-to-day practice. This was attributed to the rigidity and inefficiency of the communication guidelines and erroneous assumptions underpinning

guideline development. Guideline use was most strongly facilitated by guideline structure. Guidelines that were structured into distinct phases were considered helpful for doctors to remain in control of consultations, which was considered especially important for complicated consultations.

Although communication guidelines were generally considered useful, especially in structuring consultations, their usefulness was impaired by lack of flexibility and applicability to practice routines. It was suggested that communication guidelines would be more user centred and feasible when they combined the advantage of helping doctors structure consultations with flexibility to tailor communication strategies to specific contexts and situations. 


\section{Chapter 4}

In this study the participants in the focus groups were again asked to reflect on the strengths and weaknesses of the same communication guidelines but this time focused on the learning and teaching of the recommendations of the guidelines.

Five key attributes of guidelines for communication skill training were identified: complexity, level of detail, format and organisation, type of information, and trustworthiness/validity. Which characteristics were appreciated most for these attributes was related to specific educational purposes and learners' expertise. According to the participants the guidelines were more useful for educational purposes than for application in practice. They were negative regarding the validity of the guidelines as descriptors of best practice or when used for assessment.

These results suggest that the communication guidelines used in GP training in the Netherlands are based on an oversimplified model of doctor patient communication. While facilitating the learning and teaching of the guidelines as a set of tricks, this simplification was deemed to hamper the acceptance of the guidelines as a guide for good communicative behaviour in clinical practice.

\section{Chapter 5}

This study was inspired by the limited alignment of the communication guidelines with GPs' day-to-day practice due to the fact that the recommendations are too generic and developed for communication in general while GPs tailor their communication to the situation at hand (chapter 3 ).

Because of scant knowledge with regard to what drives doctors' communicative behaviour, stimulated recall interviews were conducted with GPs to explore how they select communicative actions during patient encounters. The GPs were asked to comment on recordings of two of their recent consultations. Based on these interviews, the goal-directed communicative action model was developed.

This model illustrates how GPs' communicative actions are shaped in a complex process in which GPs constantly adapt their selection of communicative actions to their evolving evaluation of the situation. These evaluations culminate in the selection of situation-specific goals for individual consultations. The impact of GPs' consultation goals on the selection of communicative actions outweighs all other influences. These multiple and often dynamic goals require constant revision and adaptation of the discourse during consultations. GPs go to considerable lengths to tailor their actions to individual patients. In selecting consultation goals GPs weigh patients' needs and preferences as well as the medical situation and its consequences. In the final selection of communicative actions GPs attempt to tailor their communication to individual patients.

These findings suggest that goal-related, situational communication guidelines are more in line with communicative routines in clinical practice than the existing communication guidelines. 


\section{Chapter 6}

While the study described in chapter 5 identified consultation goals as the strongest influence on communication during consultations, the study described in chapter 6 examined in more depth what drives GPs' communicative behaviour by exploring GPs' consultation goals.

Three different qualitative data sets were triangulated. The data obtained from the focus groups and stimulated recall interviews (chapters 3, 4 and 5) were reanalysed to identify consultation goals. In addition think-aloud interviews were conducted with $16 \mathrm{GPs}$, who were observed during 246 consultations and immediately after each consultation asked to describe which goals they had pursued.

The results show that GPs pursue multiple goals in the majority of consultations. Many of these goals compete with each other for time or are in direct conflict with each other. The goals concern different personal or organisational aspects: maintaining the health of the patient, the patient's well-being, work satisfaction of the GP, the organisation of care, and public health agendas.

This study indicates that GPs consider no single goal so important that they pursue it in every consultation. Besides patient centeredness, the GPs in this study discerned many other aspects of high quality health care. As high quality care takes time and time is scarce, GPs set priorities in every new consultation. The need to choose between different aspects of quality of care explains why GPs do not communicate in accordance with a single model, like the patient-centred one.

\section{Chapter 7}

In this study we tested the notion that doctors' communication is goal driven (qualitative interview study, chapter 5) against observational data by exploring the predictive value of specific consultation goals for GPs communicative behaviour. Nine hypotheses on the effect of consultation goals on communicative behaviour were tested. Data on communicative behaviour were gathered by rating consultations on the MAAS-global, a validated measurement instrument for doctors communicative behaviour. Data on consultation goals were derived from the analysis of the think-aloud interviews with the GPs immediately after each consultation.

The results confirm that GP-patient communication is goal directed. Six hypotheses were confirmed, showing moderate to large effects of goals on communication scores. The other three hypotheses showed a (non-significant) difference in the predicted direction. In general, patient-centred goals lead to higher scores on patient-centred communication items, whereas health-related goals lead to lower scores on these items. 


\section{Chapter 8}

One of the goals of training doctors in patient centred communication is to improve the match between doctors and patients goals in consultations. In this study we explored the extent to which doctors' and patients' consultation goals match in normal practice and test acceptability and validity of a measurement procedure for this purpose.

We obtained data on patients' goals and patient satisfaction from a preconsultation questionnaire and a post-consultation questionnaire, respectively. Data on doctors' goals were derived from think aloud interviews directly after consultations. Two raters independently rated three aspects of goal match on a five-point scale.

The methodology seemed acceptable to doctors and patients. High inter-rater variation necessitated consensus discussions between raters. The validity of the goal match construct was supported by a positive association of goal match with several aspects of patient satisfaction. The results for goal match were better than the predominantly negative reports in the literature had led us to expect. Further studies are needed to verify our results. Confirmation of our results would warrant exploration of how doctors achieve goal match.

\section{Chapter 9}

Many of the outcomes of doctor-patient communication that are considered relevant by doctors and researchers relate to the impact on patients. This implies that in order to evaluate the effectiveness of their communication doctors need to interpret how it affects their patients. This is problematic because the difference between doctors and patients in knowledge and roles gives rise to different perspectives on communication. This study investigated the extent of similarities in the way doctors and patients perceive doctors' communication skills.

For this study we re-analysed data obtained for psychometric evaluation of the 'Matched Pair Instrument', a communication assessment instrument that measures both doctor and patient perceptions of doctors' communication as it occurs in a single consultation. A multi-level analysis method specially developed to analyse dyadic data (i.e. a combination of doctor and patient data on the same consultation) was used to analyse to what extent: 1) doctors' perceptions of their communication skills were congruent with their patients' perceptions; 2) the patients of a specific doctor agreed on their doctor's communication skills; and 3) doctors varied in the degree to which their self-scored communication skills predicted their patients' perceptions of their skills.

With regard to question 1, we found low agreement between doctors and patients regarding doctors' communication skills. Agreement between doctors and patients in individual consultations was only just significant and agreement between doctors' self-scored consultation skills showed no statistically significant relationship with the patients' scores on these skills. With regard to question 2 , we 
found rather low agreement among patients on the communication skills of their doctors, whereas the doctors scores on their communication were quite consistent across consultations with different patients. With regard to question 3 , we found no evidence of variation between doctors in the extent to which their communication scores predicted those of their patients.

Overall, the results of this study indicate that doctors and their patients have very different perspectives on the level of doctors' communication skills.

\section{Chapter 10}

In this chapter the answers to the three questions derived from the eight studies of this thesis are integrated and discussed in the light of the strengths and weaknesses of the thesis and the broader literature. It is shown that the findings of this thesis are supported by literature describing similar findings in other areas and offering further explanations. Thus, both the trustworthiness and the validity of the findings are supported.

Next, the results are placed within the wider framework of factors relevant to the implementation of communication guidelines, described in the introduction. From the extended version of the framework it is concluded that despite the investments in communication training, factors inhibiting the implementation of communication guidelines are considerably more numerous that factors that stimulate it. The main problems identified in this thesis are:

1. A lack of objective quality of communication guidelines, leaving users with too little positive information to convince them to apply the guidelines.

2. A lack of positive experiences of users in applying the guidelines, which may be partly due to difficulties in evaluating the effects of communication on patients. The difference between doctors' and patients' opinions regarding doctors' communication may be a complicating factor in evaluating these effects.

3. The problematic fit of the guidelines with resources and existing routines in clinical practice, which seems mainly due to a discrepancy between the generic nature of communication guidelines and the situation specific and goal directed nature of doctors' communication.

This conclusion is followed by two central recommendations for practice.

1. Focus on supporting doctors in delivering high quality health care, not on changing their communicative behaviour.

2. Doctors should take responsibility for doctor-patient communication.

These recommendations are elaborated into more specific recommendations for developers of communication guidelines, communication trainers and communication researchers. This thesis concludes with a set of recommendations for future research to support the development of communication guidelines that doctors experience as helpful in improving the quality of their health care. 

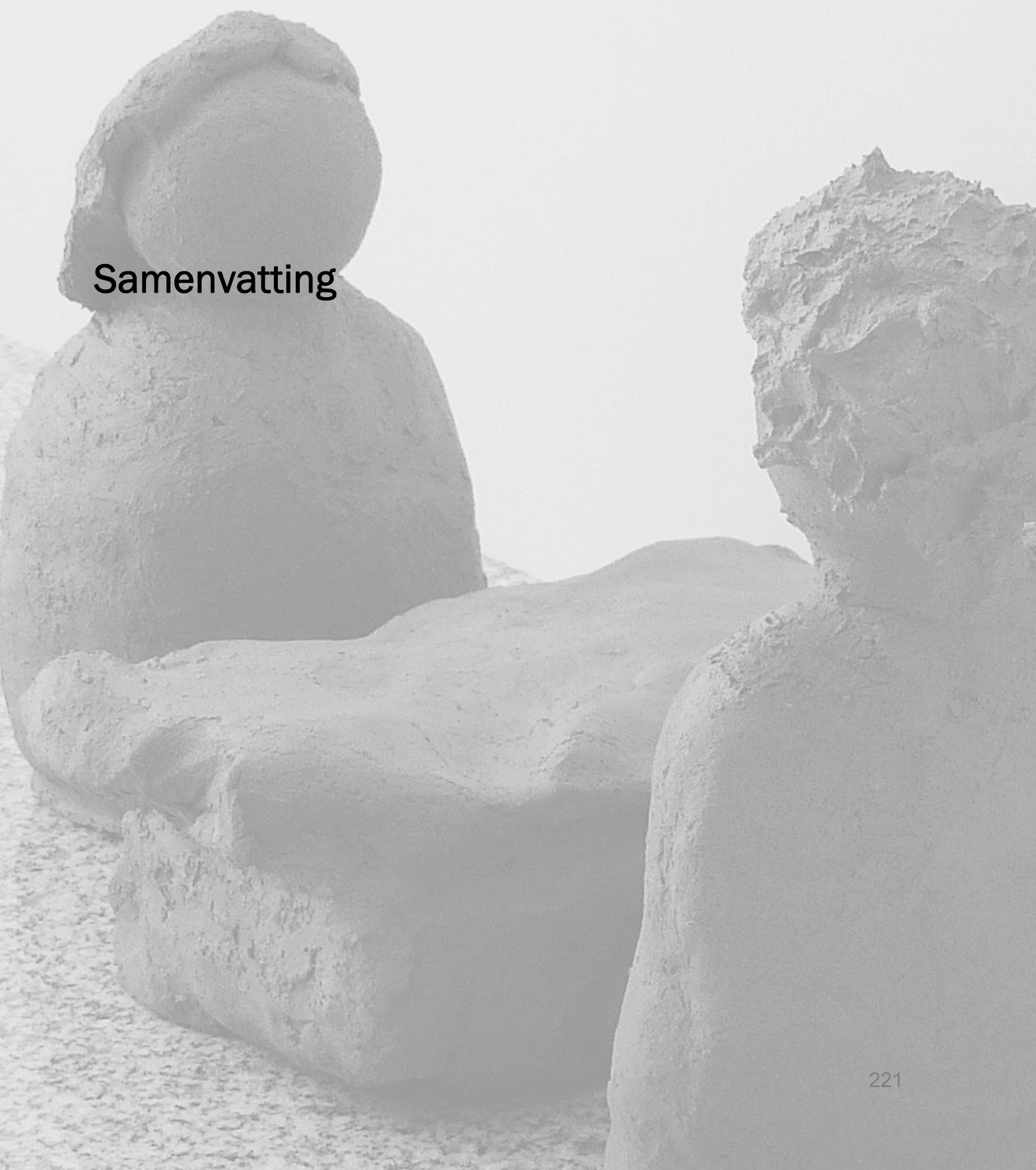



\section{Samenvatting}

\section{Hoofdstuk 1}

Dit inleidende hoofdstuk begint met het schetsen van de historische achtergrond van de wens artsen anders met patiënten te laten communiceren en beschrijft de effectiviteit van de pogingen om arts-patiënt communicatie te veranderen. Er wordt geconcludeerd dat deze effectiviteit te wensen over laat, waarna gekeken wordt naar mogelijke oorzaken. De hoofdhypothese van dit proefschrift is dat bestaande aanbevelingen voor arts-patiënt communicatie niet geschikt zijn voor de klinische praktijk. Dit enerzijds omdat ze niet goed passen binnen de randvoorwaarden die de kliniek stelt en daardoor onvoldoende werkbaar zijn, anderzijds omdat ze niet de door artsen gewenste resultaten opleveren en dus onvoldoende bruikbaar zijn. Het hoofddoel van dit proefschrift is dan ook het in kaart brengen van de werkbaarheid en bruikbaarheid van de huidige aanbevelingen voor arts-patiënt communicatie en waar mogelijk het doen van aanbevelingen om deze te verbeteren. Het achterliggende doel is om informatie te verzamelen op basis waarvan aanbevelingen kunnen worden ontwikkelt die goed aansluiten bij de praktijk en die daardoor geschikt zijn om arts-patiënt communicatie in de medische praktijk van alledag te verbeteren.

Vervolgens wordt in dit hoofdstuk het theoretisch kader beschreven. Belangrijk daarin is dat alle documenten die tips, aanbevelingen of handelingsinstructies geven voor arts-patiënt communicatie in dit proefschrift worden beschouwd als richtlijnen voor arts-patiënt communicatie. Deze interpretatie maakt het mogelijk kennis uit de literatuur over implementatie van richtlijnen in te zetten bij het analyseren van problemen bij het beïnvloeden van de communicatie van artsen. In een raamwerk dat is afgeleid van deze literatuur worden de factoren die de implementatie van aanbevelingen voor arts-patiënt communicatie beïnvloeden beschreven en welke lacunes er op dit terrein zijn in de literatuur. Dit raamwerk laat zien dat er weinig bekend is over de kwaliteit van richtlijnen voor arts-patiënt communicatie, over de manier waarop communicatie van artsen tijdens consulten tot stand komt en over de mate waarin ervaringen van artsen en patiënten tijdens consulten overeenkomen.

Dit leidt tot de volgende drie onderzoeksvragen:

1. Wat zijn sterke en zwakke kanten van de huidige richtlijnen voor arts-patiënt communicatie?

2. Hoe komt communicatie van artsen tijdens consulten tot stand?

3. In welke mate stemmen de meningen en doelen van artsen overeen met die van hun patiënten tijdens consulten. 


\section{Hoofdstuk 2}

Het doel van dit hoofdstuk was om de richtlijnen voor arts-patiënt communicatie die momenteel in op de huisartsopleidingen gebruikt worden in kaart te brengen door ze te beschrijven en hun kwaliteit vast te stellen met behulp van AGREE, een gevalideerd meetinstrument voor de kwaliteit van klinische richtlijnen. De richtlijnen bleken moeilijk te identificeren binnen het onderwijsmateriaal en sterk te variëren voor alle beschreven eigenschappen. De helft van de richtlijnen bleek generiek, dat wil zeggen dat de aanbevelingen gedaan werden onafhankelijk van consultspecieke kenmerken, zoals soort patiënt of soort probleem. De andere helft van de richtlijnen was ontwikkelt voor specifieke situaties. Voorbeelden hiervan zijn een richtlijnen voor het brengen van slecht nieuws of het counselen van patiënten met psycho-sociale problemen. In de kwaliteitsmeting scoorden de communicatierichtlijnen beduidend lager dan richtlijnen voor medisch technisch handelen. De scores voor betrokkenheid van belanghebbenden en voor toepasbaarheid waren laag, scores voor de mate waarin de richtlijnen evidence-based zijn, waren zeer laag.

\section{Hoofdstuk 3}

In dit hoofdstuk worden de sterke en zwakke kanten van communicatie richtlijnen bij toepassing in de klinische praktijk in kaart gebracht. Hiervoor hebben we studenten, praktijkopleiders en docenten in gemengde focusgroepen naar hun ervaringen gevraagd. Zij beschreven veel meer negatieve dan positieve kanten van de richtlijnen. Hun grootste probleem was dat de richtlijnen niet goed passen in de dagelijkse praktijk van de huisarts. Gebruikers ervaren de richtlijnen als rigide en gebaseerd op onterechte aannames over artsen, patiënten en de situatie tijdens consulten. De meest gewaardeerde eigenschap van de richtlijnen is hun onderverdeling in conceptueel verschillende opeenvolgende fases. Deze structuur geeft artsen meer grip op het consult doordat het overzicht geeft en duidelijk maakt wat er nog besproken moet worden. Dit vond met name voor complexe consulten belangrijk. In het algemeen werden de communicatie richtlijnen wel beschouwd als nuttig, met name voor structurering van consulten. Onze deelnemers gaven aan dat communicatie-richtlijnen bruikbaarder zouden worden voor de praktijk wanneer ze de voordelen van het structureren van consulten zouden combineren met de flexibiliteit om communicatie strategieën aan te passen aan de inhoud en omstandigheden van consulten.

\section{Hoofdstuk 4}

Dit hoofdstuk richt zich op de kenmerken van communicatierichtlijnen die het trainen en aanleren van de aanbevelingen in de richtlijnen ondersteunen. Om deze te identificeren hebben we de studenten, praktijkopleiders en docenten die deelnamen aan de focusgroepen beschreven in hoofdstuk 3, ook op dit terrein 
naar hun ervaringen gevraagd. De kenmerken die leerbaarheid en trainbaarheid beïnvloeden houden verband met 5 eigenschappen van de richtlijnen, namelijk: complexiteit, mate van detaillering, structuur, type informatie dat gegeven wordt en validiteit en betrouwbaarheid. De optimale eigenschappen van communicatierichtlijnen met betrekking tot deze eigenschappen blijken geen uniforme set te zijn. Welke eigenschappen het meest gewaardeerd worden is afhankelijk van de functie die de richtlijn op dat moment in het onderwijs vervult en van de ervaring en het niveau van de gebruikers.

\section{Hoofdstuk 5}

Hoofdstuk 5 beschrijft hoe communicatie van artsen tot stand komt. Op basis van stimulated-recall interviews met 15 huisartsen, die tijdens het interview twee eigen consulten van eerder die dag terugkijken, is een model ontwikkeld voor het proces van het selecteren van een specifieke communicatieve uiting door een huisarts op een willekeurig moment in het consult. In grote lijnen beschrijft het model dat communicatieve uitingen van artsen in consulten primair gericht zijn op het verwezenlijken van consultspecifieke doelen. Deze consultspecifieke doelen worden begrensd door de taakopvatting van de individuele arts en de doelen die deze bij zijn of haar invulling van de professie vindt passen. Consultspecifieke doelen worden vervolgens gekozen om het consult te laten aansluiten bij individuele patiënten en hun medische problemen. Vervolgens selecteren de artsen de communicatietechnieken waarvan ze verwachten dat ze het meest effectief zijn bij het realiseren van de consultspecifieke doelen in de omgang met de specifieke patiënt van dat moment. De validiteit van het model wordt ondersteund door een vergelijking met de literatuur en een beoordeling door huisartsen met ervaring in communicatie onderzoek en/of onderwijs.

\section{Hoofdstuk 6}

Hoofdstuk 6 geeft een overzicht van de consultspecifieke doelen die huisartsen nastreven. Voor deze studie zijn drie datasets gebruikt. De focusgroepinterviews uit hoofdstuk 3 en 4, de stimulated recall interviews uit hoofdstuk 5 en een nieuwe dataset bestaande uit think aloud interviews, gehouden tijdens spreekuren van huisartsen. Voor deze laatste dataset werden 16 huisartsen geobserveerd tijdens hun spreekuur en werden zij direct na elk consult geïnterviewd over de doelen die zij in dat consult nastreefden. De doelen die huisartsen nastreven hebben betrekking op het ondersteunen van de gezondheid van de patiënt, het welzijn van de patiënt, het werkplezier van de arts, de organisatie van zorg en 'public health' (vertaling?). De huisartsen streefden korte termijn doelen na 'achterhalen of de patiënt de medicatie bloeddrukmedicatie correct gebruikt', middellange termijn doelen 'zorgen dat de patiënt begrijpt waarom het gebruik van deze medicatie belangrijk is' en lange termijn doelen 'de kans dat de patiënt een hartaanval krijgt verkleinen'. Huisartsen streefden meestal meerdere doelen tegelijkertijd na. Af en 
toe bleken verschillende doelen in hetzelfde consult strijdig met elkaar, vaak was er onvoldoende tijd om alle doelen volledige aandacht te geven en moest de huisarts prioriteren.

\section{Hoofdstuk 7}

In hoofdstuk 7 wordt een bevinding uit hoofdstuk 5 gecontroleerd, namelijk dat communicatie van huisartsen doelgericht is. Hiervoor zijn negen hypotheses geformuleerd over hoe de consultdoelen van huisartsen hun communicatie scores op de MAAS-globaal beïnvloeden. Een voorbeeld van een dergelijke hypothese is: een huisarts die een patiënt emotioneel wil steunen zal in dat consult een hogere score hebben op de communicatie-items exploreren, emoties en empathie dan in consulten waarin hij dat doel niet heeft. Deze hypothese is getest met gebruik van de dataset uit hoofdstuk 6. De doelen die de huisarts nastreefden waren bekend uit de think-aloud interviews, de consulten waarin de huisartsen die doelen nastreefden waren opgenomen en zijn gescoord met de MAAS-globaal, een gevalideerd meetinstrument voor arts-patiënt communicatie. Zes van de negen hypotheses werden bevestigd. Met betrekking tot de overige drie hypotheses werd wel een effect in de voorspelde richting gevonden, dit effect bleek echter niet significant. Hieruit kan geconcludeerd worden dat huisartsen inderdaad doelgericht communiceren.

\section{Hoofdstuk 8}

In de studie voor hoofdstuk 8 werd een methode uitgeprobeerd om de doelen van huisartsen en patiënten in hetzelfde consult, met elkaar vergeleken. Dit vanuit de verwachting dat deze sterk zouden verschillen, omdat de literatuur op veel gebieden laat zien dat de perspectieven van artsen en patiënten sterk van elkaar verschillen. De doelen van de huisartsen waren verzameld tijdens de think aloud interviews tussen de consulten. De patiënten die op dat moment op consult kwamen, zijn via vragenlijsten gevraagd naar hun doelen en hun tevredenheid over het consult. De mate van overeenstemmingstemming tussen de doelen van de huisarts en de patiënt werd onafhankelijk van elkaar gescoord door twee onderzoekers. Zij scoorden drie aspecten: 1) In hoeverre de arts doelen nastreeft die de patiënt niet nastreeft 2) In hoeverre de patiënt doelen nastreeft die de arts niet nastreeft 3) De mate waarin de doelen van de patiënt en die van de arts conflicteren. De medewerking onder zowel huisartsen als patiënten was hoog, dus de methode lijkt voor beide groepen acceptabel. Een nadeel was dat de overeenstemming tussen de twee onderzoekers vrij laag was. Voor die consulten waarbij de scores afweken zijn daarom consensus discussies gehouden tussen de onderzoekers om tot overeenstemming te komen. Er worden een aantal suggesties gedaan om bij vervolgonderzoek tot een hogere onafhankelijke overeenstemming te komen. Bij de scores viel op dat de overeenstemming hoger was dan verwacht. De mate waarin artsen en patiënten doelen nastreefden die de andere partij niet 
nastreefde viel mee. Conflicten tussen doelen van artsen en doelen van patiënten waren zeldzaam.

\section{Hoofdstuk 9}

In hoofdstuk 9 wordt gekeken naar de overeenstemming in de mening van artsen en patiënten over de communicatie van de arts. Hiervoor werd gebruik gemaakt van een bestaande Canadese dataset waarin patiënt en arts aan het einde van het consult een identieke vragenlijst invulden waarin ze de communicatie van de arts beoordeelden. Voor dezen studie werd naar drie vragen gekeken. 1) In hoeverre stemt het oordeel van de patiënt en de arts over de communicatie van de arts in het consult overeen? 2) In hoeverre zijn patiënten van dezelfde arts het onderling eens over de communicatieve competentie van hun arts? 3) Zijn er verschillen tussen artsen in de mate waarin hun zelfscores de scores van hun patiënten voorspelden. Er werd nauwelijks overeenstemming aangetroffen. Er was nauwelijks een relatie tussen de scores van artsen en de scores van patiënten voor dezelfde consulten (vraag 1). Artsen scoren hun communicatie vrij consistent over verschillende consulten heen, de scores van hun patiënten variëren echter sterk per consult (vraag 2). Er zijn weinig verschillen in de mate waarin de zelfscores van de arts de scores van hun patiënten voorspellen, ze blijken bij alle artsen een slechte voorspeller te zijn. Deze studie laat zien dat er weinig overeenstemming is tussen artsen en patiënten over het niveau van communicatieve competentie van artsen tijdens consulten.

\section{Hoofdstuk 10}

In dit hoofdstuk worden de resultaten uit de verschillende hoofdstukken geïntegreerd tot samenhangende antwoorden op de drie vraagstellingen van dit proefschrift. Vervolgens wordt de waarde van deze antwoorden geëvalueerd door een analyse van de sterke en zwakke kanten van de in dit proefschrift gebruikte methoden en door een vergelijking met bestaande literatuur. Daarna wordt besproken wat de resultaten van dit proefschrift betekenen voor het raamwerk uit de inleiding waarin de factoren die de implementatie van communicatie richtlijnen beïnvloeden weergegeven worden. Geconcludeerd wordt dat ondanks de grote investeringen in communicatie onderwijs er veel meer factoren zijn die implementatie van de huidige communicatie richtlijnen hinderen, dan factoren die dit bevorderen. De belangrijkste problemen die in dit proefschrift geïdentificeerd werden zijn:

- De kwaliteit van de richtlijnen schiet te kort wat betreft objectieve kenmerken; daardoor is er te weinig informatie die gebruikers overtuigt dat het nuttig is om ze toe te passen.

- Gebruikers hebben te weinig positieve ervaringen met het toepassen van deze richtlijnen. Dit kan onder andere komen doordat het voor artsen erg moeilijk is om te weten welke effecten hun communicatie op de patiënt heeft. 
- De communicatie-richtlijnen zijn niet afgestemd op de randvoorwaarden van de praktijk. Dit lijkt voor een groot deel te komen door hun generieke aard die botst met de gewoonte van huisartsen om doelgericht te communiceren.

Om aan deze problemen tegemoet te komen worden twee hoofdaanbevelingen gedaan

1. Neem het steunen van artsen bij het leveren van goede zorg als uitgangspunt in plaats van het veranderen van hun communicatie

2. Artsen dienen zelf verantwoordelijkheid te nemen voor arts-patiënt communicatie, uiteraard met betrekking tot de uitvoering, maar ook wat betreft richtlijnontwikkeling, onderwijs en onderzoek.

Deze aanbevelingen worden uitgewerkt in meer gedetailleerde aanbevelingen voor richtlijnontwikkelaars, docenten en onderzoekers. Hierin wordt beschreven hoe zij kunnen bijdragen aan communicatie-richtlijnen en communicatie-onderwijs dat door artsen als een steun wordt ervaren bij het realiseren van goede zorg. 
Appendix

The researcher's views on and experiences with doctor-patient communication: a personal reflection 



\section{The relevance of researchers' personal views}

Research can be strongly influenced by the researcher's personal point of view. This applies to all types of research, but is more commonly acknowledged in qualitative research than in quantitative research. My position as an Aiotho (PhD student cum postgraduate trainee in general practice) was created to bridge the gap between research and clinical practice, and to enhance the clinical relevance of research. In my case, there was a great deal of interaction between clinical practice, education, and research. In addition, I served on the committee of the local association of general practice trainees where quality of education was my remit, during most of my training period. This gave me the opportunity to look at communication in general practice from different angles. The doctor in me asked practical questions: 'what to do next?' or - in retrospect -: 'what could I have done better?' The GP trainee wondered: 'how can I deal with this type of situation more effectively? Who/what can help me do that?' while the committee member was thinking: "How does the educational system tackle this type of problem? Is that appropriate? Is there a more effective training method?' The researcher asked 'Is there any knowledge on this subject that I can use? Is this knowledge supported by sound evidence? What are the underlying mechanisms? If no knowledge is available, what is the best way to gather that knowledge?' I learned a lot from the combination of these different perspectives- at least as long as my continuously shifting perspectives did not send my head spinning.

\section{Reasons for a personal perspective}

A method used in qualitative research to deal with the impact of researchers' personal views is to explicate researchers' personal backgrounds, beliefs and views with regard to the matter at hand. I think this is particularly important in my case, because of my strong personal investment in the subject of my thesis and because my personal experiences with communication skills training from a learner's perspective may be of interest to communication researchers who do not have a background in medicine. In this appendix, I describe my personal experiences as a researcher and learner of doctor-patient communication. I have not attempted to synthesise my impressions into a coherent view nor do I offer general conclusions, because I do not presume to have distanced myself sufficiently from my experiences to be able to venture a well-balanced judgement. But readers are welcome to draw their own conclusions. 


\section{My communicative competence}

I have to confess that I am not a natural when it comes to doctor-patient communication. With concrete information I do alright and usually I manage to persuade patients with regard to management decisions, but I find it difficult to build a trusting relationship with a patient. It takes some time before I can feel at ease with another person and I think this works the other way round as well. I am fine with longer-term relationships where trust can develop gradually, for instance when supervising students, but building trust in a ten-minute consultation is not my cup of tea. This is problematic, since trust between doctor and patient is prerequisite for a successful consultation. Experienced general practitioners can gradually build trustful relationships with patients over recurring ten-minute consultations, but for trainees and novice GPs, most consultations are with patients whom they see for the first time. Although my self-criticism may seem unduly harsh, unfortunately, it has been corroborated by others repeatedly. During my training I have received a great deal of negative feedback on my communication skills. This was not easy to deal with especially since I am convinced that good communication skills are a core competence for doctors. Knowing that my general willingness to work hard to achieve my goals usually reaps rewards, I set to work to improve my communication skills, but in this instance my efforts were in vain. My progress as a communicator remained long at a standstill and this made me feel insecure. From this situation arose my keen interest in communication training and my fascination with the question 'what is good communication?'

\section{Medical school: communication training during the pre- clinical years}

During my first four years in medical school, student patient contacts were rare. Every six to eight weeks a consultation with a simulated patient was video taped and discussed in a group of some twelve students and one or two supervisors. The students commented on each other's performance: What went well? What did not go well? Meetings could include role play and discussions of communication theory.

To me, the simulated patient contacts brought a mixture of tension and enjoyment. On the one hand, being able to practise consultation skills in a setting resembling clinical practice was valuable, but on the other hand it felt forced and unnatural because you had to meet certain standards and - worst of all - you were being recorded and judged. I loathed watching my own tapes and would get upset by irrelevant details: that high-pitched voice, that posh accent, those irritating ' $\mathrm{hms}$ ' every four or five sentences. Sometimes I would be given a tip or advice that was 
immediately applicable, but more often than not I left sessions with a list of shortcomings which I resolved to have remedied by the next session. Looking back I realise that I did not have a clue how to do this nor do I remember discussing ways to effectively improve my communicative behaviour. What positive feedback I remember did not give me much to go on either. "I think the patient felt understood" was good to hear, but did not tell me how to get the same result next time.

Receiving the same negative feedback over and over again, I concentrated on two learning objectives, which remained a constant feature during most of my preclinical training. The first objective was to structure consultations, and in this area there was progress, if slow. The second objective was to show empathy to patients and on that count I failed miserably. It was not that I did not feel empathy, but it was obvious that I often did not succeed in conveying it to the patient. The constant criticisms hurt. An example in point was a consultation with a simulated patient portraying a woman who had had a miscarriage. Inevitably, the conversation was emotionally charged. The patient felt miserable and I was truly empathetic. Nevertheless, the interview did not go well and the debriefing was devastating. When I asked the group what I should have done differently they said I came across as a specialist with twenty years of experience who had seen it all and just did not care anymore. I was almost in tears. I had tried so hard only to achieve no result and worst of all I had no idea what to do about it.

People kept telling me that I seemed cold and uncaring and how could I deny what was perceived by so many of my colleagues? Sadly, criticism is not the same as practical advice on how to put things right. Initially, I eagerly 'searched for useful advice, but in the end I gave up. Years later, in my final year of vocational training, a supervisor urged me not to accept vague feedback but ask for clarification. For instance, if criticism referred to things I did or did not do, I should ask what specifically was wrong. This was excellent advice and helped me to stop feeling disempowered and inadequate when I was reproached for being cold. This was an important step towards overcoming my communication problems.

My views on doctor-patient communication were not only shaped by communication skills training. A significant influence came from ethics classes where patient autonomy and informed consent were strongly advocated and enthusiastically embraced by me and my fellow students. After all, it is the patient's own body. And, of course, patients are entitled to information and to deciding what will be done to their bodies. 


\section{Medical school: doctor-patient communication during clerkships}

Clerkships did not include formal communication training but there was ample opportunity for learning by doing. A large part of the day was taken up by patient encounters, which dramatically changed both my view of good communication and my appreciation of my own skills. With real patients, empathy came naturally. To the best of my knowledge, I succeeded in conveying empathy. What I had been taught about communication I found to be of little use, however.

Communication training in the pre-clinical years had focused on new medical problems presented at a patient's first time visit to a GP or outpatient clinic . During my first - surgical - clerkship my main task was to collect a standardised set of data from patients who had already been diagnosed and were admitted to undergo elective surgery. This checklist provided a medical snapshot to determine whether the patient was in sufficiently good condition to undergo surgery and for postsurgery comparison. Getting patients to talk about their beliefs, preferences and emotions or informing and advising them - as we had been trained to do - was not required. In fact, any answer other than 'yes' or 'no' was inconvenient, since it took extra time and left me uncertain about what to enter in the list. In this setting, being able to keep patients focused and at a distance proved to be useful skills indeed.

Another reason for keeping my distance with patients was to avoid requests I knew I was unable to respond to adequately. Many patients were nervous about the upcoming surgery and had all kinds of questions about the procedure, any risks involved, and often existential questions too. Students spent more time with patients than any other staff members and they were also the most approachable. So, as a student I was an easy target for all kinds of questions, which I was too young and inexperienced to handle. I could sense patients' needs but I was too insecure about my position and too inexperienced to do anything about it. I found this so disturbing that I firmly resolved that after graduation I would go and find a job in an area that was as far removed from patient care as possible, scientific research for example.

Fortunately, things got better over the course of the clerkships. I was able to answer more and more questions as I began to find my way in the hospital organisation and my clinical knowledge expanded. Furthermore, most patients proved to be far less anxious than pre-surgery patients and later on most patient encounters were in the outpatient clinic, which was what I had been trained for. Outpatients generally had their questions answered, albeit not immediately, and usually not by me. With the removal of the burden of unanswerable needs and questions, I even enjoyed the general practice clerkship by the end of which I was able to do most consultations on my own, under supervision. For the first time, I experienced the satisfaction of helping people as a doctor. Some doctors take their 
satisfaction from saving lives. I discovered the joy of helping people deal with simple medical problems, comforting them or letting them know they did not have to face their medical problems alone. Many patients were grateful. Several times an hour I received confirmation that I was doing a good job. So I decided that patient care was the right career for me after all, but not full time, for despite the satisfaction, the work took a lot of energy. I was afraid that full time patient care would exhaust me sooner or later.

Another upshot of the general practice clerkship were ethical questions. In medical school, I was taught the central importance of informed consent. However, matters turned out to be more complicated than I had thought. Some specialists told their patients which treatments were available and after hardly any further discussion accepted a patient's decision about treatment even if they deemed it an unwise one. From their standpoint theirs was the responsibility to inform but it was up to the patient to make the final decision. And although they were unhappy with this state of affairs they accepted that this was the role assigned to them by hospital and society. I had misgivings without being able to pinpoint why and this feeling became only stronger when I witnessed the other side of the coin during my general practice clerkship. We were paying a visit to a patient who had back pain. After examining her the doctor told her not to worry, it was just muscular pain. Back in the car he explained to me that the patient was being treated for breast cancer and the back pain could be due to metastases. He had not told her this because he was afraid it would upset her so much that she would quit radiotherapy and radiotherapy was very important for her health. I was confused. Unlike the specialists whose lack of involvement I had found disconcerting, this GP I admired because of his strong involvement. Nevertheless, what had transpired was borderline deception. A classic example of the paternalism I had learned to decry. I spent weeks mulling over this incident and decided to do a research elective in medical ethics, focused on decision making in palliative care.

Reading about ethics in medicine broadened my perspective on ethical dilemmas. I was particularly impressed by discourse models like the one developed by Emanuel and Emanuel, by interpretations of patient autonomy as the right, not to noninterference, but to self-actualisation and views which conceptualised care as valuable in itself.

\section{Resident in child and juvenile psychiatry: communication with parents}

After medical school I worked for six months as a resident in child and juvenile psychiatry. This was my first real post as a doctor, but supervision being very intensive, the medical responsibility did not weigh too heavily. My main task was to interview the parents of a new patient, after which a psychiatrist interviewed the 
child. It seemed as if the consultation model inculcated by pre-clinical training had been invented with this setting in mind. First, I gave the parents ample opportunity to tell their story, then I asked more focused questions about psychiatric symptoms. When emotions arose, which happened during most of the interviews, I felt it was legitimate to explore them because this might reveal information relevant to the diagnosis. At the end of the 90-minute or so interview, it felt completely natural to explore the parents' expectations and inquire what kind of help they were hoping to receive. This I had been prepared for by communication skills training and in these interviews this approach suddenly felt appropriate and natural. The total absence of time pressure was helpful as well. I could take as much time as I needed. Looking back I think it is a tremendous luxury to be able to give so much time to people, because it opens up so many possibilities.

\section{General practice vocational training: communication skills training with video taped consultations with real patients}

In many ways, communication training during general practice vocational training mirrored communication skill training in medical school. Video taped patient contacts were discussed in small groups, so, once more, at the end of each session I had my list of suggested improvements without the faintest idea what to do about them. Luckily, some things were better. Feedback was more detailed and focused more on behaviour, while I discovered I could adopt strategies I saw my colleagues using to try and improve my own performance. But the crucial difference was that the consultations were with real patients not simulated ones.

To my mind this made a huge difference. Communicating with real patients was more demanding: consultations were more chaotic and it was not so easy to find out what patients were after. Simulated patients tended to tell a well structured story and were briefed on the purpose of their visit to the doctor. Real patients told stories in a less structured way and did often seem to be unsure of what they wanted from the doctor. Some patients were very claiming and dependent, some talked incessantly, some came from different ethnic backgrounds and still others had intellectual limitations. This was a long way from the simulated patients but the key change was that as a trainee I was medically responsible. This shifted attention away from communication skills and consulting style. I discovered that my four years of persistent training efforts to improve the structure of my consultations finally paid off. I succeeded better than most at keeping my consultations organised. Unfortunately, what had not changed were my problems with relational aspects. It remained difficult for me to meet so many new people on one day and build relationships with them. Having to explore patients' emotions and needs meant establishing personal contact and trust in a very short time and, as before, I was inept in this respect. Again I was reproached for appearing to be uncaring and 
again I did not know what to do. On one occasion I said in a mentor meeting that I was making no progress at all with regard to my learning goals for communication and I was told I was demanding too much of myself. Communication with colleagues and supervisors went quite well, so it was assumed that I would do equally well in communicating with patients. That my misgivings were well founded was brought home to me rather harshly when I came bottom of my year on the communication test.

In that same period one of my research supervisors boasted that he could teach any trainee to communicate according to the guidelines of the communication test. I did not believe him and dared him to prove his point. We did one practice session and after I had ventilated my frustrations he offered to do some individual training sessions with me. In these sessions we split learning goals into very small steps, so that I could work on discrete behaviours. Whenever the supervisor suggested I should perform an action with which I felt uncomfortable, I said so and we explored why I felt uneasy and we either looked for an alternative approach or he convinced me to try anyway. After a month we discussed my progress based on my selfreflection report and adjusted my learning goals accordingly. After two months we watched a video of a new patient contact and made a new plan. After five sessions, I actually began to do better. I developed very short protocols which I adapted for different situations. In this way I discovered that patients with a lump somewhere in their body would generally respond favourably when I asked them if they were worried and also that it was alright to ask a patient with a motion problem if he had any idea of its cause, while these questions might evoke negative responses from patients with different problems. My results on the communication test were still unsatisfactory but improving. Even more importantly, for the first time I was confident that I was able to raise the quality of my communication skills to a higher level.

\section{The doctor's opinion on the experiences of the researcher: Literature}

For my research I read numerous articles on doctor-patient communication. As a doctor I was interested to read these, hoping to pick up suggestions I could put into practice. Alas, more often than not the doctor was disappointed. Although some of the research was exciting and admirable, most of the articles I read made no significant contribution to theory development and contributed little to practical improvement. Although I do realise these articles may have been written with other stakeholders in mind, such as policy makers, researchers, or other health care workers I was disappointed, because I thought that communication research, at least in part, be relevant to practising physicians. 
Whenever practical recommendations for communication were made in articles, they were usually even more exasperating than their absence in the majority of the articles. Invariably, the advice was for health care workers to make more of an effort to apply the investigated behaviours. Apparently, according to communication researchers, health care workers show in no aspect researched sufficient adequate communicative behaviour. Additionally, it was not considered how doctors and other health care workers were supposed to apply the recommendations nor did articles investigate the potentially positive and negative consequences of adhering to the recommendations included in them. I can think of no study that suggested which communicative behaviours might be omitted in order to enable timely completion of consultations. A particularly baffling recommendation was one regarding shared decision making with non-Western patients, stating that the very least a GP should do was to ask patients to what degree they wanted to be involved in decisions about their treatment. While I agreed with the researchers that this was important knowledge, I very much doubted whether such a question could realistically be included in a standard 10 or 20 minute consultation. This would be difficult with Western patients. With nonWestern patients, this would be even harder since consultations with non-Western patients are complicated by socio-cultural differences and difficulties related to interpreting facial expressions, other non-verbal communication, and connotations and implications of many phrases and topics. In my experience, it is already difficult for non-western patients to understand my questions about the impact of their medical problem on their day-to-day lives and how worried they are. In my opinion, this recommendation regarding shared decision making was a reflection of the authors' lack of understanding of the difficulty of explaining a concept like shared decision making to non-Western patients. Even so, they said it was 'the least a GP should do'.

Another remark in the literature that I personally found rather disturbing concerned the MAAS-global, the consultation guideline I had been trained to use. It read: "it is often claimed that the way communication skills are defined in the model makes them impracticable and too time consuming, especially in the hospital setting. However, in light of the current widespread dissatisfaction with doctor-patient communication, this is rather a problem of the organization of healthcare than of communication taking too much time ${ }^{1}$." Reading this, I felt betrayed. I had worked so hard to learn to apply that guideline, only to be told that it was not really intended for practical use but designed for some utopian non-existent health care system. All I was supposed to do was figure out what to do in the real world or change health care to fit the ideal. As a trainee I feared health care was more likely to re-organise me than the other way round. To my dismay, this was not an isolated statement. It was reiterated by Silverman et al. in their handbook on communication skills ${ }^{2}$. Interestingly, in the next edition of the handbook this remark was changed to "We are not interested in promoting skills that are 
inappropriate given the time constraints within we have to practice medicine in the real world"3. Nonetheless, the guideline expanded from 68 to 71 recommendations.

Years later, I talked about this with Jan van Dalen, one of the authors of the MAASglobal. He explained that they had developed the MAAS-global as a description of a communication ideal in the belief that students should learn the ideal before making compromises in practice. Although I can follow this argument, I still deem it unwise that the problem of dealing with reality was left to the students. At the very least, I felt, I should have been forewarned during my training that I was being trained for utopia.

\section{The doctor's opinion on the experiences of the researcher: conferences}

Most of the conferences I attended in my capacity as a researcher were conferences on communication in health care $(\mathrm{EACH})$ and shared decision making (SDM). As a doctor - particularly one who believes that the current patient centred communication guidelines are not suited to all consultations - I felt somewhat out of place at my first EACH conference. Not many researchers appeared to be interested in what constitutes good communication or what mechanisms make communication work. The focus was mainly on training doctors and influencing their attitudes. The impression I gained was that the key research question was how to get those pig-headed doctors to communicate properly. At the shared decision making conferences, I felt less out of place. There were more doctors among the delegates, a stronger focus on theory and more people looking for solutions that fit clinical practice. However, the focus of these conferences was too narrow for me. There is more to good communication than shared decision making. I was therefore relieved to find a more open minded atmosphere at the latest EACH conference and to see that the two conferences are moving closer together. Nevertheless, at my second EACH conference, I was shocked by something I witnessed during a presentation on the results of a communication training programme. The researchers had measured students' attitudes to patient centeredness and found a programme-related improvement in the first year but a decline during clerkships. In the discussion, the researcher contended that the programme was fine, but as long as clinical training exposed medical students 'to the same veterinary medicine as always' it would be impossible to achieve good communication skills. Someone in the audience laughed and retorted that the researcher should not underestimate vets. There were no other reactions. Personally, I was speechless. How can someone expect to effectively teach communication skills to medical students, if her opinion of clinicians is so low and disrespectful? Had she ever talked with doctors about their communication with 
patients and taken their perspective seriously? And if she had not, why should doctors take her views seriously? Perhaps I should have asked her to explain her negative reaction but I did not. I do intend to try, however, the next time something like this happens.

Another incident at an earlier conference did not improve my opinion of communication skill trainers either. Participants in a workshop on communication skills were invited to role play, as a doctor, with an actor portraying a patient. The workshop was attended by a group of communication trainers who were behavioural scientists, a nurse researching patient-nurse interaction and me. The idea was that we would take quick turns playing the doctor in order to learn from each other's performances. The workshop moderator asked for a volunteer to play the doctor and, after a brief silence, I came forward. The actor played an extremely shy student with complaints related to loneliness. The challenge in this consultation was that her shyness made it very difficult to get her to talk and explain her problems. After about eight minutes, the workshop leader asked for a change of 'GP' and the nurse volunteered. She did a much better job than I had in putting her 'patient' at ease and it was fascinating to see how she got her to talk. The moderator then asked for another volunteer. Nobody came forward. When the silence became awkward he asked me if I would take over the role of the GP again. After my second turn, he ended the workshop. I had enjoyed the opportunity to practise and observe how someone else handled a situation that was difficult for me, but I was disenchanted by the behaviour of the group of communication trainers. The case was clearly non-medical, so there was no reason why they should not play the GP role. As a trainee, during communication training, I am expected to show how I communicate, have my performance video taped and practise on the spot when useful, and I feel vulnerable in doing so. In the group of communication trainers attending this workshop, no one had the courage to make him/herself vulnerable. In my opinion, this group of communication trainers had disqualified themselves as communication role models for doctors. I wondered whether this was just an unfortunate incident or a manifestation of a more widespread problem.

\section{Reactions from others to the research: general practitioners and general practice trainees}

The most striking reaction to my research project came very early on at a general practice conference where I attended a 'consult the expert meeting.' I explained to the experts that I was developing new communication guidelines which would be more tailored to doctors' needs and which I assumed would have to be more flexible than the current ones. When I asked them to comment on my research proposal, I was rather shocked by the angry response I received instead of the expected advice. The experts said they had been pestered with communication 
guidelines for the past twenty years. Clearly, to them my intention to develop yet another guideline was insufferable. Outraged as they were, they seemed unable to appreciate my intention to develop a guideline that would be more supportive of GPs and less of a straitjacket of rules. After bluntly telling me they did not want to be bothered with any more communication guidelines, they terminated the consultation session.

Fortunately, most GPs I approached reacted more positively to my research and I had little difficulty recruiting participants. Many GPs saw my study as an opportunity to get feedback on their communication, something most of them had not experienced since their training. My desire to take a look behind the scenes of GP-patient communication and learn how GPs communicate in day-to-day practice also appealed to them. GPs whom I met during my work as a locum were usually very interested in my research. Most of them thought the research topic was important, because they considered good communication essential to their work. Many of them believed that goal directed or context specific recommendations for communication made more sense than the prevailing generic recommendations. Some GPs provided series of examples of patient encounters, frequently illustrating that in day-to-day practice adherence to communication guidelines is not only unfeasible but undesirable as well. The examples they gave seemed to underscore that the current guidelines were created in ivory towers so remote from clinical practice that GPs cannot be expected to take them seriously. Although few of them said so explicitly, most GPs seemed to think that communication guidelines were at best of some benefit to trainees, but definitely of no use at all to experienced GPs. I found one remark from a group of GP trainees at the end of a focus group interview rather disconcerting. They suggested that communication training should no longer be given by behavioural scientists. They added, by way of explanation, that their trainer was 'a good fellow' but 'had no idea what went on in clinical practice'. I partly agreed with them. It had bothered me before that some psychologists were considered qualified to teach doctor-patient communication even though they had no relevant work experience. Their understanding of communication added relatively little to my own knowledge and their recommendations were often too vague to apply. On the other hand, some of my most useful insights into why patients reacted the way they did had come from trainers with a background in psychotherapy. I felt that their understanding of human interaction and human relationships added the kind of value to communication training that was only rarely provided by GP trainers. In my opinion this made up for their lack of hands-on experience. 


\section{Other reactions to the research: behavioural scientists}

I received different reactions to my research from communication trainers depending on whether their background was in behavioural sciences or general practice. For both groups, communication guidelines were controversial, but for different reasons. GPs considered the term appropriate and in line with their training. To their experience the recommendations used in training had the status of guidelines. They objected to this status and to the use of these recommendations as the standard by which their communicative competence was judged. Communication trainers, on the other hand, had no quarrel with the status recommendations for communication have. They objected to their being labelled 'guideline', because this suggested that they are prescriptions for behaviour, which, in their way of thinking, they were not.

My idea to develop goal-related communication guidelines raised concerns among trainers with a behavioural science background. Several of them expected that doctors would choose the wrong goals and that goal-related guidelines would legitimise such inappropriate choices. Usually, in addition to the reasons I had suggested, these trainers came up with other reasons why doctors do not engage in patient-centred communication, such as laziness or lack of motivation. My explanation for insufficiently patient-centred communication is that doctors have to prioritise goals in a time-pressed environment and try to protect themselves from emotional drain. I consider these to be perfectly legitimate reasons for not engaging in patient centred communication. Their consideration opens up room for discussion, whereas negative interpretations, like laziness or lack of motivation, tend to sabotage any discussion. Moreover, I believe that goal-related guidelines would reveal which goals doctors pursue in consultations thereby creating opportunities to discuss and influence them. This seems to me a more effective strategy for improving communication than dismissing communicative goals determined by GPs as irrelevant for fear they may be misguided. In various discussions on this topic with several people, it has not yet been possible to resolve this issue satisfactorily.

Unlike the behavioural scientists, GPs were not disturbed by the idea of goalrelated guidelines. They seemed confident that they would choose appropriate goals and only rarely expressed concern that their colleagues or trainees might not do so.

Apart from the negative reactions, the idea of goal-related guidelines was also supported by behavioural scientist trainers. These trainers saw opportunities to connect communication training with clinical practice, which might motivate doctors to apply new communication techniques. The fact that most trainers with a behavioural science background seemed to have stronger doubts than GP trainers about the effectiveness of their communication training may explain their stronger approval of strategies to enhance training effectiveness. 


\section{Disagreement between GPs and communication trainers/researchers who are behavioural scientists}

As I was working on my thesis project, my supervisors more than once censured me for polarising issues. They were probably right. I like to use polarisation as a means to organise my thoughts, clarify the arguments from different sides and challenge others to explicate their views. As soon as I feel that all arguments are out in the open and have been discussed and understood, I am usually more careful in expressing my opinions so as to do justice to all the arguments.

I suspect my supervisors will say that in the last two sections of this appendix I polarise the differences between GPs and behavioural scientists. Several of the examples I gave were extremes, which clearly explains the strong impression they made on me. However, in my opinion, there are tensions, maybe even a power struggle, between doctors and behavioural scientists with regard to doctor-patient communication. At worst, the two groups are disdainful of each other. Behavioural scientists condemn doctors for being too lazy and uninterested to try to communicate well (i.e. in a patient-centred way) with their patients. Doctors on the other hand accuse communication trainers of being ignorant of the reality of clinical practice and reject communication training and communication guidelines as impractical ivory tower products.

Unfortunately, this schism perpetuates the status quo in communication training. For behavioural scientists, it removes the responsibility for improving communication training from them because they are not to blame for the lack of effectiveness of training. For doctors, it obviates the need to change their behaviour, because to them the recommended changes are unrealistic and ineffective. Perhaps if both groups were willing to accept more responsibility for the problems in doctor-patient communication this stalemate could be ended and progress begun.

In order to achieve this, we need to re-open the discussion on what constitutes good doctor-patient communication, who is to decide this and who are the experts. I have tried to do so in the discussion section of this thesis. However, the debate on doctor-patient communication is so strongly value driven that it should not be confined to the communication research community. It should involve wider stakeholders: the training community, the medical community and probably even society at large. 


\section{Literature}

1. Van Dalen J, Bartholomeus P, Kerkhofs E, Lulofs R, Van Thiel J, Rethans JJ, Scherpbier AJ, Van Der Vleuten CP. Teaching and assessing communication skills in Maastricht: the first twenty years. Med Teach 2001, 23:245-251.

2. Silverman J, Kurtz S, Draper J. Skills for communicating with patients. Oxon: Radcliffe Medical Press; 1998.

3. Silverman J, Kurtz S, Draper J. Skills for communicating with patients. Oxford - San Francisco: Radcliffe; 2005. 
Dankwoord

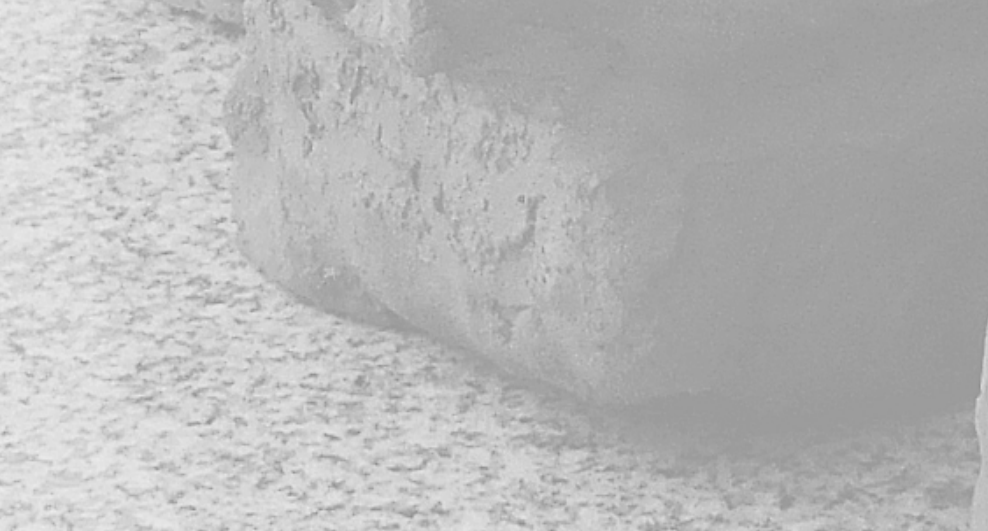





\section{Dankwoord}

'It takes a village to raise a child.' (Yvonne, voor mij ben jij de bron van dit prachtige citaat, net als van veel andere, maar van wie is het origineel?) Het vraagt om een wetenschappelijke gemeenschap, een huisartsen gemeenschap en een huisartsopleiding om een aiotho op te leiden. Ik ben dus heel veel mensen dank verschuldigd... Ik zal er nu een aantal bij name noemen, maar er zijn nog veel meer mensen die ik niet op deze paar pagina's gepropt krijg, zonder wie dit niet het boekje geworden zou zijn dat het nu is.

Paul, je hebt je rol van directe begeleider heel ruim opgevat en daardoor heb ik op heel veel terreinen steun aan je gehad. Het woord 'bedankt' schiet hier te kort. Je insteek is altijd positief kritische betrokkenheid. Wanneer ik ergens mee worstel denk je mee over oplossingen, wanneer alles soepel gaat speel je luis in de pels. Kortom of dingen nu goed of slecht gaan, je bent altijd constructief en je streeft er altijd naar het meeste uit de situatie te halen. Bedankt daarvoor!

Cees, mijn eerste promotor. Je agenda zit overvol en toch reageer je onmiddelijk op mails met vragen. Dat is exemplarisch. Je inzet is groot, en als je ergens enthousiast over bent geef je veel ruimte en ben je uitbundig in je waardering. Ik waarder je directheid, je betrokkenheid en je neiging om in oplossingen in plaats van in problemen te denken enorm.

Cees en Paul, samen stelden jullie me in de gelegenheid om te starten met een onderzoeksproject met als kernopdracht 'kleur het construct arts-patient communicatie opnieuw in'. Zo'n opdracht geeft natuurlijk alle ruimte om te verzuipen, en dat heb ik dan ook prompt gedaan, maar het heeft me ook een ruimte gegeven om mijn eigen ideen te ontwikkelen die niet veel promovendi krijgen. Daar ben ik ontzettend dankbaar voor.

Trudy, mijn tweede promotor, dankzij jou wortelde ik in de vakgroep huisartsgeneeskunde en specifiek in de onderzoeksgroep implementation of evidence. Niet alleen betrok je me lokaal, je deelde ook je internationale netwerk, wat veel boeiende ontmoetingen opleverde. Je hebt een groep bijzondere mensen om je heen verzaeld en ik ben blij daar deel van uit te maken!

Glyn, I have really enjoyed working with you. Discussions are always stimulating and very inspiring; they leave me a lot of new ideas and much enthusiasm to start working on them. The hospitality of you and your research group in Cardiff was great! I hope to come back soon, both because I so much enjoy being their, as because it gives great input to my work.

Piet, hoewel je geen lid bent van het promotieteam, was je wel het extra lid van de projectgroep voor de kwantitatieve artikelen. Ik heb enorm genoten en erg veel geleerd van onze discussies over wat de voor- en nadelen van verschillende analyse-methodes waren en wat dat zei over de betrouwbaarheid van onze resultaten. Zonder jou zouden hoofdstuk 6 en 7 er niet geweest zijn, omdat jij de 
uitvoering van de analyses op je nam, waar ik op dat moment de tijd en de kennis niet voor had. De jaren daarvoor al was je aanspreekpunt als ik frictie had met iemand in het projectteam, geïrriteerd/moedeloos werd van de (te grote) rol van politiek in onderzoek en het universitaire wereldje of anderzins behoefte had aan iemand die me hielp mijn gedachten te verzetten, bijvoorbeeld richting de handigste manier om een boot uit het water te lieren. Dank daavoor!

In het algemeen vind ik dat ik erg veel geluk gehad heb met mijn projectteam. Ondanks of dankzij de verschillen waren we een goed werkend team, met ieder zijn eigen expertise en eigen rol in discussies. We splitsen nu op in nieuwe projectteams, maar ik ben erg blij dat ik onderzoek met jullie blijf doen!

Naast de leden van de projectgroep waren ook de leden van de begeleidingscommissie

Een belangrijke ondersteuning, soms als groep maar vaak ook in individuele consultatie. Henk Goettsch, Rutger Lulofs, Paul Zwietering, Jan van Dalen, hoewel de contacten met jullie niet heel frequent waren heb ik met name de mogelijkheid om individueel een beroep op jullie te doen, erg gewaardeerd. Het was heel nuttig om mensen met zoveel verschillende perspectieven op mijn onderzoeksgebied te kunnen raadplegen en daar vanuit jullie betrokkenheid bij het onderwerp over in discussie te kunnen gaan.

Verder ben ik alle secretaresses en onderzoeksassistentes die interviews hebben uitgetypt, data invoerden of andere hand- en spandiensten leverden erg dankbaar. Dames, dat typen is een rotklus, ik weet het, en ik heb goed nieuws: in de toekomst zal ik daar een gespecialiseerd bureau inschakelen! Voor nu, Karin, Paddy, Marie-Louise, Lilian, Alexandra en Susanne, enorm bedankt voor alle hulp!

Mariet Wassing, student assistent, bedankt voor je hulp in het organiseren en beschrijven van de chaotische stapel documenten die de inventarisatie van onderwijsmateriaal opleverde. Liesbeth, veelzijdig student assistent: je deed van alles: van literatuur zoeken en typewerk tot onafhankelijke kwalitatieve analyses; en je deed het allemaal snel en goed. Het was een enorme luxe om een afgestudeerde student assistent te hebben, en ik wens je veel succes in een baan als gezondheidszorg manager!

Joep Urlings, je was tot dit jaar de enige wetenschapstudent die ik wist te interesseren voor arts-patient communicatie, maar je was dan ook gelijk een geweldige student. Je werkte hard en zelfstandig, en het project wat resulteerde in hoofdstuk 7 heb je vrijwel geheel zelf gerund en uitgevoerd. Jammer, dat je niet ook aiotho wilde worden. Je hebt in ieder geval een hoge standaard gezet voor latere studenten! 
France Légaré, it was a fantastic experience to be in Quebec in the snowiest winter for years! You put dyadic research in doctor-patient interaction on the agenda, and I'm very grateful for what I learned about that in Quebec. The hospitality of you and your research group was great, and I very much enjoyed being a part of such an important international project as the 'interpersonal perception' paper (hoofdstuk 8).

Yvonne van Leeuwen, je bent voor mij een prachtig voorbeeld van een klassieke academica: je bent enorm allround: belezen en bron van prachtige speeches en nog mooiere citaten, bevlogen docent, maatschappelijk zeer betrokken, en veel aandacht voor wat onderzoeksbevindingen waard (of niet waard) zijn voor de praktijk. Ik zou graag wat meer op je lijken, maar voorlopig heb ik mijn handen vol aan moeder, huisarts en onderzoeker zijn (en een beetje docent), de belezenheid en maatschappelijke betrokkenheid zullen moeten wachten tot de dag meer dan 24 uur telt...Verder moet ik je natuurlijk ook nog bedanken voor je hulp bij analyses, bij het leren schrijven, het ondersteunen van aiotho's binnen de huisartsopleiding en voor wat ik van jou als docent geleerd heb.

Mereike Gorsira: bedankt voor het corrigeren van het Engels. Verbazingwekkend hoeveel de overtuigingskracht van mijn artikelen toeneemt als jij er 'echt' Engels van gemaakt hebt.

Tiny Wouters: bedankt voor het lay-outen van mijn proefschrift, je maakt er iets heel moois van!

Misschien nog wel meer dan de mensen die meewerkten aan het project ben ik dank verschuldigd aan de mensen die deelnamen aan het project.

De lijnhouders arts-patient communicatie van de huisartsopleidingen die me niet alleen hun onderwijsmateriaal stuurden, maar ook op hun eigen opleiding een focus groep bijeenkomst organiseerden! Ik wil jullie enorm bedanken voor jullie hulp!

De elf gedragswetenschappers, acht huisartsbegeleiders, zes huisartsopleiders, zeven aios en vier studenten die deelnamen aan de focusgroep interviews, bedankt voor jullie openhartig meedenken over de sterke en zwakke kanten van de richtlijnen waar jullie in het onderwijs mee werkten.

De zestien huisartsen die mij in hun keuken lieten kijken: bedankt dat jullie bereid waren je zo kwetsbaar op te stellen en mij niet alleen mee lieten kijken tijdens het spreekuur, maar ook het hoe en waarom van jullie (communicatieve) handelen aan me probeerden uit te leggen. Niet alleen als onderzoeker, maar ook als huisarts heb ik hier enorm veel van geleerd.

De ruim 400 patienten die het zomaar goed vonden dat er een vreemde bij hun consult zat, dat dat consult opgenomen werd, en die ook nog vragenlijsten 
invulden: bedankt voor jullie vertrouwen en de moeite die jullie namen, op een moment dat je hoofd toch echt naar andere dingen staat.

Daarnaast waren er natuurlijk ook allerlei mensen die niet bij het promotieproject betrokken waren, waar ik veel aan gehad heb.

Allereerst de aiotho's van het eerste uur: Loes, Rogier, Paddy, Annemiek, Paul, Niels, Roelf en Katinka. Wegbereiders, vraagbaken en in mijn ogen al heel ervaren onderzoekers, ik heb veel aan jullie gehad en van jullie geleerd, met name in de eerste jaren van mijn onderzoek. Dank voor de vele boeiende gesprekken, de lekkere maaltijden en niet te vergeten de leesclub-bijeenkomsten zelf. Ik heb nooit meer zo'n kritisch publiek gevonden als jullie, waarbij het doel toch verbetering was en niet punten scoren.

Jolien, Joris, Jochem, Merijn, Eva en Martine voor mij zijn jullie de aiotho's van het tweede uur. Het contact is nooit meer zo hecht geworden als het met jullie voorgangers was, maar het is erg leuk om te zien hoe jullie het stokje overnemen en uitbreiden. De aiotho's zijn zowel landelijk als lokaal een groep aan het worden om rekening mee te houden. Voor mezelf hoop ik dat ik ook als gepromoveerd huisarts nog een poosje op de aiotho-kamer mag blijven bivakkeren, het is er erg gezellig.

Binnen O\&O heb ik jaren deelgenomen aan de aio-leesclub, de eerste jaren trouw, de laatste jaren slechts sporadisch. Een aantal namen springt er voor mij uit: Susan, Agnes, Astrid, Theo, Renée, Luc en Dineke, ik denk met veel plezier terug aan onze gesprekken! En Diana natuurlijk bedankt voor de organisatie van de aio leesclub en andere aio-ondersteunende activiteiten. Susan, jou wil ik nog in het bijzonder bedanken voor onze gezamelijke lunches waarin we ervaring rond kwalitatief onderzoek uitwisselden, en mopperden dat we de heldenverering van Cees door andere aios een beetje zat waren.

Bij het PPI heb ik lang niet zo vaak aanwezig kunnen zijn als ik wilde, maar het was wel heerlijk om een netwerk te hebben van mensen die zich met communicatieonderzoek bezig hielden. Als huisarts, met toch primair een perspectief vanuit de praktijk en pas secundair als onderzoeker, voel ik me wel eens een vreemde eend in de bijt. Toch was het altijd weer boeiend om aan de discussies deel te nemen.

Bij huisartsgeneeskunde heb ik mijn werkplek, de dagelijkse gezelligheid en de input uit de diverse bijeenkomsten. Dank voor de gezellige werkomgeving waar interesse in elkaar duidelijk hoger in het vaandel staat dan concurrentiestrijd om subsidiebronnen! 
Bij het huisarts-onderzoeker worden, was ook mijn vorming tot huisarts een belangrijk deel. Daarvoor wil ik allereerst Theo Vaessen, Arnold Verheijdt en Theo Mangnus als mijn praktijkopleiders bedanken. Theo Vaessen, onze persoonlijkheden matchten niet zo, maar ik heb erg genoten van onze vakinhoudelijke analyses van patientencasussen. Arnold, je was een geweldige baas, en je hebt een prachtige praktijk waar ik met veel plezier gewerkt heb. Theo Magngus, je bent het warme hart van huisartsenpraktijk Arcade en een zeer gastvrije opleider. Het was ontzettend leuk om mijn laatste jaar te doen bij een opleider die zo nauw betrokken was bij de recente ontwikkelingen in de huisartsgeneeskunde.

Daarnaast wil ik mijn docenten en het ondersteunend personeel van de huisartsopleiding bedanken. Jullie waren met teveel om iedereen met name te noemen, maar daar is de waardering niet minder om. Het is heel duidelijk dat julie hart voor onderwijs hebben! En dat de reacties op de knelpunten notitites die we met de MOVAH schreven veelal positief waren in plaats van geïrriteerd, illustreert het gemeenschappelijk streven naar het immer verder verbeteren van het onderwijs. Bas en Joost bedankt voor de hulp bij de logistieke problemen die je als aiotho tegen komt wanneer je onderzoek en opleiding probeert te combineren. En heel belangrijk: dank aan alle mede-aios waarmee ik in terugkomdaggroepen zat. Ik heb genoten van alle gesprekken en niet te vergeten van de lunches bij Thembi. Daarbij wil ik nog speciaal de aios van het 'zwem-groepje' noemen, met Anita, Camiel, Wouter en Marieke als harde kern, soms aangevuld met Nicole of Andre. Ook de MOVAH (Maastrichtse Organisatie van Aspirant Huisartsen) verdient een aparte vermelding. Ook daar herinneringen aan vele gezellige maaltijden en boeiende discussies over onderwijs en de toekomst van de huisartsgeneeskunde. Dennis en Wouter, mijn paranimfen, het contact met jullie komt voor een groot deel voort uit de tijd dat we maar met zijn viertjes de harde kern van de MOVAH vormen. Hard werken, maar wel heerlijk slagvaardig en boeiende discussies, soms tegen het filosofische aan. Ik ben blij met de vriendschap die hier uit voortgekomen is, en dat jullie tijdens de promotie naast me staan!

Verder wil ik de huisartsen, praktijkondersteuners en assistentes van huisartsenpraktijk Groenveld bedanken voor een fijne werkplek. Jullie zijn een schoolvoorbeeld van een goed georganiseerde praktijk die kwaliteit hoog in zijn vaandel heeft staan en waar het als vaste waarnemer een plezier is om te werken. Niet in het minst vanwege de gezamelijke koffiepauzes buiten in zonnetje. Daarnaast wil ik ook de assistentes en chauffeurs van de huisartsenpost VenloVenray bedanken voor de gezellige werksfeer. De gesprekken met jullie zijn altijd zo heerlijk relativerend, en dat scheelt een hoop als je net een paar lastige casussen achter je kiezen hebt. 
Lea, zonder jouw hulp was het me niet gelukt om een verbouwing/verhuizing/het afronden van mijn proefschrift en het wennen aan het moederschap tegelijktijd rond te krijgen. Bedankt daarvoor en voor je vriendschap!

Dan wil ik nog mijn familie en schoonfamilie bedanken voor de steun en de prettige contacten de afgelopen jaren, en niet in het minst voor het oppassen op Jorinde. Wim, jammer dat je dit niet meer meemaakt. Je zou het waarschijnlijk niet gezegd hebben, en vooral benadrukt hebben dat je op jouw boek ook had kunnen promoveren, maar ik weet dat je apetrots geweest zou zijn!

Roger, maar weinig mensen hebben het genoegen dat hun partner ze niet alleen ondersteunt en begrijpt, maar ook zelf weet hoe het is om te promoveren. Gesprekken over wetenschap tussen een wiskundig natuurkundige en een arts die op communicatie promoveert leveren interessante gezichtspunten op! Ik geniet volop van onze verschillen en toch zijn we bijna één. Wat jij aan dit boekje hebt bijgedragen krijg ik niet in woorden uitgedrukt. Dank voor deze jaren samen.

Jorinde, zonder jou zou dit boekje veel eerder af geweest zijn. Maaar dan zou ik wel veel minder vaak lachen op een dag! 


\section{Curriculum Vitae}





\section{Curriculum Vitae}

Wemke Veldhuijzen was born in Hengelo, on October 23, 1976. She grew up in Twente, first in a tiny village called Diepenheim, later in Enschede, were she finished secondary education at schoolgroup 'Zuid' in 1994. She studied medicine at Maastricht University were she graduated in February 2001. She then worked half a year for Wieckraderhaem, a center for child- and youth psychiatry. From 2001 to 2007 she participated in the combined vocational training and research programme at Maastricht University. At 2007 she finished vocational training and started working as a general practitioner in various locations in Northern Limburg, while continuing the research programme. From 2008 she works one day a week as a GP in Groenveld medical centre and about one shift a week of out of hours care. Besides this, she has a half-time position at the general practice research group at Maastricht University. Her task there is to start-up and supervise a PhD project on workplace learning and a PhD project in which training modules for goaldirected communication for general practitioners that supervise registrars will be developed and evaluated. She also works as a communication trainer for Maastricht medical school and is part of the task force 'CORE', which organises the training in communication and reflection in Maastricht medical school. She is happily married to Roger Jeurissen and is mother of Jorinde Jeurissen. 


\section{SHE dissertations series}

In the SHE Dissertation Series dissertations are published of $\mathrm{PhD}$ candidates from the School of Health Professions Education (SHE) who defended their PhD thesis at Maastricht University. The most recent ones are listed below. For more information go to: www.maastrichtuniversity.nl/she.

van Blankenstein, F. (18-05-2011) Elaboration during problem-based, small group discussion: A new approach to study collaborative learning.

van Mook, W. (13-05-2011) Teaching and assessment of professional behaviour: Rhetoric and reality.

De Leng, B. (8-12-2009) Wired for learning. How computers can support interaction in small group learning in higher education.

Maiorova, T. (29-05-2009) The role of gender in medical specialty choice and general practice preferences.

Bokken, L. (04-03-2009) Innovative use of simulated patients for educational purposes.

Wagenaar, A. (18-09-2008) Learning in internships. What and how students learn from experience.

Driessen, E. (25-06-2008) Educating the self-critical doctor. Using portfolio to stimulate and assess medical students' reflection.

Derkx, H. (18-06-2008) For your ears only. Quality of telephone triage at out-of-hours centres in the Netherlands.

Niessen, Th. (30-11-2007) Emerging epistemologies: making sense of teaching practice.

Budé, L. (05-10-2007) On the improvement of students' conceptual understanding in statistics education.

Niemantsverdriet, S. (26-07-2007) Learning from international internships: A reconstruction in the medical domain.

Marambe, K. (20-06-2007) Patterns of student learning in medical education - A Sri Lankan study in traditional curriculum.

Pleijers, A. (19-01-2007) Tutorial group discussion in problem-based learning.

Sargeant, J. (21-09-2006) Multi-source feedback for physician learning and change.

Dornan, T. (12-06-2006) Experience-based learning.

Wass, V. (12-05-2006) The assessment of clinical competence in high stakes examinations.

Prince, K. (21-04-2006) Problem-based learning as a preparation for professional practice. 